\author{
UNIVERSIDADE DE SÃO PAULO \\ INSTITUTO DE GEOCIENNCIAS
}

\title{
CONTRIBUIÇÃO A PETROLOGIA E GEOQUIIMICA DO MAGMATISMO BASÁLTICO MESOZÓICO DO ESTADO DE RORAIMA
}

\author{
ANGELA BEATRIZ DE MENEZES LEAL
}

Orientador: Prof. Dr. Vicente Antonio Vitório Girardi

TESE DE DOUTORAMENTO

COMISSÃO JULGADORA

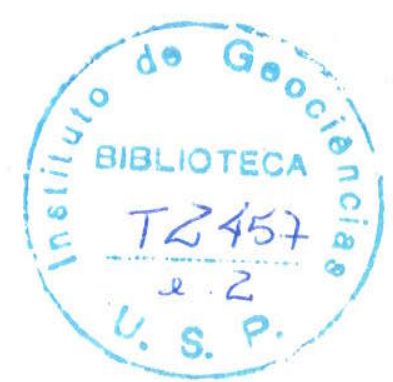

Nome

Presidente: Prof. Dr. Vicente Antonio V. Girardi

Examinadores: Prof. Dr. Ari Roisenberg

Prof. Dr. Ariplinio Antonio Nilson

Prof. Dr. Ciro Teixeira Correia

Prof $^{\text {a }} \mathrm{Dr}^{\mathrm{a}}$ Maria da Glória da Silva

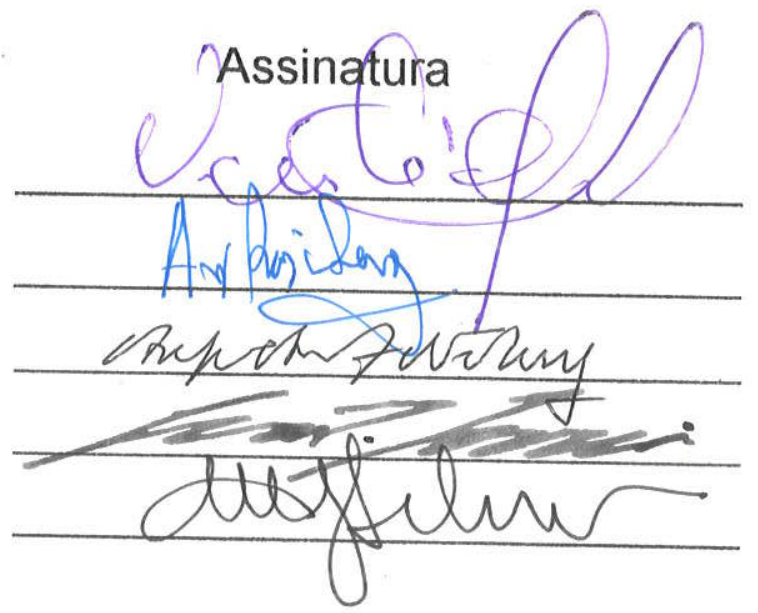

SÃO PAULO

1997 


\section{UNIVERSIDADE DE SÃO PAULO INSTITUTO DE GEOCIENCIAS}

\section{CONTRIBUIÇÃO A PETROLOGIA E GEOQUÍMICA DO MAGMATISMO BASÁLTICO MESOZÓICO DO ESTADO DE RORAIMA.}

Angela Beatriz de Menezes Leal

Orientador: Prof. Dr. Vicente Antonio Vitório Girardi

TESE DE DOUTORAMENTO

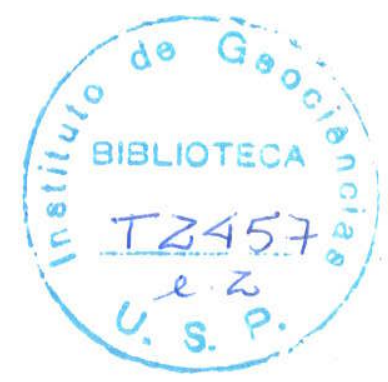

Programa de Pós-Graduação em Mineralogia e Petrologia

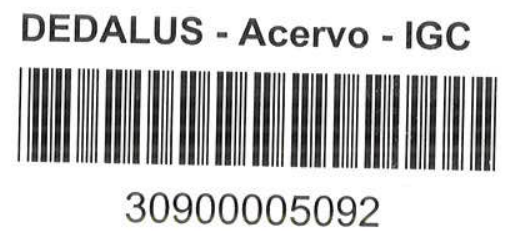

SĀO PAULO

1997 
A Luiz Rogério e Pedro, com carinho 


\section{INDICE}

CAPÍTULO 1 - INTRODUÇÃO

1.1. Tema da tese e objetivos 01

1.2. Importância do tema 01

CAPÍTULO 2 - METODOLOGIA HMPREGADA 03

2.1. Revisão bibliográfica 03

2.2. Trabalhos de campo 03

2.3. Métodos petrográficos 05

2.4. Métodos químicos 05

2.5. Métodos radiométricos 06

CAPÍTULO 3 - GEOLOGIA 10

3.1. Localização da área e vias de acesso 10

3.2. Geologia Regional 11

3.3. Contexto geológico da região estudada 17

CAPÍTULO 4- CLASSIFICAÇÃO E NOMENCLATURA 23

CAPÍYULO 5- CARACTERIZAÇÃO PETROGRÁFICA 27

5.1. Diques Máficos 28

5.2. Derrames basálticos 37

CAPÍTULO 6- QUIMISMO DAS FASES MINERAIS 42

6.1. Diques Máficos 43

6.2. Derrames Basálticos 66

CAPÍTULO 7- CARACTERIZAÇÃO GEOQUÍMICA 76

7.1. Geoquímica de elementos maiores 76

7.2. Geoquímica de elementos traços 79

7.3. Elementos terras raras 87

CAPÍTULO 8 - GEOCRONOLOGIA E GEOQUÍMICA ISOTÓPICA 92

CAPÍTULO 9- ASPECTOS PETROGENÉTICOS DO MAGMAISMO 106 MESOZÓICO DO ESTADO DE RORAIMA

9.1. Características da fonte 111

9.2. Caracterização dos processos magmáticos 113

9.3. Comparação com outras rochas basálticas 119 mesozóicas

CAPÍtulo 10- CONSIDERAÇões FINAIS 120

CAPÍTULO 11- REFERÊNCIAS BIBLIOGRÁFICAS 123 


\section{ÍNDICE DAS FIGURAS}

1- Mapa de amostragem das rochas pertencentes a suite

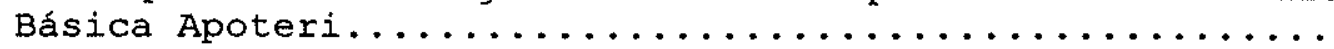

2- Mapa de localização da área estudada..............

3- Localização esquemática da área de estudo, segundo o

arranjo das Províncias do Craton Amazônico.............

4- Mapa geológico simplificado da porção NE do estado de

5- Diagrama silica-álcalis total (TAS) segundo Le Bas et

al. (1986) para as rochas da Suíte Básica Apoteri......

6- Classificação e nomenclatura adotada para as rochas pertencentes a Suíte Básica Apoteri com base no diagrama R1xR2 (De La Roche et al.(1980); Bellieni et al. (1981).

7- Diagrama $\mathrm{A}\left(\mathrm{Na}_{2} \mathrm{O}+\mathrm{K}_{2} \mathrm{O}\right), \quad \mathrm{F}\left(\mathrm{FeO}+0.8998 \mathrm{Fe}_{2} \mathrm{O}_{3}\right), \quad \mathrm{M}(\mathrm{MgO})$ das

rochas pertencentes a suite Básica Apoteri............

8- Quadrilátero dos piroxênios $\left(\mathrm{Ca}-\mathrm{Mg}-\mathrm{Fe}^{\star}\right)$, segundo Poldervaart \& Hess (1951) para os diques máficos da Suíte

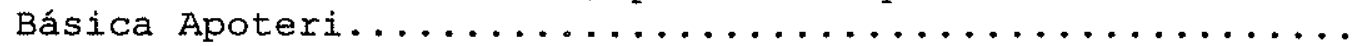

9- Variação composicional em termos de Ca-Mg-Fe* (8 atômica) dos piroxênios dos diques máficos da suite

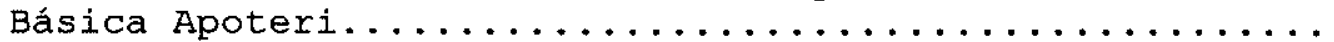

10- Diagrama Hiperstênio(Hy)-Diopsidio(Di)-Nefelina(Ne) normativos (CIPW) para os piroxênios dos diques máficos da Suíte Básica Apoteri.....................

11- Variação composicional com base no conteúdo de albita (Ab)-anortita (An)-ortoclásio(Or) ( 8 em peso) dos plagioclásios dos diques máficos (bth) da suíte Básica

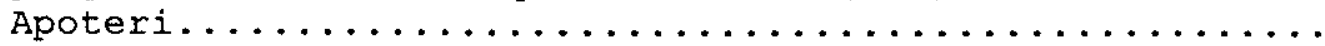

12- Variação composicional com base no conteúdo de albita ( $A b)$-anortita (An)-ortoclásio(Or) (o em peso) dos plagioclásios dos diques máficos (ab) da suíte Básica

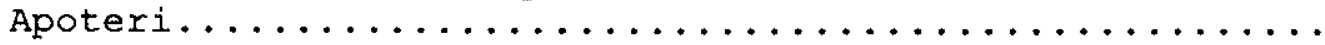

13- Quadrilátero dos piroxênios ( $\mathrm{Ca}-\mathrm{Mg}-\mathrm{Fe}^{\star}$ ), segundo Poldervaart \& Hess (1951) para os derrames basálticos da Suíte Básica Apoteri........................

14- Variação composicional em termos de Ca-Mg-Fe* ( 8 atômica) dos piroxênios dos derrames basálticos da suite Básica Apoteri..........................

15- Diagrama Hiperstênio(Hy)-Diopsidio(Di)-Nefelina(Ne) normativos (CIPW) para os piroxênios dos derrames basálticos da Suíte Básica Apoteri................. 
16- Variação composicional com base no conteúdo de albita (Ab)-anortita ( $\mathrm{A} n$ )-ortoclásio(Or) ( 8 em peso) dos plagioclásios dos derrames basálticos da suite Básica

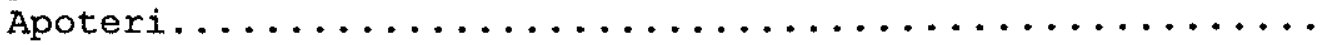

17- Diagrama de variação entre mg\# valores $\left[\mathrm{Mg}^{+2} / \mathrm{Mg}^{+2}+\mathrm{Fe}^{+2}\right.$; $\left.\mathrm{Fe}_{2} \mathrm{O}_{3} / \mathrm{FeO}=0.15\right]$ vs elementos maiores ( 8 em peso) para as rochas da Suíte Básica Apoteri...................

18- Diagrama de variação entre mg\# valores $\left[\mathrm{Mg}^{+2} / \mathrm{Mg}^{+2}+\mathrm{Fe}^{+2}\right.$; $\left.\mathrm{Fe}_{2} \mathrm{O}_{3} / \mathrm{FeO}=0.15\right]$ vs elementos traços (ppm) para as rochas

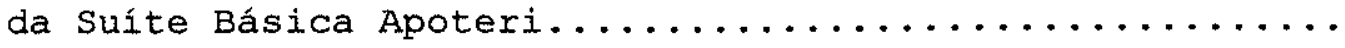

19- Diagrama de variação entre mg\# valores $\left[\mathrm{Mg}^{+2} / \mathrm{Mg}^{+2}+\mathrm{Fe}^{+2}\right.$; $\left.\mathrm{Fe}_{2} \mathrm{O}_{3} / \mathrm{FeO}=0.15\right]$ vs elementos maiores ( $8 \mathrm{em}$ peso) das amostras representativas da borda ao centro do dique máfico do ponto 18 da Suíte Básica Apoteri............

20- Diagrama de variação entre mg\# valores $\left[\mathrm{Mg}^{+2} / \mathrm{Mg}^{+2}+\mathrm{Fe}^{+2}\right.$; $\left.\mathrm{Fe}_{2} \mathrm{O}_{3} / \mathrm{FeO}=0.15\right]$ vs elementos traços (ppm) das amostras representativas da borda ao centro do dique máfico do ponto 18 da Suíte Básica Apoteri..................

21- Diagrama de correlação entre $\mathrm{Zr}$ (ppm) e elementos traços (ppm) das rochas da Suíte Básica Apoteri........

22- Padrão de distribuição dos elementos terras raras para as rochas da Suíte Básica Apoteri..............

23- Padrão de distribuição dos elementos incompatíveis para as rochas da Suite Básica Apoteri..............

24- Diagrama de frequencia de distribuição das idades KAr por países no tempo geológico para os diques máficos da Suíte Básica Apoteri......................

25- Diagrama de frequência de distribuição das idades KAr por países no tempo geológico para os derrames basálticos da Suíte Básica Apoteri................

26- Diagrama isocrônico Rb-Sr dos diques máficos da suíte Básica Apoteri........................... 27- Diagrama isocrônico Rb-Sr dos derrames basálticos da Suíte Básica Apoteri........................

28- Diagrama de evolução isotópica do $\mathrm{Sr}\left({ }^{8 /} \mathrm{Sr} /{ }^{46} \mathrm{Sr}\right.$ inicial) e Nd $\left({ }^{143} \mathrm{Nd} /{ }^{144} \mathrm{Nd}\right.$ inicial) no tempo geológico para os diques máficos da Suite Básica Apoteri............

29- Diagrama ESr vs eNd dos diques máficos com valores recalculados para 204Ma da Suíte Básica Apoteri....... 
30- Diagrama de evolução isotópica do $\mathrm{Sr}\left({ }^{8 / 6} \mathrm{Sr} /{ }^{86} \mathrm{Sr}\right.$ inicial) no tempo geológico para os derrames basálticos da Suíte Básica Apoteri......................

31- Diagrama $\varepsilon S x$ vs $\varepsilon N d$ dos derrames basálticos com 105 valores recalculados para $136 \mathrm{Ma}$ (DE) da Suíte Básica

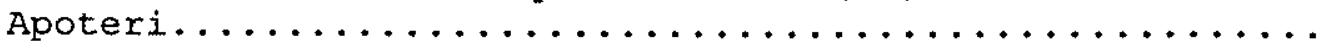

32- Diagrama de correlação entre Sri e $\mathrm{SiO}_{2}, \mathrm{~K}_{2} \mathrm{O}, \mathrm{Rb} / \mathrm{Sr}$, 109

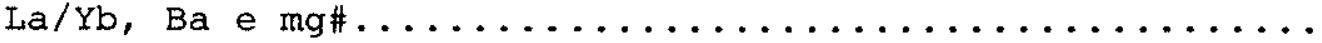
33- Diagrama de correlação entre $\mathrm{Ndi}$ e $\mathrm{SiO}_{2}, \mathrm{~K}_{2} \mathrm{O}, \mathrm{Rb} / \mathrm{Sr}$,

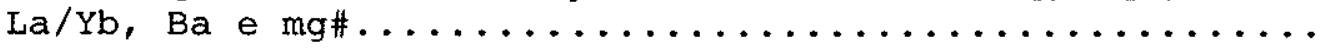
33- Variação do modelo de elementos traços incompatíveis das rochas "primárias" da Suíte Básica Apoteri.........

\section{INDICE DAS TABELAS}

1- Microanálise química dos piroxênios ricos em cálcio dos diques máficos da Suíte Básica Apoteri............

2- Microanálise química dos piroxênios pobres em cálcio dos diques máficos da Suite Básica Apoteri...........

3- Temperatura de cristalização dos piroxênios dos diques máficos (bth) da Suíte Básica Apoteri...............

4- Temperatura de cristalização dos piroxênios dos diques máficos (ab) da Suíte Básica Apoteri................

5- Microanálise química dos plagioclásios dos diques

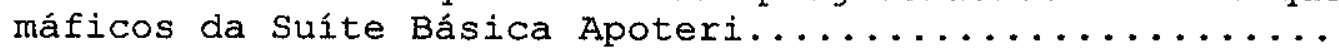

6- Temperatura dos plagioclásios dos diques máficos (bth)

da Suíte Básica Apoteri.......................

7- Temperatura dos plagioclásios dos diques máficos (ab)

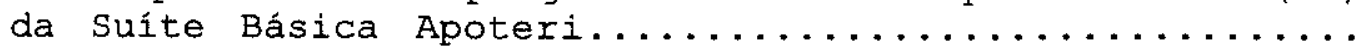

8- Microanálise química dos anfibólios dos diques máficos

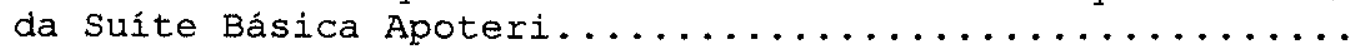

9- Microanálise química das magnetitas dos diques máficos

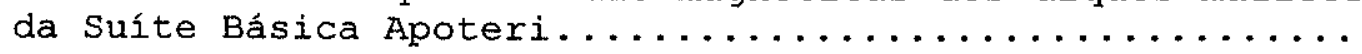

10- Microanálise química das ilmenitas dos diques máficos

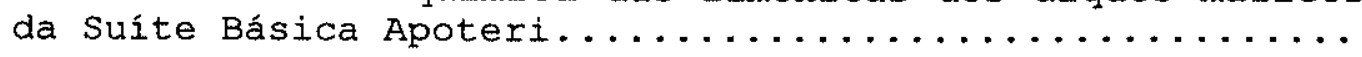

11- Microanálise química dos piroxênios ricos em cálcio dos derrames basálticos da Suíte Básica Apoteri......... 
12- Microanálise química dos piroxênios pobres em cálcio dos derrames basálticos da Suíte Básica Apoteri.........

13- Temperatura de cristalização dos piroxênios dos derrames basálticos da Suíte Básica Apoteri..........

14- Microanálise química dos plagioclásios dos derrames basálticos da Suíte Básica Apoteri.................

15- Microanálise química das magnetitas dos derrames basálticos da Suíte Básica Apoteri................

16- Média dos elementos maiores ( 8 em peso) das rochas da Suíte Básica Apoteri........................

17- Média dos elementos traços (ppm) das rochas da Suite Básica Apoteri..........................

18- Média dos elementos maiores (o em peso) e traços (ppm) dos diques máficos de granulação fina e média da Suíte Básica Apoteri.......................

19- Tabela geocronológica $K-A r$ para as rochas da suite Básica Apoteri..........................

20- Dados analiticos Rb-Sr das rochas da Suite Básica Apoteri...............................

21- Dados analíticos Sm-Nd das rochas da Suite Básica

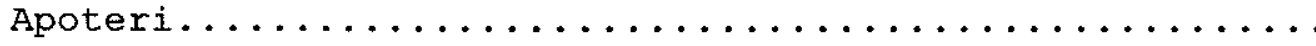

22- Razões iniciais ${ }^{87} \mathrm{Sr} /{ }^{86} \mathrm{Sr}$ e ${ }^{143} \mathrm{Nd} /{ }^{144} \mathrm{Nd}$, ESr, ENd, razões 101 $\mathrm{Rb} / \mathrm{Sr}$ e $\mathrm{Sm} / \mathrm{Nd}$ das rochas da Suíte Básica Apoteri..............................

24- Resultados obtidos na aplicação do modelo de 116 cristalização fracionada para os elementos maiores dos diques máficos da Suíte Básica Apoteri.............

25- Resultados do modelamento geoquímico para elementos traços e terras raras para os diques máfciso da suite

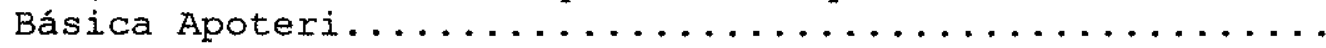

\section{ÍNDICE DAS FOTOGRAFIAS}

1- Dique máfico em contato com rocha vulcânica do Grupo

Surumu.............................

2- Detalhe da porção mais diferenciada do dique máfico..

3- Vista geral do Morro Redondo.................

4- Vista geral da Pedreira Santa Fé- Nova Olinda....... 


\section{INDICE DAS FOTOMICROGRAFTAS}

1- Amostra RR-18A. Contato rocha vulcânica do Grupo

Surumu/ dique máfico......................

2- Amostra RR-18D. Dique máfico. Andesi-basalto. Aspecto

geral da textura fracamente porfirítica.............

3- Amostra RR-18E. Dique máfico. Basalto Toleítico. Aspecto geral da textura intergranular..............

4- Amostra RR-18F. Dique máfico. Basalto Toleítico. Aspecto geral da textura subofítica...............

5- Amostra RR-18G. Dique máfico. Basalto toleitico.

Aspecto geral da textura subofitica.................

6- Amostra RR-17. Dique máfico. Andesi-basalto........

7- Amostra RR-17. Dique máfico. Andesi-basalto. Aspecto

geral da textura subofitica....................

8- Amostra RR-06B. Derrame basáltico. Andesi-basalto. Aspecto geral da disposição dos minerais. Material vítreo

de coloração castanha........................

9- Amostra RR-06B. Derrame basáltico. Andesi-basalto. Aspecto geral da textura intergranular a intersertal....

10- Amostra RR-08A. Derrame basáltico. Lati-basalto.

Aspecto geral da textura intergranular..............

\section{ARÊNDICES}

1- Tabela com os dados de campo das rochas da suite Básica Apoteri

2- Análise química de rocha total para as rochas da suíte Básica Apoteri

3- Análise química dos elementos terras raras para as rochas da Suíte Básica Apoteri

4- Tabela com as descrições petrográficas simplificadas das rochas da Suíte Básica Apoteri

5- Análise química da olivina e apatita utilizadas no cálculo do balanço de massa para elementos maiores

6- Coeficientes de partição mineral/líquido utilizados nos modelos de cristalização fracionada para os diques máficos 
originados por cristalização fracionada. Cálculo de balanço de massa (elementos maiores) mostra que a passagem dos DM menos evoluidos para os mais evoluídos é compatível com o modelo de cristalização fracionada do tipo gabro com fracionamento de plagioclásio e piroxênio, bem como para os elementos traços e terras raras (fracionamento de Rayleigh) que demonstrou diferenças mínimas entre as concentrações dos elementos observados e calculados a exceção do $\mathrm{Cr}$ e $\mathrm{Ni}$.

Em relação aos $\mathrm{DE}$, os valores de $\mathrm{mg} \#\left[\mathrm{Mg}^{+2} /\left(\mathrm{Mg}^{+2}+\mathrm{Fe}^{+2}\right)\right.$; $\left.\mathrm{Fe}_{2} \mathrm{O}_{3} / \mathrm{FeO}=0.15\right]$ variam de 0.45 a 0.53 e possuem comportamento geoquímico dos elementos maiores, traços e terras raras bastante semelhantes aos DM, exceto para $\circ \mathrm{K}_{2} \mathrm{O}, \mathrm{Na}_{2} \mathrm{O}$ e $\mathrm{H}_{2} \mathrm{O}$ que mostram valores um pouco mais elevados, provavelmente associado a presença de zeólitas nas amígdalas. Razões (La/Yb)n variam de 3.48 e 3.72 (média de $3.64 \pm 0.11$ ), (La/Sm) n entre 2.21 e 2.39 (média de $2.22 \pm 0.09)$ e $(\mathrm{Sm} / \mathrm{Yb}) \mathrm{n}$ entre 1.55 e 1.66 (média de $1.61 \pm 0.04)$. Através dos diagramas de elementos maiores, menores e traços verifica-se que o processo de cristalização fracionada é compatível com o processo evolutivo destas rochas.

- padrão de distribuição dos elementos incompatíveis normalizados para o manto primitivo tanto para os DM como para os $\mathrm{DE}$ mostra padrão mais enriquecido emo $\mathrm{Rb}$ em relação ao $\mathrm{K}$ e $\mathrm{Ba}$ e nestes elementos em relação a todos os outros incompatíveis. Possuem altas razões $\mathrm{Rb} / \mathrm{Sr}$ e são fortemente empobrecidos em $\mathrm{Nb} e$ Ti.

- conjunto de dados isotópicos $\mathrm{K}$-Ar referenciados na literatura revela picos de idades em torno de $200 \mathrm{Ma}$ para os DM e de $150 \mathrm{Ma}$ para os DE. De outra parte dados isotópicos Rb-Sr produziram idades de $311 \pm 40 \mathrm{Ma}(1 \sigma)$ e razão ${ }^{87} \mathrm{Sr} /{ }^{86} \mathrm{Sr}$ inicial $\left(S r_{i}\right)$ em torno de 0,707 para os DM e idade de $136 \pm 13 \mathrm{Ma}$ ( $\left.1 \sigma\right)$ com razão inicial ${ }^{87} \mathrm{Sr} /{ }^{86} \mathrm{Sr}\left(\mathrm{Sr}_{i}\right)$ de 0,710 para os $\mathrm{DE}$.

A evolução isotópica do $\mathrm{Sr}$ e $\mathrm{Nd}$ indica que os $\mathrm{DM}$ e os DE foram derivados de uma fonte mantélica enriquecida comparativamente a "Terra Global" e que fenômenos de contaminação crustal estiveram presentes na formação destas rochas. A correlação entre as razões iniciais ${ }^{87} \mathrm{Sr} /{ }^{86} \mathrm{Sr} e$ ${ }_{143} \mathrm{Nd} /{ }^{144} \mathrm{Nd} e \mathrm{SiO}_{2}, \mathrm{~K}_{2} \mathrm{O}, \mathrm{Rb} / \mathrm{Sr}, \mathrm{Ba}, \mathrm{La} / \mathrm{Yb}$ e mg\# evedenciam este fato.

Considerando as amostras menos contaminadas e recalculandoas para possíveis composições "primitivas" de um magma tipo olivina toleito (mg\# 0.86-0.88) observa-se que seriam necessários graus de fusão em torno de $10 \%$ para gerar os DM $e$ DE. Atribuindo-se $10 \%$ de grau de fusão para a geração destas rochas, a fonte mantélica seria enriquecida em elementos LILE ( $\mathrm{K}, \mathrm{Rb}$ e $\mathrm{Ba}$ ) e ETR leves (La e Ce) e empobrecida em $\mathrm{Nb}$ e $\mathrm{Ti}$. 
The mesozoic basaltic magmatism of the northeastern of the state of Roraima within the Guiana sield is formed by dykes and flows of the Apoteri Basic suite. The mafic dykes (DM) intrude precambriam rocks and are predominantly oriented N40-50E and NNESSW. Widths vary from a few $\mathrm{cm}$ to hundreds of $\mathrm{m}$, with a predominance between 3 and $8 \mathrm{~m}$, while lenghts are very variable. The basaltic flows (DE) are massive and amygdaloid anf from small hills.

The DM have subophitic to ophitic textures. The predominant minerals are plagioclase $\left(\mathrm{An}_{43-70}\right)$ and pyroxenes (augite $\left(W_{31-42}\right)$, ortopyroxene $\left(W_{1-4}\right)$ and pigeonite $\left.\left(W_{10-16}\right)\right)$. Quartz occurs in graphic intergrowth with alkali feldspar. Opaques minerals, amphibole (ferrohornblende and ferro- actinolitic hornblende), biotite and apatite are accessory minerals. The DE have intergranular to interseral textures, with sericitized/saussuritized plagioclase and augite (Wo34-40) often with chlorite borders as the predominat minerals accompanied by scarce pigeonite (Wog-11). The accesories are opaque minerals and apatite. Interstitial glass is common, and amygdales are filled by quartz, carbonate minerals, apatite and zeolites.

Crystallization temperatures obtained for pyroxenes and plagioclase in $D M$ and $D E$ reveal a minimum temperature of about $1110^{\circ} \mathrm{C}$.

The DM are mainly tholeitic basalts and andesi-basalts while the DE are andesi-basalts or lati-basalts.

DM have mg\# $\left(\mathrm{Mg}^{+2} / \mathrm{Mg}^{+2}+\mathrm{Fe}^{+2} ; \quad \mathrm{Fe}_{2} \mathrm{O}_{3} / \mathrm{FeO}=0.15\right)$ values between 0.37 and 0.57 and are therefore envolved types. During differentiation, $\mathrm{CaO}, \mathrm{Al}_{2} \mathrm{O}_{3}, \mathrm{Cr}, \mathrm{Ni}$ and $\mathrm{Sc}$ decrease while $\mathrm{SiO}_{2}$, $\mathrm{TiO}_{2}, \mathrm{Na}_{2} \mathrm{O}, \mathrm{K}_{2} \mathrm{O}, \mathrm{P}_{2} \mathrm{O}_{5}$ and incompatible elements increase. Condrite-normalized rare earth element (REE) patterns show moderate enrichment of the light REE relative to the heavY REE.

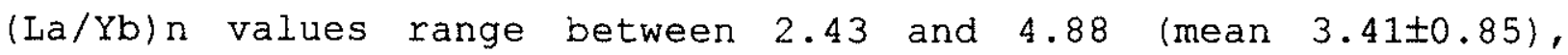

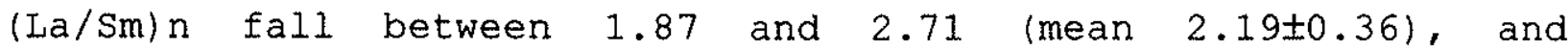
$(\mathrm{Sm} / \mathrm{Yb}) \mathrm{n}$, between 1.25 and 1.78 (mean $1.54 \pm 0.16$ ). Diagrams of incompatible elements $v s \mathrm{Zr}$ suggest that the source composition was relatively homogeneous and that DM formed by fractional crystallization. Mass balance calculation for the major elements show that fractionation of gabbro (plagioclasetpyroxene) is adequate to produce the DM suite, while Rayleigth fractionation of most trace elements includig $\mathrm{REE}$ but excluding $\mathrm{Cr}$ and $\mathrm{Ni}$ results in minimal differences between observed and calculated compositions.

Values of $\mathrm{mg \#}$ in $\mathrm{DE}$ range between 0.45 and 0.53 . The geochemical behavior of the major and trace elements is similar to that observed in $D M$, except $\mathrm{K}_{2} \mathrm{O}, \mathrm{Na}_{2} \mathrm{O}$ and $\mathrm{H}_{2} \mathrm{O}$ contents are slightly higher in DE, perhaps associated with the presence of 
zeolites in the amyddales. ( $\mathrm{La} / \mathrm{Yb}) \mathrm{n}$ values are between 3.48 and

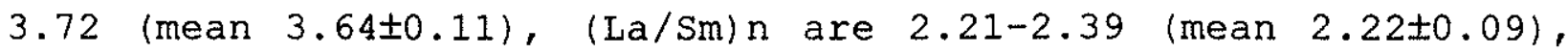

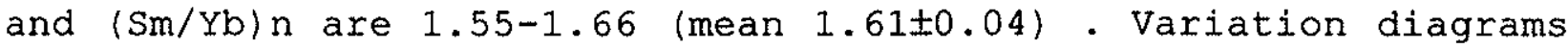
show that fractional crystallization could be the petrogenetic process involved.

Patterns of incompatible elements normalized to primitive mantle show that both $D M$ and $D E$ has enrichment of $R b$ relative to $\mathrm{K}$ and $\mathrm{Ba}$, while these three elements are enriched relative to the other incompatible elements. $\mathrm{Rb} / \mathrm{Sr}$ ratios are high, and the rocks are strongly impoverished in $\mathrm{Nb}$ and $\mathrm{Ti}$.

Published $\mathrm{K}-\mathrm{Ar}$ data reveal age frequency peaks around $200 \mathrm{Ma}$

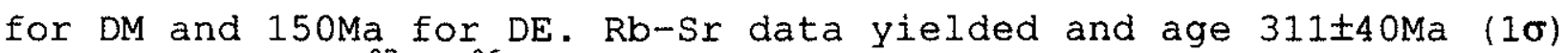
and an initial ${ }^{87} \mathrm{Sr} /{ }^{86} \mathrm{Sr}$ ratio (Sri) of about 0.707 for DM and an age of $136 \pm 13 \mathrm{Ma}(1 \sigma)$ with $\mathrm{Sri}=0.710$ for $\mathrm{DE}$.

The isotopic evolution of $\mathrm{Sr}$ and $\mathrm{Nd}$ show both $\mathrm{DM}$ and $\mathrm{DE}$ were derived from a mantle source which was enriched relative to the whole earth, and that crustal contamination also occurred in these rocks. Correlations between Sri, Ndi and $\mathrm{SiO}_{2}, \mathrm{~K}_{2} \mathrm{O}, \mathrm{Rb} / \mathrm{Sr}$, $\mathrm{Ba}, \mathrm{La} / \mathrm{Yb}$ e mg\# confirm this.

Using the least contaminated samples, and calculating possible primitive composition of olivine tholeiites (mg\# $0.86-$ 0.88 ) show that about $10 \%$ partial melting would yield DM and DE magmas. With this degree of melting, the mantle source would have to be enriched in LILE ( $\mathrm{K}, \mathrm{Rb}$ and $\mathrm{Ba}$ ) and light REE (La and $\mathrm{Ce}$ ), and improverished in $\mathrm{Nb}$ and $\mathrm{Ti}$. 
Gostaria de externar os meus agadecimentos a pessoas $\epsilon$ entidades que de uma forma ou de outra contribuiram para a realização deste trabalho:

Ao Prof. Dr. Vicente Vitório Girardi pelo apoio e orientaçãc durante todo o desenvolvimento da pesquisa, estando em todos os momentos presente, sugerindo, questionando e ajudando para que o trabalho tivesse êxito.

Ao Conselho Nacional de Desenvolvimento Científico e Tecnológico (CNPq) pela concesão de bolsa de estudo e a Fundação de Amparo à Pesquisa do Estado de São Paulo (FAPESP) pela ajuda financeira para a realização dos trabalhos de campo e experimentais, através do processo 97/00640-5.

A Companhia de Pesquisa e Recursos Minerais (CPRM-MA) pelo apoio logístico nas etapas de campo, especialmente ao geólogo Sandoval da Silva Pinheiro.

Ao Prof. Dr. Wilson Teixeira pelas valiosas sugestões e discussões no capítulo da geologia e geocronologia.

Ao Prof. Dr. Ian McReath pela ajuda na confecção do abstract.

Ao Instituto de Geociências da Universidade Federal do Pará pelo uso doo Laboratório de Microscopia Óptica.

Ao corpo técnico do CPGeo-USP nas pessoas de Liliane Petronilho, Ivone Sonoki, Helen Sonoki, Artur onoe e Solange pela amizade e ajuda na execução das análises $\mathrm{Rb}-\mathrm{Sr}$ e $\mathrm{Sm}-\mathrm{Nd}$.

Aos colegas e amigos do curso de Pós-Graduação do Instituto de Geociências-USP, em especial a Alcina Magnólia Franca Barreto, Maria Zélia Aguiar de Sousa, Geysa Abreu Machado, Mírian Chieco, Rosana Pepporine, Raquel e Víctor Velasquez pelo grande estímulo e companherismo.

A Marta e ao Tadeu secretários do Departamento de Mineralogia e Petrologia, pelo atendimento cotidiano e amigo.

Aos técnicos da gráfica do Instituto de Geociências, especialmente ao Sr. Dalton da Silva, pela montagem dos exemplares da tese.

A equipe da biblioteca do Instituto de Geociências -USP pelo atendimento sempre muito acolhedor. 
Ao Instituto de Geoiências da Universidade de São Paulo e ac corpo docente nele lotado, por permitirem a utilização de suas instalações e equipamentos.

A Luiz Rogério e Pedro, um agradecimento muito especial, pelc companheirismo, amizade e carinho durante 0 decorrer deste trabalho. 


\subsection{TEMA DA TESE E OBJETIVOS}

o magmatismo basáltico situado na região nordeste do estado de Roraima, têm sido amplamente divulgado na literatura, especialmente através de projetos realizados por empresas e orgãos governamentais (ex: Companhia de Pesquisa e Recursos Minerais - CPRM, Departamento Nacional da Produção Mineral DNPM e projeto Radambrasil). Estes trabalhos enfocam especialmente a distribuição geográfica e posicionamento geológico deste magmatismo, existindo uma lacuna quanto 'aos estudos de caráter petrográfico, geoquímico, isotópico e petrogenético detalhados.

A pesquisa abrangerá o magmatismo basáltico intrusivo (sob a forma de diques) e extrusivo (lavas basálticas) que ocorre na porção nordeste do estado de Roraima, correspondentes a unidade Suíte Básica Apoteri, evoluída durante o Mesozóico. Através de estudos geológicos, petrográficos, mineralógicos, geoquímicos e isotópicos, pretende-se contribuir para o conhecimento deste magmatismo básico, possibilitando a comparação com outros eventos magmáticos mesozóicos de caráter básico da Plataforma Sul-Americana e fornecendo novas informações para o entendimento dos processos envolvidos na fragmentação do supercontinente Gondwana e a abertura do oceano Atlântico.

\subsection{TMPORTÂNCIA DO THYMA}

A importância do tema no estudo dos processos geodinâmicos tem sido destacada por vários autores (e.g. Halls, 1982; Windley, 1984; Collerson \& Sheraton, 1986; Halls \& Fahrig, 1987) mostrando que os enxames de diques máficos e seus correspondentes extrusivos são indicadores importantes da natureza e evolução das fontes mantélicas no tempo geológico, marcadores de esforços em regiões complexamente deformadas, estimadores de níveis de erosão, monitores de deformação associados a zonas de cisalhamento, podendo ainda, refletir a configuração de placas tectônicas (paleo stress). Adicionalmente enxame de diques máficos de diferentes idades estão registrados tanto no Gondwana como na Laurásia, e podem fornecer valiosas informações para o estudo da evolução da litosfera ao longo do tempo geológico (Halls \& Fahrig, 1987).

No Brasil, o estudo dos enxames de diques máficos e seu vulcanismo associado, tem sido frequentemente abordado, nos últimos dez anos, por vários pesquisadores através de estudos 
sistemáticos envolvendo tanto magmatismo precambriano como fanerozóico (ex: Sial et al., 1987; Pinesi, 1989; Bellienni et al., 1991, Menezes, 1992; Bastos Leal et al., 1994; Menezes Leal et a1., 1995; Pinesi, 1997).

Os dados apresentados para o magmatismo basáltico do nordeste de Roraima (petrográficos, geoquímicos, isotopicos e petrogenéticos) vem preencher uma lacuna existentes quanto ao posicionamento crono-estratigráfico da Suíte Básica Apoteri de idade mesozóica, bem como contribuir com novas informações para - entendimento dos processos envolvidos na gênese destas rochas. 


\subsection{REVISÃO BIBLIOGRÁFICA}

Foi realizada uma revisão bibliográfica pormenorizada da literatura existente sobre o contexto geológico regional do estado de Roraima, abrangendo mais especificamente publicações relacionadas ao magmatismo básico (intrusivo e extrusivo) localizado na porção nordeste deste estado. Este estudo bibliográfico foi seguido por um exame minucioso da literatura referente ao tema basaltos em geral, incluindo-se aí as ocorrências brasileiras e de outros países.

Nesta etapa da pesquisa bibliográfica, procurou-se sumarizar de maneira seletiva, as principais conclusões dos autores, bem como efetuar um apanhado dos assuntos desenvolvidos, abordando tanto os aspectos fisiográficos, geológicos e informações de caráter mais específico do estudo (ex.: petrografia, geoquímica, geocronologia, inferências tectônicas, entre outros assuntos).

\subsection{TRABATHOS DE CAMPO}

Para esta programação foram utilizadas as seguintes bases geológicas: Mapa Geológico do Projeto RADAMBRASIL (Montalvão et al., 1975) na escala de 1:1.000.000, Mapas Geológicos do Projeto Molibdênio em Roraima (Melo et al., 1978) na escala de 1:100.000 (Folhas NA.21-V-A-I, NA.20-X-B-I a VI, NB.20-Z-D-II a VI, NA.20-X-D-II, NA.21-V-A-I e IV E NB.21-Y-C-IV), além de Mapas Geológicos do projeto FUA/CNPq (Haddad et al., 1987) realizados por alunos de graduação da Fundação da Universidade do Amazonas, Instituto de Ciências Exatas, na escala de $1: 25.000$.

Foi realizada uma missão de campo, em janeiro de 1994, a qual contou com apoio da Companhia de Pesquisa e Recursos Minerais (CPRM-AM), através do acompanhamento do geólogo Sandoval da Silva Pinheiro. Durante esta etapa de campo, percorreu-se uma área equivalente a $5500 \mathrm{Km}^{2}$, objetivando familiarização com o contexto geólogico das principais unidades litoestratigráficas da região e proceder amostragem sistemática dos diferentes corpos básicos.

Considerando-se as peculariedades da região, como ausência ou escassez de estradas transitáveis, dificultando o acesso à área de trabalho, foi possível a realização de uma amostragem sistemática e controlada dos corpos intrusivos e 
extrusivos, fazendo-se descrição completa dos afloramentos, incluindo estudos sobre as formas, dimensões, contatos, espessuras, rochas encaixantes, atitudes, etc.

Os corpos amostrados totalizaram 79 amostras assim distribuídas: 57 amostras de diques máficos, 16 amostras dos derrames basálticos e 6 amostras do embasamento. O mapa de amostragem pode ser visto na figura-1, ao passo que no apêndice-1 são apresentadas informações detalhadas de cada afloramento visitado.

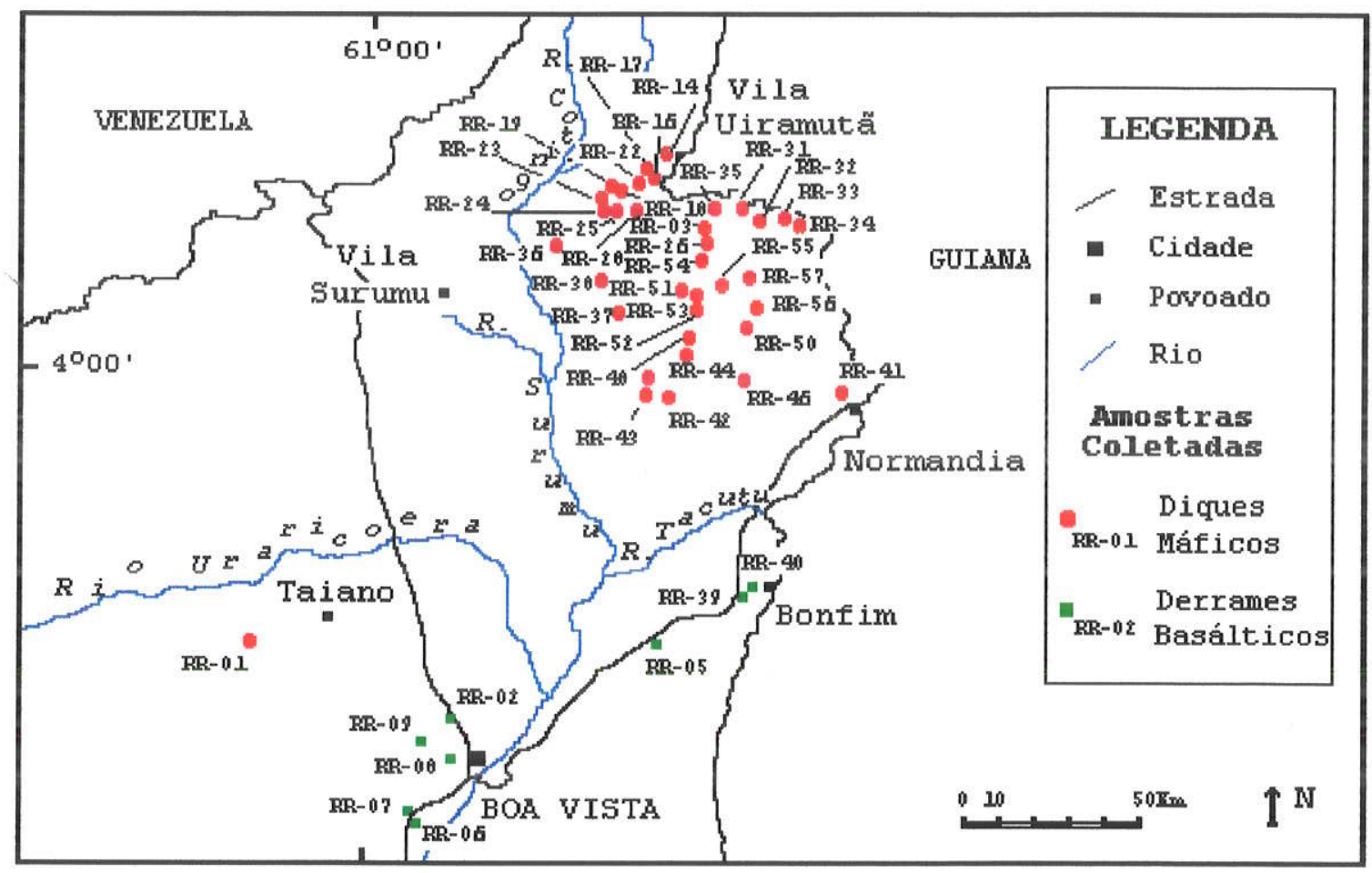

Figura 1 - Mapa de amostragem das rochas (diques máficos e derrames basálticos) da Suíte Básica Apoteri.

\subsection{MÉTODOS PETROGRÁFICOS}

Todas as amostras coletadas foram analisadas macro e microscopicamente. O microscópio petrográfico que foi utilizado é um aparelho binocular de fabricação Leitz, modelo Ortholux Pol, do Instituto de Geociências/Departamento de Mineralogia e Petrologia-USP e do Instituto de Geociência da UFPa. 
As análises petrográficas constaram de caracterização granulométrica, mineralógica e textural das rochas, bem como a avaliação dos porcentuais em volume de seus constituintes minerais.

É importante saliéntar que os dados petrográficos obtidos foram utilizados para separar conjuntos de rochas e serviram como elementos de orientação para seleção de amostras para estudos geoquímicos e geocronológicos.

\subsection{MÉTODOS QUÚMICOS}

Um total de 50 amostras (42 amostras dos diques máficos e 8 amostras dos derrames basálticos), foram analisadas quimicamente para determinação das concentrações de elementos maiores, menores e traços, através de Fluorescência de Raios X, na Universidade de Modena, Itália (Apêndice-2).

O método analítico utilizado foi o de Franzini et al.(1975) e Leoni \& Saitta (1976). Os erros analíticos para os elementos maiores são em geral menores que 38 , a exceção de $\mathrm{P}_{2} \mathrm{O}_{5}$ ( $\sim 8 \%), \mathrm{Na}_{2} \mathrm{O}$ ( $\left.\sim 5 \%\right), \mathrm{TiO}_{2}$ ( $\sim 5 \%$ ) e MnO ( 15\%) e para os elementos traços os limites de detecção foram sempre inferiores a $6 \mathrm{ppm}$.

A preparação das amostras foi realizada no Laboratório de Preparação de Amostras do DMP/Instituto de Geociências/USP, seguindo as seguintes etapas: após a prensa e moagem em moinhos de ágata, foram confeccionadas pastilhas de pó para prensagem durante 30 segundos à pressão de 60 bar, em invólucro contendo ácido bórico, que constitui a parte externa e manipulável da pastiliha.

A ánalise de perda ao fogo foi realizada no Laboratório de Química Quantitativa do DMP/Instituto de Geociências/USP, utilizando o método de Gravimetria.

As composições químicas de elementos terras raras (ETR) foram realizadas por Ativação Neutrônica em laboratório comercial do Canadá (ACTLABS - Activation Laboratories, Ontário). OS ETR analisados e seus respectivos limites de detecção, em ppm, foram os seguintes: Ce e Nd (1), $\mathrm{Tb}$ (0.1), La, Eu e Yb (0.05) e Sm e Lu (0.01) (Apêndice-3).

No Laboratório de Microssonda e Microscopia Eletrônicä de Varredura do DMP/Instituto de Geociências-USP, foram realizadas análises químicas minerais quantitativas nas fases feldspatos, piroxênios, anfibólios e minerais opacos. O aparelho utilizado foi uma microssonda eletrônica JEOL, modelo JXA-8600, com 5 espectrômetros. Utilizou-se nas análises quantitativas (WDS - 
Wavelenght Dispersive System) o sistema de análises automatizada Tracor-Northern (Noran Instruments, 1990), nas seguintes condições de rotina: voltagem de aceleração $15 \mathrm{KW}$, corrente do feixe $20 \mathrm{nA}$, diâmetro do feixe $5 \mu \mathrm{m}$. Correções quantitativas ZAF para, efeitos de matriz ( $z-n^{\circ}$ atômico, $A-$ absorção atômica, F-fluorescêncial foram executadas através do programa Flextron PR2 (Noran Instruments, 1990). O erro analítico máximo estimado é de $\pm 3 \%$ para os elementos maiores analisados.

os elementos analisados são apresentados a seguir, com os respectivos cristais e padrões utilizados, sendo que a exceção do $\mathrm{Na}$ (5 segundos) todos os outros elementos tiveram seu tempo de contagem em 10 segundos:

\begin{tabular}{|c|c|c|}
\hline ELEMENTO & CRISTAI & PADRÃO \\
\hline $\mathrm{Si}$ & TAP & wollastonita \\
\hline $\mathrm{Ti}$ & LiE & rutio \\
\hline $\mathrm{A}$ & $\mathrm{TAP}$ & coríndon \\
\hline $\mathrm{Cr}$ & $\mathrm{Li}$ & cromita \\
\hline $\mathrm{Ee}$ & LiF & hematita \\
\hline $\mathrm{Mn}$ & $\overline{\mathrm{L}} \mathrm{iF}$ & rodonita \\
\hline $\mathrm{Mg}$ & $\mathrm{TAP}$ & periclásio \\
\hline Ni & $\overline{\mathrm{LiF}}$ & Ni-olivina \\
\hline $\mathrm{Ca}$ & $\mathrm{PET}$ & wollastonita \\
\hline $\mathrm{Na}$ & $\mathrm{TAP}$ & andesina \\
\hline $\mathrm{K}$ & $\mathrm{PET}$ & microclina \\
\hline
\end{tabular}

- material a ser analisado foi preparado em forma de seções delgadas polidas circulares, metalizadas com carbono. O acervo analisado compreende 17 amostras (13 dos diques máficos e 4 dos derrames basálticos).

\subsection{MÉTODOS RADTOMÉTRICOS}

Foram analisadas um total de 14 amostras ( 7 dos diques máficos e 7 das lavas basálticas) pelos métodos $\mathrm{Rb}-\mathrm{Sr}$ e $\mathrm{Sm}-\mathrm{Nd}$ em rocha total no centro de Pesquisa Geocronológica do Instituto de Geociências-CPGeo da Universidade de São Paulo.

\subsubsection{METODOLOGIA Rb-Sx}

Todas as amostras pulverizadas foram inicialmente submetidas a uma dosagem prévia dos elementos Rb e $\mathrm{Sr}$ através de fluorescência de raios $X$ (análise semi-quantitativa). Em função dos valores obtidos, foram então selecionadas as 
amostras mais favoráveis, levando-se em conta a razão $\mathrm{Rb} / \mathrm{Sr}$ total e a distribuição dos pontos analíticos nos diagramas isocrônicos (as que apresentaram bom espalhamento ao longo da abcissa $x$ ).

Obedecendo a rotina para análises Rb-Sr do CPGeo, as dosagens quantitativas de $\mathrm{Rb}_{t}$ e $\mathrm{Sr}_{t}$ foram efetuadas por fluorescência de raios $x$ para as amostras com teores destes elementos entre 50 e 500 ppm. Ao passo que amostras com teores fora deste intervalo, tem suas concentrações determinadas por diluição isotópica, utilizando-se traçadores enriquecidos de $\mathrm{Rb}_{87}$ e $\mathrm{Sr}_{84}$ ("spike"), de acordo com o procedimento descrito por Kawashita (1972). O procedimento para o ataque químico utliza, principalmente os ácidos nítrico $\left(\mathrm{HNO}_{3}\right)$ a $50 \%$ concentrado e destilado, clorídrico ( $\mathrm{HCl}$ ) $2,62 \mathrm{~N}$ e $6,0 \mathrm{~N}$, fluorídrico (HF) e perclórico $\left(\mathrm{HClO}_{4}\right)$ a 508 .

Algumas amostras dos diques máficos e dos derrames necessitaram ser quantificados por diluição isotópica para a determinação precisa dos conteúdos de $\mathrm{Rb}$ e Sr. A separação do estrôncio foi feita em colunas de troca iônica, da mesma forma que o rubídio das amostras com teores muito baixos deste elemento.

As medidas da composição isotópica de estrôncio foram feitas em espectrômetro de massa VG-354 termoiônico, dotado de coletor múltiplo opcional ( 5 coletores) com amplificador Daly e sistema automático ou semi-automático.

A reprodutividade analítica para o método geocronológico $\mathrm{Rb}-\mathrm{Sr}$ no CPGeo-USP, é controlada pela repetição de análises do padrão internacional NBS-987 (carbonato de estrôncio), tendo sido obtido um valor médio de $0.71026+/-0.0 .0003$ no período das amostras aqui estudadas.

Os valores das razões ${ }^{87} \mathrm{Sr} /{ }^{86} \mathrm{Sr}$ foram normalizadas em função da relação ${ }^{86} \mathrm{Sr} /{ }^{88} \mathrm{Sr}$ igual a 0.1194 , tendo sido utilizadas nos cálculos as constantes recomendadas por steiger \& Jäeger (1978), a saber:

$\lambda \mathrm{Rb}=1,42 \quad \cdot 10^{-11}$ anos $^{-1}$
${ }^{84} \mathrm{Sr} /{ }^{86} \mathrm{Rb}=0,056584$
${ }^{85} \mathrm{Rb} /{ }^{87} \mathrm{Rb}=2,59265$




\subsubsection{METODOLOGIA Sm-Nd}

- procedimento para a preparação da amostra na metodologia $\mathrm{Sm}-\mathrm{Nd}$ em rocha total é semelhante ao do $\mathrm{Rb}-\mathrm{Sr}$ em rocha total em termos de separação e escolha das amostras.

O procedimento químico é semelhante ao do Rb-Sr, porém utiliza-se os ácidos $\mathrm{HCl} 6,2 \mathrm{~N}$ e 2,5N. A quantidade de "spike" combinado Sm-Nd depende da amostra e da concentração do "spike". Caso haja residuo, deixar em aquecimento por mais tempo e, se o resíduo persistir secar e atacar novamente com $\mathrm{HNO}_{3}$ e $\mathrm{HF}$.

$\mathrm{Na}$ metodologia Sm-Nd os elementos são separados em duas etapas, sendo a primeira em coluna de troca iônica (separa-se o conjunto de elementos terras raras dos outros elementos) e a segunda em coluna de pó de teflon (separamse o $\mathrm{Sm} e \circ \mathrm{Nd}$ dos demais elementos terras raras).

Trabalhos sobre a implantação da metodologia Sm-Nd no CPGeo-USP com detalhes dos procedimentos químicos e espectrométricos utilizados são encontrados em sato et al., 1995.

As constantes utilizadas no cálculo isotópico foram as seguintes (Michard et al., 1985):

$$
\begin{array}{|l}
\lambda_{147}=6,54 \cdot 10^{-12} \text { anos } \\
\left({ }^{143} \mathrm{Nd} /{ }^{144} \mathrm{Nd}\right) \\
\left({ }^{147} \mathrm{Sm} /{ }^{144} \mathrm{Nd}\right){ }_{0} \mathrm{CHUR}=0,512638-\mathrm{DM}=0,1967-\mathrm{DM}=0,513114 \\
\hline
\end{array}
$$

\subsection{TRATAMBNTO DOS DADOS ANAAIITICOS}

Os dados obtidos, tanto das análises químicas de rocha total como de minerais foram processadas e estudadas com auxilio de programa para processamento de dados mineralógicos e petrológicos Minpet for Windows (versões 2.0 e 2.02, Minpet Geological Software; Richard, 1995)) e Newpet for Dos (versão 7.10, Newpet Copyrigth Microsoft Corporation; Clarke, 1993)).

O procedimento inclui organização dos arquivos, digitação dos dados, correções e cálculos de fórmulas estruturais, razões entre constituintes e normas, entre outros, e lançamento dos dados processados em diagramas de variação e classificatórios binários e ternários para interpretação. 
Para o cálculo das idades Rb-Sr e parâmetros isotópicos $\left(\varepsilon_{\mathrm{Sx}}\right.$ e $\left.\varepsilon_{\mathbb{N d}}\right)$ foram utilizados os programas do Centro de Pesquisas Geocronológicas da USP/CPGeo-USP. 


\subsection{IOCALIZAÇÃO DA ÁREA ESTUDADA E VIAS DE ACESSO}

A área de estudo localiza-se aproximadamente entre as coordenadas $2^{\circ} 39^{\prime}$ e $4^{\circ} 39^{\prime}$ de latitude norte e $59^{\circ} 30^{\prime}$ e $61^{\circ} 20^{\prime}$ de longitude oeste, no extremo nordeste do estado de Roraima, situando-se desde as circunvizinhanças da cidade de Boa Vista até as imediações da Vila Uiramutã (Figura-2).

- acesso a área de pesquisa em sua porção mais nordeste, a partir de Boa Vista, foi realizado através da rodovia não pavimentada BR-174 que liga esta capital a Santa Helena de Uairen, na Venezuela. Na altura do $\mathrm{Km}-170$ toma-se a rodovia RR06, seguindo-se até a localidade denominada de placa e, a partir deste local é utilizada uma estrada vicinal em direção às localidades denominadas de Caju, Puxa-Faca e Bandeira Branca (a oeste) e a Vila Uiramutã (a leste).

- acesso ao setor ocidental da área pode ser feito, a partir de Boa Vista, através da rodovia federal não pavimentada BR-401, que liga esta cidade a localidade de Bonfim na fronteira com a Guiana, apresentando uma variante para a Vila Normandia, principal aglomerado urbano desta região.

A área pesquisada, de maneira geral, apresenta-se entrecortada por estradas carroçáveis e trilhas que ligam as sedes de diversas fazendas da região. Entretanto, vale destacar que no período de realização dos trabalhos de campo (entre 06/01/1994 e 22/01/1994), o acesso a alguns setores das áreas estudadas foi realizado com grande dificuldade, devido a conflitos entre a população indígena da região (índios Macuxins) e brancos com o consequente abandono populacional nesta região. Este trabalho de campo foi desenvolvido com apoio da CPRM (Companhia de Pesquisa e Recursos Minerais), Manaus. 


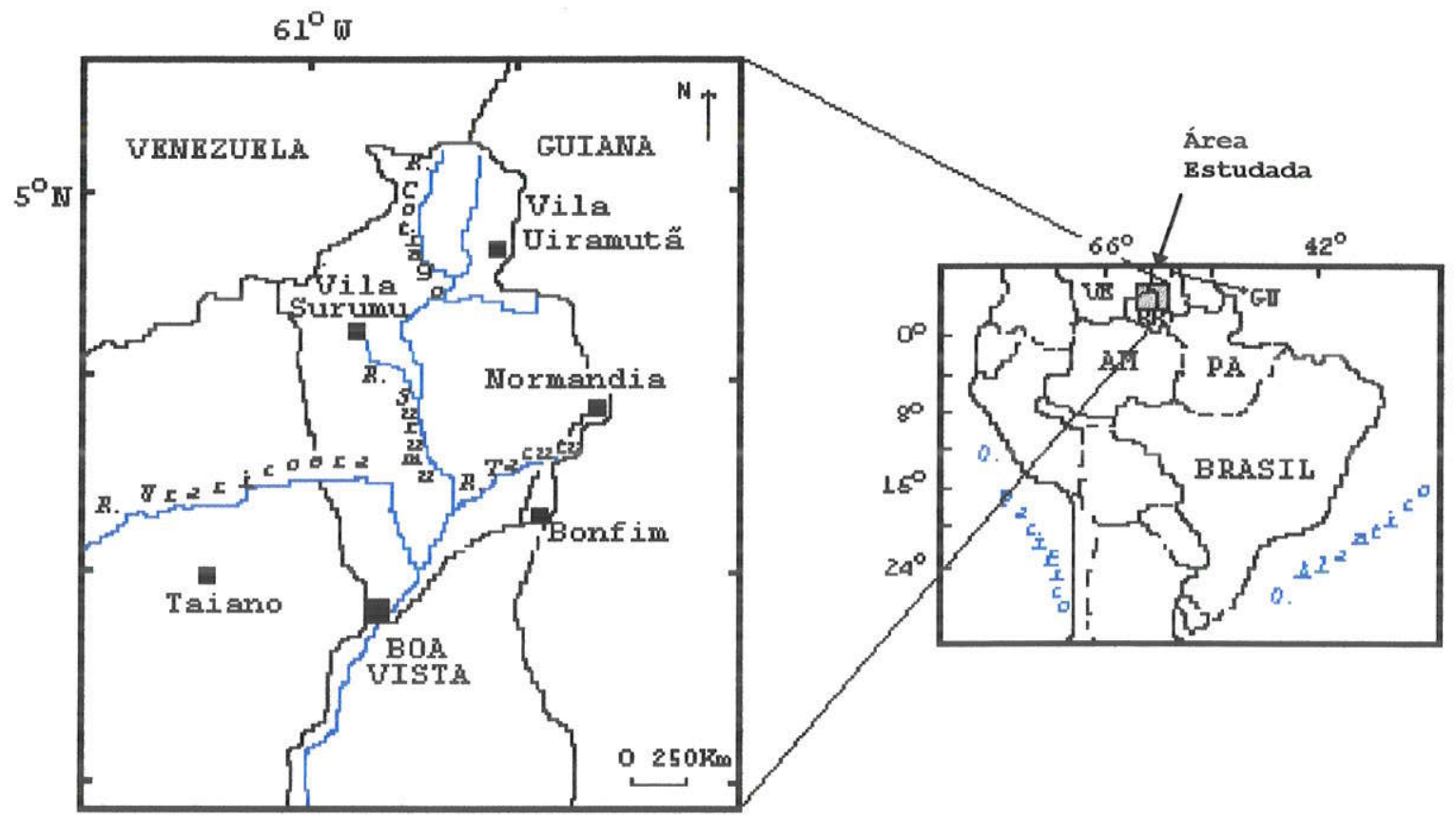

Figura 2- Mapa de localização da área estudada. GU= Guiana; $\mathrm{VE}=$ Venezuela; $\mathrm{RR}=$ Roraima; $\mathrm{AM}=$ Amazonas; $\mathrm{PA}=$ Pará.

\subsection{GEOLOGIA REGIONAL}

O Cráton Amazônico (CA) (Figura-3), formado pelos escudos das Guianas e Brasil Central (Almeida et al.,1968; Almeida et al.,1981; Hasui \& Almeida, 1985), representa uma das maiores unidades geotectônicas do Continente Sul-Americano. Atingiu sua estabilidade tectônica no final do Mesoproterozóico ao término do desenvolvimento do Cinturão Sunsás(Cordani \& Brito Neves, 1982; Teixeira et al.,1989).

As várias tentativas de compartimentação tectônica do CA têm-se fundamentado em dois modelos evolutivos: i) O CA representaria uma grande plataforma arqueana que foi parcialmente retrabalhada e reativada durante o Proterozóico (e.g. Amaral, 1974; Santos \& Loguercio, 1984; Montalvão \& Bezerra, 1985; Jones, 1985; Hasui \& Almeida, 1985); ii) sua individualização se deu envolvendo fundamentalmente acresções crustais durante o Proterozóico com a preservação de núcleos arqueanos isolados (e.g. Cordani et al.,1979; Cordani \& Brito 
Neves, 1982; Gibbs \& Barron, 1983; Gaudette \& Olszewski, 1985; Tassinari et al.,1989; Teixeira et al.,1986; Teixeira et a1.,1989).

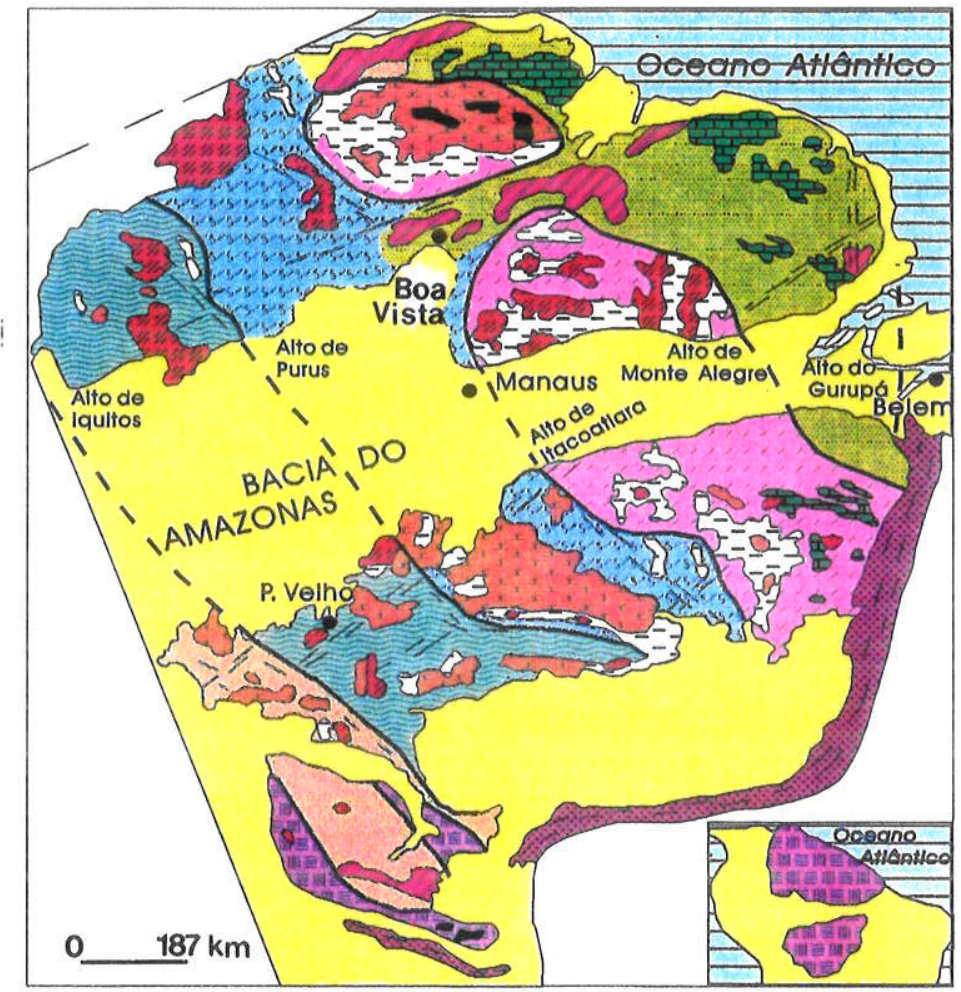

PROVINCIAS GEOCRONOLOGGICAS

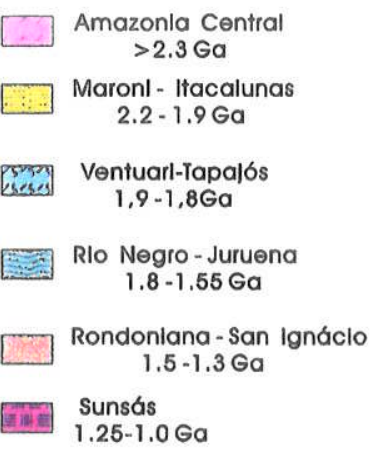

UNIDADES GEOLÓGICAS

\begin{tabular}{|c|c|}
\hline & Coberturas Fanerozólcas \\
\hline & Granltóldes \\
\hline & $\begin{array}{l}\text { Coberturas Sedimentares } \\
\text { Pré-cambrlanas }\end{array}$ \\
\hline & $\begin{array}{l}\text { Coberturas Vulcânlcas } \\
\text { Ácldas-Intermedlárlas }\end{array}$ \\
\hline & Vulcanlsmo básico \\
\hline & Greenstone Belts \\
\hline & Complexos Granulfilcos \\
\hline & $\begin{array}{l}\text { Falxa de Dobramentos } \\
\text { Neobroterozólca }\end{array}$ \\
\hline
\end{tabular}

Figura 3- Localização esquemática da área de estudo, segundo 0 arranjo das Províncias do Cráton Amazônico. Modificado de Teixeira et al. (1989) e compilado de Tassinari (1996). 
- modelo de evolução geotectônica apresentado para o CA na área do escudo das Guianas (Figura-3), assume o desenvolvimento de cinturões móveis do Paleoproterozóico e Mesoproterozóico (cinturões Maroni-Itacaiunas $(2,25-1,95 \mathrm{Ga})$, Rio Negro-Juruena $(1,80-1,55 \mathrm{Ga})$, Rondoniano-San Ignacio $(1,45-1,30 \mathrm{Ga})$ e Sunsás $(1,30-1,00 \mathrm{Ga})$ circundando núcleos antigos de idade arqueana (Província Amazônica Central) (Cordani \& Brito Neves, 1982; Tassinari et al.,1989; Teixeira et al.,1989). Tal modelagem foi recentemente confirmada por dados isotópicos $\mathrm{Sm}-\mathrm{Nd}$ (idades modelo), revelando que os principais períodos de diferenciação manto-crosta no $\mathrm{CA}$ foram entre $1,9-2,2$ Ga atrás (Sato \& Tassinari, 1996; Tassinari et al.,1996). Recentemente foi definido por Tassinari (1996) o Domínio Ventuari-Tapajós (1,95$1,80 \mathrm{Ga}$ que trunca o segmento NE-SW do domínio MaroniItacaiunas (Figura-3). Seus limites, entretanto, com a província Maroni-Itacaiunas são imprecisos, em particular pela carência de dados isotópicos.

A área pesquisada está situada na porção central do escudo das Guiana, na região nordeste do estado de Roraima (Figuras-2 e 3). As principais unidades litoestratigráficas presentes nesta região são apresentadas na Eigura-4, com destaque para o magmatismo basáltico mesozóico (Suíte Básica Apoterí), tema principal desta pesquisa.

As unidades geológicas formadas no Paleoproterozóico na região (Figura-4) são representadas por gnaisses, migmatitos, granitos, granodioritos, adamelitos, tonalitos e anfibolitos, as quais foram englobadas no Complexo Guianense (Montalvão et al.,1975; Melo et al.,1978) admitidas como representantes do embasamento da região. Estas rochas ocupam a porção ocidental da região (Figura-4) e se caracterizam por formarem serras alongadas, com direção WNW-ESE, coincidente com os lineamentos tectônicos regionais. Seus contatos com unidades mais jovens podem ser tectônicos ou normais, localmente podem estar recobertos pelos sedimentos cenozóicos da Formação Boa Vista, sendo por vezes interceptados por diques da suíte Básica Apoterí.

Dados isotópicos disponíveis posicionam as rochas do embasamento Paleoproterozóico com idades $\mathrm{Rb}-\mathrm{Sr}$ variando entre 1,9-2,3 Ga (Mandetta, 1970; Amaral, 1974; Basei \& Teixeira, 1975; Santos, 1976; Teixeira et al.,1989). 


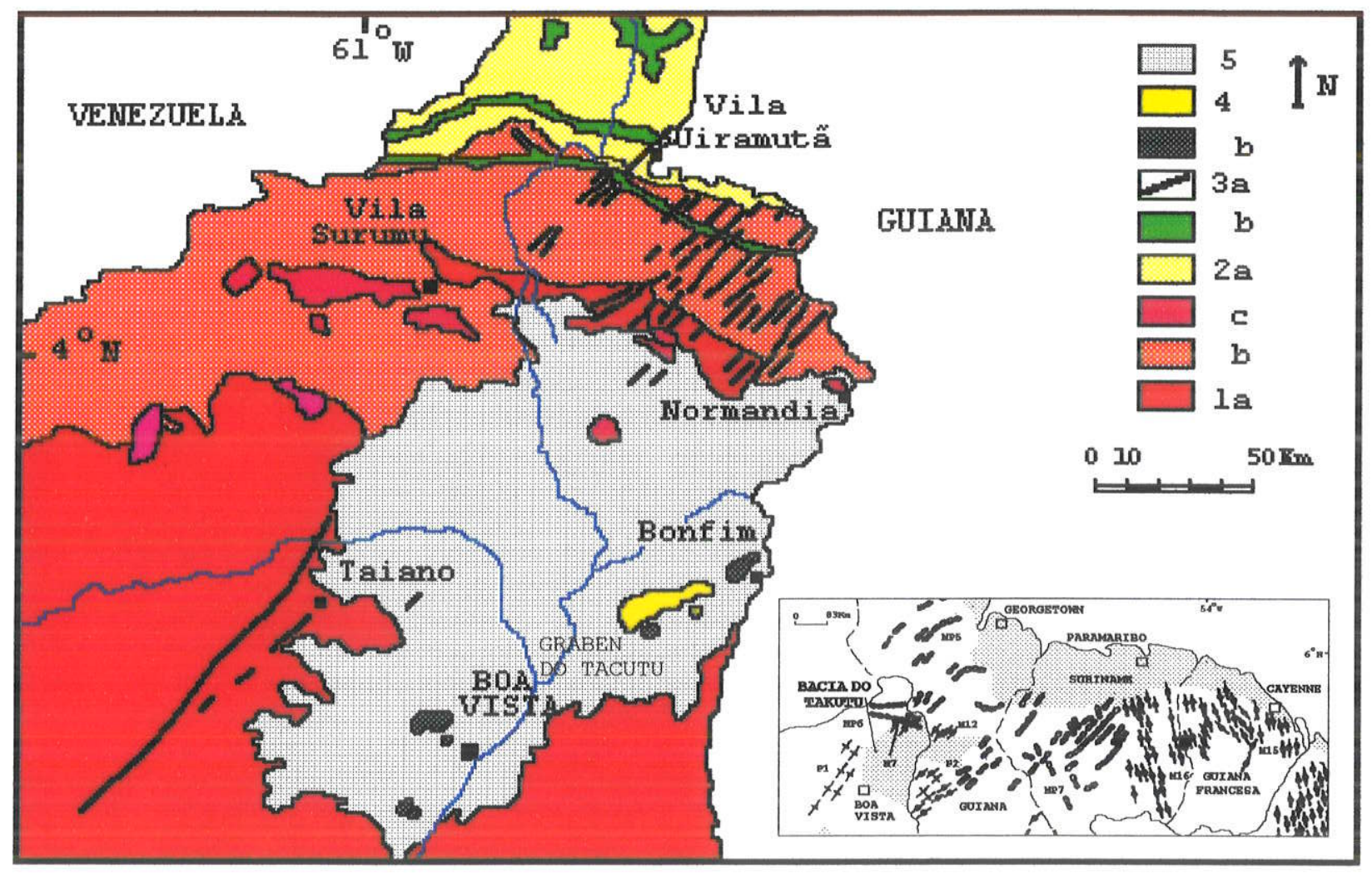

Figura 4- Mapa geológico simplificado da porção NE do estado de Roraima. 1= Paleoproterozóico: (a) Complexo Guianense; (b) Grupo Surumu; (c) Suíte Intrusiva Saracura. 2= Mesoproterozóico: (a) Supergrupo Roraima; (b) Magmatismo Avanavero. 3= Mesozóico: Suíte Básica Apoteri (a) diques máficos; (b) derrames basálticos. 4= Jurássico-Cretáceo: Formação Tacutu. 5= Cretáceo: Formação Boa Vista. Modificado de Montalvão et al. (1975) e Melo et al. (1978). O quadro inferior mostra os principais enxames de diques e "sills" no Escudo das Guianas (modificado de Gibbs \& Barron, 1983 e Oliveira \& Montes, 1984). MP6=Diabásio Avanavero; MP7=Diques do Suriname (W); P1 e M7=Suíte Básica Apoteri (Brasil); P2=Diques Rupununi (Guiana); M12=Minor Dykes (Guiana); M15=Cayenne Dykes (Guiana Francesa); M16=Apatoe Dykes (Suriname)

A unidade subsequente é representada pelo Supergrupo Uatumã, que reúne as rochas efusivas sob a denominação de Grupo Surumu e as rochas intrusivas designadas de suíte Intrusiva Saracura (Melo et al.,1978). Esta unidade está situada na porção centro-norte da área (Figura-4), e se distribue por uma ampla faixa de aproximadamente $500 \mathrm{Km}$ de extensão, com média de $60 \mathrm{Km}$ de largura e orientação aproximadamente E-W.

o Grupo surumu engloba as rochas vulcânicas ácidas (dacitos, riodacitos e riolitos) localmente associadas a 
piroclásticas e ignimbritos de caráter ácido a intermediário e com andesitos subordinados, além de rochas cataclásticas (milonitos, filonitos). Os dados geocronológicos disponíveis para estas rochas ( $\mathrm{K}-\mathrm{Ar}$ e $\mathrm{Rb}-\mathrm{Sr}$ ), revelaram idades em torno de $1,9 \mathrm{Ga}$ (Priem et al, 1971; Amaral, 1974; Basei \& Teixeira, 1975; Basei, 1978). Idades $\mathrm{U}-\mathrm{Pb}$ em zircões nas rochas riolíticas do Grupo Surumu produziram idades de $1966 \pm 9 \mathrm{Ma}$ (Schobbenhaus et al., 1994) interpretadas como a idade de cristalização do protolito vulcânico.

A Suíte Intrusiva Saracura é formada por granitos, biotitagranitos, alaskitos e subordinadamente quartzo dioritos. Ocorrem sob a forma de corpos circulares, alongados ou elípticos em meio as rochas vulcânicas do Grupo surumu, com dimensões de "stocks" cujos eixos maiores geralmente dispõem-se segundo a direção das grandes estruturas regionais de direção WNW-ESE. Recentemente (Fraga et al.,1996) incluiu os granitos Viaquário na suite Intrusiva saracura com base em dados de campo e petroquímicos. Estes granitóides estão associados a evolução do ciclo Transamazônico, com idades $\mathrm{Rb}-\mathrm{Sr}$ variando entre $1,7-1,8 \mathrm{Ga}$ (Basei, 1975; Montalvão et al.,1975; Melo et al.,1978; Santos \& Reis Neto, 1982).

Após a evolução transamazônica na região $(2,1-1,8 \mathrm{Ga})$, o Escudo das Guiana passou por um período de tectônica extensional, com desenvolvimento de bacias continentais e extenso vulcanismo básico associado. Neste aspecto, destaca-se a bacia sedimentar que é formada pelos sedimentos do supergrupo Roraima, ocupando toda a extremidade norte da área pesquisada (Santos, 1985; Pinheiro et al.,1989; Pinheiro et al.,1990).

A sedimentação da bacia é representada por quatro divisões principais, respectivamente da base para o topo: Formação Araí, Grupo Suapi, Formação Uailã e Formação Mataui. Esta unidade geológica é representada por uma sequência basal de arenitos conglomeráticos, arcóseos e conglomerados, seguida de sedimentos predominantemente pelíticos, tais como argilitos e siltitos com intercalações de "chert" e piroclásticas. Via de regra, o pacote sedimentar apresenta-se quase horizontalizado, inclinado suavemente para norte, desenvolvendo um relevo tabular. Quatro níveis de soleiras de rochas básicas relacionadas ao Magmatismo Avanavero se intercalam nesta sequencia sedimentar. O acervo geocronológico disponível aponta que a instalação da cobertura Roraima ocorreu no intervalo entre 1,6-1,8 $\mathrm{Ga}$ atrás. Tais idades foram obtidas nos "sills" básicos do Magmatismo Avanavero e em granitóides cogenéticos ao vulcanismo surumu respectivamente (Pinheiro et al.,1990; Costa et al.,1991).

- Magmatismo Avanavero, situado na porção norte do Escudo das Guianas, representa uma das mais expressivas atividades 
magmáticas de caráter básico do Mesoproterozóico no Craton Amazônico. Este magmatismo é representado por "sills" e diques máficos de caráter toleítico, intrusivos nos vulcanitos do Supergrupo Uatumã e nos sedimentos do Supergrupo Roraima (Figura4). As soleiras, com direção geral $E-W$, estendem-se pela República da Guiana, estado de Roraima e Venezuela, distribuindose em quatro níveis altimétricos, da base para o topo e denominadas informalmente por Pinheiro et al. (1990) de: Cotingo, Pedra Preta, Básicas Cipó e Monte Roraima. Quase em sua totalidade estas rochas afloram em extensos vales abertos e em exposições sob a forma de lajeiros. Já os diques máficos, apresentam-se orientados preferencialmente na direção $\mathrm{NE}-\mathrm{SW} e$ subordinadamente WNW-ESE, truncam todas as unidades precambrianas da região e constituem por vezes apófises que partem dos "sills" básicos.

Diversos diques e sills pertencentes ao Magmatismo Avanavero foram alvo de estudos geocronológicos (K-Ar e RB-Sr) tanto no Brasil, como na Guiana, Venezuela e Suriname. O conjunto de idades até então disponíveis sugerem que este magmatismo se formou a cerca de $1,6 \mathrm{Ga}$ atrás (e.g. Snelling \& McConnell, 1969; Mandetta, 1970; Hebeda et al.,1973; Priem et al.,1973; Amaral, 1974). Dados isotópicos $\mathrm{Rb}-\mathrm{Sr}$ adicionais realizados neste trabalho nas rochas do sill pedra Preta, confirmam a idade de $1,6 \mathrm{Ga}$. Entretanto, há registro de idades $\mathrm{Rb}-\mathrm{Sr}$ (Basei \& Teixeira, 1975) e $\mathrm{Ar}^{40}-\mathrm{Ar}^{39}$ (Onstott et $\mathrm{al} .1984$ ) mais antigas (aproximadamente $1.8 \mathrm{Ga}$ ), obtidas em diques e sills básicos no sul da Guiana.

Eventos tectono-metamórficos do Mesoproterozóico estão registrados na região através do Episódio K'Mudku (Barron, 1966), cujos dados isotópicos revelam idades em torno de 1,2 Ga. Tratase de período de intensa movimentação tectônica, com falhamentos de direção WNW, associados a metamorfismo que imprimiram modificações texturais e mineralógicas nas diversas unidades litoestratigráfica da região (Costa et al.,1991).

No Mesozóico, destaca-se na porção norte do Escudo das Guianas, a Suíte Básica Apoteri (Melo et al.,1978). Esta Suíte é formada por enxame de diques máficos e vulcanitos de caráter básico a intermediário, que seccionam indistintamente as unidades precambrianas da região (Eigura-4).

A Suíte Básica Apoteri tem sido relacionada à formação do Graben do Tacutu, que teria reativado antigos lineamentos tectônicos NE-SW e consequente coloção destes corpos e ao sistema de rifteamento associado a abertura do Atlântico Central e sul (Tomaz Filho et al.,1974; Berrangé \& Dearnley, 1975; Gibbs, 1987). O conjunto de idades $\mathrm{K}$-Ar obtidas para este magmatismo, posicionam os diques em dois pulsos principais, sendo o primeiro 
entre o Devoniano Inferior e o Carbonifero Inferior, e o outro segundo entre o Triássico Superior e o Jurássico Superior. De outra parte, os derrames basálticos apresentam idades entre 0 Jurássico Superior e o Cretáceo Inferior (Mandetta, 1970; Amaral, 1974; Berrangé \& Dearnley, 1975).

- Mesozóico foi encerrado com a deposição dos sedimentos terrígenos continentais da Formação Tacutu durante o JurássicoCretáceo (Melo et al.,1978) que recobre grandes partes dos derrames Apoteri e acham-se localizados na porção SE da Figura-4.

$\mathrm{Na}$ porção centro-nordeste da área estudada (Figura-4), ocorre a Formação Boa Vista, composta por sedimentos arenosos subarcoseanos e argilosos inconsolidados, frequentemente laterizados de idade cenozóica. De outra parte, coberturas aluvionares, coluvionares e eluvionares recentes são comuns em toda a região. Os aluviões, constituídos de areias e cascalhos, ocorrem ao longo dos principais cursos d'água; os colúvios ocorrem geralmente no sopé de vertentes enquanto que os eluviões constituem depósitos detríticos localizados.

\subsection{CONHEXTO GEOLÓGICO DA REGIÃO ESTUDADA}

\subsubsection{SUÍTE BÁSICA APOTERT}

Vários são os trabalhos realizados nos tipos litológicos que constituem a Suíte Básica Apoteri, principalmente nos paises da Guiana, Venezuela e Suriname $(\mathrm{e} . \mathrm{g}$. Brown \& Sawkins, 1875; Barron, 1966; McConnell et al.,1969; Priem, 1970; Choudhuri \& Milner, 1971; Priem et al.,1971; 1973; Bellizzia, 1972; Berrangé \& Dearnley, 1975; Choudhuri, 1978; Choudhuri, 1981; entre outros). No Brasil, esta unidade é pouco conhecida e se restringe a estudos de caráter regional envolvendo aspectos geológicos, petroquímicos e geocronológicos de pouco detalhe (e.g. Amaral et al.,1970; Mandetta, 1970; Montalvão et a1.,1975; Berrangé \& Dearnley, 1975; Santos et al.,1977; Melo et al.,1978; Santos \& Reis Neto, 1982; Reis \& Pinheiro, 1986; Pinheiro et al.,1990). A distribuição regional das rochas basálticas mesozóicas no Brasil e países vizinhos, no Escudo das Guianas, é mostrada no quadro da Eigura-4.

Os trabalhos mais recentes das rochas da Suíte Básica Apoteri no Brasil, incluem estudos petrográficos, geoquímicos e isotópicos de mais detalhes (Menezes Leal, 1994; Menezes \& Girardi, 1994; Menezes Leal et al.,1996).

A Suite Básica Epoteri (SBA) é representada na região de estudo por rochas de caráter intrusivo, sob a forma de diques máficos, e sob a forma extrusiva, constituindo extensos derrames 
de lavas basálticas. Os diques máficos tem ampla distribuição regional, localizando-se preferencialmente a $\mathrm{NE}$ da cidade de Boa Vista, nas proximidades das localidades de Normandia, Vila Uiramutã e Vila surumu onde constituem um enxame de diques e com menor expressão geográfica, a WNW da cidade de Boa Vista, próximo a localidade do Taiano (Eigura-4). Estas rochas cortam indistintamente todas as unidades precambrianas do complexo Guianense, Grupo Surumu, Suíte Intrusiva Saracura e Supergrupo Roraima.

De maneira geral, os diques máficos afloram preferencialmente sob a forma de blocos rolados alinhados segundo uma direção, nos leitos dos rios e riachos e mais raramente nos cortes de estradas e caminhos carroçáveis. Exibem coloração preta a acinzentada, granulação fina a média e são dominantemente isotrópicos e maciços, apresentando-se, em raros casos, tipos mais diferenciados localizados principalmente nas porções mais centrais dos corpos. Possuem espessuras que variam de poucos centimetros a dezenas de metros com predomínio médio em torno de 5-8 metros e extensões variando desde algumas centenas de metros até aproximadamente $50 \mathrm{~km}$.

Morfologicamente são retilineos a levemente sinuosos e
curvos, caracterizados pela formação de cristas alongadas,
principalmente no sentido $\mathrm{NE}$, bem distintas das unidades
encaixantes, nas quais se desenvolvem vegetaça mais rala e
arbustiva, contrastando visivelmente com a cobertura vegetal
densa desenvolvida nas rochas graniticas encaixantes e com a
vegetação rasteira das rochas vulcânicas do Grupo surumu.

Estes diques preenchem fraturas extensionais segundo direções N40-50E e NNE-SSW coerentes com a estruturação do graben do Takutu e menos comumente NS e NW-SE. Seus contatos com as rochas encaixantes, na maioria das vezes não são observados devido a gradação solo-rocha, apesar de serem observadas margens de congelamento ("chilled margin") em alguns afloramentos. Nestes casos, observa-se redução da granulometria nas margens dos corpos e colorações mais escuras (Fotografia-1) e nas porções mais internas dos corpos (porções mais diferenciadas) observa-se um aumento de granulometria e colorações mais claras (Fotografia-2).

Por outro lado, as rochas de caráter extrusivo ocorrem de forma menos expressiva que os diques máficos na região, sendo muito raro seus afloramentos. Ocorrem em superficie sob a forma de colinas e pequenos morros a noroeste (Serra Nova Olinda), a sul (pequenos morrotes) e a nordeste (Morro Redondo-margem da BR-401) da cidade de Boa Vista e nos leitos dos rios Arraia e Tacutu, próximo a localidade de Bonfim (Figura-4). Segundo Berrangé \& Dearnley (1975), a distribuição destes corpos vulcânicos está condicionada ao interior e as margens do "Graben do Tacutu", sendo que em subsuperficie ocorrem com espessura 
relativamente uniforme (podendo atingir $1500 \mathrm{~m}$ ), formando o substrato sobre o qual os sedimentos da cobertura cenozóica (Formação Boa Vista) foram depositados.

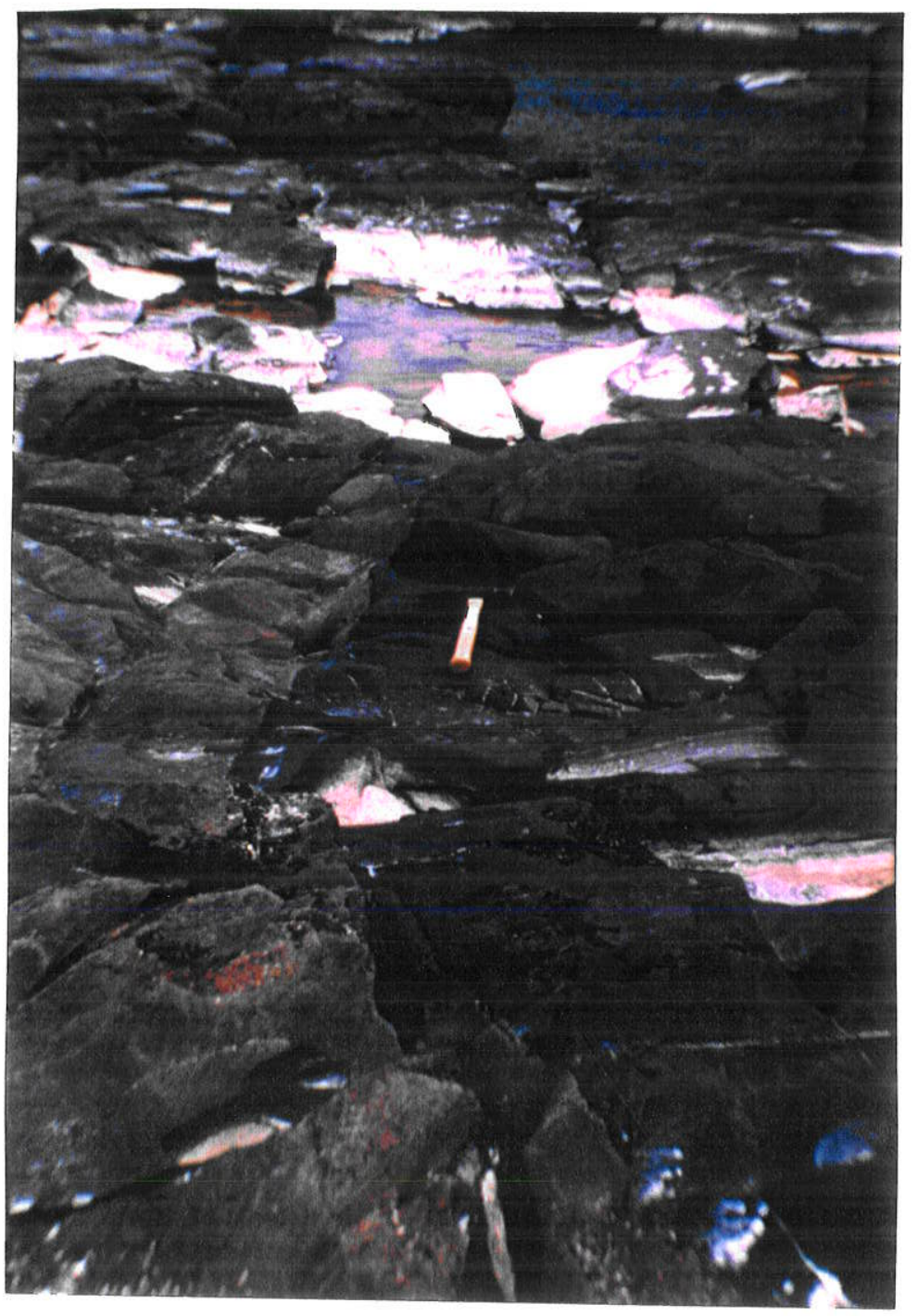

Fotografia 1- Dique máfico (a direita) em contato com rocha vulcânica do Grupo Surumu (a esquerda) no leito do rio Cotingo, mostrando "chilled margin" e contatos sinuosos. Ponto 18. 


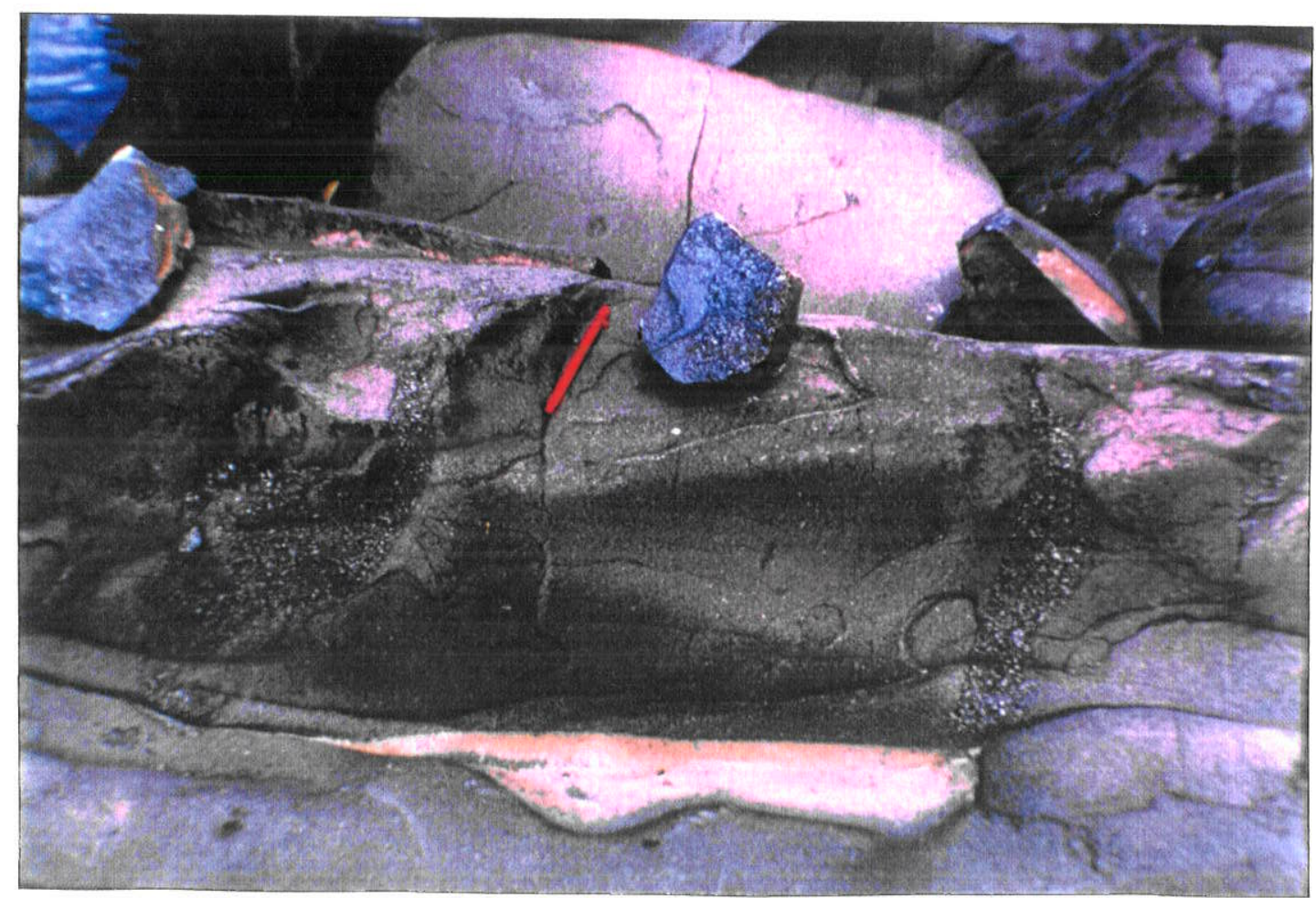

Fotografia 2- Detalhe da porção mais diferenciada do dique máfico localizado mais no centro do corpo ( 20m do contato. Ponto 18.

De modo geral, os derrames basálticos são de coloração cinza escuro a esverdeados, muito finos a afaníticos, amigdaloidais e com fraturas conchoidais. Não raramente, apresentam-se muito alterados, formando exfoliações esferoidais, constituindo por vezes solos de coloração avermelhada até formarem capas lateriticas.

No Morro Redondo (Eotografia-3) foram observados basaltos de granulação fina, maciços e isotrópicos na base, até níveis amigdaloidais preferencialmente localizados no topo. Estas amígdalas, amplamente distribuídas no basalto, possuem formas elípticas a esferoidais, com dimensões variando de poucos milímetros até cerca de $2 \mathrm{~cm}$ de diâmetro, embora tenham sido observado dimensões de até $10 \mathrm{~cm}$, nos leitos dos rios Arraia e Tacutu, sendo preenchidas por calcita, quartzo, clorita e zeólitas. 


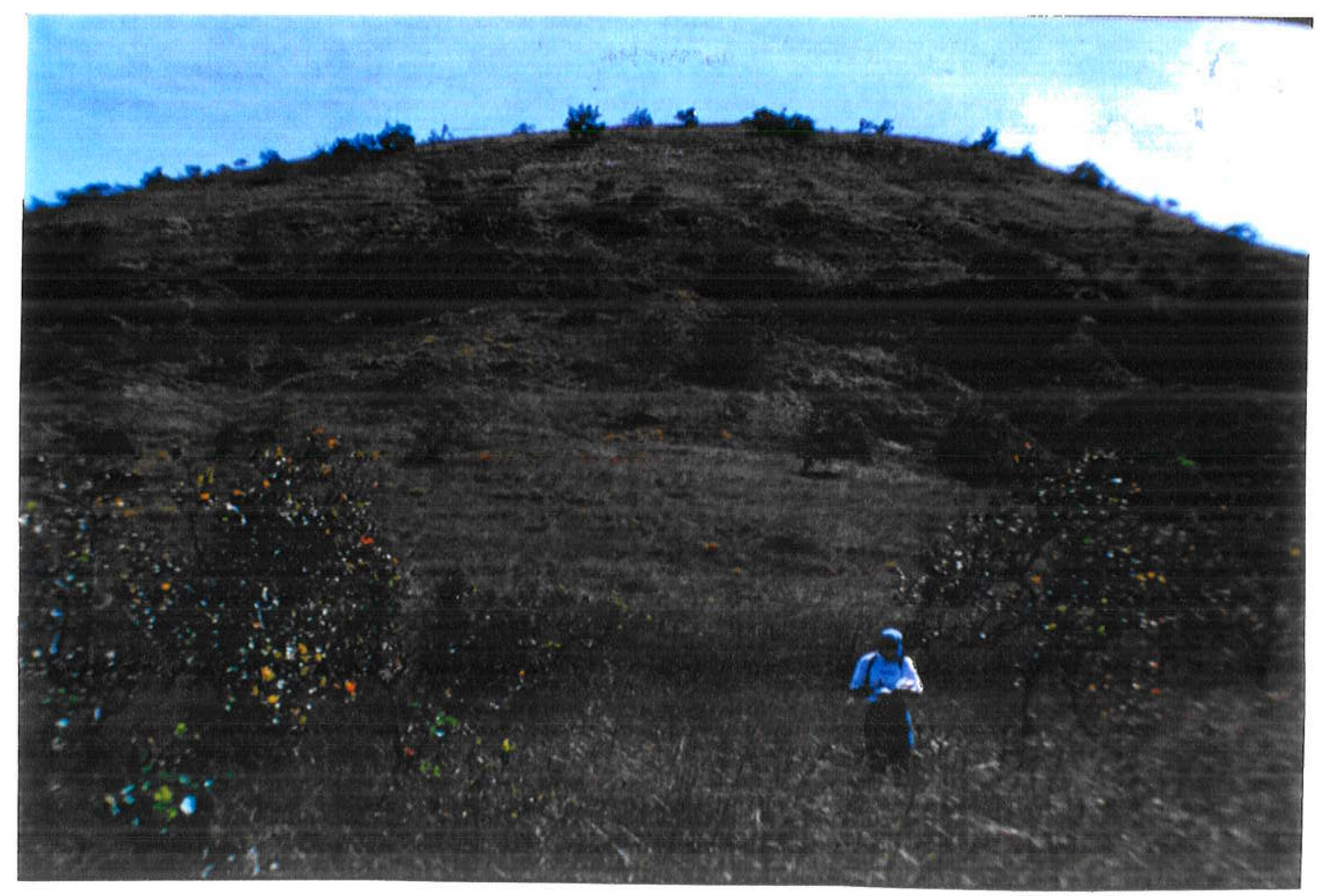

Fotografia 3- Vista geral do Morro Redondo. Derrame Basáltico. Ponto 05.

Na Pedreira Santa Fé, na Serra Nova Olinda pode-se observar basaltos finos, maciços, com nítido sistema poligonal de juntas verticais, entrecortados por fendas secundárias de pequenos espaçamento (Fotografia-4). Segundo Berrangé \& Dearnley (1975) este padrão de fraturas indica que o basalto ainda estava muito quente quando as fraturas primárias foram formadas, gerando novos focos de resfriamento. Algumas feições almofadadas no leito do rio Rewa, na Guiana, levaram também esses autores a concluir que pelo menos alguns dos derrames ocorreram subaquosamente. Entretanto, nos trabalhos de campo por nós realizados, estas feições de "pillow" lavas não foram observadas. 


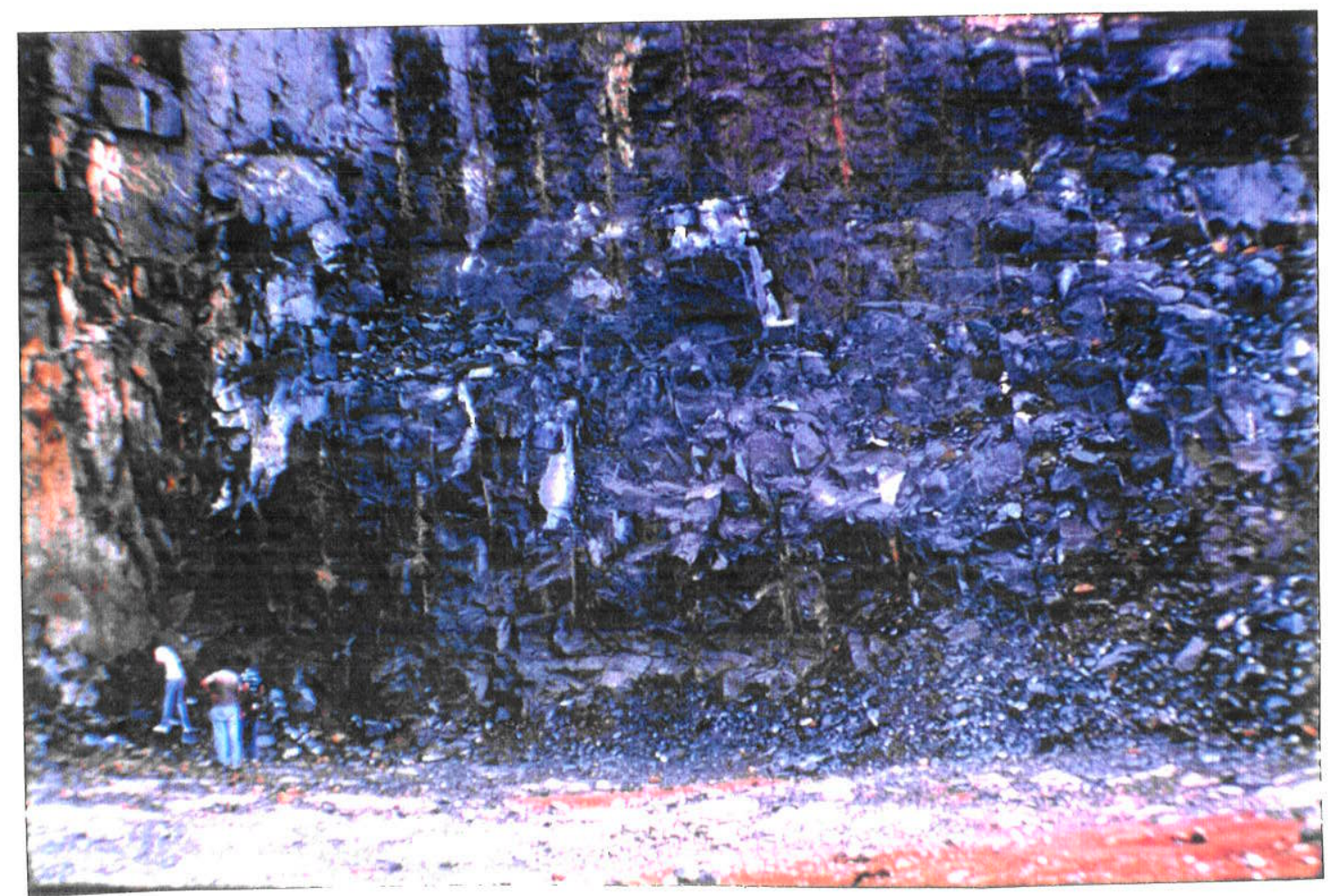

Fotografia 4- Vista geral da Pedreira Santa Fé-Serra Nova Olinda, mostrando fraturas subverticais. Derrame Basáltico. Ponto 02 . 


\subsection{CLASSIFICAÇÃO BASEADA NO CONTEÚDO DE ÁLCALIS E SÍLICA (TAS)}

Esta classificação baseada no conteúdo de sílica versus álcalis total (TAS) proposta por Le Bas et al. (1986) e recomendada pela Subcomissão de Sistemática de Rochas Ígneas da IUGS como um esquema classificatório internacionalmente aceito para as rochas vulcânicas. Tal classificação é consistente com a classificação modal QAPF e baseia-se em composições químicas de rocha total.

$\mathrm{Na}$ figura-5 observa-se o diagrama TAS onde verifica-se que os diques máficos posicionam-se no campo dos basaltos, abaixo da linha divisória de Zanettin (1984), representados por basaltos subalcalinos, a exceção de uma amostra (RR-16) que posicionou-se no campo dos basaltos alcalinos (acima da referida linha), e no campo dos andesi-basaltos. Por outro lado, os derrames posicionaram-se no campo dos andesibasaltos, traqui-basaltos e traqui-andesito basaltos.

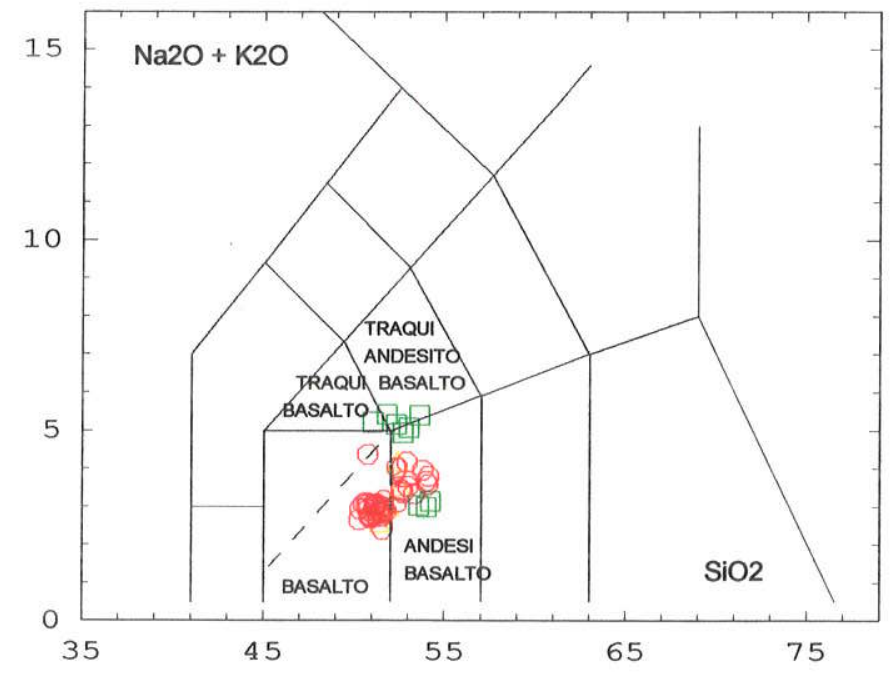

Figura 5- Diagrama sílica-álcalis total (TAS) segundo Le Bas et al.(1986) para as rochas da Suíte Básica Apoteri. Linha tracejada divide o campo dos basaltos de acordo com Zanettin (1984). Círculos vermelhos = diques máficos; quadrados verdes = derrames basálticos. 
Observa-se ainda neste diagrama que para uma mesma concentração de sílica, os diques máficos apresentam razões álcalis/sílica relativamente baixas, caracterizando o caráter toleítico destes corpos. De outra parte, algumas amostras das lavas basálticas apresentaram teores de álcalis relativamente mais elevados demonstrando uma natureza mais transicional/alcalina, embora apresentem para três amostras (RR-06A, RR-06B e RR-07) valores uma pouco mais baixos implicando um caráter toleítico para as mesmas.

Vale acrescentar que todos os óxidos de elementos maiores foram normalizados para 100\%, livres de água, para que não houvesse interferência na classificação.

\subsection{CLASSIFICAÇÃO SEGUNDO O DIAGRAMA R1 X R2}

Por melhor retratar e discriminar o campo das rochas basálticas, adotou-se na presente pesquisa pela classificação com base no diagrama multicatiônico $\mathrm{R}_{1}[4 \mathrm{Si}-11(\mathrm{Na}+\mathrm{K})$ $\left.2\left(\mathrm{Fe}^{+2}+\mathrm{Fe}^{+3}+\mathrm{Ti}\right)\right]$ versus $\mathrm{R}_{2}(6 \mathrm{Ca}+2 \mathrm{Mg}+\mathrm{Al})$ (De La Roche et.al, 1980; modificado para o campo dos basaltos por Bellieni et al., 1981). Neste diagrama classificatório (Figura-6), que se utiliza de vários óxidos de elementos maiores, os diques máficos posicionaram-se no campo dos basaltos toleíticos (bth) e andesi-basaltos (ab) e os derrames basálticos plotaram no campo dos andesi-basaltos (ab) e lati basaltos (lb) .

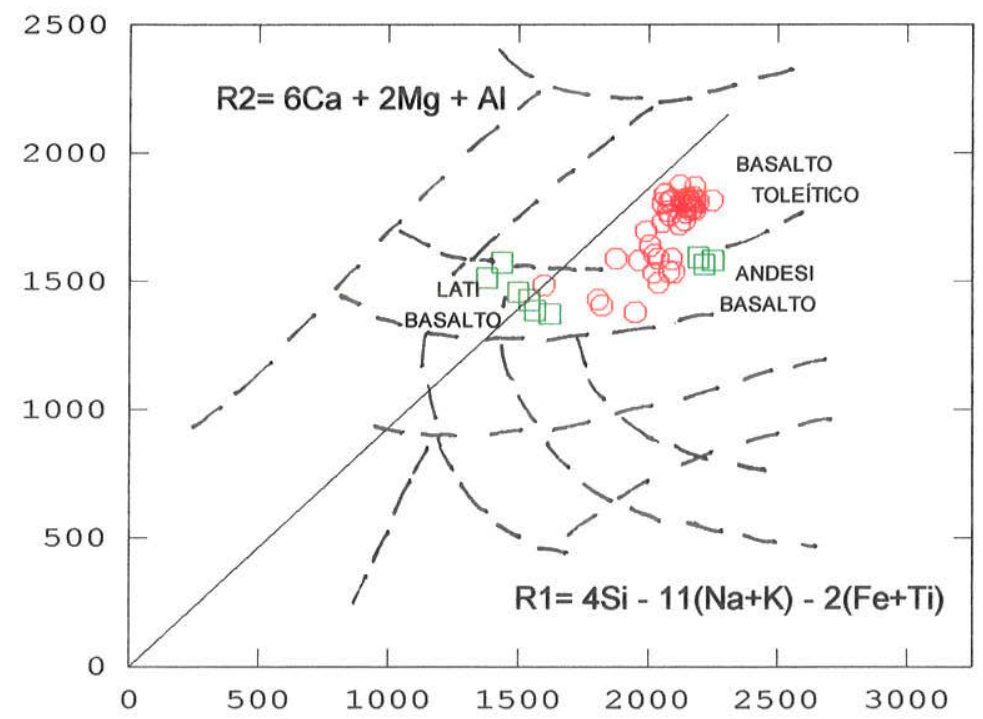

Figura 6- Classificação e nomenclatura adotada para as rochas pertencentes a Suíte Básica Apoteri, com base no diagrama $R_{1} \times R_{2}$ (De La Roche et al. (1980); Bellieni et al. (1981). Símbolos como na figura-5. 
Vale a pena salientar que as amostras dos derrames basálticos RR-08A e RR-09C (lb) e RR-02A, RR-02B e RR-39 (ab) apresentam variação de alto (lb) a médio grau (ab) de saussuritização dos plagioclásios e transformação dos piroxênios (capítulo-5). Isto pode possivelmente implicar em um deslocamento do campo classificatório original (amostras mais transformadas) até um deslocamento no próprio campo (amostras menos transformadas) mascarando as características primárias destes corpos.

A figura-7 mostra $\mathrm{O}$ diagrama $\mathrm{A}\left(\mathrm{Na}_{2} \mathrm{O}+\mathrm{K}_{2} \mathrm{O}\right)$, $\mathrm{F}\left(\mathrm{FeO}+0.8998 \mathrm{Fe}_{2} \mathrm{O}_{3}\right), \mathrm{M}(\mathrm{MgO})$, no qual observa-se que todas as amostras dos diques máficos seguem o "trend" da suíte toleítica do Hawaii (MacDonald \& Katsura, 1964; Irvine \& Baragar, 1971) destacando-se um enriquecimento em $\mathrm{FeO}_{t}$ em relação ao Mgo, típico de suítes evoluídas a baixa $\mathrm{fO}_{2}$; enquanto que a maioria das amostras dos derrames basálticos seguem uma tendência calcio-alcalina à exceção de 3 amostras (RR-06A, RR-06B e RR07) que posicionaram-se no "trend" toleítico.

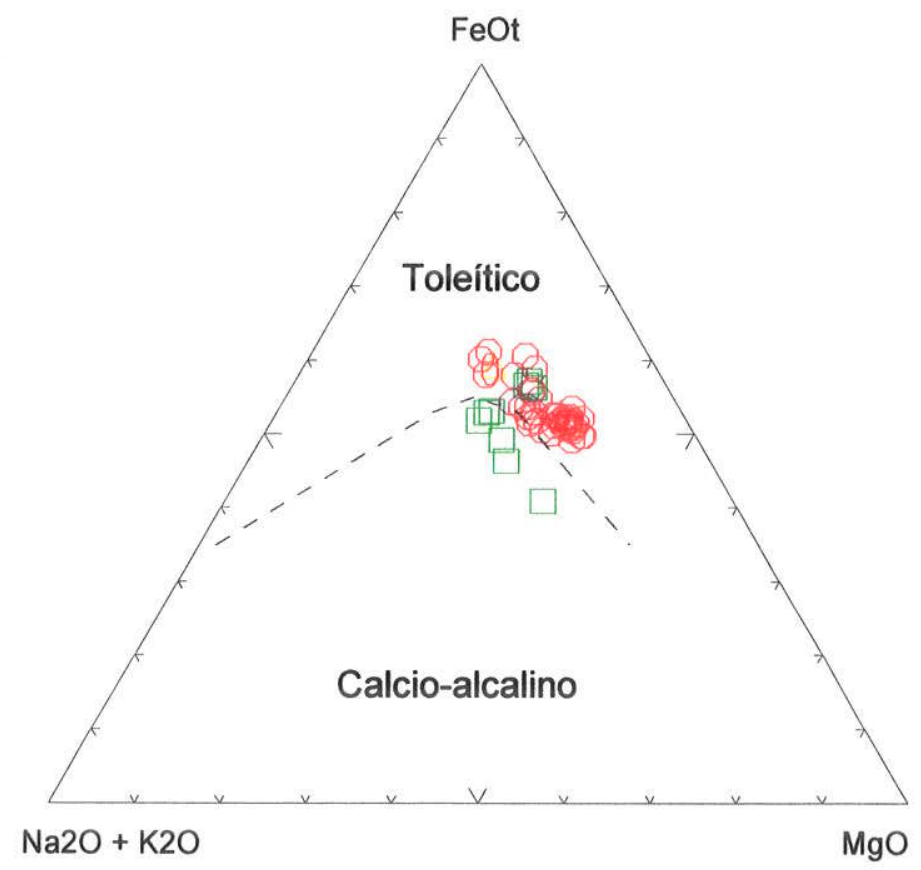

Figura 7- Diagrama $\mathrm{A}\left(\mathrm{Na}_{2} \mathrm{O}+\mathrm{K}_{2} \mathrm{O}\right), \mathrm{F}\left(\mathrm{FeO}+0.8998 \mathrm{Fe}_{2} \mathrm{O}_{3}\right)$, $\mathrm{M}(\mathrm{MgO})$ das rochas pertencentes a suíte Básica Apoteri. Linha tracejada representa a suíte toleítica do Hawaii, segundo MacDonald \& Katsura (1964). Símbolos como na figura-5. 
Pode-se dizer que as suites toleíticas caracterizam-se quimicamente por apresentar enriquecimento em $\mathrm{FeO}_{t}$ em relação ao Mgo e baixa razão silica/álcalis (e.g. MacDonald \& Katsura, 1964; Carmichael, 1974; Irvine \& Baragar, 1971, entre outros) e petrograficamente por apresentar coexistência de piroxênios ricos e pobres em cálcio, escassa proporção ou ausência de olivina e presença de minerais opacos, principalmente na matriz (ver capítulo-5) (Yoder \& Tylley, 1962; MacDonald \& Katsura, 1964; Carmichael et al., 1974). 
Neste capitulo serão caracterizados petrograficamente os diferentes tipos de diques máficos e derrames basálticos que ocorrem na região a NE do estado de Roraima, com base em dados petrográficos de detalhe, obtidos através do exame de 71 lâminas delgadas. Dados de quimismo de plagioclásio, piroxênios, anfibólios e minerais opacos, obtidos por microssonda eletrônica, serão utilizados sempre que necessário, nas descrições petrográficas afim de possibilitar uma melhor caracterização mineralógica. Entretanto antes de descrever esses litotipos, faz-se necessário a conceituação dos critérios adotados nas análises petrográficas:

1- Quanto a granulometria (em $\mathrm{mm}$ ): muito fina ( $\varnothing \leq 0.1$ ); fina $(0.1<\varnothing \leq 1.0)$; média $(1.0<\varnothing \leq 5.0) ; \operatorname{grossa}(5.0<\varnothing \leq 20.0)$; muito grossa $(\varnothing \geq 20.0)$.

2- Quanto ao tamanho do cristal (em $\mathrm{mm}$ ): matriz ( $\varnothing \leq 0.1$ ); microfenocristal $(0.1<\varnothing \leq 0.5)$; fenocristal $(0.5<\varnothing \leq 2.0)$; macrofenocristal $(2.0<\varnothing \leq 10.0)$; megafenocristal $(\varnothing \geq 10.0)$.

3- Quanto ao conteúdo em fenocristal ( 8$)$ : fracamente porfiritica $(F \leq 5)$; moderadamente porfiritica $(5<F \leq 10)$; fortemente porfiritica $(F \geq 10)$.

Em geral, as rochas são holocristalinas, mas registram-se raros casos nos derrames basálticos de rochas hipocristalinas a hipovítrea. As amostras apresentam-se de granulação fina a muito fina e média, sendo que esta granulometria acompanha respectivamente das margens a porções mais centrais dos corpos. Nas lavas basálticas a presença de amígdalas também foi observada.

O material intersticial comumente observado nestas rochas são de dois tipos diferentes; o micropegmatito (constitui intercrescimento micrográfico ou granofírico de composição quartzo-feldspato alcalino) nos diques máficos e substância de natureza vítrea (coloração negra a castanha) nos derrames.

As texturas mais comuns observadas nas rochas da área de estudo são:

- Subofitica: as ripas de plagioclásio encontram-se parcialmente englobadas por cristais opticamente contínuos de piroxênio, cujo tamanho médio é inferior ao dos plagioclásios; 
- Intergranular: as ripas de plagioclásio unem-se formando um arcabouço, onde os interstícios são preenchidos por pequenos grãos de clinopiroxênio;

- Porfiritica: é caracterizada por apresentar macrofenocristais, fenocristais e mais raramente microfenocristais de plagioclásio e/ou piroxênio imersos em matriz de granulação fina a muito fina;

- Intersertal: se diferencia da intergranular, por apresentar material vitreo preenchendo os intersticios;

- Ofítica: caracterizada por cristais de plagioclásio completamente englobados por piroxênios.

As principais características petrográficas de cada amostra encontram-se resumidas no apêndice-4.

\subsection{DIQUES MÁETCOS (DM)}

\subsubsection{BASALTOS TOLEITICOS (bth)}

Este tipo litológico é representado por 32 amostras, das quais 54 o de granulação fina (tamanho máximo=0.9mm) e $46 \%$ apresentam granulação média (tamanho máximo=3.5mm). Predomina a textura subofitica e subordinadamente a intergranular e ofitica, sendo que os minerais em geral estão dispostos em fenocristais (tamanho médio $=1.0 \mathrm{~mm}$ ), microfenocristais (tamanho médio $=0.3 \mathrm{~mm}$ ) e mais raramente em macrofenocristais (tamanho médio=3.0mm). Observa-se ainda com menor frequência a textura moderadamente porfiritica (amostra RR-18A) com fenocristais de plagioclásio (tamanho médio $=0.8 \mathrm{~mm}$ ) e piroxênio (tamanho médio $=0.6 \mathrm{~mm}$ ) dispersos numa matriz afanitica.

A associação mineralógica fundamental é constituída por plagioclásio (precoce $A n=52-708$; tardio $A n=43-70 \%$ ), augita (precoce $W o=31-40 \%$; tardia Wo $=31-39 \%$ ), pigeonita (precoce Wo $=5-$ 168; tardia Wo=9-13\%) e ortopiroxênio (precoce Wo $=1-4 \%$ ) que juntos chegam a ocupar cerca de $85 \%$ do volume total da rocha. Subordinadamente, assinala-se a presença de minerais opacos, enquanto os minerais acessórios mais comuns são clorita, biotita, anfibólio, apatita e quartzo.

Os plagioclásios possuem uma representação volumétrica expressiva (entre 40-45\% da rocha), com dimensões variando entre 0.05 a $3.5 \mathrm{~mm}$, com predomínio médio em torno de $0.8 \mathrm{~mm} e$ ocorrem dominantemente como fenocristais e microfenocristais e menos abundantes como matriz e macrofenocristais. De um modo geral, apresentam-se em ripas euédricas a subédricas, hábitos curtos a alongados, dispostos sob a forma esferulítica, em leques de grande abertura, angularmente englobando os piroxênios. Ocorrem ainda em glômeros formando geometria em " $X$ " 
ou em cruz e, mais raramente, anédricos. Possuem contatos entre si e com piroxênios, retos, curvos, embaiados ou reentrantes e bordas corroídas. Exibem em algumas amostras, coloração acastanhada no núcleo do cristal, dando-1he aspecto nublado e difuso, onde é possível distinguir essencialmente sericitas e calcitas, com bordas de coloração mais claras.

Os plagioclásios encontram-se ainda maclados polissinteticamente segundo a lei da albita, albita-Carlsbad e periclíneo, sendo que muitas vezes as lamelas de geminação mostram-se completas, parciais ou até mesmo ausentes, formando num mesmo grão grandes áreas não geminadas e microfraturadas. Suas composições obtidas através dos geminados albita, pelo método Michel-Levy (Kerr, 1959) forneceram valores que se referem a variação bytownita-andesina (An 80-408). Zoneamento e extinção ondulante normal ocorrem muito comumente, além de microfraturamentos preenchidos por calcita e sericita. Casos esporádicos de saussuritização incipiente em microfissuras ou completas são assinaladas no interior de alguns cristais, onde é possivel distinguir cloritas, sericitas e epídotos. Incluem além desses produtos de alteração, piroxênios, anfibólios, minerais opacos e apatita.

Os piroxênios ocupam cerca de 30-40\% do volume total da rocha, podendo chegar a proporções mais elevadas (40-45의 em algumas amostras (ex: RR-36A, RR-48). São representados predominantemente por micro $e$ fenocristais de augitas $e$ subordinadamente por pigeonitas e ortopiroxênios.

As augitas (tamanho máximo=3.4m e tamanho mínimo=0.05mm) caracterizam-se principalmente por seu relevo médio-baixo e pelo ângulo " $2 \mathrm{~V}^{\prime}$ médio $\left(>20^{\circ}\right)$ e ocorrem cerca de 20-25\% do volume total. Geralmente apresentam-se anedrais a subeuedrais, com geminação simples e frequentemente englobam parcialmente os plagioclásios ou preenchem seus intersticios. Não raramente os cristais apresentam bordas e fraturas alteradas para cloritas e biotitas.

As pigeonitas (tamanho máximo $=1.9 \mathrm{~mm}$ e tamanho mínimo=0.08mm) destacam-se pelo relevo alto e pelo ângulo " $2 \mathrm{~V}^{\prime}$ pequeno $\left(<20^{\circ}\right)$ e ocupam cerca de $10-15 \%$ do volume total. São euedrais a subeuedrais, esporadicamente geminadas e levemente uralitizadas ou alteradas para clorita em suas bordas e fraturas. Embora apresentem-se frequentemente em grãos distintos, diversas amostras assinalam uma intima associação da pigeonita com augita, onde preferencialmente a pigeonita encontra-se inclusa nos núcleos dos cristais de augita.

Os grãos de ortopiroxênios (não mais que $10 \%$ da rocha) são róseos a verde pálidos ocorrendo em pequenos cristais 
(tamanho médio=0.07 a $0.5 \mathrm{~mm}$ ) subédricos a anédricos e são, via de regra, alterados em suas bordas e fraturas para clorita.

Os minerais opacos (5-8\% em volume) são representados por magnetitas e rara ilmenita. Apresentam-se preferencialmente como microfenocristais e na matriz (0.02-0.4mm) e mais raramente como macrofenocristais e fenocristais (tamanho máximo=2.0mm). As magnetitas são subédricas, as vezes na forma cúbica-octaédrica e, quando em fenocristais apresentam-se esqueletais envolvendo piroxênios e plagioclásios. As ilmenitas possuem hábitos aciculares e são restritas a algumas amostras deste litotipo.

- anfibólio restringe-se as bordas das augitas, normalmente em lamelas anédricas de coloração castanha, fortemente pleocróica, as vezes interdigitadas com cristais anédricos de biotita. O contato anfibólio-augita sugere a possibilidade do primeiro ter sido gerado por um processo de transformação tardia a partir do piroxênio.

A biotita ocorre sob a forma lamelar subédrica de coloração castanha avermelhada em grãos individuais ou interdigitada em cristais anédricos de anfibólio e piroxênios. Incluem minerais opacos e apatita.

Restrito a matriz em grãos individualizados ou associados a feldspatos (micropegmatito), o quartzo é observado na maioria das amostras estudadas.

A apatita é pouco expressiva e não ultrapassa $3 \frac{0}{8}$ do volume total. Ocorre em todas as amostras deste litotipo sob a forma basal ou acicular.

- micropegmatito (cerca de $2 \%$ em volume) é o material intersticial mais frequente seguido pela mesostase.

A clorita, sericita, epidoto e calcita constituem os minerais provenientes da desestabilização dos plagioclásios e piroxênios, além de preencherem microfissuras nos minerais.

Coletadas num único dique (ponto 18), as amostras RR-18A, RR-18D, RR-18E e RR-18G representam respectivamente a migração da borda para o centro do corpo, sendo que somente a amostra RR-18D posicionou-se no campo dos andesi-basaltos (Eigura-6). Petrograficamente constatou-se uma evolução granulométrica e textural dada da seguinte forma: 


\begin{tabular}{|c|c|c|c|c|}
\hline AMOSTRA & $\begin{aligned} & \text { POSIÇÃO DA } \\
& \text { AMOSTRA }(\mathrm{m})\end{aligned}$ & TEXIURA & GRANULOMETRIA & $\begin{array}{l}\text { MICROFOTO } \\
\text { GRAFIA }\end{array}$ \\
\hline $\mathrm{RR}-18 \mathrm{~A}$ & contato & $\begin{array}{l}\text { Moderadamente } \\
\text { porfirítica com matriz } \\
\text { afanítica }\end{array}$ & $\begin{array}{l}\text { Fina a muito } \\
\text { fina }\end{array}$ & 1 \\
\hline $\mathrm{RR}-18 \mathrm{D}$ & $5 \mathrm{~m}$ do contato & $\begin{array}{l}\text { Fracamente porfirítica } \\
\text { com matriz fanerítica } \\
\text { fina }\end{array}$ & Fin & \\
\hline $\mathrm{R} R-18 \mathrm{E}$ & $10 \mathrm{~m}$ do contato & Intergranular & Fina & 3 \\
\hline $\mathrm{RR}-18 \mathrm{~F}$ & $15 \mathrm{~m}$ do contato & Subofitica & Médiä & 4 \\
\hline $\mathrm{RR}-18 \mathrm{G}$ & $20 \mathrm{~m}$ do contato & subofítica & Médià & 5 \\
\hline
\end{tabular}

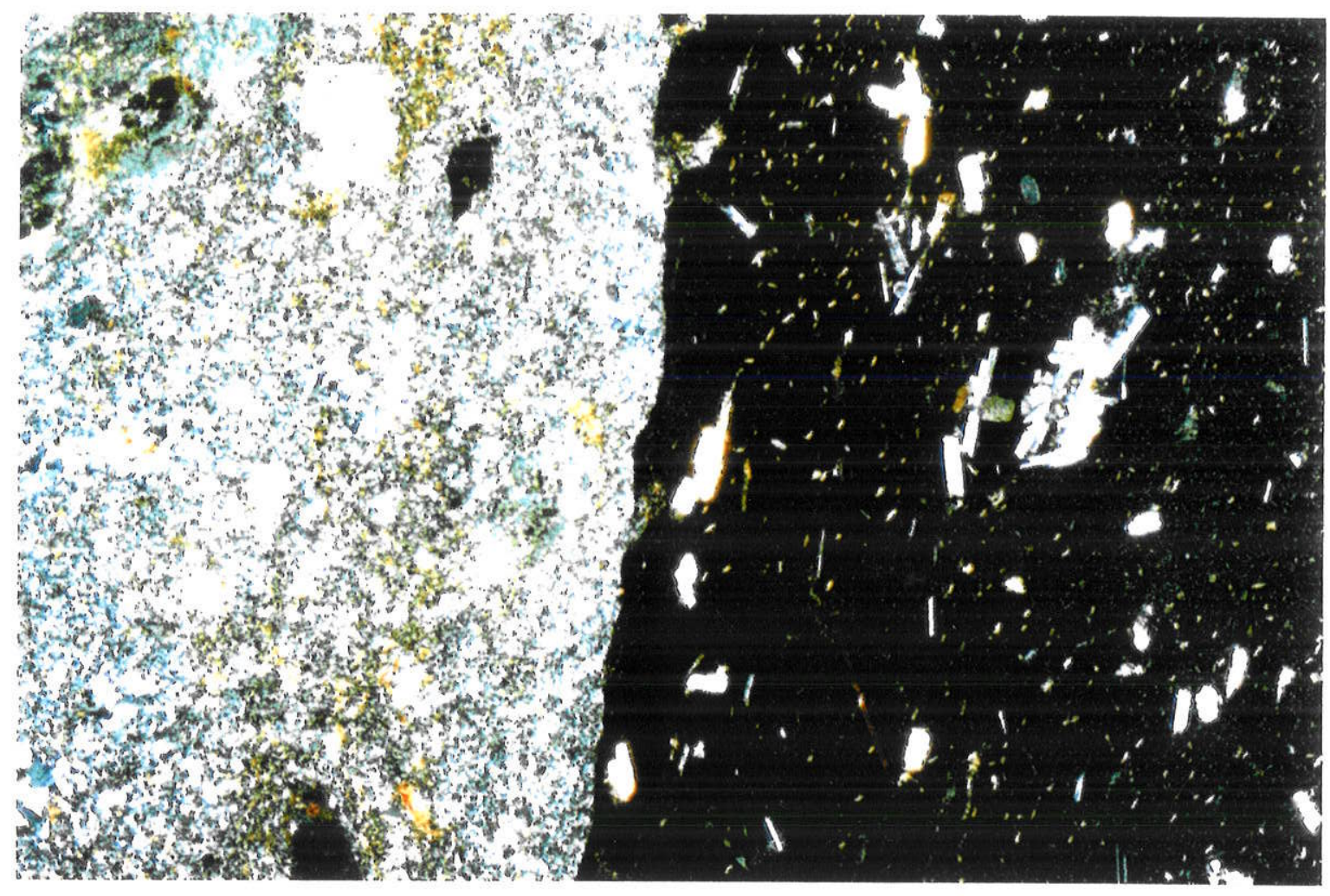

Fotomicrografia 1- Amostra RR-18A. Contato rocha vulcânica do Grupo Surumu(lado esquerdo)/dique máfico (lado direito). Basalto Toleítico. Aspecto geral da textura moderadamente porfirítica cujos fenocristais de plagioclásio e piroxênio encontram-se imersos numa matriz afanítica. Nicóis cruzados. 25X. 


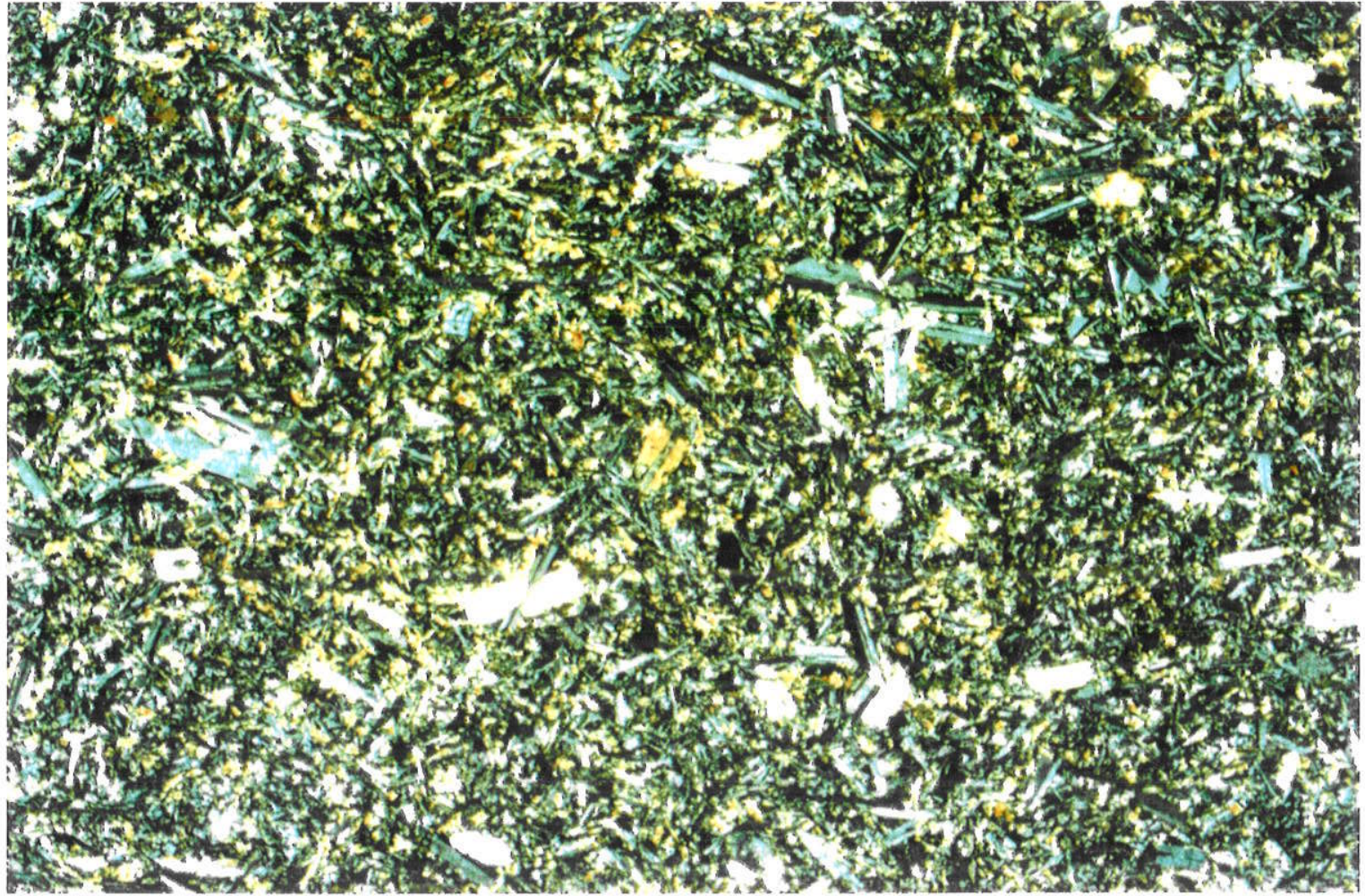

Fotomicrografia 2- Amostra RR-18D. Dique máfico. Andesi-Basalto. Aspecto geral da textura fracamente porfirítica cujos fenocristais de plagioclásio e piroxênio encontram-se imersos numa matriz fanerítica fina. Nicóis cruzados. 25x.

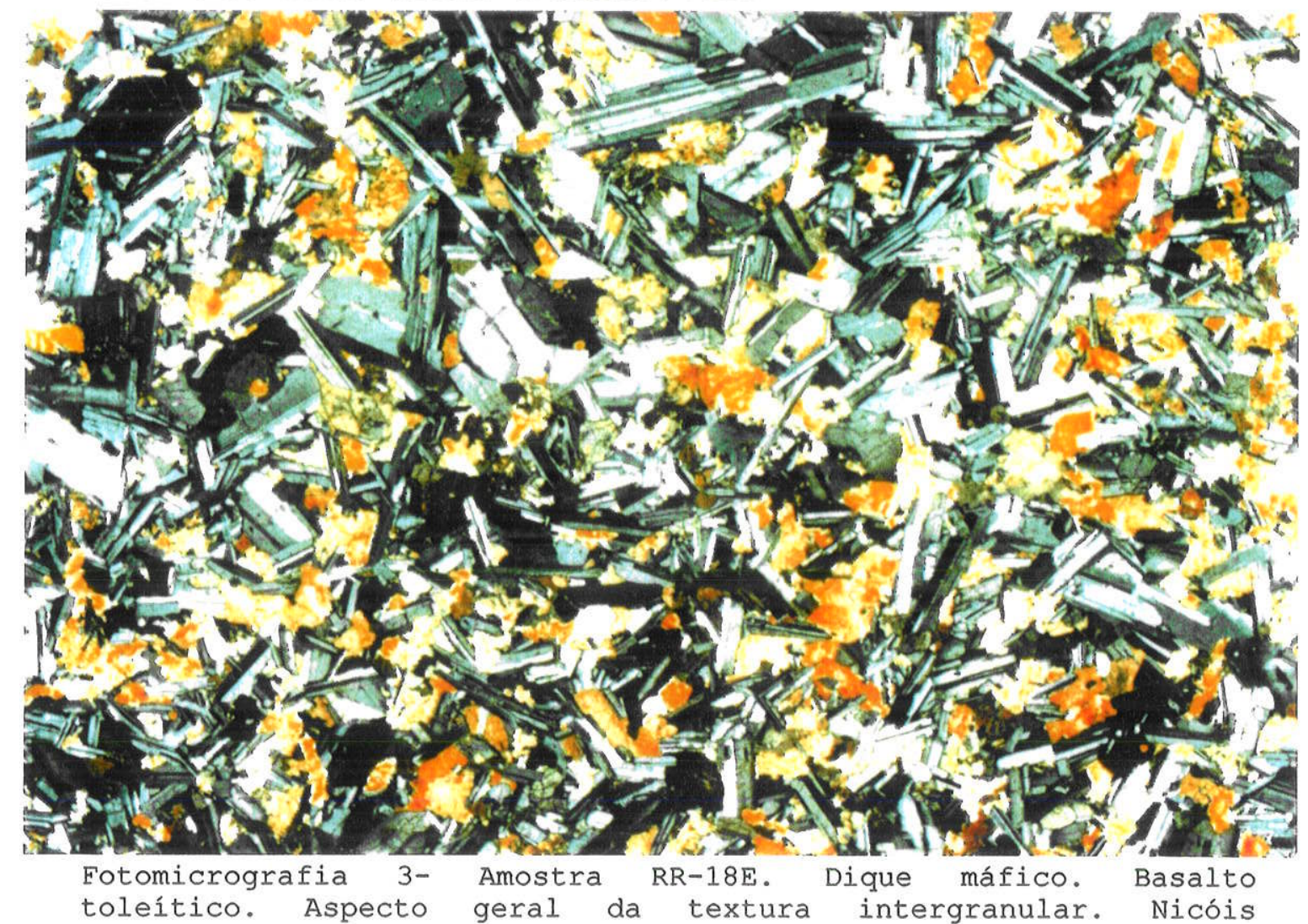

cruzados. $25 x$. 


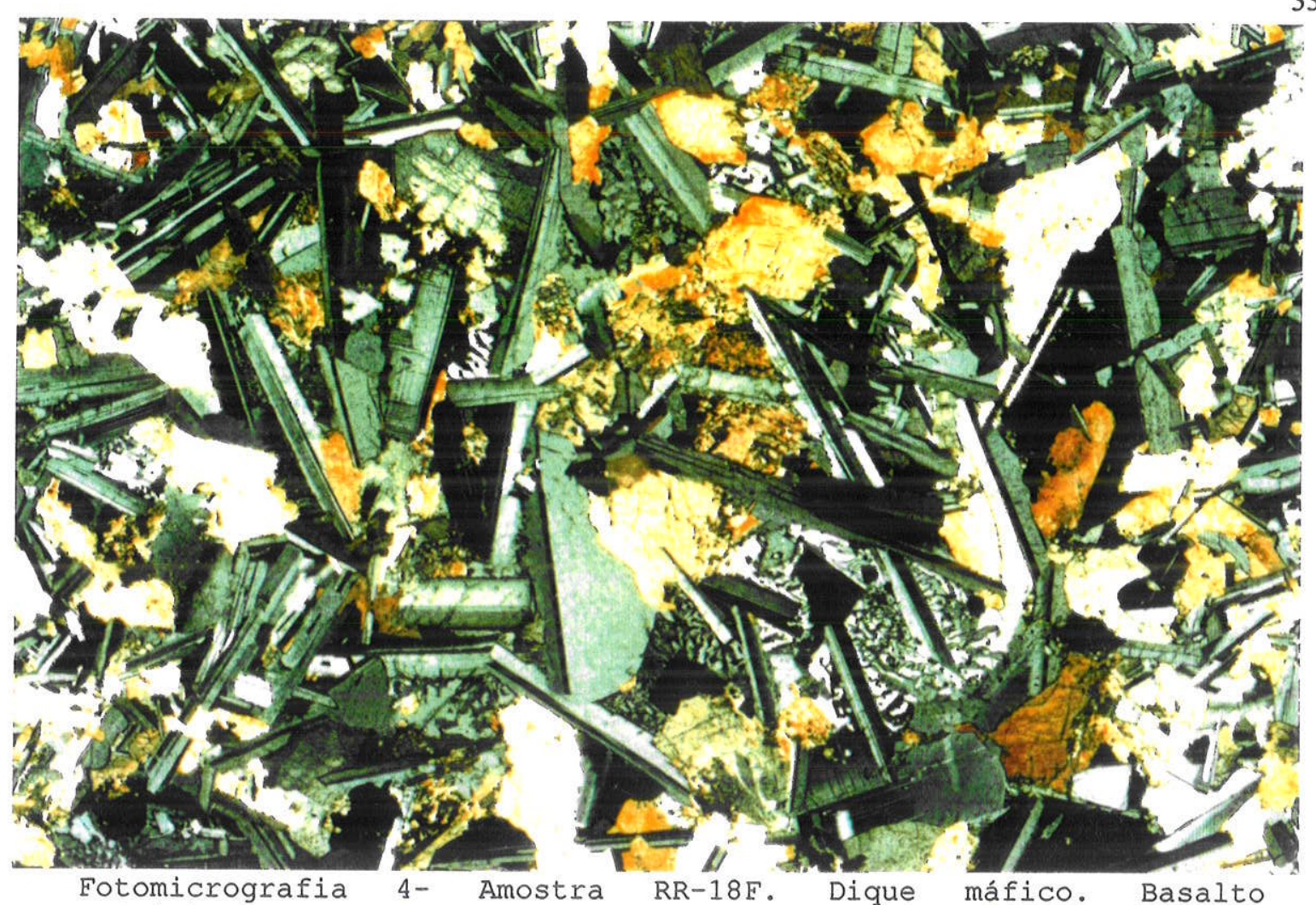

toleítico. Aspecto geral da textura subofítica. Nicóis cruzados. $25 x$.

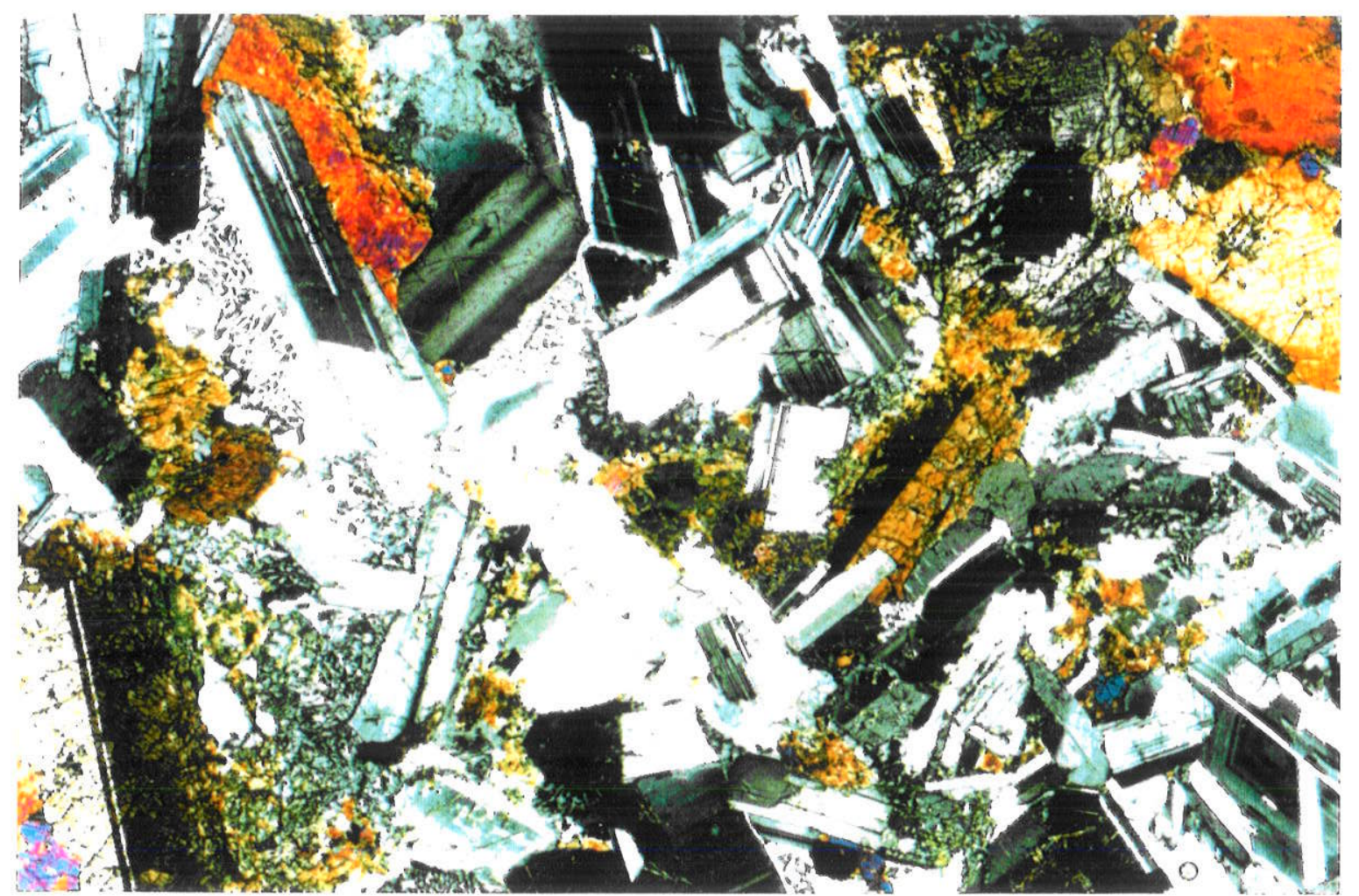

Fotomicrografia 5- Amostra RR-18G. Dique máfico. Basalto toleítico. Aspecto geral da textura subofítica. Observa-se granulação média e maior quantidade de micropegmatito. Nicóis cruzados. $25 x$. 


\subsubsection{ANDESI-BASALTO (ab)}

Este litotipo é constituído por $40 \%$ de rochas com granulação média (tamanho máximo $=4.0 \mathrm{~mm}$ ) e $60 \%$ de granulação fina (tamanho máximo=0.9mm) perfazendo um total de 10 amostras. Nestas rochas observa-se o predomínio de textura subofítica (Fotomicrografia 6 e 7), cujos minerais dispõem-se em fenocristais (tamanho médio=1.3mm), microfenocristais (tamanho médio $=0.4 \mathrm{~mm}$ ) e macrofenocristais (tamanho médio=2.8mm) e raramente a textura fracamente porfirítica cujos fenocristais (tamanho médio=1.4mm) de plagioclásio, piroxênios e minerais opacos encontram-se isolados e dispersos numa matriz intergranular de granulação fina constituída essencialmente de microfenocristais (tamanho médio=0.2mm) de plagioclásio, piroxênio e minerais opacos (Fotomicrografia-2).

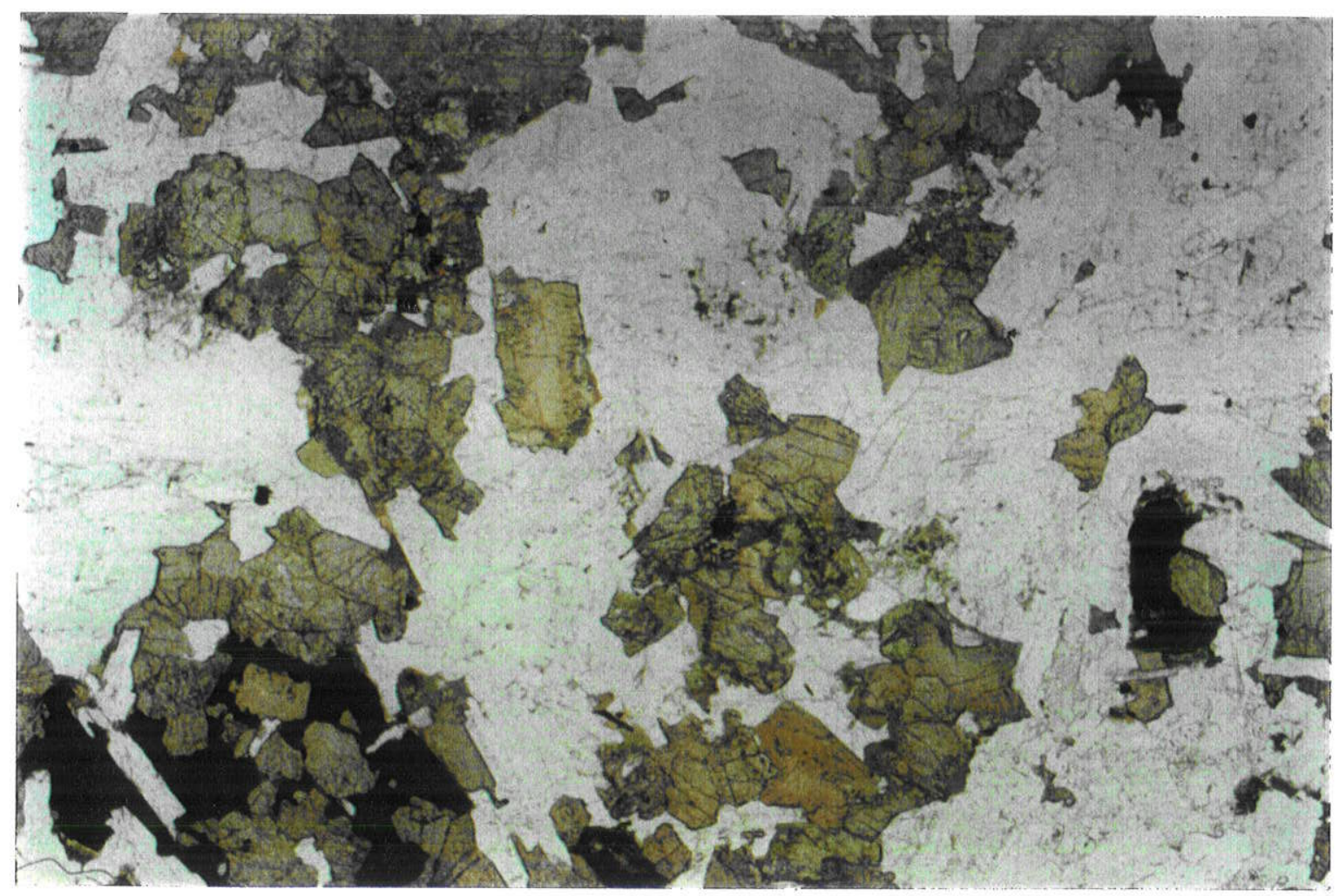

Fotomicrografia 6- Amostra RR-17. Dique máfico. Andesi-basalto. Aspecto geral da disposição dos minerais. Nicóis paralelos. $25 \mathrm{x}$. 


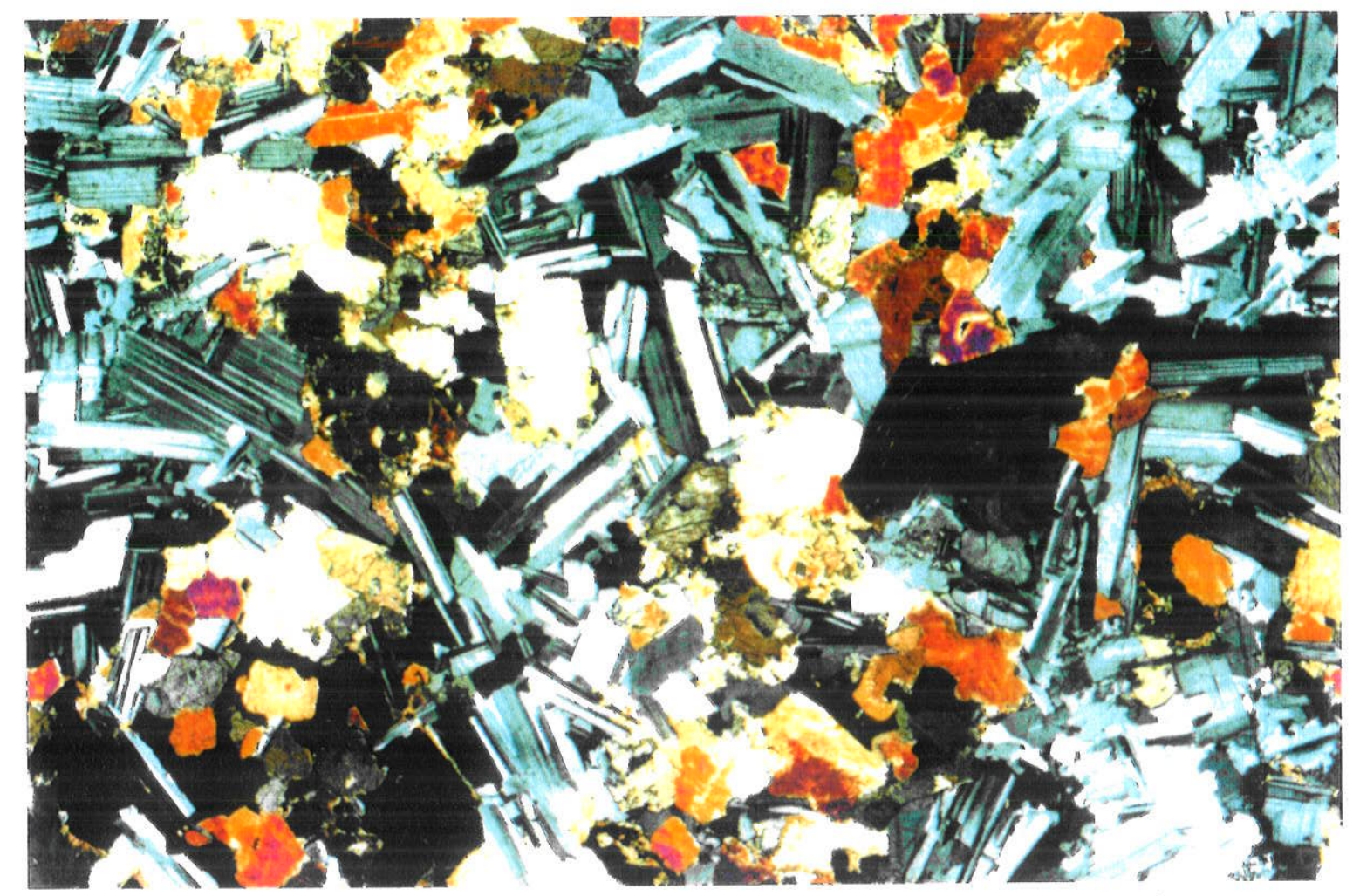

Fotomicrografia 7- Amostra RR-17. Dique máfico. Andesi-basalto. Aspecto geral da textura subofítica. Nicóis cruzados, 25x.

Em geral a associação mineralógica essencial é constituída por plagioclásio (precoce An=51-75\%; tardio An=3872\%), augita (precoce Wo=28-42\%; tardio Wo=31-36\%), pigeonita (precoce Wo=15\%), ortopiroxênio (precoce Wo=4\%; tardio Wo=4-5\%) e minerais opacos. A associação plagioclásio e piroxênios chegam a ocupar 70-80\% do volume total da rocha. Minerais como clorita, biotita, anfibólio, quartzo e apatita também são observados.

Os plagioclásios (tamanho máximo=2.6mm; tamanho mínimo=0.02mm) ocupam cerca de 45-50\% do volume da rocha e são mais abundantes em feno e microfenocristais do que em macrofenocristal e na matriz. Geralmente são ripiformes euedrais a subeuedrais, moderadamente zonados, apresentando extinsão ondulante normal e geminados segundo a lei polissintética da albita, albita-Carlsbad e albita periclíneo, sendo que em raros casos as lamelas de geminação encontram-se completas, parciais ou até mesmo ausentes formando grandes áreas não geminadas. Conteúdos de anortita (\%) obtidos através dos geminados albita, pelo método Michel-Levy (Kerr, 1959), referem-se a variação andesina-labradorita (An=40-70\%). Saussuritização incipiente nas fraturas ou pequenas manchas no interior das ripas são esporádicas, resgitrando-se no entanto, 
raras amostras elevadamente transformadas, onde é possivel distinguir minerais como sericita, clorita e epídoto.

Em quantidade inferior aos plagioclásios, os piroxênios ocupam entre 25-30\% do volume da rocha e preferencialmente encontram-se representados por micro e fenocristais de augita e de pigeonita e mais raramente ortopiroxênio, podendo-se elevar este percentual quando a pigeonita é ausente.

As augitas (tamanho máximo $=2.5 \mathrm{~mm}$; tamanho mínimo=0.02mm) são anedrais a subeuedrais de formas granulares a prismáticas, raramente geminadas e via de regra envolvendo parcialmente os plagioclásios ou preenchendo seus intersticios. Nas bordas e fraturas destaca-se a alteração para clorita, além de interdigitações lamelares da associação anfibólio, biotita e clorita.

As pigeonitas (tamanho máximo=2.0m; tamanho mínimo $=0.06 \mathrm{~mm}$ ) são euedrais a subeuedrais em formas prismáticas alongadas, com raros cristais geminados. Apresentam características marcantes como relevo alto e ângulo " $2 \mathrm{~V}$ " muito pequeno $\left(<20^{\circ}\right)$ e praticamente em todas as amostras alguns cristais mostram-se uralitizados ou alterados para clorita. Casos em que a pigeonita encontra-se associada a augita são observados e frequentemente a primeira encontra-se nucleada nos cristais de augita.

Os ortopiroxênios (tamanho máximo=0.4m; tamanho mínimo=0.05mm) ocupam não mais que $8 \%$ do volume total da rocha. Ocorrem em pequenos cristais de coloração rósea, subédricos a anédricos, em íntima associação ora com a augita ora com a pigeonita. Não raramente suas bordas e fraturas encontram-se alteradas para clorita.

Magnetita e ilmenita representam os minerais opacos (5$10 \%$ em volume) que se distribuem na maior parte em microfenocristais, matriz e fenocristais. As magnetitas (tamanho máximo $=1.5 \mathrm{~mm}$ e tamanho mínimo=0.02mm) são subeudrais e quando dispostas em fenocristais são esqueletais e poiquiliticas. As ilmenitas (tamanho máximo=1.0mm; tamanho mínimo $=0.03 \mathrm{~mm}$ ) são menos expressivas e possuem hábitos aciculares e ocorrem em todas as amostras.

- anfibólio encontra-se em lamelas de cor esverdeada sempre associada a augita e frequentemente interdigitada com cristais de biotita.

A biotita que preferencialmente está associada ao anfibólio, cuja transformação anfibólio $\rightarrow$ clorita $\rightarrow$ biotita é

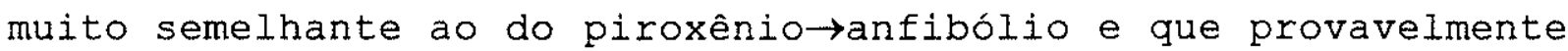


representa para ambos uma origem a partir de transformações tardias. Observa-se também como cristais isolados lamelares de coloração castanha avermelhada.

Em pequenos cristais individualizados ou associados a feldspatos (micropegmatito), o quartzo é assinalado na maioria das amostras do litotipo.

A apatita não ultrapassa $2 \%$ em volume e ocorre de forma acicular e hexagonal.

A clorita ocorre de forma bastante representativa associada as bordas dos piroxênios ou preenchendo planos de fissuras nos plagioclásios, juntamente com sericita, calcita e epídoto.

\subsection{DERRAME BASÁITICO (DE)}

\subsubsection{ANDESI-BASALTO (ab)}

Este litotipo apresenta amostras predominantemente com granulação fina a muito fina (tamanho máximo=0.8 a $0.1 \mathrm{~mm}$ ) e é representado por 6 amostras. A maioria destas rochas apresentam textura intergranular, onde os minerais são abundantes em microfenocristais (tamanho médio $=0.5 \mathrm{~mm}$ ) e matriz (tamanho médio $=0.05 \mathrm{~mm}$ ) e mais raros como fenocristais (tamanho médio $=0.7 \mathrm{~mm})$. Ocorre menos frequentemente a textura intersertal a qual se diferencia da intergranular pela presença de material vítreo intersticial (Fotomicrografias 8 e 9).

A associação mineralógica fundamental é dada por plagioclásio (precoce $A n=60-67 \%$; tardio $A n=54-63 \%$ ), augita (precoce Wo $=35-36 \%$; tardio $W o=34-35 \%$ ), pigeonita (precoce Wo=9$108)$ e minerais opacos. Juntos, plagioclásio e piroxênios correspondem a cerca de 70-808 do volume da rocha.

De maneira geral, os plagioclásios (tamanho máximo=$1.5 \mathrm{~mm}$; tamanho mínimo=0.02mm) são abundantes em microfenocristais e fenocristais e mais escassos na matriz. Apresentam percentual volumétrico variando entre 40-45\% da rocha e frequentemente são dispostos em ripas euédricas a subédricas. Via de regra são geminados segundo a lei da albita e albita-Carlsbad. Determinações efetuadas nos geminados albita, pelo método Michel-Levy, forneceram valores do conteúdo em anortita ( 8$)$ que se situam no campo da labradorita-andesina $(50-60 \%)$. O fenômeno de saussuritização é bastante expressivo em alguns cristais de algumas amostras, podendo chegar a recobrir quase que inteiramente as ripas de plagioclásio. 


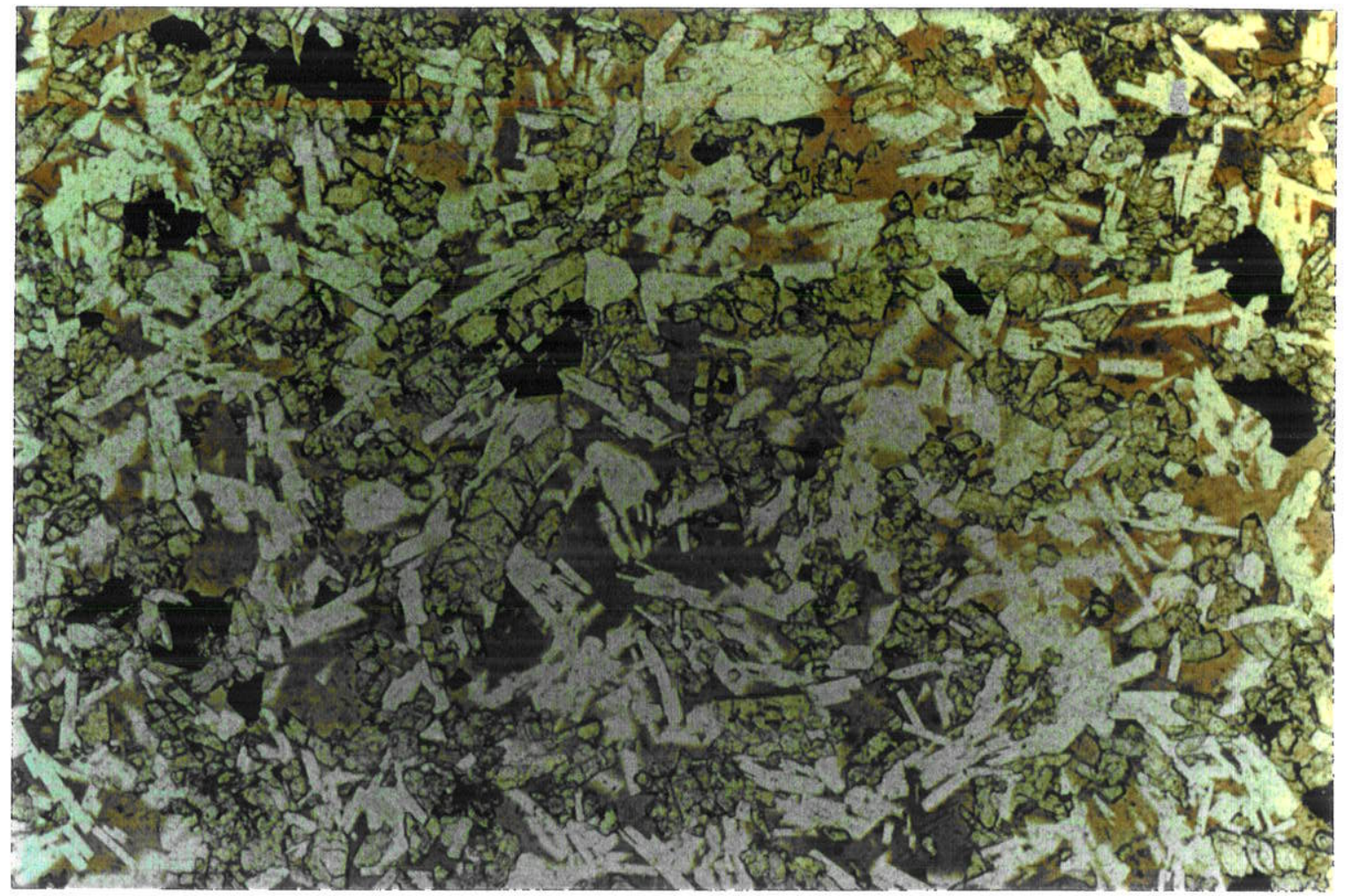

Fotomicrografia 8- Amostra RR-06B. Derrame basáltico. Andesibasalto. Aspecto geral da disposição dos minerais. Material vítreo de coloração castanha. Nicóis paralelos, 50x.

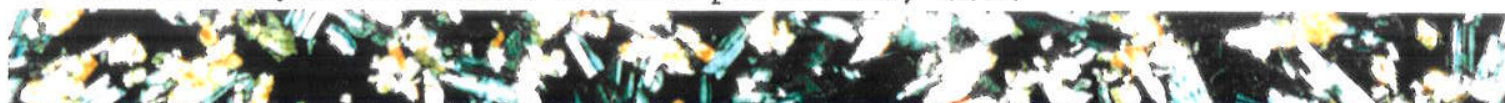
(5)

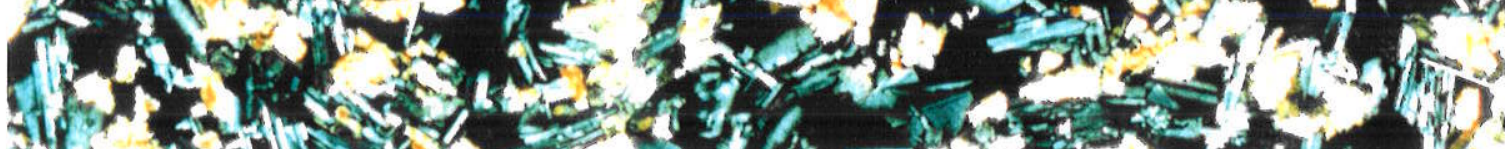

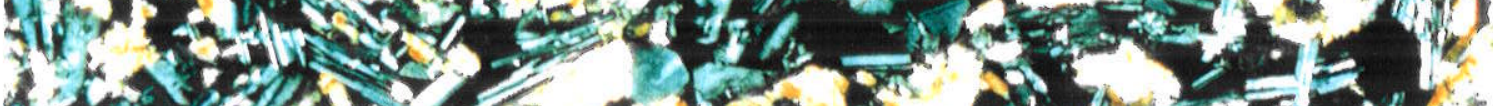

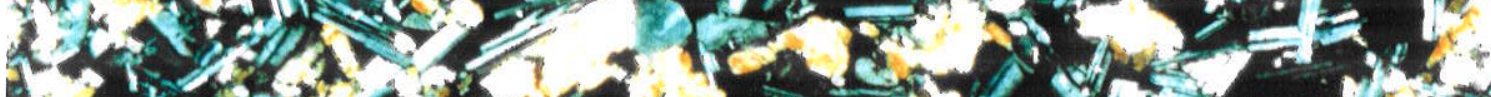
17 T.

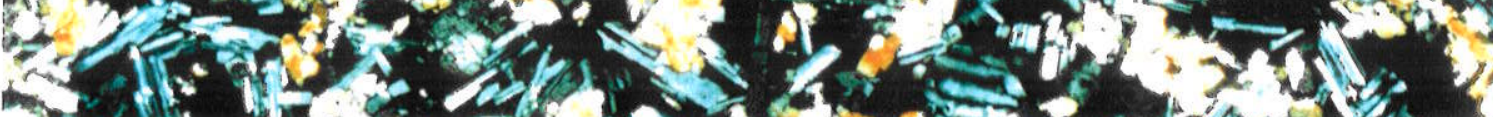

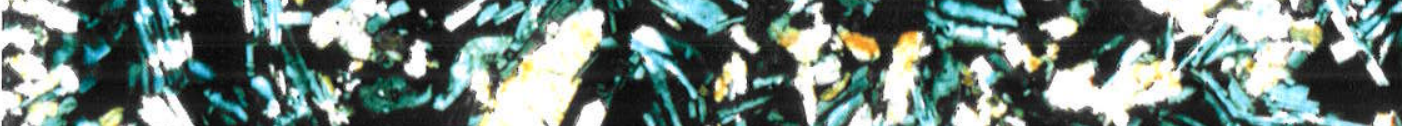

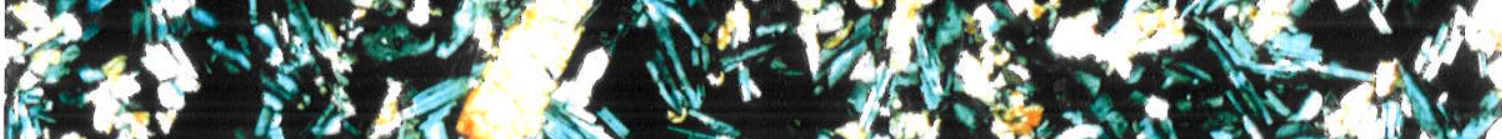

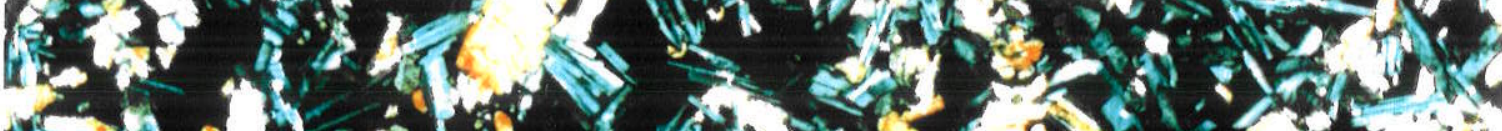

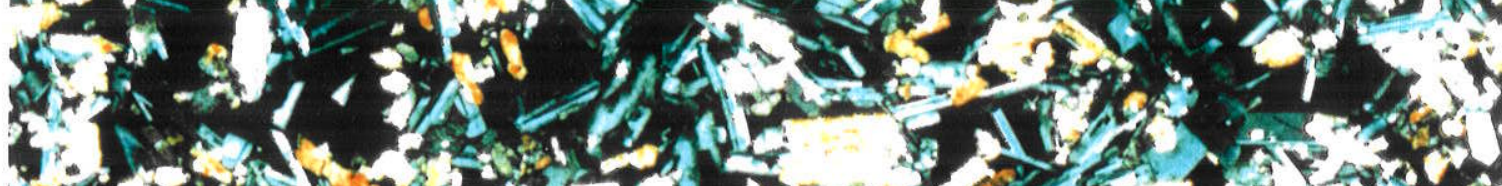

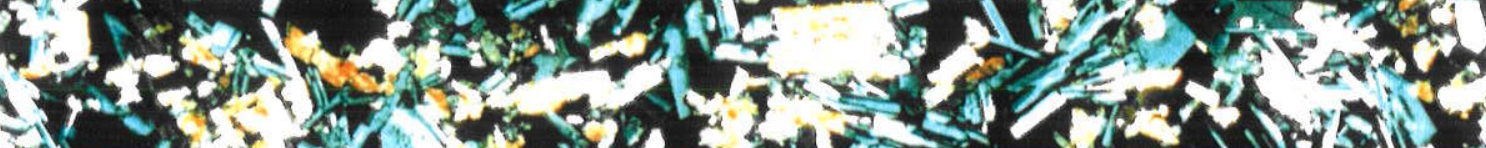

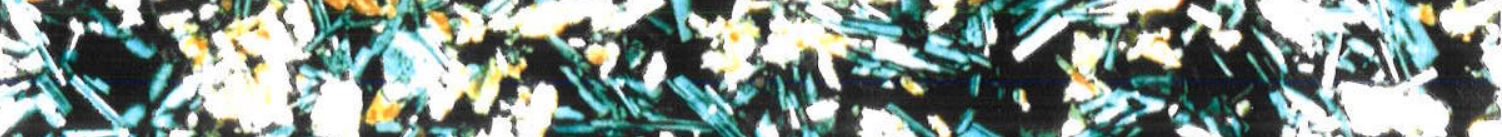
Fotomicrografia 9- Amostra RR-06B. Derrame Basáltico. Andesibasalto. Aspecto geral da textura intergranular a intersetal. Nicóis cruzados, $50 \mathrm{x}$. 
Representados por augita (20\% em volume) e pigeonita (10\% em volume), os piroxênios possuem uma distribuição em volume da rocha inferior ao dos plagioclásios.

As augitas (tamanho máximo=1.3mm; tamanho mínimo=0.03mm) são comuns em microfenocristais e matriz e mais escassas em fenocristais. São caracterizadas principalmente pelo relevo médio e pelo ângulo " $2 \mathrm{~V}$ " médio-elevado. Erequentemente apresentam cristais anedrais com formas granulares e subeudrais com formas prismáticas e geralmente estão envolvendo parcialmente ripas de plagioclásio ou preenchendo seus interstícios. Alguns cristais demonstram moderada alteração para clorita e só esporadicamente que se verifica a presença de anfibólio nas bordas.

As pigeonitas (tamanho máximo=0.4mm; tamanho mínimo $=0.01 \mathrm{~mm}$ ) estão presentes predominantemente em microfenocristais e matriz e ocorrem muito raramente. São euedrais a subeuedrais em formas prismáticas alongadas e poucos cristais demonstram fraturas e bordas alteradas para clorita.

Os minerais opacos (magnetitas) (tamanho máximo=0.3mm; tamanho mínimo=0.01mm) ocupam cerca de $10 \%$ do volume da rocha e ocorrem normalmente como microfenocristais e matriz. São esqueletais quando em cristais de maior dimensão e subeuedrais quando em menor dimensão.

Observa-se ainda minerais como apatita, carbonato e zeólitas, este último restrito as vesículas.

O material intersticial comumente observado é o vidro, de coloração castanha (amostras RR-06A, RR-06B e RR-07).

\subsubsection{LATI-BASALTOS (Ib)}

Este litotipo é representado apenas por duas amostras (RR-08A e RR-09C) as quais apresentam granulação fina (tamanho máximo=1.2mm) e textura intergranular com minerais dispostos preferencialmente em microfenocristais (tamanho máximo=0.3mm) e matriz (tamanho máximo=0.05mm), sendo mais raros em fenocristais (tamanho máximo=0.6mm) (Fotomicrografia-10). 


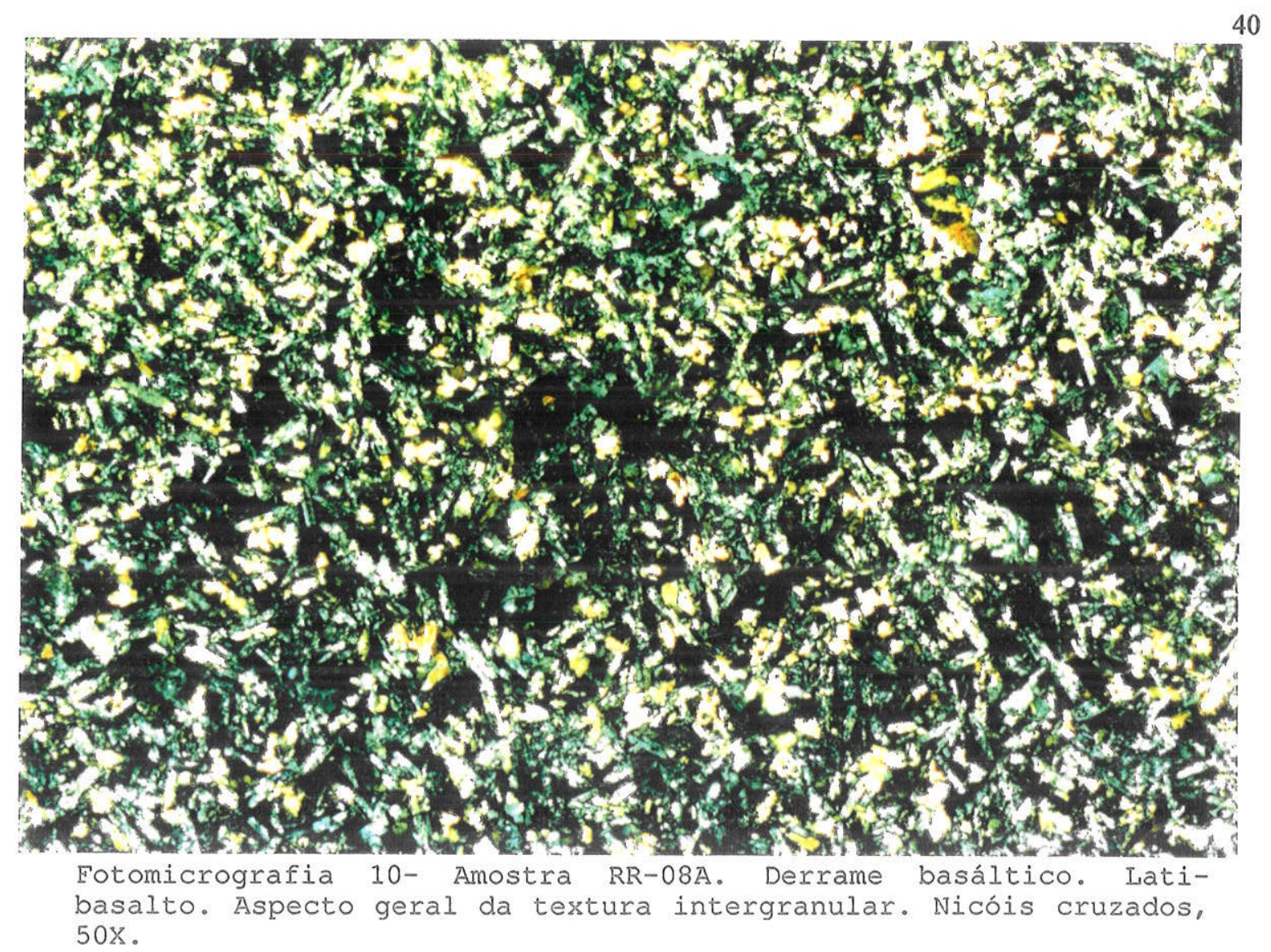

basalto. Aspecto geral da testura intergranular. Nicóis cruzados,

Os constituintes mineralógicos essenciais na rocha são plagioclásio (precoce $A n=61 \%$ ), augita (precoce Wo=36-40\%); tardio Wo=36-37\%) e minerais opacos. Subordinadamente observase minerais como clorita, apatita e quartzo.

Os plagioclásios (tamanho máximo=1.2mm; tamanho mínimo=0.05mm) distribuem-se por cerca de 50\% do volume da rocha, sendo frequentes como microfenocristais e matriz e menos comum como fenocristais. São euédricos a subédricos, na forma de ripas, as quais apresentam manchas de saussuritização por todo o cristal, com raríssimos casos em que esta alteração não recobriu inteiramente o indivíduo. Nestas manchas é possível distinguir principalmente carbonato, sericitas, cloritas e epídotos. Nas porções menos alteradas foi possível verificar que os plagioclásios são geminados segundo a lei polissintética da albita e albita-Carslbad. No entanto, as diversas tentativas para determinação do conteúdo de anortita(\%) nestes geminados pelo método Michel-Levy (Kerr, 1959) não foram bem sucedidas.

Em quantidades menores que os plagioclásios, as augitas (tamanho máximo=1.1mm; tamanho mínimo=0.05mm) ocupam cerca de 20-25\% em volume e ocorrem essencialmente na matriz e em microfenocristais, mas alguns fenocristais são assinalados. De modo geral são anédricas, granulares, com relevo médio-baixo e 
ângulo "2V" médio, indicando composição augítica. Com frequência encontra-se cristais agregados ou indidualizados parcialmente alterados nas bordas para clorita.

As magnetitas (tamanho máximo=0.1m; tamanho mínimo= $0.02 \mathrm{~mm}$ ) estão presentes principalmente na matriz e em microfenocristais. Predominantemente são anédricas de formas irregulares, mas observa-se cristais octaédricos.

Minerais como apatita, clorita, carbonato, quartzo e zeólitas também são observados, muitas vezes preenchendo amígdalas/vesículas. 
Este capitulo tem por objetivos, a partir do quimismo das principais fases minerais (plagioclásio, piroxênios, anfibólio e minerais opacos) das rochas basálticas pertencentes a suite Básica Apoteri, determinar a variação química, em termos de seus membros finais, no inicio (núcleo dos fenocristais e/ou microfenocristais) e no fim (matriz e/ou bordas dos fenocristais e/ou microfenocristais) da cristalização; discrimar suas respectivas variedades mineralógicas; estimar, dentro das limitações dos geotermômetros, as condições de temperatura de cristalização de algumas dessas fases minerais, além de comparar os "trends" de variação química obtidos com de outras suites basálticas amplamente divulgadas na Iiteratura (e.g. Brown, 1957; Brown \& Vincent, 1963; MacDonald \& Katsura, 1964; Irvine \& Baragar, 1971; entre outras).

Para isto as amostras selecionadas tenderam a representar do ponto de vista petrográfico e geoquímico os conjuntos litológicos estudados.

Os pontos analisados foram sempre que possivel localizados do núcleo para a periferia do mesmo grão (fenocristais, microfenocristais e/ou matriz) ou entre um fenocristal e um grão da matriz (principalmente nas rochas com textura porfiritical ou ainda entre um grão maior e menor (rochas com texturas afíricas). Não raramente foram analisados mais de um grão mineral de uma mesma fase mineral numa mesma amostra. Aqueles pontos localizados no núcleo do fenocristal e/ou microfenocristal foram denominados, neste trabalho, de fase cristalizada precocemente (P), enquanto que aqueles pontos localizados na periferia dos fenocristais e/ou microfenocristais ou em grãos da matriz receberam a denominação de fase cristalizada tardiamente (T).

O tratamento químico fornecido as diversas fases minerais analisadas seguiu o seguinte procedimento:

\section{DIAGRAMAS INTERPRETATIVOS:}

- Piroxênios: nomenclatura de piroxênios (Poldervaart \& Hess, 1951); diagrama normativo (CIPW) Hy-Di-Ne (conforme Bellieni et al., 1984).

- Plagioclásio: Diagrama An (Anortita)-Ab (Albita)-Or (Ortoclásio) (o em peso).

- Anfibólio: nomenclatura de anfibólio (Leake, 1978). 


\section{GEOTERMÔMETROS :}

- Piroxênios: Wood \& Banno (1973), Kretz (1982) e Ishii (1975).

- Plagioclásio: Kudo \& Weill (1970) e Mathez (1973).

A seguir serão descritas as principais fases minerais.

\subsection{DIQUES MÁEICOS}

Para este conjunto de rochas foram selecionadas 12 amostras $(8$ amostras dos basaltos toleiticos (bth) e 4 amostras dos andesi-basaltos (ab)).

\subsubsection{PIROXÊNIOS}

As tabelas-1 e 2 mostram, respectivamente, as composições químicas dos piroxênios ricos e pobres em cálcio, para os estágios de cristalização precoce (P) e para os estágios de cristalização tardia (T). A grande maioria das amostras estudadas, a exceção da RR-36B (bth) e RR-17 e RR-28 (ab), é confirmada a coexistência de piroxênios ricos (augita e ferroaugita) e pobres (pigeonita e ortopiroxênio) em cálcio, coincidindo, como era de se esperar, com a análise petrográfica (conforme visto no capítulo-5) (Figura-8).

No diagrama $\mathrm{Ca}-\mathrm{Mg}-\mathrm{Fe} e^{*} \quad\left(\mathrm{Fe}^{*}=\mathrm{Fe}^{+2}+\mathrm{Fe}^{+3}+\mathrm{Mn}\right)$ estão representados os piroxênios ricos (augita e Ee-augita) e pobres (pigeonita e ortopiroxênio) em cálcio, das fases precoces (Figura-9-A) e tardias (Figura-9-B) reunidas por litotipos. Nestes diagramas estão representadas ainda a linha de evolução dos piroxênios da intrusão de Skaergaard (Brown, 1957; Brown \& Vincent, 1963) e as linhas tracejadas unindo os piroxênios correspondentes à mesma amostra. Observa-se nestes diagramas ampla distribuição entre os dois tipos litológicos (bth e ab), fruto da variação dos conteúdos em (Ca) e/ou (Fe), sobretudo de Fe* nos piroxênios pobres em cálcio. Também pode ser observado que a grande maioria dos piroxênios posicionamse abaixo do "trend" de evolução de skaergaard. 
Litotipo: Basalto Toleítico

\begin{tabular}{|c|c|c|c|c|c|c|c|c|c|c|c|c|}
\hline AMOSTRA & \multicolumn{4}{|c|}{ RR - 01A (bth) } & \multicolumn{3}{|c|}{ RR- $18 \mathrm{E}$ (bth) } & \multicolumn{2}{|c|}{$\begin{array}{r}R R-18 A \\
\text { (bth) } \\
\end{array}$} & \multicolumn{3}{|c|}{$\begin{array}{lll}\text { RR- } & 33 & \text { (bth) }\end{array}$} \\
\hline & $T_{1}$ & $P_{1}$ & $T_{1}$ & $T_{2}$ & $\bar{T}$ & $\mathbf{P}$ & $\mathbf{P}$ & $T\left({ }^{*}\right)$ & $\bar{P}$ & $T_{1}$ & $P_{1}\left(^{\star}\right)$ & 12 \\
\hline $\mathrm{SiO}_{2}$ & 50.55 & 51.78 & 50.49 & 51.91 & 52.56 & 53.86 & 52.84 & 49.99 & 51.98 & 51.16 & 51.22 & 51.23 \\
\hline $\mathrm{TiO}_{2}$ & 0.81 & 0.59 & 0.53 & 0.38 & 0.42 & 0.35 & 0.47 & 0.73 & 0.52 & 0.70 & 0.00 & 0.66 \\
\hline $\mathrm{Al}_{2} \mathrm{O}_{3}$ & 1.71 & 1.79 & 1.66 & 1.83 & 2.74 & 2.14 & 2.45 & 2.33 & $3.80^{-}$ & 1.51 & 0.40 & 1.88 \\
\hline $\mathrm{FeO}_{\mathrm{t}}$ & 16.86 & 11.77 & 18.64 & $1240^{\circ}$ & 8.29 & 8.54 & 10.73 & $16.89^{\circ}$ & 10.33 & 16.53 & 22.06 & $15.66^{\circ}$ \\
\hline $\mathrm{MnO}$ & 0.48 & 0.24 & 0.39 & 0.27 & 0.24 & 0.26 & 0.26 & 0.42 & 0.17 & 0.35 & 0.50 & 0.38 \\
\hline $\mathrm{MgO}$ & 13.20 & 15.88 & 13.76 & 16.61 & 17.63 & 17.64 & 18.17 & $14.00^{\circ}$ & 16.82 & 13.74 & 8.46 & 14.13 \\
\hline $\mathrm{CaO}$ & 16.26 & 17.80 & 14.63 & 16.03 & 18.28 & 18.56 & 15.29 & $15.69^{\circ}$ & 15.80 & 16.63 & 18.69 & 16.61 \\
\hline $\mathrm{Na}_{2} \mathrm{O}$ & 0.22 & 0.21 & 0.23 & 0.20 & 0.23 & 0.23 & 0.16 & 0.22 & 0.47 & 0.26 & 0.20 & 0.21 \\
\hline $\mathrm{Cr}_{2} \mathrm{O}_{3}$ & 0.01 & 0.16 & 0.11 & 0.00 & 0.10 & 0.09 & 0.04 & 0.00 & 0.00 & 0.06 & 0.05 & 0.06 \\
\hline SOMA & 100.10 & 100.22 & 100.44 & 99.63 & 100.49 & 101.67 & 100.41 & 100.27 & 99.89 & 100.94 & 101.58 & 100.82 \\
\hline $\mathrm{Fe}_{2} \mathrm{O}_{3}{ }^{*}$ & 1.62 & 1.83 & 2.02 & 1.47 & 1.35 & 0.41 & 0.11 & 2.76 & 0.31 & 1.57 & 1.09 & 1.81 \\
\hline $\mathrm{Si}$ & 1.922 & 1.924 & 1.918 & 1.936 & 1.918 & 1.946 & 1.938 & 1.891 & 1.916 & 1.926 & 1.979 & 1.921 \\
\hline $\mathrm{A}^{i v}$ & 0.077 & 0.076 & 0.074 & 0.064 & 0.082 & 0.054 & 0.062 & 0.104 & 0.084 & 0.067 & 0.018 & 0.079 \\
\hline SOMA & 1.999 & 2.000 & 1.993 & $2.000^{\circ}$ & 2.000 & 2.000 & 2.000 & 1.995 & 2.000 & 1.993 & 1.997 & 2.000 \\
\hline $\mathrm{Al}^{\mathrm{v}}$ & 0.000 & 0.002 & 0.000 & 0.016 & 0.036 & 0.037 & 0.044 & 0.000 & 0.081 & 0.000 & 0.000 & 0.004 \\
\hline $\mathrm{Fe}^{+2}$ & 0.490 & 0.315 & 0.535 & 0.345 & 0.216 & 0.247 & 0.326 & 0.456 & 0.310 & 0.476 & 0.681 & 0.440 \\
\hline $\mathrm{Fe}^{73}$ & 0.046 & 0.015 & 0.058 & 0.041 & 0.037 & 0.011 & 0.003 & 0.079 & 0.009 & 0.045 & 0.032 & 0.051 \\
\hline $\mathrm{Cr}^{73}$ & 0.000 & 0.005 & 0.003 & $0.000^{-1}$ & 0.003 & 0.003 & 0.001 & 0.000 & $0.000^{-1}$ & 0.002 & 0.002 & 0.002 \\
\hline $\mathrm{Mg}$ & 0.748 & 0.879 & 0.779 & 0.923 & 0.959 & 0.950 & 0.993 & 0.789 & 0.924 & 0.7711 & 0.487 & $0.790^{\circ}$ \\
\hline $\mathrm{Mn}$ & 00.015 & 0.008 & 0.013 & 0.009 & 0.007 & 0.008 & 0.008 & 0.013 & 0.005 & 0.011 & 0.016 & 0.012 \\
\hline $\mathrm{Ti}$ & 0.023 & 0.016 & 0.015 & 0.011 & 0.012 & 0.010 & 0.013 & 0.021 & 0.014 & 0.020 & 0.000 & 0.019 \\
\hline $\mathrm{Ca}$ & 0.663 & 0.709 & 0.596 & $0.640^{-1}$ & 0.715 & 0.719 & 0.601 & 0.636 & 0.624 & 0.671 & 0.774 & 0.667 \\
\hline $\mathrm{Na}$ & 0.076 & 0.015 & 0.017 & 0.014 & 0.016 & 0.016 & 0.011 & 0.016 & 0.034 & 0.019 & 0.015 & 0.015 \\
\hline SOMA & 2.002 & 2.000 & 2.015 & 1.999 & 2.000 & 2.000 & 2.000 & 2.000 & 2.001 & 2.014 & 2.007 & 1.999 \\
\hline $\mathrm{Ca}$ & 34.86 & 37.25 & 31.19 & 33.55 & 37.83 & 37.52 & 31.29 & 33.81 & 33.59 & 34.98 & 39.84 & 35.18 \\
\hline $\mathrm{Mg}$ & 39.36 & 46.22 & 40.81 & 48.36 & -50.74 & 49.59 & 51.72 & 41.96 & 49.73 & 40.20 & 25.08 & 41.63 \\
\hline $\mathrm{Fe}^{*}$ & 25.78 & 16.53 & 28.00 & 18.09 & 11.43 & 12.89 & 16.98 & 24.23 & 16.68 & 24.82 & 35.07 & 23.19 \\
\hline
\end{tabular}

Tabela 1- Microanálise química dos piroxênios ricos em cálcio dos diques máficos da Suite Básica Apoteri. $P=$ fase de cristalização precoce; $T=$ fase de cristalização tardia; $P_{1,2}=$ fase de cristalização precoce do grão mineral 1,2 , respectivamente; $T_{1,2}=$ fase de cristalização tardia do grão mineral 1,2 , respectivamente. $\mathrm{Fe}_{2} \mathrm{O}_{3}$ * calculado segundo Papike et al., 1974 (adaptado por Sílvio Vlach). Fe*= $\mathrm{Fe}^{+2}+\mathrm{Fe}^{+3}+\mathrm{Mn}$. bth= basalto toleítico; $\mathrm{ab}=$ andesi-basalto; (*) análises utilizadas no cálculo de balanço de massa para elementos maiores. 
Litotipo: Basalto Toleítico

\begin{tabular}{|c|c|c|c|c|c|c|c|c|c|c|c|}
\hline \multirow[t]{2}{*}{ AMOSTRA } & \multicolumn{3}{|c|}{ RR -35B (bth) } & \multicolumn{4}{|c|}{ RR - 36A (bth) } & \multicolumn{3}{|c|}{ RR- $\quad$ 42B (bth) } & \multirow{2}{*}{$\begin{array}{c}\begin{array}{c}\text { RR-53B } \\
\text { (bth) }\end{array} \\
T_{1}\end{array}$} \\
\hline & $T$ & $\bar{P}$ & $\mathrm{~T}$ & $T_{1}$ & $\overline{P_{1}\left(^{*}\right)}$ & $T_{2}$ & $\mathbf{P}_{2}\left(^{*}\right)$ & $T_{1}$ & $P_{1}$ & $\overline{P_{2}}$ & \\
\hline & 50.8 : & 51.20 & 51.64 & 52.12 & & & & 49.72 & 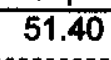 & & 2 \\
\hline & 87 & 0.67 & 0.6 & 0.62 & 0.3 & 0.74 & 0.71 & 0.61 & 0.47 & 0.70 & 6.6 \\
\hline & 1.62 & 1.66 & 1.9 & 2.07 & 2.0 & 1.60 & 1.51 & 1.29 & 2.17 & 2.32 & 2.1 \\
\hline & 16.20 & 13.85 & 12.59 & 10.32 & 6.7 & 16.87 & 18.01 & 20.78 & 12.16 & 14.19 & 12.7 \\
\hline & 0.22 & 0.28 & 0.1 & 0.17 & 0.1 & 0.35 & 0.43 & 0.49 & 0.30 & 0.33 & 0.3 \\
\hline & .50 & 15 & 15. & 10 & 17 & 2 & 13 & 3 & 15.93 & 3.54 & 4.2 \\
\hline & .95 & 16.90 & 17.76 & 18.33 & 19.43 & 16.19 & 15.02 & 15.69 & $17.48^{\circ}$ & 18.19 & 17.6 \\
\hline & 0.25 & 0.23 & 0.78 & 0.16 & 0.2 & 0.23 & 0.26 & 0.16 & 0.26 & 0.22 & 0.2 \\
\hline & 0.09 & 0.00 & 0.0 & 0.08 & 0.18 & 0.00 & 0.06 & 0.00 & 00.01 & .03 & 0.0 \\
\hline & 0.51 & 99.95 & 100.02 & 0.45 & 51.16 & 0.40 & 01.47 & 99.87 & 0.18 & 100.52 & 00.37 \\
\hline $\mathrm{Fe}_{2} \mathrm{O}_{3}$ & 1.43 & 1.85 & 1.02 & 1.54 & 0.87 & 1.62 & 1.15 & 21 & 2.86 & 1.52 & 1.15 \\
\hline & 23 & 1.923 & 931 & $321 !$ & 1.923 & 921 & 1.939 & : & 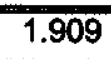 & 1.915 & 02 \\
\hline & 72 & 0.073 & 0.069 & 0.079 & 0.077 & 0.079 & 0.061 & 059 & 0.091 & 0.085 & .07 \\
\hline & 1.995 & 1.996 & 2.000 & 2.000 & 2.000 & 92 & 2.000 & 991 & $2.000^{\circ}$ & 2.000 & 2.00 \\
\hline & 0.000 & 0.000 & $\overline{0.016}$ & 011 & 004 & 0.000 & $\overline{0}$ & .000 & 0.00 & 0.018 & .02 \\
\hline & 71 & 0.383 & 0.365 & 275 & 0.179 & 0.488 & 0.533 & 640 & 0.298 & 0.403 & 36 \\
\hline$F \epsilon$ & 0.041 & 0.052 & 0.029 & 0.043 & 0.024 & 0.046 & 0.033 & .035 & $0.080^{\circ}$ & 0.043 & $0.0 \overline{3}$ \\
\hline & 0.000 & 0.000 & 0.001 & 0.002 & 0.005 & 0.000 & 0.002 & 0.000 & $0.000^{\circ}$ & 0.001 & 0.003 \\
\hline & 0.760 & 0.848 & 0.842 & 171 & 0.966 & 0.775 & 0.771 & 0.644 & 0.882 & 0.758 & 0.83 \\
\hline$\ddot{\mathrm{M}}$ & 0.007 & 0.009 & 0.005 & 0.005 & 0.005 & 0.011 & 0.014 & 0.016 & 0.009 & 0.070 & 0.00 \\
\hline$\therefore$ & 0.025 & 0.019 & 0 & 017 & 0.008 & 0.021 & 0.020 & .018 & 0.013 & 0.020 & 0.01 \\
\hline $\mathrm{C}$ & 0.686 & 0.680 & 0.712 & 0.724 & 0.751 & 0.657 & 0.604 & 653 & 0.696 & 0.732 & 0.70 \\
\hline & & 0.017 & & 11 & 0.015 & 0.017 & 0.019 & 012 & 0.019 & 0.016 & 0.01 \\
\hline $5 \mathrm{M}$ & 2.008 & 2.008 & 2.000 & 2.000 & 2.009 & 2.015 & 2.000 & 2.019 & 2.001 & 2.000 & 2.001 \\
\hline & & & & & & & 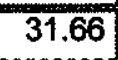 & 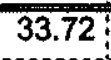 & 37.10 & 38.68 & 37.08 \\
\hline & 39.64 & 44.40 & 43.87 & 47.68 & 50.97 & 40.34 & 40.42 & 3.26 & 47.02 & 40.04 & 43.73 \\
\hline$=8$ & 24.57 & 20.02 & 19.03 & 14.42 & ה-ם"ה & 25.43 & 27.92 & 33.02 & 15.88 & 21.28 & 19.18 \\
\hline
\end{tabular}

Tabela 1- Continuação 
Litotipo: Basalto Toleítico; Andesi-basalto

\begin{tabular}{|c|c|c|c|c|c|c|c|c|c|c|c|c|}
\hline \multirow[t]{2}{*}{ AMOSTRA } & \multicolumn{3}{|c|}{ RR $\quad-53 B \quad$ (bth) } & \multicolumn{3}{|c|}{$\begin{array}{lll}R R & -16 & (a b)\end{array}$} & \multicolumn{3}{|c|}{$\begin{array}{lll}R R & -17 & (a b)\end{array}$} & \multicolumn{2}{|c|}{$\begin{array}{r}18 D \\
(a b)\end{array}$} & \multirow{2}{*}{$\begin{array}{c}\begin{array}{c}\text { RR-28 } \\
(a b)\end{array} \\
P\end{array}$} \\
\hline & $\overline{P_{1}}$ & $\overline{\mathrm{T}_{2}}$ & $P_{2}$ & $T$ & $P\left({ }^{*}\right)$ & $T$ & $T$ & $P$ & $\mathrm{~T}$ & $T$ & $P$ & \\
\hline & $\overline{516}$ & 51.40 & 52.84 & 51.16 & 50.39 & 51.06 & 50.48 & 50.96 & 49.92 & 53.18 & 52.24 & 42.36 \\
\hline &.-1 & 0.41 & 0.44 & 0.65 & 0.80 & 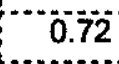 & 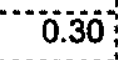 & 0.7 & 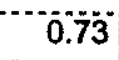 & 2 & $0 . \mathrm{C}^{2}$ & 2.6 \\
\hline & 2.43 & 2.27 & 1.97 & 1.64 & 2.87 & 2.12 & 1.88 & 1.80 & 2.12 & 2.000 & 0.71 & 6.9 \\
\hline & 7.84 & 9.43 & 8.17 & 20.21 & 15.35 & 13.49 & 19.10 & 17.19 & 17.81 & 9.94 & 15.93 & 25.6 \\
\hline & 0.12 & 0.21 & 0. & & 0.34 & 0. & 0.33 & 0.35 &.- & 0.38 & 0.43 & 0.4 \\
\hline & 14 & 16.94 & 18.68 & 12.83 & 13.45 & 13.65 & 12.57 & 14.47 & 1.04 & 9.21 & 11.31 & 5.0 \\
\hline & 18.98 & 18.78 & 17 & 14.69 & $i$ & $18.50^{\circ}$ & 4 & 15.43 & 7 & 5.12 & 19.94 & .9 \\
\hline & 0.16 & 0.22 & 0.20 & 0.15 & 0.18 & 0.23 & 0.13 & 0.23 & 0.19 & 0.22 & 0.17 & 1.40 \\
\hline & 0.28 & 0.01 & 0.06 & 0.01 & 0.05 & 0.09 & 0.01 & 0.09 & 0.07 & 0.09 & 0.03 & 0.0 \\
\hline & 99.92 & 99.67 & 99.87 & 01.78 & 100.89 & 100.22 & 99.84 & 00.96 & 99.75 & 50.58 & 100.76 & 93.78 \\
\hline & 3.28 & 3. & 1.32 & 1.42 & 2. & 1.39 & 1.20 & 2.44 & 0.02 & 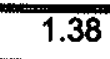 & 0. & 1.20 \\
\hline & 39 & 1.900 & 1.933 & 30 & 1.890 & 1.920 & $936 !$ & 914 & .923 & 34 & 1.9 & 178 \\
\hline & $\ddot{0}$ & & 0.0 & & & & & 080 & & 0.066 & 0.016 & \\
\hline SON & 1.996 & 1.999 & 2.000 & $2.000^{\circ}$ & 2.000 & 2.000 & 2.000 & 1.993 & $2.000^{-1}$ & 2.000 & 2.00000 & $2.00 \mathrm{c}$ \\
\hline $\mathrm{Al}$ & 00 & 0.000 & 0.018 & 0.003 & 0.017 & 0.014 & 0.021 & 0.000 & 0.020 & 0.034 & 0.015 & 0.13 \\
\hline $\mathrm{Fe}^{+}$ & $0.150^{\circ}$ & 0.200 & 0.214 & 0.597 & 0.422 & 0.385 & 0.578 & 0.479 & 0.547 & 0.265 & 0.493 & 0.846 \\
\hline & 009 & 0.092 & 0.036 & $0.040^{\circ}$ & 0.059 & 0.039 & 0.035 & 0.069 & 0.027 & 0.038 & 0.012 & 0.061 \\
\hline $\mathrm{Cr}^{7}$ & 0.008 & 0.000 & 0.002 & $0.000^{\circ}$ & 0.001 & 0.003 & 0.000 & 0.003 & 0.002 & 0.003 & 0.001 & 0.001 \\
\hline$N$ & 0 o & 0.933 & & 17 & 0.752 & 0.765 & 0.719 & 0.810 & 0.634 & 1.041 & $0.640^{-1}$ & 0.315 \\
\hline & 04 & 0.007 & 0.006 & 14 & 0.011 & & & 0.017 & & 011 & 0.014 & 0.01 \\
\hline$\cdots$ & 0.009 & 0.011 & 0.012 & 0.018 & 0.023 & 0.020 & 0.009 & 0.012 & 0.021 & 0.003 & 0.000 & 0.06 \\
\hline $\mathrm{Ca}$ & 0.745 & 0.744 & 79 & 594 & 0.702 & 0.745 & 0.618 & 0.621 & 0.725 & 589 & 0.811 & 448 \\
\hline & 0.011 & 0.016 & 0.014 & 0.011 & 0.013 & 0.017 & 0.010 & 0.017 & 0.014 & 0.016 & 0.013 & 0.11 \\
\hline . & 2.007 & 2.003 & 2.000 & 2.000 & 2.000 & 2.000 & 2.000 & 2.014 & 1.999 & 2.000 & 2.000 & 2.000 \\
\hline & & 39.63 & I & .05 & 37.41 & 39.33 & 32.28 & 32.65 & 38.05 & 1.09 & 41.72 & 7.86 \\
\hline & & 49.72 & & & 40.09 & & 37.53 & 42.59 & 33.25 & 4.95 & 32.91 & $9.59^{\circ}$ \\
\hline $\mathrm{Fe}^{*}$ & 7.94 & 10.65 & 11.17 & 31.23 & 22.50 & 20.31 & 30.19 & 24.77 & $28.70^{\circ}$ & 13.96 & 25.37 & 52.56 \\
\hline
\end{tabular}

Tabela 1- Continuação 
Litotipo: Andesi-basalto

\begin{tabular}{|c|c|c|c|c|}
\hline \multirow{2}{*}{ AMOSTRA } & \multicolumn{4}{|c|}{$R R-35 C$} \\
\hline & $\overline{P_{1}}$ & $T_{1}$ & $P_{2}$ & $T_{2}$ \\
\hline $\mathrm{SiO}_{2}$ & 52.14 & 53.02 & 52.23 & 51.04 \\
\hline $\mathrm{TiO}_{2}$ & 0.34 & 0.15 & $0.60^{\circ}$ & $0.70^{\circ}$ \\
\hline $\mathrm{Al}_{2} \mathrm{O}_{3}$ & 1.88 & 1.89 & 2.05 & 1.84 \\
\hline $\mathrm{FeO}$ & 11.15 & 9.75 & 10.66 & 14.66 \\
\hline MnO & 0.18 & 0.23 & 0.24 & 0.18 \\
\hline $\mathrm{MgO}$ & 17.09 & 17.98 & 17.04 & $14.49^{\circ}$ \\
\hline $\mathrm{CaO}$ & -17.29 & 17.05 & 17.74 & 76.74 \\
\hline $\mathrm{Na}_{2} \mathrm{O}$ & 0.20 & 0.19 & 0.21 & 0.25 \\
\hline $\mathrm{C}_{2} \mathrm{O}_{3}$ & 0.03 & 0.04 & 0.02 & 0.001 \\
\hline SOMA & 100.30 & 100.30 & 100.79 & 99.91 \\
\hline $\mathrm{Fe}_{2} \mathrm{O}_{3}{ }^{*}$ & 2.46 & 1.35 & 2.20 & 1.79 \\
\hline Si & 1.922 & 1.943 & 1.916 & 1.923 \\
\hline $\mathrm{A}^{i{ }^{N}}$ & 0.078 & 0.057 & 0.084 & 0.077 \\
\hline SOMA & 2.000 & $\overline{2} .000$ & 2.000 & $2.000^{\circ}$ \\
\hline$\overline{A 1^{n}}$ & 0.004 & 0.024 & 0.005 & 0.005 \\
\hline$F E$ & 0.275 & 0.261 & 0.266 & 0.411 \\
\hline$F_{\epsilon}$ & 0.068 & 0.037 & 0.061 & 0.0051 \\
\hline$C r$ & 0.001 & 0.001 & 0.001 & 0.000 \\
\hline $\mathrm{Mg}$ & 0.939 & 0.982 & 0.932 & 0.814 \\
\hline $\mathrm{Mn}$ & 0.006 & 0.007 & 0.007 & 0.006 \\
\hline $\mathrm{Ti}$ & 0.009 & 0.004 & 0.017 & $0.020^{-}$ \\
\hline $\mathrm{Ca}$ & 0.683 & 0.669 & 0.697 & 0.676 \\
\hline $\mathrm{Na}$ & 0.014 & 0013 & 0.015 & 0.018 \\
\hline SOMA & 2.000 & $" 1.999$ & 2.000 & 2.000 \\
\hline $\mathrm{Ca}$ & 36.00 & 35.00 & 36.79 & 35.56 \\
\hline $\mathrm{Mg}$ & 49.49 & 51.33 & 49.15 & 42.81 \\
\hline $\mathrm{Fe}^{\star}$ & 14.52 & 13.67 & 14.05 & 21.63 \\
\hline
\end{tabular}

Tabela 1-Continuação 
Litotipo: Basalto Toleítico

\begin{tabular}{|c|c|c|c|c|c|c|c|c|c|c|c|}
\hline \multirow{2}{*}{ AMOSTRA } & $\begin{array}{c}\text { RR-01A } \\
(b(t)\end{array}$ & & $\begin{array}{l}18 \mathrm{~A} \\
\text { (bth) }\end{array}$ & $\begin{array}{c}\text { RR-18E } \\
\text { (bth) }\end{array}$ & \multicolumn{4}{|c|}{$R R-33$} & \multirow{2}{*}{ 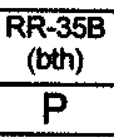 } & \multicolumn{2}{|c|}{$\begin{array}{lr}\text { RR- } & \begin{array}{r}428 \\
(\mathrm{bth})\end{array}\end{array}$} \\
\hline & $P\left({ }^{*}\right)$ & $\bar{P}$ & $T$ & $P\left({ }^{*}\right)$ & $\left({ }^{*}\right)$ & $\overline{T_{1}}$ & $\overline{P_{2}}$ & $\overline{T_{2}}$ & & $T_{1}$ & \\
\hline $\mathrm{SiO}_{2}$ & 52.60 & 52.97 & 54.49 & 54.78 & 54.41 & 50.78 & 53.24 & 52.21 & 31.52 & $\frac{1}{50.22}$ & $\frac{2}{51.58}$ \\
\hline Tic & 0.30 & 0.11 & 0.17 & 0.13 & 0.26 & 0.32 & 0.13 & 0.34 & 0.09 & 0.62 & 0.26 \\
\hline & 1.33 & 0.94 & 1.11 & 1.63 & 1997 & 0.86 & 0.97 & 1.08 & 12.64 & 1.16 & 1.01 \\
\hline$\ddot{F}$ & 20.71 & 20.47 & 14.06 & 12.47 & 15.45 & 28.34 & 21.01 & 21.74 & 30.85 & 26.59 & 23.84 \\
\hline & 0.45 & 0.52 & 0.25 & 0.38 & 0.27 & 0.71 & 0.41 & 0.48 & 0.20 & 0.52 & 0.53 \\
\hline & 19.08 & 21.40 & 23.86 & 24.11 & 26.86 & 14.99 & 20.85 & 19.94 & 12.09 & 14.81 & 18.06 \\
\hline & 6.31 & 4.26 & 6.69 & 8.01 & 2.36 & 4.65 & 4.10 & 4.95 & 0.35 & 6.14 & 4.94 \\
\hline & 0.18 & 0.12 & 0.14 & 0.08 & 0.04 & 0.03 & 0.10 & 0.01 & 0.00 & 0.17 & 0.12 \\
\hline 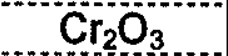 & 0.02 & 0.05 & 0.00 & 0.01 & 0.02 & 0.01 & 0.00 & $0.00^{\circ}$ & $0.00^{\circ}$ & 0.01 & 0.02 \\
\hline sôi & 100.98 & 100.84 & 100.77 & 001.60 & 101.64 & 100.69 & 00.81 & 100.75 & 87.74 & 100.24 & 100.36 \\
\hline $\mathrm{Fe}_{2} \mathrm{O}_{3}{ }^{*}$ & 1.02 & 1.51 & 0.83 & 0.93 & 1.67 & 0.77 & 0.58 & 1.04 & 16.98 & $1.01 !$ & 1.35 \\
\hline $8:$ & 1.954 & 1.955 & 1.965 & 1.952 & 1.931 & 1.959 & 1.971 & 1.948 & 1.388 & 1.940 & 1.952 \\
\hline & 0.046 & 0.041 & 0.035 & 0.048 & 0.069 & 0.039 & 0.029 & 0.047 & 0.6612 & 0.053 & 0.045 \\
\hline SÖM & 2.000 & 1.996 & 2.000 & $2.000^{\circ}$ & 2.000 & 1.998 & 2.000 & 1.995 & 2.000 & 1.993 & 1.997 \\
\hline$\overline{\mathrm{Al}}{ }^{n}$ & 0.013 & 0.000 & 0.013 & 0.021 & 0.013 & 0.000 & 0.013 & 0.000 & 0.044 & 0.000 & 0.000 \\
\hline $\mathrm{Fe}$ & 0.615 & 0.590 & 0.402 & 0.347 & 0.414 & 0.892 & 0.634 & 0.649 & 0.573 & $" 0.830$ & 0.716 \\
\hline & 0.029 & 0.042 & 0.022 & 0.025 & 0.045 & 0.022 & 0.016 & 0.029 & 0.562 & 0.029 & 0.038 \\
\hline & 0.001 & 0.001 & 0.000 & 0.000 & 0.001 & 0.000 & 0.000 & $0.000^{\circ}$ & 0.000 & 0.000 & 0.00 \\
\hline $\mathrm{M}$ & 1.067 & 1.177 & 1.283 & 1.281 & 1.420 & 0.862 & 1.150 & 1.108 & 0.793 & 0.853 & 1.018 \\
\hline $\mathrm{Mn}$ & 0.014 & 0.016 & 0.008 & 0.011 & 0.008 & 0.023 & 0.013 & 0.015 & 0.007 & 0.0917 & 0.017 \\
\hline Tii & 0.008 & 0.003 & 0.005 & 003 & 0.007 & 0.009 & 0.004 & 0.010 & 0.003 & 0.018 & 0.007 \\
\hline$\ddot{c}$ & 0.251 & 0.169 & 0.259 & 0. & 0.090 & 0.192 & 0.163 & 0.198 & 0.017 & 0.254 & 0.20 \\
\hline $\mathrm{N}$ & 0.013 & 0.009 & 0.010 & 0.006 & 0.003 & 0.002 & 0.007 & 0.001 & $0.000^{\circ}$ & 0.013 & 0.009 \\
\hline SOMA & 2.000 & 2.008 & 2.001 & 2.001 & 2.001 & 2.003 & 2.000 & $2.010^{\circ}$ & 2.0000 & 2.014 & 2.007 \\
\hline$\overline{\mathrm{Ca}}$ & 13.07 & 8.70 & 13.31 & 15.82 & 4.66 & $\overline{9.88}$ & 8.35 & 10.12 & 1.19 & 13.12 & 10.35 \\
\hline IVI & 54.95 & 60.82 & 66.02 & 66.24 & 73.83 & 44.29 & 59.07 & 56.69 & 57.35 & 44.03 & 52.64 \\
\hline re & 31.98 & 30.48 & 20.67 & 17.94 & 21.51 & 45.83 & 32.58 & 33.19 & 41.46 & 42.85 & 37.01 \\
\hline
\end{tabular}

Tabela 2- Microanálise química dos piroxênios pobres em cálcio dos diques máficos da Suíte Básica Apoteri. Símbolos como na tabela-1. 
Litotipo: Basalto Toleítico; Andesi-basalto

\begin{tabular}{|c|c|c|c|c|c|c|}
\hline \multirow[t]{2}{*}{ AMOSTRA } & \multicolumn{2}{|c|}{$\begin{array}{r}R R-\begin{array}{l}53 B \\
\text { (bth) }\end{array} \\
\end{array}$} & \multirow{2}{*}{$\begin{array}{c}\begin{array}{c}\text { RR-16 } \\
\left(\begin{array}{c}6) \\
(6)\end{array}\right.\end{array} \\
P\left({ }^{*}\right)\end{array}$} & \multirow{2}{*}{$\begin{array}{c}\mathrm{RR}- \\
18 \mathrm{D} \\
(\mathrm{ab}) \\
\mathrm{T}\end{array}$} & \multicolumn{2}{|c|}{$\begin{array}{r}R R-35 C \\
(a b)\end{array}$} \\
\hline & $T$ & $P$ & & & $\overline{T_{1}}$ & T. \\
\hline$\overline{\mathrm{SiO}_{2}}$ & 52.77 & 53.31 & 52.26 & 49.51 & 54.26 & $\because 4$ \\
\hline TiO2 & 0.32 & 0.36 & 0.35 & 0.41 & 0.07 & 0.1 \\
\hline $\mathrm{Al}_{2} \mathrm{O}_{3}$ & 1.21 & 1.45 & $1.70^{\circ}$ & 1.51 & 1.11 & 1.5 \\
\hline $\mathrm{FeO}_{\mathrm{t}}$ & 20.77 & 15.80 & 23.10 & 27.21 & 16.16 & 14.8 \\
\hline $\mathrm{MnO}$ & 0.43 & 0.30 & 0.35 & 0.63 & 0.23 & 0. \\
\hline $\mathrm{MgO}$ & 20.66 & 23.33 & 20.82 & 14.22 & 26.49 & $" 26.8$ \\
\hline $\mathrm{Ca}$ & 63 & 6.17 & 2.03 & 6.67 & 2.33 & 2.4 \\
\hline $\mathrm{N}$ & 11 & 0.13 & 0.04 & 0.14 & 0.02 & 0.0 \\
\hline$\ddot{\mathrm{C}}$ & 0.05 & 0.00 & 0.00 & 0.07 & 0.05 & 0.0 \\
\hline SOMA & 100.95 & 100.85 & 100.65 & 100.37 & 100.72 & 100.8 \\
\hline $\mathrm{Fe}_{2} \mathrm{O}_{3}{ }^{*}$ & 1.20 & 1.89 & 0.60 & 0.10 & 1.60 & 1.3 \\
\hline Si & 1.951 & 1.934 & 1.946 & 1.955 & 1.950 & 1.948 \\
\hline$A I^{i v}$ & 0.049 & 0.062 & 0.054 & 0.045 & 0.047 & 0.05 \\
\hline SÖMÄ & 2.000 & 1.996 & 2.000 & 2.000 & 1.997 & 2.00 \\
\hline$A l^{\prime \prime}$ & $\overline{0.004}$ & 0.000 & 0.021 & 0.026 & 0.000 & 0.01 \\
\hline $\mathrm{Fe}^{+2}$ & 0.609 & 0.428 & 0.703 & 0.806 & 0.442 & 0.40 \\
\hline $\mathrm{Fe}^{73}$ & 0.033 & 0.052 & 0.017 & 0.003 & 0.043 & 0.03 \\
\hline $\mathrm{Cr}^{+3}$ & 0.001 & 0.000 & 0.000 & 0.002 & 0.001 & 0.00 \\
\hline $\mathrm{Mg}$ & 1.139 & 1.261 & 1.155 & 0.837 & 1.419 & $1 . \overline{3}$ \\
\hline $\mathrm{Mn}$ & 0.013 & 0.009 & 0.011 & 0.021 & 0.007 & 0.01 \\
\hline ii & 0.009 & 0.010 & 0.010 & 0.012 & 0.002 & 0.00 \\
\hline $\mathrm{Ca}$ & 0.183 & 0.240 & 0.081 & 0.282 & 0.090 & 0.094 \\
\hline $\mathrm{Na}$ & 0.008 & 0.009 & 0.003 & 0.011 & 0.001 & 0.00 \\
\hline$\overline{\text { SOMA }}$ & 2.000 & 2.009 & 2.000 & 2.000 & 2.006 & 2.00 \\
\hline $\mathrm{Ca}$ & 50 & 12.43 & 4.18 & 14.66 & 4.60 & 4.8 \\
\hline $\mathrm{Mg}$ & 58.96 & 65.39 & 59.59 & 43.48 & 72.72 & 74.07 \\
\hline $\mathrm{Fe}^{*}$ & 31.54 & 22.18 & 36.23 & 41.86 & 22.68 & 21.06 \\
\hline
\end{tabular}

Tabela 2- Continuação 

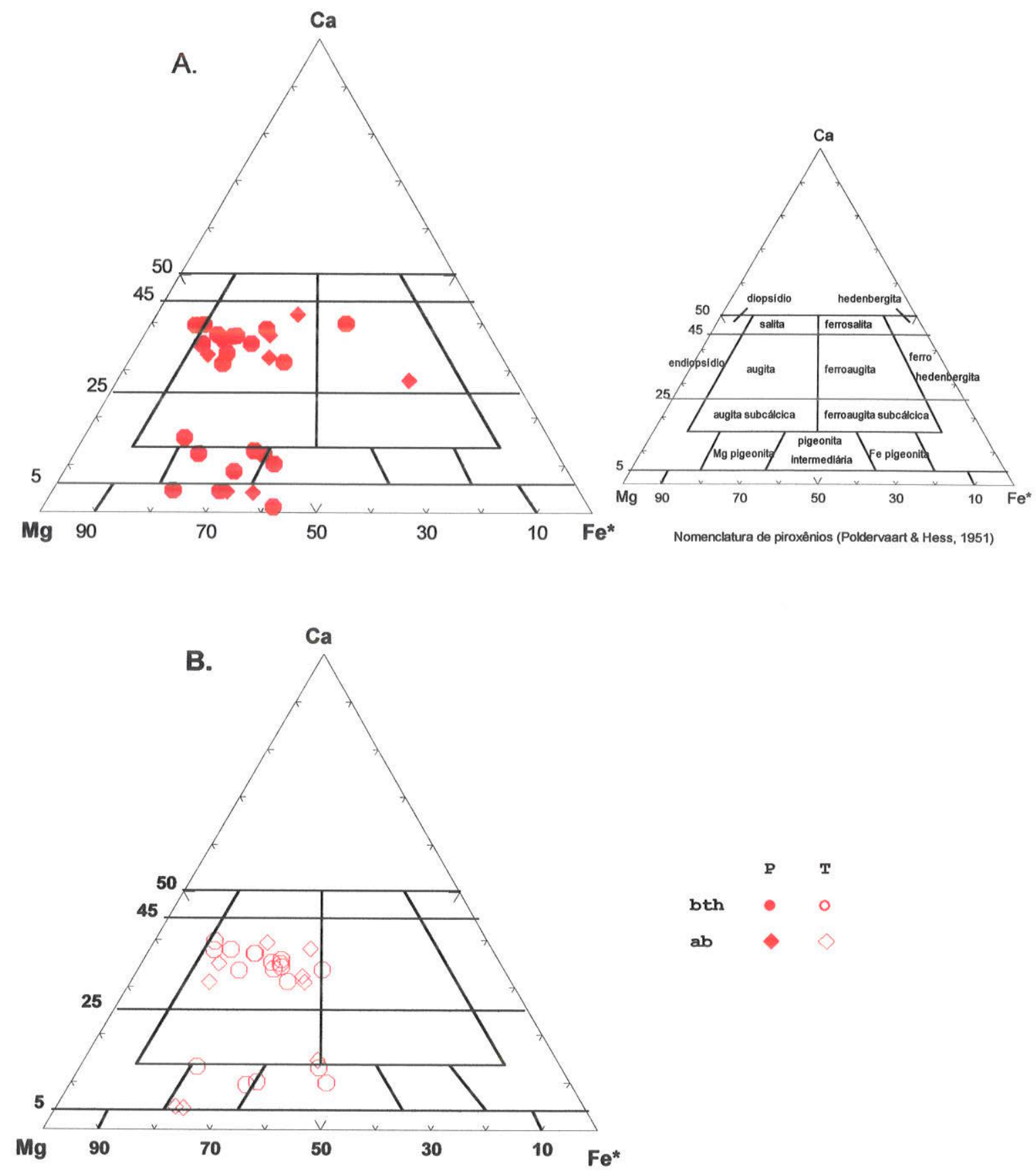

Figura 8- Quadrilátero dos piroxênios ( $\left.\mathrm{Ca}-\mathrm{Mg}-\mathrm{Fe}^{*}\right)$, segundo Poldervaart \& Hess (1951) para as fases de cristalização precoce (A) e tardia (B) dos piroxênios dos diques toleíticos (bth) e andesi-basaltos (ab) da Suíte Básica Apoteri. 

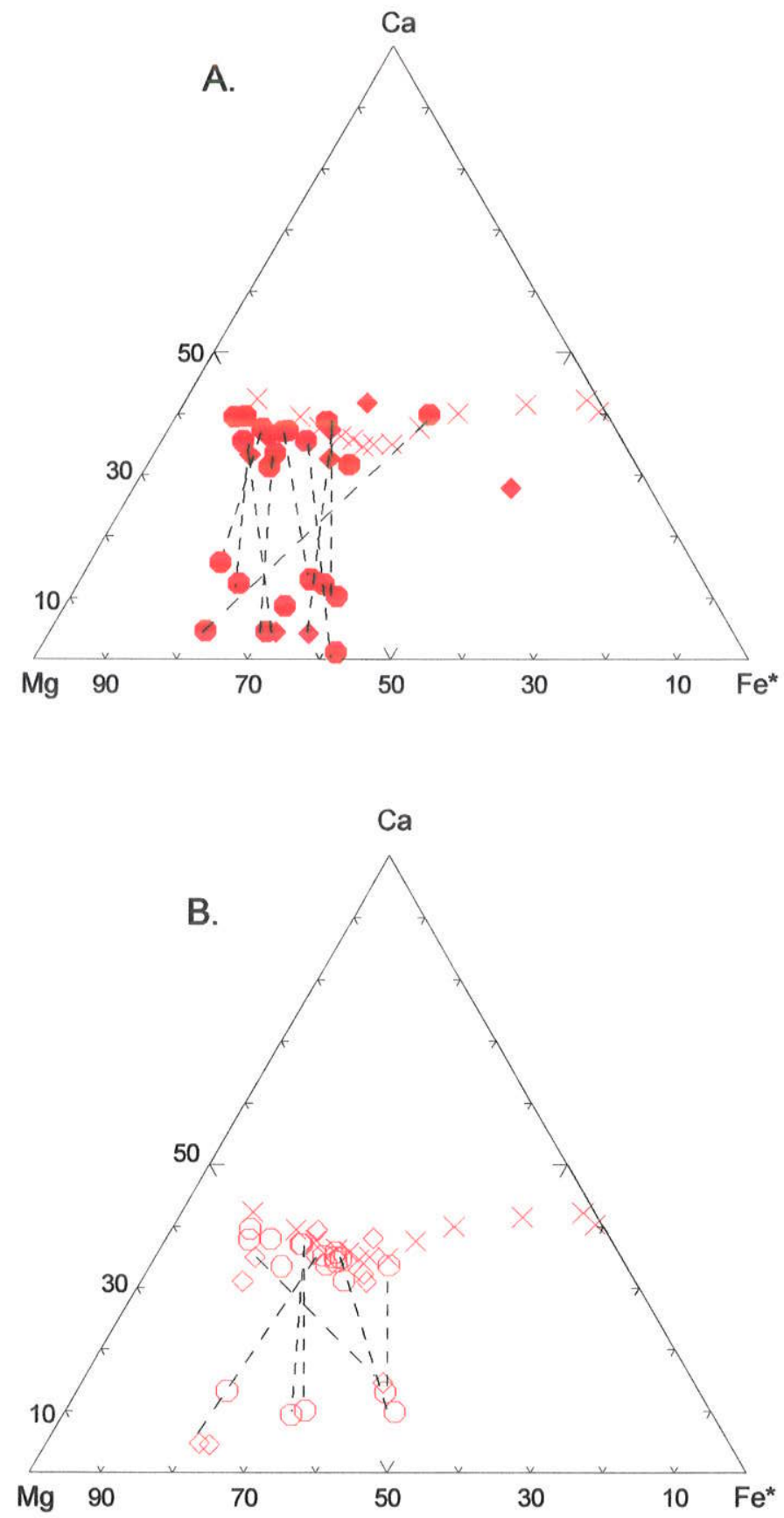

Figura 9- Variação composicional em termos de Ca-Mg-Fe* (응 atômica) dos piroxênios ricos e pobres em cálcio de cristalização precoce (A) e tardia (B) dos diques toleíticos e andesi-basaltos da suíte Básica Apoteri. Linhas tracejadas unem pontos de mesma amostra. $\mathrm{Fe}^{*}=\mathrm{Fe}^{+2}+\mathrm{Fe}^{+3}+\mathrm{Mn}$. Símbolos em "X" representam a linha de evolução dos piroxênios da intrusão de skaergaard (Brown, 1957; Brown \& Vincent, 1963). Símbolos como na figura-8. 
Na figura-9 observa-se também, tanto para os piroxênios ricos quanto pobres em cálcio, dos bth e ab que os conteúdos de Ca (Wo) decrescem dos estágios precoces para os tardios acompanhados de um aumento dos teores de Fe (Fs), embora nas pigeonitas e ortopiroxênio (piroxênios pobres em cálcio) demonstrem um fraco incremento em cálcio, e moderado enriquecimento em $\mathrm{Fe}^{\star}$. Este padrão evolutivo é característico em piroxênios de suites toleíticas.

Diversos autores (e.g. Bellieni et al.,1981; Leterrier et al.,1982) têm demonstrado que a composição dos piroxênios variam em função da composição química das suas respectivas rochas hospedeiras, embora alguns fatores como a sequência de cristalização, razão de resfriamento do magma, entre outros possam afetar este comportamento.

A composição normativa (CIPW) dos clinopiroxênios ricos em cálcio tem demonstrado ser útil para distinguir diferentes tipos de basaltos (Coombs, 1963; Bellieni et al., 1984). Geralmente os piroxênios de basaltos alcalinos possuem usualmente nefelina normativa, ao passo que os basaltos a dois piroxênios tem alto conteúdo de hiperstênio normativo, enquanto que os basaltos transicionais possuem de baixo a moderado conteúdo de hiperstênio normativo. Na figura-10 é mostrado o diagrama $\mathrm{Hy}-\mathrm{Di}-\mathrm{Ne}$ normativos com a distribuição dos piroxênios cálcicos dos tipos litológicos analisados, além dos "trends" de Skaergaard (Brown \& Vincent, 1963) e de Thingmuli (Carmichael, 1964) para efeito de comparação. Observa-se que todas as amostras possuem alto conteúdo de Hy normativos acompanhado de um aumento desse das fases precoces para as tardias, evidenciando uma evolução toleítica para estes corpos.

\subsubsection{GEOTERMOMETRIA}

Para a determinação das temperaturas de criatalização dos piroxênios laugitas coexistentes com pigeonita e/ou ortopiroxênio numa mesma amostra), utilizou-se as equações dos geotermômetros de Wood \& Banno (1973) (WB) e Kretz (1982) (K). Estes geotermômetros baseiam-se, fundamentalmente, no equilíbrio natural do intervalo de miscibilidade da assembléia de dois piroxênios. 


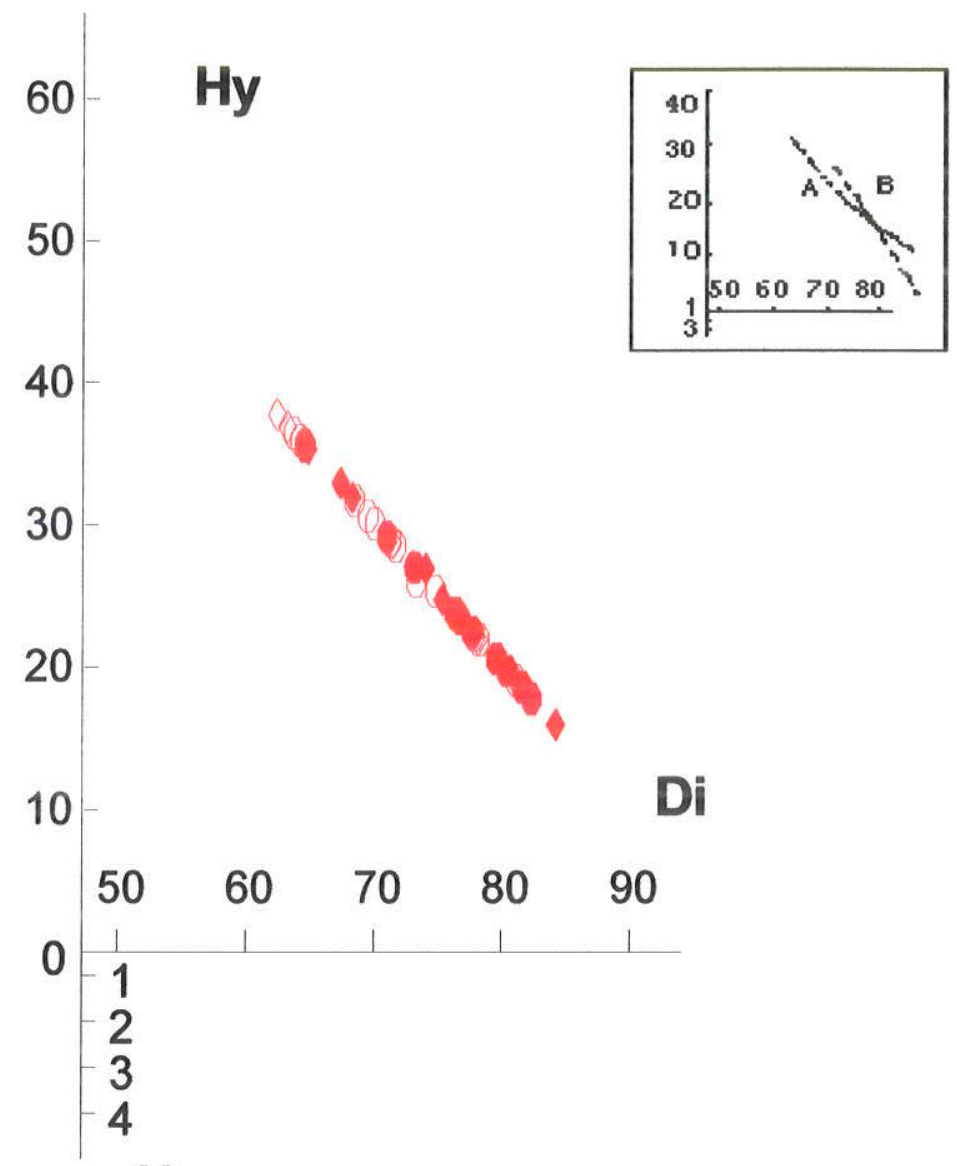

$\mathrm{Ne}$

Figura 10- Diagrama Hiperstênio (Hy)-Diopsídio (Di)-Nefelina (Ne) normativos (CIPW) dos piroxênios de cristalização precoce e tardia dos diques máficos da Suíte Básica Apoteri. Q-Hy-Di-Ol-Ne recalculados para 100\%. Diagrama conforme Bellieni et al., 1984. Para efeito de comparação, acima e a direita estão representados os "trends" da intrusão de Skaergaard (A) (Brown, 1957; Brown \& Vincent, 1963) e de Thingmuli (B) (Carmichael, 1964). Símbolos como na figura-8. 
As Tabelas 3 e 4 mostram a média dos valores das temperaturas, em ${ }^{\circ} \mathrm{C}$, obtidas para cada par de geotermômetro, considerando as fases de cristalização precoces e tardias dos piroxênios para os bth e ab.

\begin{tabular}{|c|c|c|c|c|}
\hline \multicolumn{2}{|c|}{ AMOSTRAS } & FB (1973) & K $(1982)$ & I (1975) \\
\hline RR-01A & (P) & 1000.4 & 1153.0 & 1093.4 \\
\hline$R R-18 A$ & (P) & 1201.0 & 1184.0 & 1167.8 \\
\hline \multirow[t]{2}{*}{ RR-33 } & (P) & 1030.8 & 1064.9 & 1061.5 \\
\hline & (T) & 1077.2 & 1135.1 & 1026.2 \\
\hline \multirow[t]{2}{*}{$R R-36 B$} & (P) & 1166.6 & 1144.0 & 1148.6 \\
\hline & (T) & 1167.9 & 920.1 & 1003.0 \\
\hline RR-18E & (P) & 1174.1 & 970.7 & 1109.7 \\
\hline \multirow[t]{2}{*}{$R R-42 B$} & (P) & 1117.9 & 1163.7 & 1071.8 \\
\hline & $(\mathrm{T})$ & 1044.2 & 1099.7 & 1033.4 \\
\hline RR-53B & (P) & 1185.9 & 1159.7 & 1068.9 \\
\hline \multirow[t]{2}{*}{ MÉDIA } & (P) $n=7$ & $1125(73.7)$ & $1120(70.3)$ & $1103(38.3)$ \\
\hline & (T) $n=3$ & $1096(52.3)$ & $1051(94.1)$ & $1054(34.6)$ \\
\hline
\end{tabular}

Tabela 3- Temperatura dos piroxênios de cristalização precoce (P) e tardia (T) de cada amostra e seu valor médio para os diques toleiticos da Suite Básica Apoteri. WB (1973)= Wood \& Banno (1973); K (1982)= Kretz (1982); I (1975)= Ishii (1975); $\mathrm{n}=$ número de amostras; $(52.3)=$ desvios padrões.

\begin{tabular}{|c|c|c|c|c|}
\hline \multicolumn{2}{|c|}{ AMOSTRAS } & WB (1973) & K (1982) & $I \quad(1975)$ \\
\hline RR-16 & (P) & 1112.5 & 1097.5 & 1088.6 \\
\hline$R R-18 D$ & (I) & 1137.6 & 943.1 & 1034.8 \\
\hline RR-35C & (P) & 1216.1 & 1109.2 & 1112.6 \\
\hline \multirow{3}{*}{ MÉADIA } & $(T)$ & 1217.9 & 988.1 & 1063.9 \\
\hline & (P) $n=2$ & $1164(51.8)$ & $1103(5.8)$ & $1100(12)$ \\
\hline & (T) $n=2$ & $1178(40.1)$ & $965(22.5)$ & $1049(14.5)$ \\
\hline
\end{tabular}

Tabela 4- Temperatura dos piroxênios de cristalização precoce (P) e tardia (T) de cada amostra e seu valor médio para os diques anciesi-basálticos da suite Básica Apoteri. WB (1973)= Wood \& Banno (1973); $K(1982)=\operatorname{Kretz}(1982) ; I$ (1975) = Ishii (1975); $\mathrm{n}=$ número de amostras; $(51.8)=$ desvios padrões. 
Observa-se que as temperaturas fornecidas pelos geotermômetros de Wood \& Banno (1973) e Kretz (1982) estão muito próximas e oferecem resultados bastante precisos e coerentes com a cristalização magmática dos piroxênios. Desta forma, pode-se considerar que as temperaturas de cristalização precoce e tardia dos piroxênios dos bth foram respectivamente da ordem de $1120 \pm 70.3$ (K), $1125 \pm 73.7$ (WB) e $1051 \pm 94.1$ (K), $1096 \pm 52.3$ (WB) enquanto que para os ab variaram entre $1103 \pm 5.8(\mathrm{~K}), 1164 \pm 51.8$ (WB) para os piroxênios precoces e $965 \pm 22.5$ (K), $1178 \pm 40$ (WB) para os piroxênios tardios.

Para a determinação da temperatura de cristalização das pigeonitas foi utilizada a equação do geotermômetro de Ishii (1975) (I), o qual forneceu os seguintes valores (tabelas-3 e 4): para os bth as temperaturas variaram de $1103 \pm$ 38.3 (P) a $1054 \pm 34.6$ (T), enquanto que para os ab $1100 \pm 12$

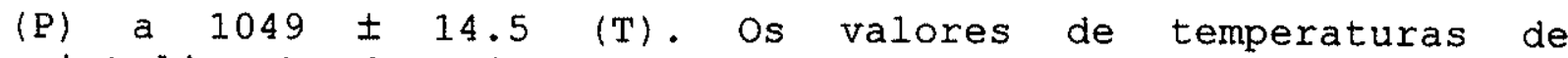
cristalização das pigeonitas são via de regra mais baixos que os das augitas, e isto, está de acordo com a cristalização tardia das pigeonitas.

\subsubsection{PLAGIOCLÁSIO}

Os resultados das microanálises químicas dos plagioclásios precoces (P) e tardios ( $T$ ) correspondentes aos diques máficos (bth e ab) estão mostrados na tabela-5.

No diagrama Albita (Ab)-Anortita (An)-Ortoclásio (Or), em of em peso, estão representados todos os plagioclásios analisados que cristalizaram precocemente (Figuras-11A e 12A) e tardiamente (Figuras-11B e 12B).

Observa-se que, para os plagioclásios referentes aos núcleos dos fenocristais ou microfenocristais (precoces), mostrado na Figura-11A e 12A, há um predomínio da composição labradoritica, tanto nos bth ( $A n=53.31-66.978$ ) como nos $a b$ $(A n=50.13-63.318)$, embora algumas amostras (RR-36B-bth e RR18D-ab) apresentem conteúdos de anortita correspondentes a composição bytownítica ( $\mathrm{An}=70.45$ e 75.698 , respectivamente). 
Litotipo: Basalto Toleítico

\begin{tabular}{|c|c|c|c|c|c|c|c|c|c|c|c|c|}
\hline \multirow[t]{2}{*}{ AMOSTRA } & \multicolumn{6}{|c|}{ RR - 01A (bth) } & \multicolumn{4}{|c|}{ RR - $18 A$ (bth) } & \multicolumn{2}{|c|}{$\begin{aligned} R R- & 18 E \\
& (b t h)\end{aligned}$} \\
\hline & T1 & $P_{1}\left(^{*}\right)$ & $\overline{T_{1}}$ & $T_{2}$ & $P_{2}$ & $\mathrm{~T}_{2}$ & $T$ & $\mathbf{P}$ & $P_{1}$ & $\mathrm{~T}$ & $T_{1}$ & $P\left({ }^{*}\right)$ \\
\hline $\mathrm{SiO}_{2}$ & 55.03 & 53.55 & 53.88 & 58.19 & 53.59 & 56.88 & 56.17 & 53.58 & 52.98 & 57.70 & 55.86 & $\frac{1}{53.31}$ \\
\hline $\mathrm{Al}_{2} \mathrm{O}_{3}$ & 28.66 & 29.92 & 29.39 & 26.99 & 29.69 & 26.98 & 27.65 & 29.86 & 30.42 & 277.25 & 28.49 & 30.19 \\
\hline $\mathrm{CaO}$ & 11.80 & 100.00 & 13.03 & 9.42 & $12.70^{\circ}$ & 10.18 & 10.80 & 12.90 & 13.85 & 10.17 & 11.41 & 13.34 \\
\hline $\mathrm{Na}_{2} \mathrm{O}$ & 4.44 & 3.96 & 4.13 & 5.69 & 4.10 & 5.44 & 4.86 & 3.76 & 3.50 & 5.34 & 4.64 & 3.48 \\
\hline $\mathrm{K}_{2} \mathrm{O}$ & 0.32 & 0.20 & 0.22 & 0.44 & 0.17 & 0.40 & 0.35 & 0.25 & 0.18 & 0.46 & 0.29 & 0.27 \\
\hline SOMA & 100.25 & 100.70 & 100.65 & 100.73 & 100.30 & 99.88 & 999.84 & 100.36 & 100.91 & 100.92 & 100.68 & $100.60^{\circ}$ \\
\hline Or \% & 1.87 & 1.19 & 1.28 & 2.59 & 1.03 & 2.35 & 2.11 & 1.50 & 1.03 & 2.69 & 1.72 & 1.63 \\
\hline $\mathrm{Ab} \%$ & 39.73 & 35.01 & 35.99 & 50.87 & 36.50 & 48.04 & 43.96 & 34.04 & 31.04 & 47.43 & 41.68 & 31.53 \\
\hline $\mathrm{An} \%$ & $58.40^{\circ}$ & 63.80 & 62.73 & 46.54 & 62.47 & 49.61 & 53.93 & 64.46 & 67.93 & 49.88 & $56.60^{\circ}$ & 66.84 \\
\hline
\end{tabular}

\begin{tabular}{|c|c|c|c|c|c|c|c|c|c|c|c|c|}
\hline \multirow[t]{2}{*}{ MOSTRA } & \multicolumn{3}{|c|}{ RR- $18 \mathrm{E}$ (bth) } & \multicolumn{4}{|c|}{$R R-33$} & \multicolumn{2}{|l|}{ (bth) } & \multicolumn{2}{|l|}{ RR } & $35 \mathrm{~B}$ \\
\hline & $T_{1}$ & $I_{2}$ & $\overline{P_{2}}$ & $\overline{T_{1}}$ & $P_{1}$ & $T_{1}$ & $\overline{T_{2}}$ & $\mathrm{P}_{2}\left(^{*}\right)$ & $\overline{T_{2}}$ & $\bar{T}$ & $\bar{P}$ & $T$ \\
\hline & 53.10 & 55.33 & 53.40 & 59.17 & 56.7 & 56.89 & 53.82 & 55.70 & 54.68 & 53.92 & 51.17 & \\
\hline & 30.45 & 28.63 & 29.52 & 26.35 & 28.11 & 27.43 & 29.52 & 28.11 & 29.18 & 29.21 & & \\
\hline & 13.67 & $" 11.41$ & 12.9 & 86 & $10 \% 89$ & 10.09 & 12.95 & $10.89^{\circ}$ & 12.29 & 12.25 & 4.22 & \\
\hline & 3.52 & 4.76 & & 6.0 & 5.00 & 5.32 & 4.02 & 5.01 & 4.26 & 4.85 & 3.87 & \\
\hline & $0.1 \bar{c}$ & 0.28 & 0.1 & 0.49 & (3.33 & 0.35 & 0.20 & 0.33 & 0.26 & 0.27 & 0.16 & $\ddot{0}$. \\
\hline & 6.89 & 00.41 & 9.97 & 00.65 & 101.10 & 10000 & 00.52 & 101.26 & 100.67 & 50.50 & 9.74 & $\ddot{9}$. \\
\hline & $\overline{0.9}$ & 1.6 & 1.08 & & 0.93 & & $\overline{18}$ & 06 & 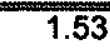 & 4 & & \\
\hline & 1.46 & 42.35 & 35 & 5 & 44.56 & 7.83 & 35.52 & 33.46 & 37.96 & 41.14 & 2.68 & 34. \\
\hline & 67.59 & 56.04 & 4.27 & 42.74 & 5 & 50.00 & 3.30 & & & 7.37 & & 4. \\
\hline
\end{tabular}

\begin{tabular}{|c|c|c|c|c|c|c|c|c|c|c|c|c|}
\hline \multirow[t]{2}{*}{ AMOSTRA } & \multicolumn{4}{|c|}{$R R-36 \mathrm{~B} \quad$ (bth) } & \multicolumn{6}{|c|}{ RR - 42A (bth) } & \multicolumn{2}{|c|}{$R R=-\begin{array}{l}53 \mathrm{~B} \\
\left(b^{\mathrm{t}} \mathrm{h}\right)\end{array}$} \\
\hline & $\mathrm{P}\left(^{*}\right)$ & $\bar{P}$ & $T$ & $T$ & $T_{1}$ & $\overline{P_{1}}$ & $\overline{T_{1}}$ & $\overline{T_{2}}$ & $\overline{P_{2}}$ & T2 & $T$ & $\mathrm{P}$ \\
\hline $\mathrm{SiO}_{2}$ & 51.91 & 56.99 & 51.66 & 52.25 & 54.30 & 52.97 & 54.07 & 52.92 & 53.35 & 53.35 & 58.57 & 55.53 \\
\hline $\mathrm{Al}_{2} \mathrm{O}_{3}$ & 30.60 & 26.88 & 30.45 & 30.14 & 29.16 & 30.33 & 29.02 & 29.27 & 29.78 & 29.97 & 27.02 & $27.98^{\circ}$ \\
\hline $\mathrm{CaO}$ & 14.44 & 10.33 & 14.19 & 13.91 & 12.31 & 13.52 & 12.15 & 12.77 & 13.41 & 12.99 & 9.02 & $11.44^{\circ}$ \\
\hline $\mathrm{Na}_{2} \mathrm{O}$ & 3.25 & 5.08 & 3.33 & 3.53 & 4.20 & 3.64 & 4.46 & 3.96 & 3.51 & 3.79 & 5.72 & $4.61^{\circ}$ \\
\hline $\mathrm{K}_{2} \mathrm{O}$ & 0.14 & 0.32 & 0.16 & 0.15 & 0.32 & 0.16 & 0.26 & 0.27 & 0.22 & 0.26 & 0.46 & 0.45 \\
\hline SOMA & 100.35 & 99.60 & 99.78 & 99.99 & 100.38 & 100.62 & 99.95 & $99.20^{\circ}$ & 100.28 & 100.36 & 100.80 & 100.01 \\
\hline Or \% & 0.81 & 1.90 & 0.92 & 0.88 & $\overline{1.86}$ & 0.97 & 1.50 & 1.60 & $1.30 !$ & \begin{tabular}{|c|}
1.54 \\
\end{tabular} & 2.73 & 2.64 \\
\hline$A B \%$ & 28.74 & 46.20 & 29.52 & 31.22 & 37.93 & 32.41 & 39.31 & 35.36 & 31.73 & 34.04 & 52.00 & 41.03 \\
\hline An \% & 70.45 & 51.90 & 69.56 & $67.90^{\circ}$ & 60.21 & 66.62 & 59.19 & 63.04 & 66.97 & 64.42 & 45.27 & 56.33 \\
\hline
\end{tabular}

Tabela 5- Microanálise química dos plagioclásios dos diques máficos da Suite Básica Apoteri. $\mathrm{P}=$ cristalização precoce; $\mathrm{T}=$ cristalização tardia. $P_{1,2}$ e $T_{1,2}=$ cristalização precoce e tardia dos grãos minerais 1,2 , respectivamente. (*) amostras utilizadas no cálculo do balanço de massa dos elementos maiores; bth= basalto toleitico; ab=andesi-basalto. 
Litotipo: Basalto Toleítico; Andesi-basalto

\begin{tabular}{|c|c|c|c|c|c|c|c|c|c|c|c|c|}
\hline \multirow[t]{2}{*}{ AMOSTRA } & \multicolumn{2}{|c|}{$\begin{aligned} R R- & 53 B \\
& \text { (bth) }\end{aligned}$} & \multicolumn{7}{|c|}{ RR- $16 \quad(a b)$} & \multicolumn{3}{|c|}{ RR- $17 \quad(a b)$} \\
\hline & $P$ & $\mathrm{~T}$ & $\overline{\mathrm{T}_{1}}$ & $\overline{P_{1}}$ & $P_{1}\left(^{*}\right)$ & $\overline{T_{1}}$ & $\overline{T_{2}}$ & $P_{2}$ & $T_{2}$ & $T$ & $\bar{P}$ & $\mathrm{~T}$ \\
\hline $\mathrm{SiO}_{2}$ & 53.56 & 56.08 & 56.69 & 55.04 & 54.18 & 54.64 & 53.32 & 52.50 & 55.27 & 51.33 & 51.54 & 53.82 \\
\hline $\mathrm{Al}_{2} \mathrm{O}_{3}$ & 29.80 & 27.70 & 25.47 & 26.64 & 27.93 & 27.17 & 28.68 & 29.74 & 27.40 & 29.35 & 29.99 & 28.55 \\
\hline $\mathrm{CaO}$ & 13.01 & 10.81 & 8.48 & 10.31 & 11.000 & 10.57 & 12.16 & 12.83 & 10.24 & 13.03 & $13.40^{\circ}$ & 11.31 \\
\hline $\mathrm{Na}_{2} \mathrm{O}$ & 3.72 & 5.15 & 7.07 & 6.06 & 5.74 & 5.83 & 5.34 & $4.75^{\circ}$ & 6.32 & 4.59 & 4.35 & $5.56^{\circ}$ \\
\hline $\mathrm{K}_{2} \mathrm{O}$ & 0.18 & 0.28 & 0.71 & 0.59 & 0.47 & 0.53 & 0.21 & $0.29^{\circ}$ & $0.40^{\circ}$ & 0.29 & 0.25 & 0.38 \\
\hline SOMA & 100.25 & 100.03 & 98.42 & 98.64 & 99.31 & 98.84 & 99.71 & 100.11 & 99.63 & 98.59 & 99.53 & 99.61 \\
\hline Or \% & 1.05 & 1.63 & 3.83 & 3.18 & 2.57 & 2.90 & 1.14 & 1.59 & 2.16 & 1.61 & 1.36 & 2.06 \\
\hline$A B \%$ & 33.76 & 45.54 & 57.85 & $49.91^{\circ}$ & 47.30 & 48.91 & 43.76 & 39.52 & 51.62 & 38.28 & 36.50 & 46.12 \\
\hline $\mathrm{An} \%$ & 65.19 & 52.83 & 38.32 & $46.91^{\circ}$ & 50.13 & 48.19 & $55.10^{\circ}$ & 58.89 & 46.22 & 60.11 & 62.14 & 51.82 \\
\hline
\end{tabular}

Litotipo: Andesi-basalto

\begin{tabular}{|c|c|c|c|c|c|c|c|c|c|c|}
\hline \multirow[t]{2}{*}{ AMOSTRA } & \multicolumn{4}{|c|}{$R R=18 D \quad(a b)$} & \multirow{2}{*}{$\frac{\text { RR- }}{T}$} & \multicolumn{2}{|c|}{$28 \quad(a b)$} & \multicolumn{3}{|c|}{ RR- 35C (ab) } \\
\hline & T1 & P1 & T2 & P2 & & $P$ & $T$ & $\mathrm{~T}$ & $P$ & $T$ \\
\hline$J_{2}$ & 49.55 & 49.24 & 53.92 & 51.87 & 53.94 & 53.86 & 53.53 & 55.15 & 54.41 & 56.56 \\
\hline $\mathrm{Al}^{\circ} \mathrm{O}$ & $30.40^{\circ}$ & 31.20 & 27.51 & 29.70 & 28.04 & 29.21 & 27.98 & 27.42 & 27.57 & 26.38 \\
\hline & 15.61 & 15.99 & 11.95 & 13.88 & 12.03 & 13.25 & 12.24 & 10.53 & 11.05 & 9.86 \\
\hline$\overline{\mathbf{A}}$ & 3.22 & 2.76 & 5.37 & 4.29 & 4.97 & 4.33 & 4.91 & 5.90 & 5.62 & 6.46 \\
\hline & 0 & 0.11 & 0.37 & 0.24 & 0.31 & 0.21 & 0.26 & 0.33 & 0.31 & 0.42 \\
\hline & 98.94 & 99.30 & 99.11 & 99.97 & 99.29 & 00.86 & 98.93 & 99.42 & 98.97 & 99.68 \\
\hline & 0.82 & 0.65 & 1.97 & & 1.70 & 1.17 & $\overline{1.4}$ & 1.78 & 1.70 & 2.2 \\
\hline & 26.94 & 23.66 & 43.96 & & 05 & 36.71 & & 49.81 & 47.11 & 53.02 \\
\hline $\mathrm{An} \%$ & 72.24 & 75.69 & 54.07 & 63.31 & 56.25 & 62.12 & 57.09 & 48.41 & 51.19 & $44.70^{\circ}$ \\
\hline
\end{tabular}

Tabela 5- Continuação 

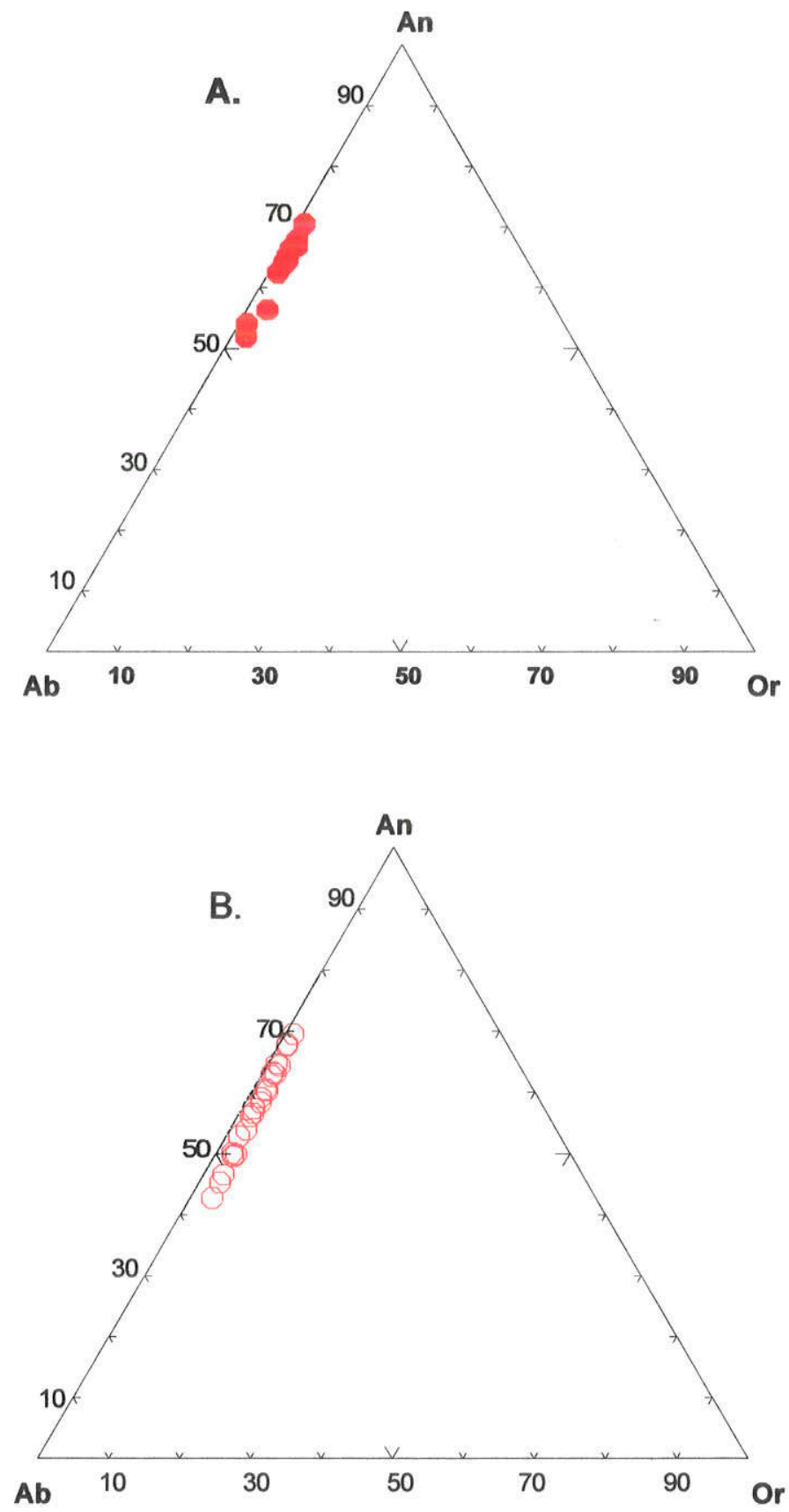

Figura 11- Variação composicional com base no conteúdo de albita (Ab) - Anortita (An) Ortoclásio (Or) ( $\frac{\circ}{8}$ em peso) dos plagioclásios de cristalização precoce (A) e tardia (B) dos diques toleíticos da Suíte Básica Apoteri. Símbolos como na figura-8. 

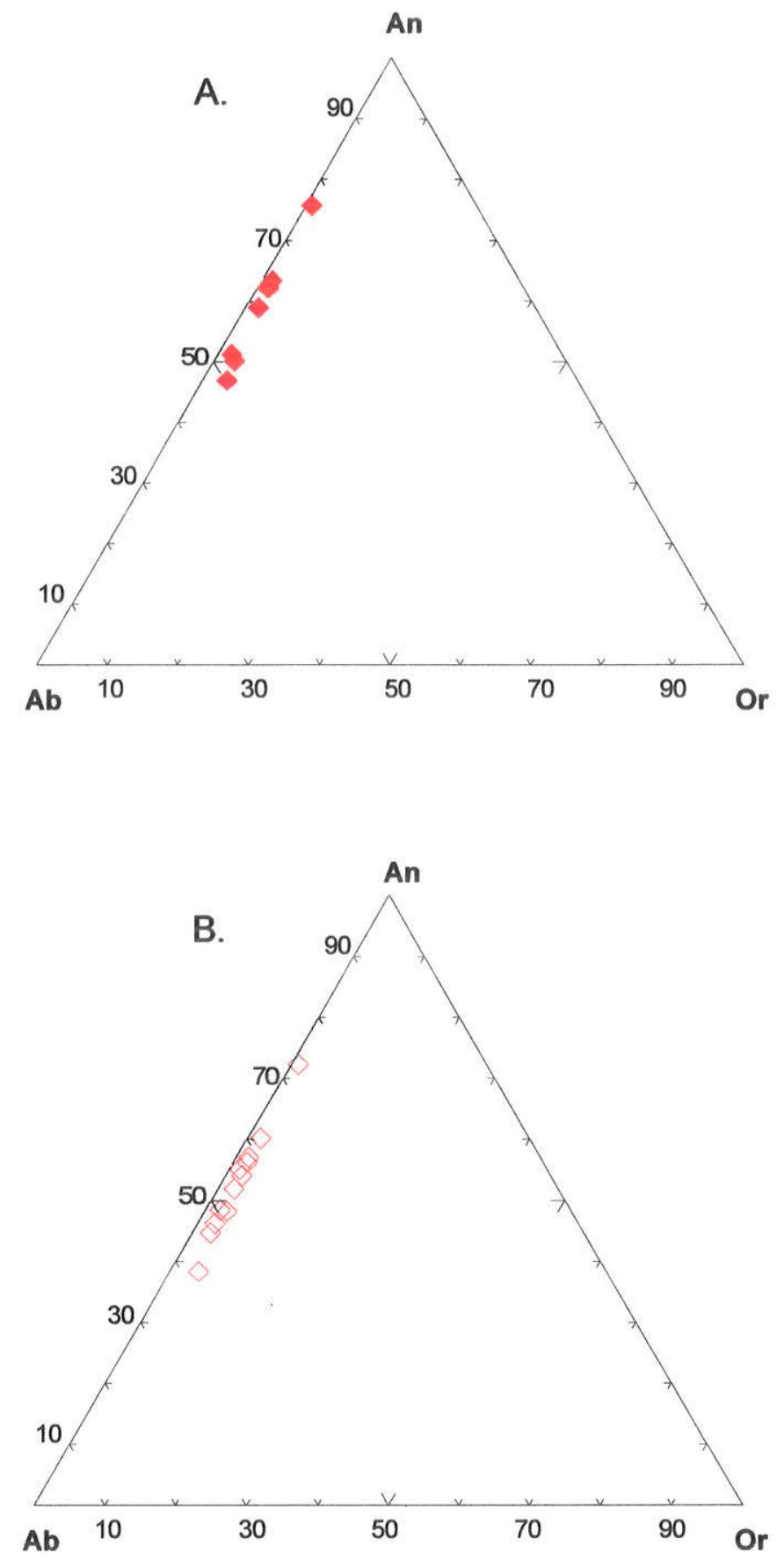

Figura 12- Variação composicional com base no conteúdo de Albita (Ab) - Anortita (An) Ortoclásio (Or) ( $\frac{\circ}{8}$ em peso) dos plagioclásios de cristalização precoce (A) e tardia (B) dos diques andesi-basalto da Suíte Básica Apoteri. Símbolos com na figura-8. 
Nos estágios tardios de cristalização dos plagioclásios (Figura-11B e 12B), nota-se que há uma predominância da composição labradorítica nos bth ( $\mathrm{An}=50.09-69.568$ ) e ab (51.82-60.11\%). No entanto, algumas amostras de ambos tipos litológicos alcançam teores de andesina (amostras RR-01A, RR18A, RR-33, RR-53B dos bth e RR-16, RR-35C dos $a b)$.

Nota-se que de maneira geral (Tabela-5 e Figuras-11 e 12), os plagioclásios de ambos litotipos demonstraram uma variação no conteúdo de anortita, do centro (fase precoce de cristalização-P) para a periferia (fase tardia de cristalização-T) do cristal. Isto sugere, concordante com as observações petrográficas (capítulo-5), que os plagioclásios apresentam zoneamentos.

\subsubsection{GEOTERMOMETRIA}

Para a determinação das temperaturas nos estágios de cristalização precoce (P) e tardia (T) dos plagioclásios dos tipos litológicos analisados, utilizaram-se os geotermômetros de Kudo \& Weill (1970) (KW) e Mathez (1973) (M), assumindo condições anidras. Os valores obtidos para cada amostra e sua média, em ${ }^{\circ} \mathrm{C}$, estão mostrados nas tabelas-6 e 7 .

As temperaturas médias para a cristalização dos plagioclásios nos bth estão entre $1098 \pm 58{ }^{\circ} \mathrm{C}$ (P) (KW) e $1053 \pm$ 76 (P) (M) e $1103 \pm 96{ }^{\circ} \mathrm{C}$ (T) (KW) e $1070 \pm 108$ (P) (M) enquanto que para os $a b$ estão entre $1092 \pm 96{ }^{\circ} \mathrm{C}$ (P) (KW) e $1073 \pm 66$ (P) (M) e $1073 \pm 66^{\circ} \mathrm{C}$ (T) (KW) e $1059 \pm 73$ (T) (M). 


\begin{tabular}{|c|c|c|c|}
\hline \multicolumn{2}{|c|}{ AMOSTRAS } & $\mathrm{KW}(1970)$ & M (1973) \\
\hline \multirow{5}{*}{$R R-01 A$} & $\left(P_{1}\right)$ & 1057.9 & 1044.3 \\
\hline & $\left(\mathbf{P}_{2}\right)$ & 1013.7 & 1006.8 \\
\hline & $\left(T_{1}\right)$ & 986.1 & 1026.7 \\
\hline & $\left(T_{1}\right)$ & 998.7 & 994.3 \\
\hline & $\left(T_{2}\right)$ & 1151.0 & 1112.9 \\
\hline \multirow{4}{*}{$R R-18 A$} & $(P)$ & 1061.5 & 1047.4 \\
\hline & (P) & 1147.3 & 1110.1 \\
\hline & (T) & 985.6 & 872.7 \\
\hline & (T) & 1153.9 & 1054.1 \\
\hline \multirow{5}{*}{ RR-18E } & $\left(P_{1}\right)$ & 1168.3 & 1140.1 \\
\hline & $\left(P_{2}\right)$ & 1045.3 & 1033.5 \\
\hline & $\left(\mathrm{T}_{1}\right)$ & 885.9 & 762.8 \\
\hline & $\left(T_{1}\right)$ & 1157.9 & 1131.0 \\
\hline & $\left(T_{2}\right)$ & 790.4 & 617.3 \\
\hline \multirow{6}{*}{ RR-33 } & $\left(P_{1}\right)$ & 986.7 & 874.0 \\
\hline & $\left(\mathbf{P}_{2}\right)$ & 1094.4 & 1075.6 \\
\hline & $\left(T_{1}\right)$ & 1212.7 & 1107.7 \\
\hline & $\left(T_{1}\right)$ & 1102.9 & 997.8 \\
\hline & $\left(\mathrm{T}_{2}\right)$ & 1015.2 & 1008.1 \\
\hline & $\left(T_{2}\right)$ & 1156.7 & 1175.2 \\
\hline \multirow{3}{*}{ RR-35B } & (P) & 1206.9 & 1174.2 \\
\hline & (T) & 1117.9 & 1146.4 \\
\hline & (T) & 1164.1 & 1136.5 \\
\hline \multirow{4}{*}{$R R-36 B$} & (P) & 1143.0 & 1106.4 \\
\hline & (P) & 1106.7 & 997.3 \\
\hline & (T) & 1179.0 & 1149.6 \\
\hline & (T) & 1231.3 & 1195.9 \\
\hline \multirow{4}{*}{$R R-42 B$} & $\left(P_{1}\right)$ & 1142.1 & 1117.2 \\
\hline & $\left(P_{2}\right)$ & 1109.1 & 1088.3 \\
\hline & $\left(T_{1}\right)$ & 1174.8 & 1189.2 \\
\hline & $\left(T_{2}\right)$ & 1138.3 & 1161.3 \\
\hline \multirow{3}{*}{$R R-53 B$} & (P) & 1122.8 & 972.7 \\
\hline & (P) & 1068.1 & $1053.0^{\circ}$ \\
\hline & (T) & 1238.4 & 1134.5 \\
\hline \multirow[t]{2}{*}{ MEDIA } & (P) $n=15$ & $1098.2(57.8)$ & $1053.1(76.5)$ \\
\hline & (T) $n=20$ & $1103.7(96.1)$ & $1070.3(108.1)$ \\
\hline
\end{tabular}

Tabela 6- Temperatura dos plagioclásios para cada amostra e seu valor médio para os bth da Suite Básica Apoteri. (P) estágio de cristalização precoce; $(T)=$ estágio de cristalização tardia; $K W$ $(1970)=$ Kudo \& Weill (1970); M (1973)= Mathez (1973); $(57.8)=$ desvios padrões; $n=$ número de amostras. 


\begin{tabular}{|c|c|c|c|}
\hline \multicolumn{2}{|c|}{ AMOSTRA } & $\mathrm{KW}(1970)$ & M (1973) \\
\hline \multirow{7}{*}{$R R-16$} & $\left(P_{1}\right)$ & 1136.5 & 1032.2 \\
\hline & $\left(\mathrm{p}_{1}\right)$ & 1234.6 & 1118.9 \\
\hline & $\left(\mathrm{P}_{2}\right)$ & 1003.1 & 998.0 \\
\hline & $\left(T_{1}\right)$ & 1259.1 & 1153.2 \\
\hline & $\left(T_{1}\right)$ & 1070.7 & 964.4 \\
\hline & $\left(\mathrm{T}_{2}\right)$ & 982.6 & 1062.8 \\
\hline & $\left(\mathrm{T}_{2}\right)$ & 1124.2 & 1019.7 \\
\hline \multirow{3}{*}{$R R-17$} & (P) & 1114.3 & 1092.9 \\
\hline & (I) & 1052.4 & 1039.6 \\
\hline & (T) & 1239.2 & 1138.2 \\
\hline \multirow{4}{*}{$R R-18 D$} & $\left(P_{1}\right)$ & 1196.4 & 1151.9 \\
\hline & $\left(p_{2}\right)$ & 1117.8 & 1095.9 \\
\hline & $\left(T_{1}\right)$ & 1238.8 & 1192.4 \\
\hline & $\left(T_{2}\right)$ & 1134.0 & 990.6 \\
\hline \multirow{3}{*}{$R R-28$} & (P) & 952.0 & 955.9 \\
\hline & (T) & 979.9 & 996.1 \\
\hline & (T) & 960.5 & 1053.6 \\
\hline \multirow{3}{*}{$R R-35 C$} & (P) & 981.0 & 1140.9 \\
\hline & (T) & 1079.7 & 973.8 \\
\hline & (T) & 1232.3 & 1128.5 \\
\hline \multirow[t]{2}{*}{ MEDIA } & (P) $n=8$ & $1091.9(96.3)$ & $1073.3(66.0)$ \\
\hline & (T) $n=12$ & $1112.8(105.2)$ & $1059.4(73.3)$ \\
\hline
\end{tabular}

Tabela 7- Temperatura dos plagioclásios para cada amostra e seu valor médio para os ab da Suite Básica Apoteri. (P) estágio de cristalização precoce; $(T)=$ estágio de cristalização tardia; KW $(1970)=$ Kudo \& Weill (1970); M $(1973)=$ Mathez $(1973) ;(96.3)=$ desvios padrões; $n=$ número de amostras.

\subsubsection{ANFIBÓLIOS}

A presença de anfibólios foi reconhecida em todos os conjuntos de diques estudados. Em geral, em todos os tipos litológicos foi caracterizada sua natureza secundária, proveniente de transformações tardias de piroxênios.

A tabela-8 mostra as composições químicas dos anfibólios analisados (bth e ab) correspondentes ao núcleo (N) e borda (B) do cristal. 
Segundo a nomenclatura de anfibólios proposta por Leake (1978) os anfibólios analisados foram classificados, para os bth, em ferro-hornblenda e ferro-actinolita-hornblenda, e ferro-hornblenda para os ab.

\begin{tabular}{|c|c|c|c|c|c|c|c|c|c|}
\hline$\overline{A M}$ & $\begin{array}{c}\text { RR- } \\
01 A \\
\text { (bth) }\end{array}$ & $\begin{array}{l}\text { RR-33 } \\
\text { (bth) }\end{array}$ & $\begin{array}{c}R R- \\
358 \\
\text { (bth) } \\
\end{array}$ & $\begin{array}{c}\text { RR- } \\
42 B \\
\text { (bth) }\end{array}$ & RR- & 16 & (ab) & $\begin{array}{c}R R-17 \\
(\mathrm{ab})\end{array}$ & $\begin{array}{l}R R- \\
35 \mathrm{C} \\
(\mathrm{ab}) \\
\end{array}$ \\
\hline & B & B & B & B & $\bar{N}$ & $B$ & B & B & B \\
\hline$\overline{\mathrm{SiO}_{2}}$ & 46.27 & 43.65 & 49.94 & 42.99 & 44.62 & 44.56 & 45.90 & 43.87 & 42.61 \\
\hline $\mathrm{TiO}_{2}$ & 1.41 & 1.40 & 0.25 & 1.44 & 1.12 & 1.06 & 0.65 & 1.32 & 1.81 \\
\hline $\mathrm{Al}_{2} \mathrm{O}_{3}$ & $5.87^{\circ}$ & 6.45 & 2.98 & 7.39 & 7.12 & 7.04 & 6.39 & 7.42 & 6.69 \\
\hline FeO & 21.90 & 24.84 & 23.74 & 26.71 & 22.20 & 22.19 & 21.92 & 22.30 & 26.20 \\
\hline F & $=$ & 1.32 & 1.34 & 0.09 & 1.41 & 1.52 & 1.01 & 0.85 & 0.83 \\
\hline Mno & 0.24 & 0.12 & 0.32 & 0.23 & 0.26 & 0.24 & 0.29 & 0.22 & 0.23 \\
\hline $\mathrm{MgO}$ & 0.17 & 10.53 & $10^{\circ} 90^{\circ}$ & 9.87 & 10.82 & 10.49 & 10.72 & 10.77 & 10.38 \\
\hline$\ddot{c}$ & 10.17 & 10.53 & $10.90^{\circ}$ & 9.87 & 10.82 & 10.49 & 10.72 & 10.77 & 10.38 \\
\hline $\mathrm{Na}_{2} \mathrm{O}$ & $1.59^{\circ}$ & 1.71 & 0.39 & 1.56 & $1.50^{\circ}$ & 1.32 & 1.20 & 1.31 & 1.49 \\
\hline & 0.85 & 0.93 & $0.30^{\circ}$ & $0.98^{-}$ & $0.97^{\circ}$ & 0.93 & 0.85 & 1.29 & 1.06 \\
\hline sos & 98.47 & 98.12 & 98.77 & 97.24 & 98.54 & 97.81 & 97.79 & 97.55 & -97.1 \\
\hline$s$ & 7.015 & .811 & 7.544 & 6.797 & 6.830 & 6.862 & 7.029 & 6.795 & 6.770 \\
\hline & .985 & 1.187 & 0.456 & $1.203^{\circ}$ & $1.170^{-}$ & 1.138 & 0.971 & 1.205 & $1.230^{\circ}$ \\
\hline soma & 8.000 & $8.000^{\circ}$ & $8.000^{\circ}$ & 8.0000 & 8.0000 & $8.000^{\circ}$ & $8.0000^{\circ}$ & 8.000 & $" 8.000$ \\
\hline A1 & 065 & 000 & .075 & 0.175 & 0.115 & 0.140 & 0.183 & 0.151 & 0.024 \\
\hline $\mathrm{Fe}^{+2}$ & 2.476 & 3.015 & 2.804 & 3.234 & 2.649 & 2.619 & 2.604 & 2.704 & 3.279 \\
\hline $\mathrm{Fe}^{+3}$ & & 0.154 & 0.152 & 0.010 & 0.163 & 0.177 & 0.116 & 0.099 & 0.099 \\
\hline$M$ & 2.298 & $1.667^{\circ}$ & 1.941 & $1.400^{\circ}$ & $1.944^{\circ}$ & 1.941 & 2.022 & 1.893 & 1.381 \\
\hline $\mathbf{M}$ & 0.031 & 0.016 & 0.041 & 0.031 & $0.034^{\circ}$ & 0.031 & 0.038 & 0.029 & 0.031 \\
\hline $\mathbf{T i}$ & 0.161 & 0.164 & 0.028 & 0.171 & $0.129^{\circ}$ & 0.123 & 0.075 & 0.154 & 0.216 \\
\hline $\mathrm{Ca}$ & 1.652 & 1.757 & 1.764 & 1.671 & 1.774 & $1.730^{\circ}$ & 1.758 & 1.787 & 1.767 \\
\hline $\mathrm{Na}$ & 0.451 & 0.517 & 0.114 & 0.478 & 0.445 & 0.394 & 0.356 & 0.393 & 0.459 \\
\hline $\mathrm{K}$ & 0.164 & 0.185 & 0.058 & 0.198 & $0.189^{\circ}$ & 0.183 & 0.166 & 0.255 & 0.215 \\
\hline SOMA & 7.692 & 7.475 & 6.902 & 7.202 & 7.327 & 7.198 & 7.135 & 7.314 & 7.447 \\
\hline & .481 & .356 & 0.409 & 0.303 & 0.423 & 0.426 & 0.437 & 0.412 & 0.296 \\
\hline $\begin{array}{l}\text { TOMARCIA } \\
\text { TURA (I) }\end{array}$ & $\begin{array}{l}\text { Fe=" } \\
\text { hbl }\end{array}$ & $\begin{array}{l}\mathrm{Fe}- \\
\mathrm{hbl}\end{array}$ & act- & $\begin{array}{l}\mathrm{Fe}- \\
\mathrm{hbl}\end{array}$ & $\begin{array}{l}\mathrm{Fe}- \\
\mathrm{hbl}\end{array}$ & $\begin{array}{l}\mathrm{Fe}- \\
\mathrm{hbI}\end{array}$ & $\begin{array}{l}\mathrm{Fe}- \\
\mathrm{hbl}\end{array}$ & $\begin{array}{l}\mathrm{Fe}- \\
\mathrm{hbl}\end{array}$ & $\begin{array}{l}\mathrm{Fe}- \\
\mathrm{hbl}\end{array}$ \\
\hline
\end{tabular}

Tabela 8- Microanálise química dos anfibólios dos diques máficos da Suíte Básica Apoteri. $B=$ borda do microfenocristal; $N=$ núcleo do microfenocristal; $\mathrm{Fe}-\mathrm{hbl}=$ Ferro-hornblenda; $\mathrm{Fe}$-act-hbl= Ferroactinolita-hornblenda; (L)= Classificação segundo Leake (1978). 


\subsubsection{MINERAIS OPACOS}

$\mathrm{Na}$ análise petrográfica foi assinalada a presença de minerais opacos em todos os conjuntos de diques estudados, representados predominantemente por magnetita como microfenocristais e na matriz e mais raro como fenocristal e, eventualmente, por Ti-magnetita, comumente em microfenocristal e matriz.

As microanálises quimicas dos minerais opacos revelaram que não houve uma variação composicional significante entre os litotipos analisados, demonstrando a presença de magnetitas e ilmenitas sem coexistência numa mesma amostra.

As microanálises quimicas das magnetitas e ilmenitas presentes nos bth $e$ ab encontram-se respectivamente nas tabelas-9 e 10. Os dados constantes nas tabelas não evidenciam variações composicionais significativas entre os opacos distribuidos nos diferentes tipos litológicos.

\begin{tabular}{|c|c|c|c|c|c|c|c|c|c|c|}
\hline \multirow[t]{2}{*}{ ALOSTRA } & \multicolumn{2}{|c|}{ RR-01A (bth) } & \multirow{2}{*}{$\begin{array}{c}\begin{array}{c}R R-18 A \\
(b+h)\end{array} \\
M A T \\
(*)\end{array}$} & \multicolumn{2}{|c|}{$R R-18 \bar{E} \quad(b t h)$} & \multicolumn{2}{|c|}{ RR-33 (bth) } & \multicolumn{3}{|c|}{ RR-35B (bth) } \\
\hline & FEN & $\begin{array}{c}M A T \\
(\star)\end{array}$ & & MIC & MAT & $\begin{array}{c}F E N \\
(\star)\end{array}$ & MAT & $\overline{E E N}$ & $\overline{M I C}$ & MAT \\
\hline$\overline{\mathrm{SiO}_{2}}$ & 2.37 & 0.71 & 0.21 & 1.58 & 1.94 & 0.48 & 0.57 & 0.19 & $1.32:$ & 2.28 \\
\hline $\mathrm{TiO}_{2}$ & 19.38 & 18.37 & 14.86 & 12.27 & 13.49 & 18.93 & 18.33 & 18.57 & 21.98 & 17.89 \\
\hline $\mathrm{Al}_{2} \mathrm{O}_{3}$ & 1.69 & 1.48 & 1.52 & 0.94 & 1.46 & 1.34 & 2.06 & 0.82 & 1.001 & 1.58 \\
\hline $\mathrm{FeO}_{\mathrm{t}}$ & 66.01 & 71.50 & 75.98 & 76.63 & $74.13^{\circ}$ & 70.45 & 70.02 & 71.99 & 67.32 & 69.07 \\
\hline Mino & 0.96 & 0.98 & 0.24 & 0.51 & 0.51 & 1.01 & 1.54 & 0.38 & 1.22 & 0.14 \\
\hline $\mathrm{MgO}$ & 0.33 & 0.22 & 0.09 & 0.10 & 0.33 & 0.35 & 0.11 & 0.26 & 0.10 & 0.16 \\
\hline $\mathrm{CaO}$ & 1.39 & 0.24 & 0.07 & 1.43 & 1.33 & 0.13 & 0.45 & 0.18 & 0.85 & 1.98 \\
\hline $\mathrm{Cr}_{2} \mathrm{O}_{3}$ & 0.01 & 0.10 & 0.01 & 0.02 & 0.03 & 0.05 & $0.2 \mathrm{i}$ & 0.05 & 0.06 & 0.04 \\
\hline SOMA & 42.14 & 93.60 & 92.98 & 93.48 & 93.22 & 92.74 & 93.29 & 92.44 & $93 \% .86$ & 93.14 \\
\hline FeO & 36.84 & 33.48 & 39.68 & 46.25 & 34.50 & 28.14 & 17.08 & 36.17 & $30.92 !$ & 35.94 \\
\hline $\mathrm{Fe}_{2} \mathrm{O}_{3}$ & 32.42 & 42.25 & 40.34 & 33.76 & 44.03 & 47.01 & 58.83 & 39.81 & 40.45 & 36.82 \\
\hline SOMA & 95.39 & 97.83 & 97.021 & 98.96 & 97.62 & 97.44 & 99.18 & 96.43 & 97.91 & 96.83 \\
\hline
\end{tabular}

Tabela 9- Microanálise química das magnetitas dos diques toleiticos e andesi-basalto da Suite Básica Apoteri. $\mathrm{FEN}=$ fenocristal; MIC= microfenocristal; $\mathrm{MAT}=$ matriz. FeO e $\mathrm{Fe}_{2} \mathrm{O}_{3}$ calculados segundo Carmichael (1967). (*) amostras utilizadas no cálculo do balanço de massa de elementos maiores. 


\begin{tabular}{|c|c|c|c|c|c|c|c|c|c|}
\hline \multirow[t]{2}{*}{ ANOSTRA } & \multicolumn{2}{|c|}{ RR-42B (bth) } & \multicolumn{3}{|c|}{$R R-53 B(a b)$} & \multicolumn{2}{|c|}{$R R-16 \quad(a b)$} & \multicolumn{2}{|c|}{$R R-28 \quad(a b)$} \\
\hline & MIC & MIC & FEN & MIC & MAT & FEN & $\begin{array}{c}M I C \\
(\star)\end{array}$ & MIC & MAT \\
\hline$\overline{\mathrm{SiO}_{2}}$ & 1.45 & 2.68 & 0.31 & 2.89 & 2.34 & 1.05 & 0.28 & 0.35 & 0.37 \\
\hline $\mathrm{TiO}_{2}$ & $19.01:$ & 15.71 & 16.56 & 17.72 & 18.17 & 24.97 & 3.94 & 18.02 & 19.09 \\
\hline $\mathrm{AI}_{2} \mathrm{O}_{3}$ & 1.72 & 1.38 & 1.44 & 1.46 & 1.18 & 2.38 & 0.72 & 1.67 & 1.49 \\
\hline $\mathrm{FeO}_{t}$ & 69.44 & 71.36 & 74.78 & 68.24 & 67.77 & 61.88 & 90.04 & 71.44 & $70^{\circ} .00^{\circ}$ \\
\hline Mno & 0.54 & 0.58 & 0.29 & 0.25 & 0.697 & 0.59 & 0.03 & 0.35 & 0.035 \\
\hline $\mathrm{MgO}$ & 0.30 & 0.17 & 0.12 & 0.16 & 0.22 & 0.25 & 0.06 & 0.11 & 0.19 \\
\hline $\mathrm{CaO}$ & 0.59 & 1.85 & 0.23 & 0.00 & 4.26 & 0.06 & 0.05 & 0.18 & 0.25 \\
\hline $\mathrm{Cr}_{2} \mathrm{O}_{3}$ & 0.10 & 0.03 & 0.00 & 0.06 & $0.05^{\circ}$ & 0.04 & 0.08 & 0.06 & 0.00 \\
\hline SOMA & 93.15 & 93.76 & 93.73 & 90.78 & 54.68 & 91.22 & 95.20 & 92.18 & 91.74 \\
\hline FeO & $32.52 !$ & 33.41 & 36.58 & 30.76 & 17.45 & $32.02 !$ & 53.28 & 56.43 & 31.94 \\
\hline $\mathrm{Fe}_{2} \mathrm{O}_{3}$ & 41.04 & 42.18 & 42.45 & 41.65 & 55.92 & 33.18 & 40.84 & 16.69 & $42.30^{\circ}$ \\
\hline soma & 97.26 & 97.99 & 97.98 & 94.95 & 100.28 & 94.54 & 99.28 & 93.86 & 95.98 \\
\hline
\end{tabular}

Continuação da tabela-9.

\begin{tabular}{|c|c|c|c|c|c|c|c|c|c|c|}
\hline \multirow[t]{2}{*}{ AMOSTRA } & \multirow{2}{*}{\begin{tabular}{|c|}
$\begin{array}{c}\text { RR-01A } \\
\text { (bth) }\end{array}$ \\
MAT \\
\end{tabular}} & \multirow{2}{*}{$\begin{array}{c}\begin{array}{c}\text { RR-18A } \\
(\mathrm{b} t \mathrm{~h})\end{array} \\
M I C \\
\end{array}$} & \multicolumn{2}{|c|}{ RR-18E (bth) } & \multirow{2}{*}{$\begin{array}{c}\begin{array}{c}\text { RR-33 } \\
\text { (bth) }\end{array} \\
M A T\end{array}$} & \multicolumn{2}{|c|}{ RR-36A (bth) } & \multirow{2}{*}{$\begin{array}{c}\begin{array}{c}\text { RR-53B } \\
\text { (bth) }\end{array} \\
\text { MAT }\end{array}$} & \multirow{2}{*}{$\begin{array}{l}\text { RR-16 } \\
(\mathrm{ab}) \\
M A T\end{array}$} & \multirow{2}{*}{$\begin{array}{c}\begin{array}{c}R R-17 \\
(a b)\end{array} \\
M A T\end{array}$} \\
\hline & & & & & & & & & & \\
\hline & 4 & 9 & & & 02 & & & .04 & 0.21 & 0.16 \\
\hline & 19 & .47 & & & $20-8$ & & & & $6.20^{\circ}$ & 46.13 \\
\hline & 015 & 0.16 & 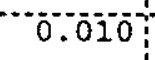 & 0.16 & 0.07 & 0.12 & 7 & 0.05 & 0.10 & 0.00 \\
\hline & 47.91 & 48.13 & & 7.97 & 8.44 & & & .54 & 47.70 & 48.70 \\
\hline & 0.72 & 1.09 & & 0.44 & 0.50 & & & 0.81 & 0.78 & 0.044 \\
\hline & $14]$ & 0.23 & 0.179 & $1.00^{\circ}$ & 0.45 & & & 0.26 & $0.0 \overline{8}$ & 0.1 \\
\hline & 0.32 & 0.09 & 0.03 & 0.06 & 0.18 & & 0.08 & 0.013 & 0.00 & 0.05 \\
\hline & 0.06 & 0.00 & 0.100 & $0.00^{\circ}$ & 0.03 & $\overline{0}$ & 0.001 & 0.00 & 0.00 & 0.00 \\
\hline & 95.63 & 97.26 & 97.83 & $97.40^{\circ}$ & 97.91 & & 70 & 98.02 & 907.07 & 95.75 \\
\hline & 0.32 & 10.36 & 1.31 & 9.61 & 17.87 & & & 9.77 & 15.22 & 13.0 \\
\hline & 71 & & & 42 & 33.97 & & & 43.00 & 36.09 & 39.67 \\
\hline SOMA & 99.82 & 101.47 & 101.98 & 101.67 & $101.31^{n}$ & 100.34 & 99.82 & 102.34 & 98.68 & 99.72 \\
\hline
\end{tabular}

Tabela 10- Microanálise química das ilmenitas presentes nos diques toleiticos (bth) e andesi-basaltos (ab) da Suíte Básica Apoteri. MIC= microfenocristal; $\mathrm{MAT}=$ matriz. $\mathrm{FeO} e \mathrm{Fe}_{2} \mathrm{O}_{3}$ calculado segundo Carmichael (1967). 


\subsection{DGRRAMES BASÁLTICOS}

Para este conjunto de rochas foram selecionadas 4 amostras $: 2$ representativas dos andesi-basaltos (ab) e 2 dos lati basaltos (lb).

\subsubsection{PIROXÊNIOS}

As Tabelas-11 e 12 mostram, respectivamente, as composições químicas dos piroxênios ricos e pobres em cálcio, para os estágios de cristalização precoce (P) e para os estágios de cristalização tardia (T). Foi detectado apenas nos ab a coexistência de dois tipos de piroxênios numa mesma amostra, um rico em cálcio (augita) e outro pobre em cálcio (pigeonita) (Figura-13).

No diagrama $\mathrm{Ca}-\mathrm{Mg}-\mathrm{Fe}^{*} \quad\left(\mathrm{Fe}^{*}=\mathrm{Fe}^{+2}+\mathrm{Fe}^{+3}+\mathrm{Mn}\right.$ ) estão representadas os piroxênios ricos (augita) e pobres (pigeonita) em cálcio, das fases precoces (Figura-14-A) e tardias (Figura14-B) reunidas por litotipos. Nestes diagramas estão representadas ainda a linha de evolução dos piroxênios da intrusão de Skaergaard (Brown,1957; Brown \& Vincent, 1963) e as linhas cheias unindo os piroxênios correspondentes à mesma amostra. Observa-se nestes diagramas moderada distribuição dos piroxênios dos $a b$, fruto da variação dos conteúdos em (Ca) e/ou (Fe), enquanto que os $1 b$ distribuem-se de forma mais regular, situados nos campos dos piroxênios ricos em cálcio (augita). Também pode ser observado que a grande maioria dos piroxênios posicionam-se abaixo do "trend" de evolução de skaergaard.

A composição normativa (CIPW) dos clinopiroxênios ricos em cálcio tem demonstrado ser útil para distinguiir diferentes tipos de basaltos (Coombs,1963; Bellieni, et al.,1984). Geralmente os piroxênios de basaltos alcalinos possuem usualmente nefelina normativa, os basaltos a dois piroxênios tem alto conteúdo de hiperstênio normativo, enquanto que os basaltos transicionais possuem de baixo a moderado conteúdo de hiperstênio normativo. $\mathrm{Na}$ figura-15 é mostrado o diagrama Hy-Di-Ne normativos com a distribuição dos piroxênios cálcicos dos tipos litológicos analisados, além dos "trends" de skaergaard (Brown \& Vincent, 1963 ) e de Thingmuli (Carmichael, 1964) para efeito de comparação. Observa-se que a grande maioria das amostras dos ab e lb posicionam-se no campo de Hy normativo moderado a alto, com aumento deste dos estágios de cristalização precoce para os tardio. 
Litotipo: Andesi-basalto; Lati Basalto

\begin{tabular}{|c|c|c|c|c|c|c|c|c|c|c|}
\hline \multirow[t]{2}{*}{ AMOSTRA } & \multicolumn{3}{|c|}{ RR- 02A (ab) } & \multicolumn{2}{|c|}{$\begin{array}{r}\mathrm{RR}-{ }^{06 \mathrm{~B}} \\
(\mathrm{ab})\end{array}$} & \multicolumn{3}{|c|}{ RR- 08A (lb) } & \multicolumn{2}{|c|}{$\begin{array}{r}R R-09 C \\
\text { (lb) }\end{array}$} \\
\hline & $\overline{\mathrm{T}}$ & $\bar{P}$ & $T$ & $\bar{T}$ & $\bar{P}$ & $\bar{T}$ & $\bar{P}$ & $\bar{P}$ & $T$ & \\
\hline $\mathrm{O}_{2}$ & 51.59 & 52.49 & 51.67 & 51.09 & 52.43 & 51.99 & 52.19 & 51.69 & 51.33 & 51. \\
\hline & 0.40 & 0.26 & 0.53 & 0.58 & 0.56 & 0.22 & 0.52 & 0.29 & 0.81 & 0.3 \\
\hline & & 1.49 & & & 1.50 & 2.46 & 1.41 & & 1.62 & \\
\hline & 1.02 & 91.85 & 14.05 & 13.65 & 10.77 & 11.11 & 12.21 & 8.1 & 5.4 & 9 \\
\hline & 22 & 0.29 & 0.38 & 0.29 & 0.29 & 0.28 & 0.24 & 0.19 & 0.24 & 0.2 \\
\hline & 37 & 16.23 & 15 & 15.04 & 16.39 & 6.10 & 5.18 & 16.99 & 13.45 & 17.0 \\
\hline & & 16.93 & 16. & & 97.60 & 7.42 & 17.74 & 19.3 & 77.40 & 17.7 \\
\hline & & 0.17 & 0.22 & 0.2 & 0.17 & 0.41 & 0.23 & 0.18 & 0.18 & \\
\hline & 01 & 0.00 & 0.00 & 0.08 & 0.05 & 0.20 & 0.01 & 0.28 & 0.05 & 0.4 \\
\hline & 99.34 & 99.71 & 100.85 & 98.67 & 99.76 & 100.19 & 99.73 & 98.86 & 100.51 & 98.7 \\
\hline $\mathrm{Fe}_{2} \mathrm{C}$ & 2.08 & 0.61 & 2.15 & 1.31 & 0.46 & 2.16 & 0.47 & 2.24 & 0.74 & 2.0 \\
\hline & 1.922 & 1.958 & 1.922 & 1.942 & 1.950 & 1.922 & 1.956 & 1.924 & 1.936 & 1.934 \\
\hline & 32 & 0.042 & 74 & 58 & 0.050 & 078 & 0.044 & 0.074 & 064 & 0.06 \\
\hline šö & 64 & 2.000 & 1.996 & 2.000 & 2.000 & 000 & 2.000 & 1.998 & 000 & 2.00 \\
\hline & 00 & 0.023 & 0.000 & 003 & 0.016 & 029 & 0.018 & 0.000 & .008 & 0.00 \\
\hline & 0.285 & 0.353 & 0.377 & 396 & 0.322 & .283 & 0.369 & 0.191 & 0.466 & 0.24 \\
\hline & 0.058 & 0.017 & 0.060 & 0.038 & 0.013 & 0.060 & 0.013 & 0.063 & 0.021 & 0.056 \\
\hline & & 0.000 & 0.0 & 0.002 & 0.001 & 006 & 0.000 & 0.008 & 0.001 & 0.00 \\
\hline & & 0.902 & 0.857 & 0.852 & 0.909 & 887 & 0.848 & 0.942 & 756 & ö. \\
\hline & & 0.009 & 0.012 & 109 & 0.000 & 009 & .008 & .006 & 008 & 0.00 \\
\hline$T$ & 0.011 & 0.007 & 0.015 & 0.017 & 0.016 & 0.006 & 0.015 & 0.008 & 0.023 & 0.01 \\
\hline & & 0.677 & & 0.665 & 0.7 & 30 & 0.712 & 0.773 & 703 & 0.70 \\
\hline & & & & & 0. & & 17 & .073 & 013 & 0.07 \\
\hline & 12 & 2.000 & & 2.000 & 2.00 & 2.000 & 2.000 & 2.005 & .000 & 2.00 \\
\hline & & 35.03 & $\sqrt{35}$ & 1.77 & 36.30 & $\overline{09}$ & 6.92 & 0.55 & 5.53 & 37.2 \\
\hline & .05 & 17 & 44.98 & 44.52 & 47.02 & 47.68 & 43.94 & 49.42 & 9.27 & 49.6 \\
\hline re & 14.79 & 18.25 & 19.77 & 20.71 & 96.67 & 15.24 & 19.14 & 10.03 & 84.20 & $13 . \mathrm{C}$ \\
\hline
\end{tabular}

Tabela 11- Microanálise química dos piroxênios ricos em cálcio dos derrames basálticos da Suíte Básica Apoteri. $P=$ fase de cristalização precoce; $T=$ fase de cristalização tardia; $a b=$ andesi-basalto; $\mathrm{Ib}=$ lati basalto; $\mathrm{Fe}_{2} \mathrm{O}_{3}$ calculado segundo Papike et al. (1974) (adaptado por Silvio Vlach). $\mathrm{Fe}^{\star}=\mathrm{Fe}^{+2}+\mathrm{Fe}^{+3}+\mathrm{Mn}$. 
Litotipo: Andesi-basalto

\begin{tabular}{|c|c|c|}
\hline \multirow[t]{2}{*}{ AMOSTRA } & $\begin{array}{l}\text { RR- } \\
02 A \\
\text { (ab) }\end{array}$ & $\begin{array}{l}R R- \\
068 \\
\text { (ab) }\end{array}$ \\
\hline & $P$ & 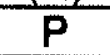 \\
\hline $\mathrm{SiO}_{2}$ & 52.56 & 51.15 \\
\hline $\mathrm{TiO}_{2}$ & 0.47 & 0.41 \\
\hline $\mathrm{Al}_{2} \mathrm{O}_{3}$ & 0.86 & 0.64 \\
\hline $\mathrm{Fe}$ & 20.20 & 26.48 \\
\hline $\mathrm{MnO}$ & 0.46 & 0.50 \\
\hline $\mathrm{MgO}$ & 20.69 & 16.32 \\
\hline $\mathrm{CaO}$ & 4.74 & 4.3 \\
\hline $\mathrm{Na}_{2} \mathrm{O}$ & 0.08 & 0.08 \\
\hline $\mathrm{Cr}_{2} \mathrm{O}_{3}$ & 0.02 & 0.11 \\
\hline SOMA & 100.08 & 100.02 \\
\hline $\mathrm{Fe}_{2} \mathrm{O}_{3}{ }^{*}$ & 0.59 & 0.27 \\
\hline Si & 1.960 & 1.969 \\
\hline $\mathrm{Al}^{\mathrm{i}}$ & 0.038 & 0.02 \\
\hline SOMÄ & 1.998 & 1.99 \\
\hline$\overline{A l^{n}}$ & 0.000 & 0.00 \\
\hline $\mathrm{Fe}^{72}$ & 0.613 & 0.84 \\
\hline $\mathrm{Fe}^{73}$ & 0.017 & 0.008 \\
\hline $\mathrm{Cr}^{+3}$ & 0.001 & 0.00 \\
\hline $\bar{M}$ & ${ }^{1} 1.150$ & 0.936 \\
\hline $\mathrm{Mn}$ & 0.015 & 0.016 \\
\hline $\mathrm{ii}$ & 0.013 & 0.012 \\
\hline $\mathrm{Ca}$ & 0.189 & 0.175 \\
\hline $\mathrm{Na}$ & 0.006 & 0.006 \\
\hline SOMA & 2.003 & 2.005 \\
\hline$\overline{\mathrm{Ca}}$ & 9.70 & 9.11 \\
\hline$\ddot{M}$ & 58.89 & 47.78 \\
\hline $\mathrm{Fe}^{*}$ & 31.41 & 43.1 \\
\hline
\end{tabular}

Tabela 12- Microanálise química dos piroxênios pobres em cálcio dos derrames basálticos da suíte Básica Apoteri. $\mathrm{P}=$ fase de cristalização precoce; $T=$ fase de cristalização tardia; $a b=$ andesi-basalto; $\mathrm{Fe}_{2} \mathrm{O}_{3}$ calculado segundo Papike et al. (1974) (adaptado por Silvio Vlach). $\mathrm{Fe}^{\star}=\mathrm{Fe}^{+2}+\mathrm{Fe}^{+3}+\mathrm{Mn}$. 

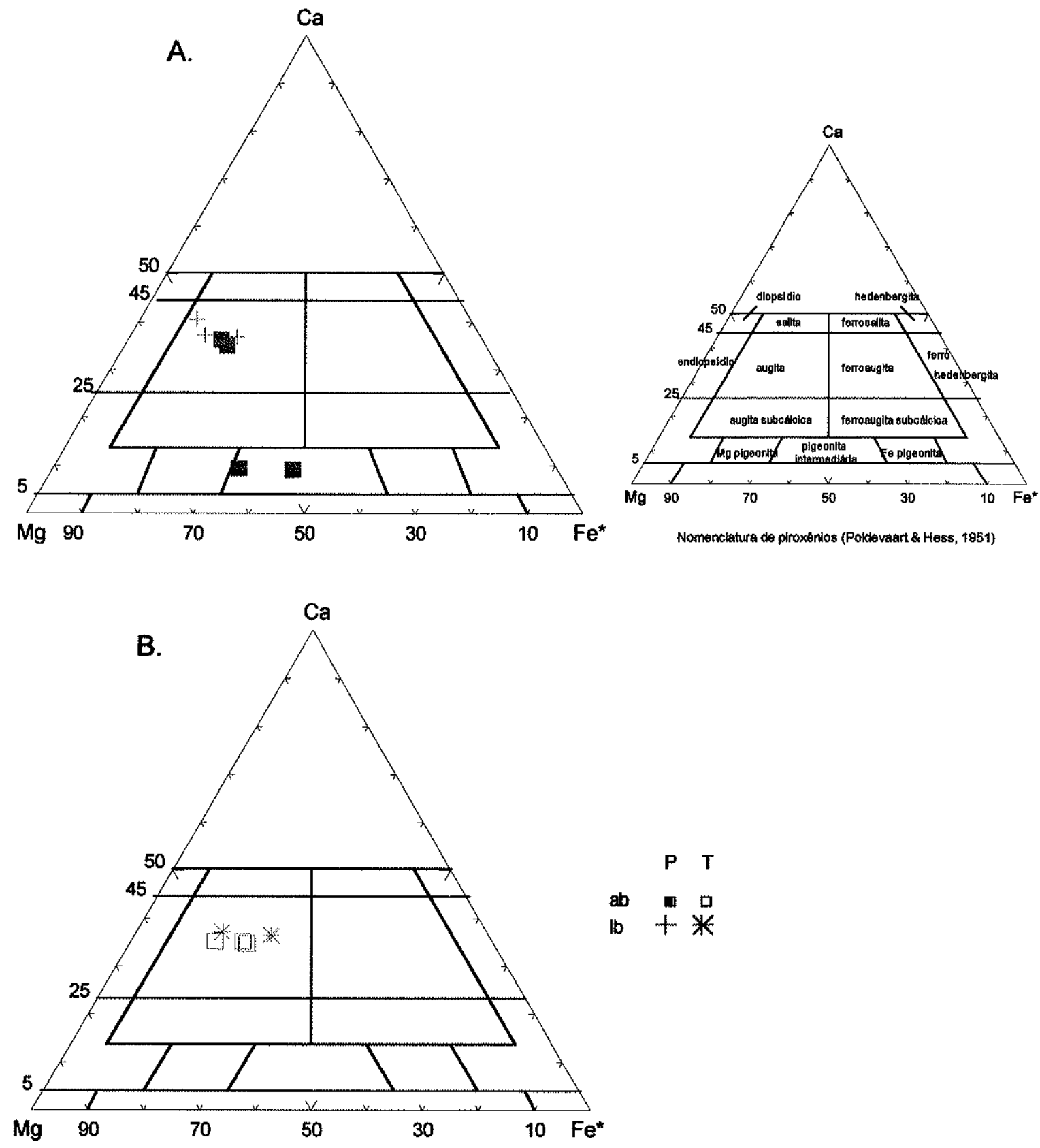

Figura 13- Quadrilátero dos piroxênios (Ca-Mg-Fe*), segundo Poldervaart \& Hess (1951) para as fases de cristalização precoce (A) e tardia (B) dos piroxênios dos derrames basálticos da Suite Básica Apoteri. ab= andesi-basalto; $1 \mathrm{~b}=$ lati basalto. 

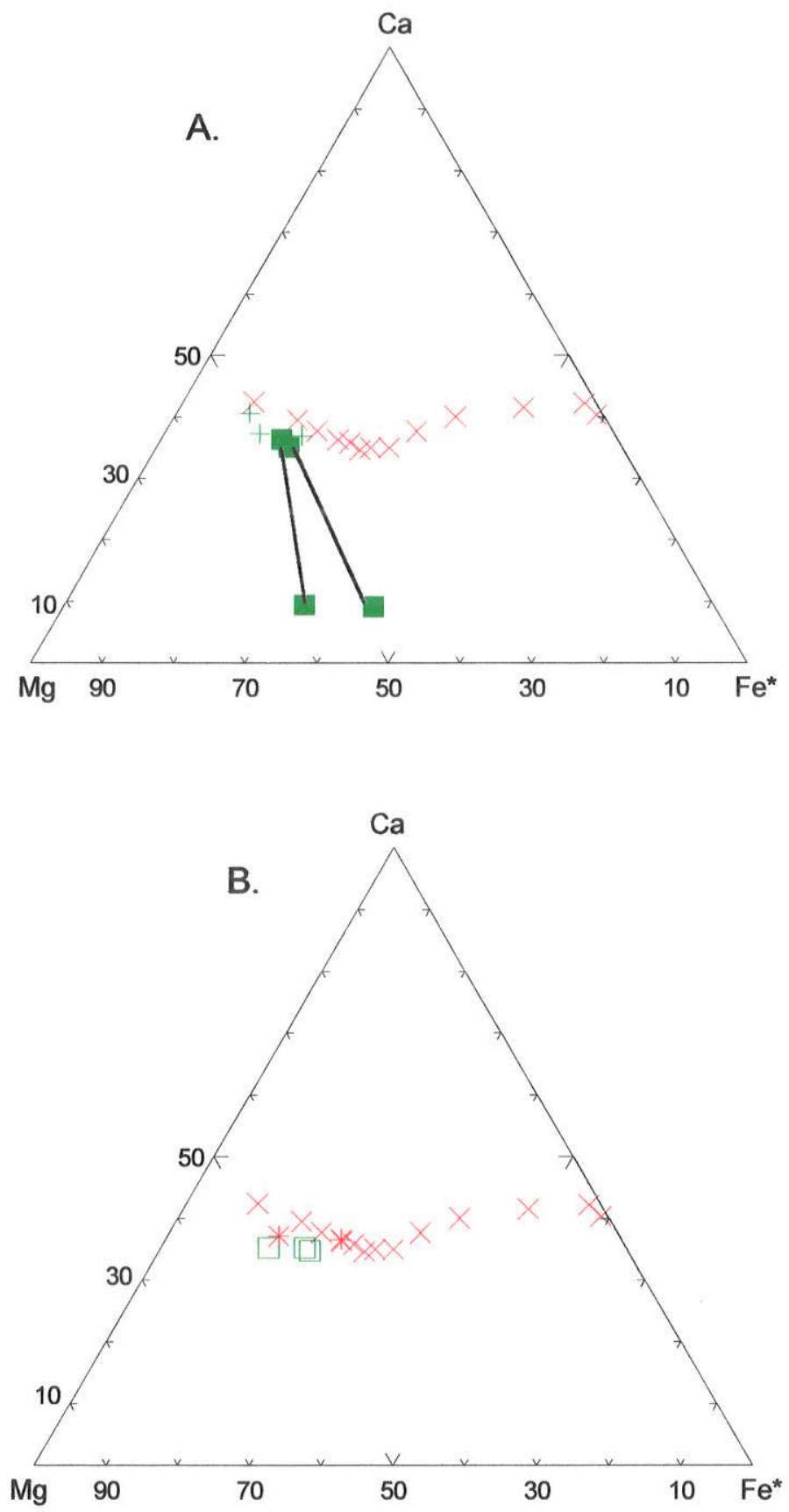

Figura 14- Variação composicional em termos de $\mathrm{Ca}-\mathrm{Mg}-\mathrm{Fe}$ * (\% atômica) dos piroxênios ricos e pobres em cálcio de cristalização precoce (A) e tardia (B) dos andesibasaltos e lati basaltos. Linhas cheias unem pontos de mesma amostra. $\mathrm{Fe}^{*}=\mathrm{Fe}^{+2}+\mathrm{Fe}^{+3}+\mathrm{Mn}$. Símbolos em " $\mathrm{X}^{\prime \prime}$ representam a linha de evolução dos piroxênios da intrusão de Skaergaard (Brown, 1957; Brown \& Vincent, 1963). Símbolos como na figura-13. 


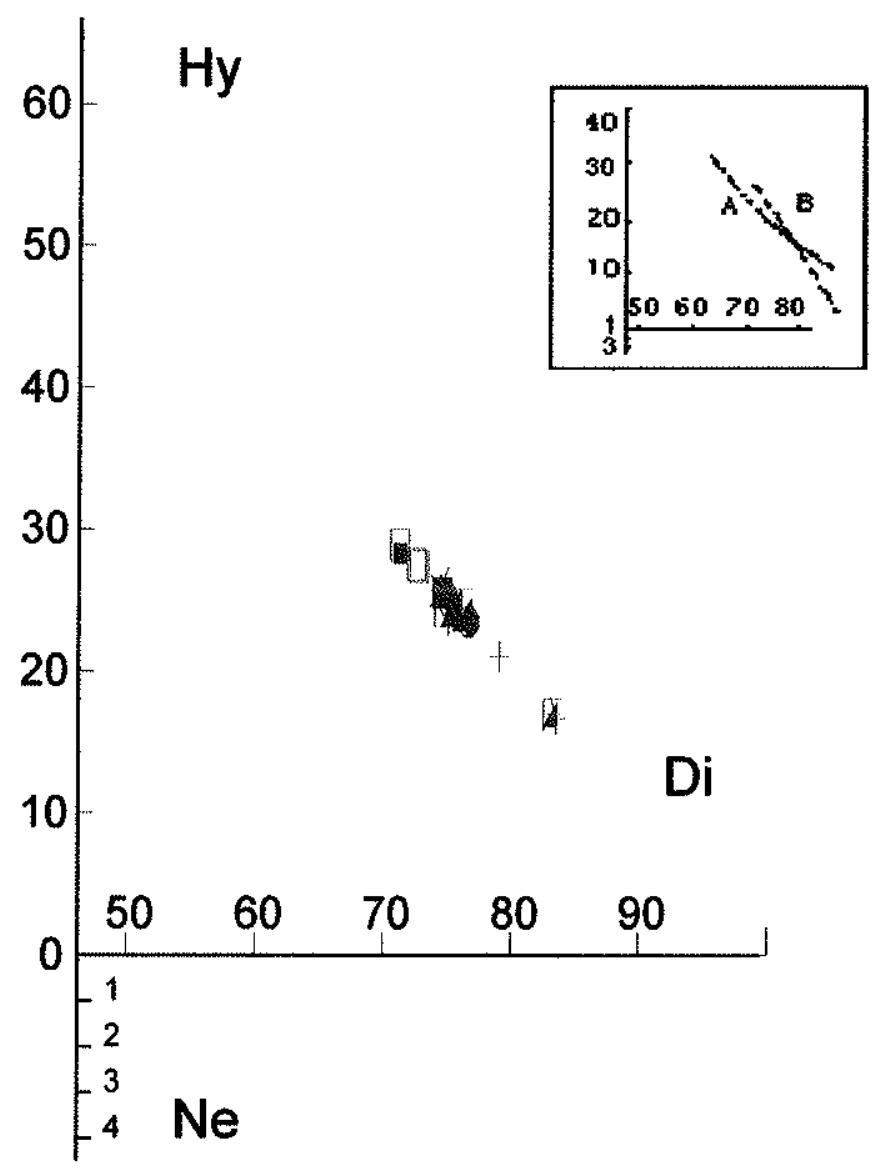

Figura 15- Diagrama Hy(Hiperstênio)-Di(diopsidio)-Ne(Nefelina) normativo CIPW dos piroxênios cálcicos de cristalização precoce e tardia dos derrames $a b$ e $l b$ da Suíte Básica Apoteri. Diagrama conforme Bellieni et al. (1984). Diagrama acima e a direita mostrando os "trends" de skaergaard (A) (Brown, 1957; Brown \& Vincent, 1963) e Thingmuli (B) (Carmichael, 1964), para efeito de comparação. Símbolos como na figura-13.

\subsubsection{GEOTERMOMETRIA}

A tabela-13 mostra a média dos valores das temperaturas, em ${ }^{\circ} \mathrm{C}$, obtidas para cada par de geotermômetro, considerando as fases de cristalização precoces e tardias dos piroxênios para os tipos litológicos analisados.

$$
\text { As temperaturas variaram de } 1141 \pm 30 \text { (P) a } 1060 \pm 46 \text { (T) }
$$
para os ab e $1158 \pm 24$ a $1118 \pm 8$ para os $1 b$. 
(a)

\begin{tabular}{|c|c|c|c|c|}
\hline \multicolumn{2}{|c|}{ AMOSTRAS } & WB (1973) & K (1982) & $I \quad(1975)$ \\
\hline \multirow[t]{2}{*}{ RR-02A } & (P) & 1195.1 & 1111.3 & 1103.0 \\
\hline & (T) & ----- & 1106.5 & ----- \\
\hline \multirow[t]{2}{*}{ RR-06B } & (P) & 1133.3 & 1170.9 & 1042.5 \\
\hline & (T) & ---- & 1014.1 & ----- \\
\hline \multirow[t]{2}{*}{ MÉDIA } & (P) $n=2$ & $1164.2(30.9)$ & $1141.1(29.8)$ & $1072.7(30.2)$ \\
\hline & (T) $n=2$ & $---\cdots$ & $1060.3 \quad(46.2)$ & $-----m$ \\
\hline
\end{tabular}

(b)

\begin{tabular}{|c|c|c|}
\hline \multicolumn{2}{|c|}{ AMOSTRAS } & $K$ (1982) \\
\hline RR-08A & (P) & 1133.9 \\
& (T) & 1127.4 \\
\hdashline RR-09C & (P) & 1182.9 \\
& (T) & 1110.4 \\
\hline MÉDIA & (P) $\mathbf{n}=\mathbf{2}$ & $1158(24.5)$ \\
& (T) $\mathbf{n}=\mathbf{2}$ & $1118(8.5)$ \\
\hline
\end{tabular}

Tabela 13- Temperatura dos piroxênios de cristalização precoce (P) e tardia ( $T$ ) de cada amostra e seu valor médio para os derrames basálticos da Suite Básica Apoteri: (a) andesi-basalto; (b) lati basalto. WB= Wood \& Banno (1973); K $(1982)=\operatorname{Kretz}(1982) ;$ I $(1975)=$ Ishii (1975); $n=$ número de amostras; $($ )= desvio padrão.

\subsubsection{PLAGIOCLÁSIO}

Os resultados das microanálises químicas dos plagioclásios precoces (P) e tardios (T) correspondentes aos derrames basálticos ( $a b$ e $1 b$ ) estão mostrados na tabela-14.

No diagrama Albita (Ab) - Anortita (An)-Ortoclásio (Or), em \% em peso, estão representados todos os plagioclásios analisados que cristalizaram precocemente (Eigura-16-A) e tardiamente (Figura-16-B).

Observa-se que, para os plagioclásios referentes aos núcleos dos

fenocristais ou microfenocristais (precoces)


Litotipo: Andesi-basalto; Lati Basalto

\begin{tabular}{|c|c|c|c|c|c|c|c|c|c|c|c|}
\hline \multirow[t]{2}{*}{ AMOSTRA } & \multicolumn{6}{|c|}{ RR - 02A (ab) } & \multicolumn{4}{|c|}{ RR - 06B (ab) } & \multirow{2}{*}{\begin{tabular}{|c}
$\begin{array}{c}\text { RR-9C } \\
\text { (b) }\end{array}$ \\
$P$
\end{tabular}} \\
\hline & $T_{1}$ & $\overline{P_{1}}$ & $T_{1}$ & $T_{2}$ & $P_{2}$ & $T_{2}$ & $T$ & $P$ & $\mathbf{P}$ & $\bar{T}$ & \\
\hline $\mathrm{SiO}_{2}$ & 54.81 & 53.58 & 53.54 & 54.48 & & 56.63 & 55.33 & 53.02 & 53.37 & 54.29 & 52.24 \\
\hline $\mathrm{Al}_{2} \mathrm{O}_{3}$ & 29.74 & 29.48 & 29.44 & 28.92 & 28.83 & 27.57 & 28.95 & 30.07 & 30.05 & 29.22 & 28.07 \\
\hline $\mathrm{CaO}$ & 12.61 & 12.77 & 12.69 & 12.07 & 12.30 & 10.67 & 12.24 & 13.35 & 13.39 & 12.59 & 12.80 \\
\hline $\mathrm{Na}_{2} \mathrm{O}$ & 4.11 & 3.93 & 3.97 & 4.22 & 4.27 & 5.04 & 4.31 & 3.63 & 3.54 & 3.91 & 4.26 \\
\hline $\mathrm{K}_{2} \mathrm{O}$ & 0.24 & 0.24 & 0.26 & 0.27 & 0.28 & 0.33 & 0.27 & 0.21 & 0.26 & $0.30^{\circ}$ & 0.30 \\
\hline SOMA & 101.51 & 100.00 & 99.90 & 99.96 & 100.40 & 100.24 & 101.09 & 100.29 & 100.61 & 100.32 & 97.67 \\
\hline Or $\%$ & $\overline{1.41 !}$ & 1.44 & 1.56 & 1.61 & 1.61 & 1.95 & 1.59 & 1.25 & 1.54 & 1.81 & 1.71 \\
\hline $\mathrm{Ab} \%$ & 36.59 & 35.24 & 35.61 & 38.11 & 37.95 & 45.19 & 38.29 & 32.59 & 31.85 & 35.37 & 36.97 \\
\hline $\mathrm{An} \%$ & 62.00 & 63.32 & 62.83 & 60.28 & 60.44 & 1.95 & 60.12 & 66.16 & 66.61 & 62.82 & 61.32 \\
\hline
\end{tabular}

Tabela 14- Microanálise química dos plagioclásios dos derrames basálticos de Roraima. $\mathrm{P}=$ fase de cristalização precoce; $\mathrm{T}=$ fase de cristalização tardia; $\mathrm{P}_{1,2}=$ fase de cristalização precoce do grão mineral 1,$2 ; \mathrm{T}_{1,2}=$ fase de cristalização precoce do grão mineral 1,2; $\mathrm{ab}=$ andesi-basalto; $\mathrm{lb}=$ lati basalto.

mostrado na figura-16-A, há um predomínio da composição labradoritica nos ab $(\mathrm{An}=60.44-66.618)$ e $\mathrm{lb}(\mathrm{An}=61.32 \%)$.

Nos estágios tardios de cristalização dos plagioclásios (Figura-16-B), nota-se que há uma dominância da composição labradorítica nos ab $(A n=53.86-62.828)$.

Devido ao alto grau de alteração verificado para os plagioclásios dos lb conforme descrito nas análises petrográficas (capítulo-6), foi dificil a sua determinação química das análises por microssonda eletrônica.

\subsubsection{MINERAIS OPACOS}

Os minerais opacos ocorrem tanto nos andesi-basaltos (ab) como nos lati-basaltos, representados por magnetita em microfenocristais e na matriz.

As microanálises químicas dos minerais opacos revelaram que não há grande variação composicional entre os litotipos analisados, demonstrando apenas a presença de magnetitas (Tabela-15). 

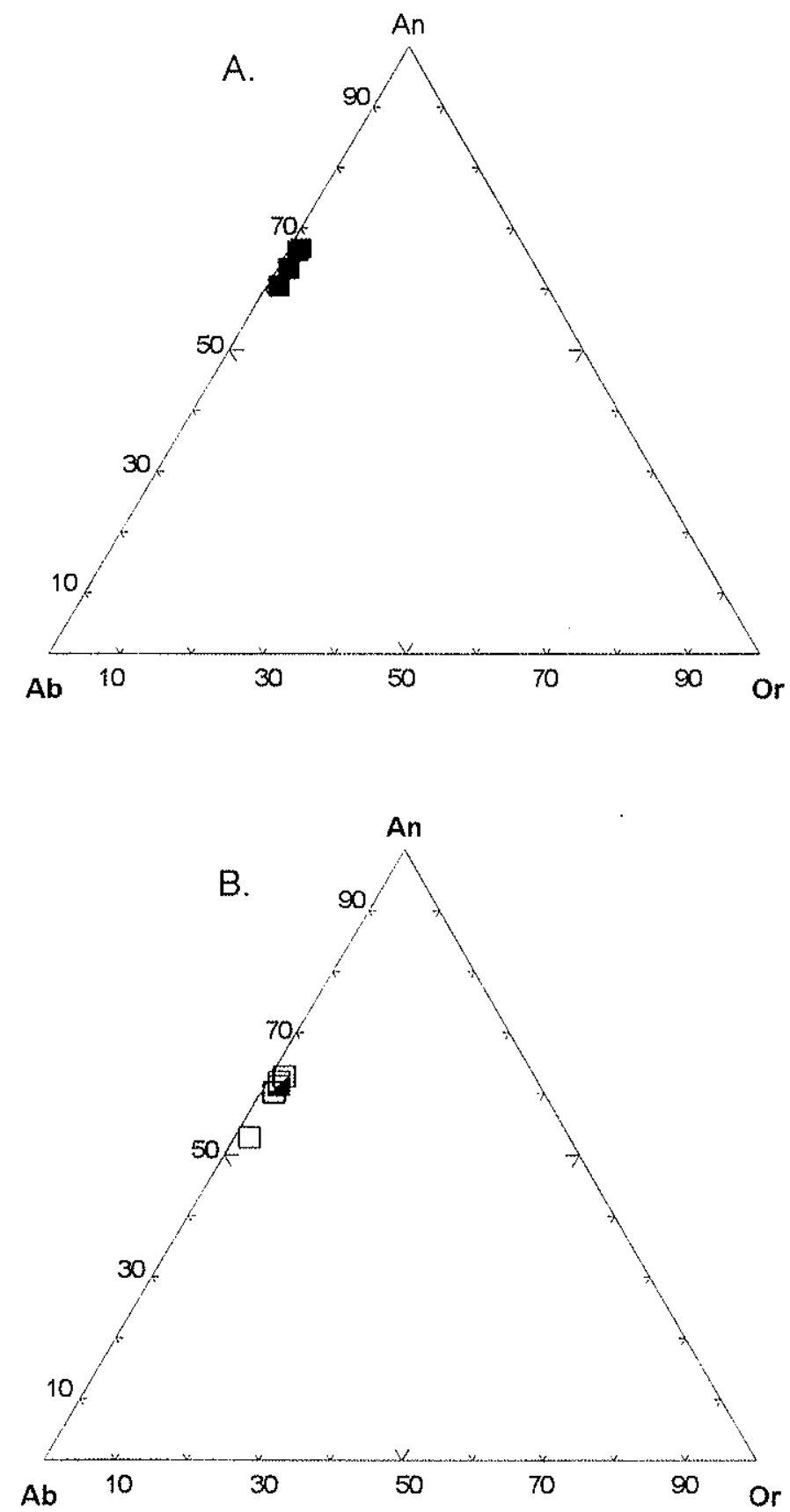

Figura 16- Variação composicional com base no conteúdo de Albita (Ab) - Anortita (An) - Ortoclásio (Or) ( 8 em peso) dos plagioclásios de cristalização precoce (A) e tardia (B) dos derrames basálticos (ab). Símbolos com na figura-13. 


\begin{tabular}{|c|c|c|c|c|}
\hline \multirow[t]{2}{*}{ AMOSTRA } & $\begin{array}{l}\text { RR- } \\
02 A \\
(\mathrm{ab}) \\
\end{array}$ & \multicolumn{2}{|c|}{$\begin{array}{c}R R-06 B \\
\text { (ab) }\end{array}$} & $\begin{array}{l}\text { RR- } \\
08 A \\
\text { (1b) }\end{array}$ \\
\hline & $M I C$ & MIC & $M A T$ & MAT \\
\hline $\mathrm{SiO}_{2}$ & 0.16 & 0.50 & 0.11 & 1.03 \\
\hline $\mathrm{TiO}_{2}$ & 13.42 & 24.35 & 9.54 & 37.50 \\
\hline $\mathrm{Ai}_{2} \mathrm{O}_{3}$ & 0.86 & 1.43 & 1.57 & 0.76 \\
\hline $\mathrm{FeO}_{\mathrm{t}}$ & 73.90 & 67.03 & 83.20 & 53.77 \\
\hline $\mathrm{MnO}$ & 0.22 & 0.83 & 0.11 & 0.027 \\
\hline $\mathrm{MgO}$ & 0.76 & 0.06 & 0.24 & 0.43 \\
\hline $\mathrm{CaO}$ & 0.05 & 0.13 & 0.05 & 0.63 \\
\hline $\mathrm{Cr}_{2} \mathrm{O}_{3}$ & 0.011 & 0.10 & 0.07 & 0.01 \\
\hline SOMA & 89.48 & 94.46 & 94.89 & $94.40^{\circ}$ \\
\hline EeO & 37.52 & 31.64 & 45.80 & 29.54 \\
\hline $\mathrm{Fe}_{2} \mathrm{O}_{3}$ & 40.42 & 39.33 & 41.57 & $35.80^{\circ}$ \\
\hline SOMA & 93.52 & 98.37 & 99.06 & 96.97 \\
\hline
\end{tabular}

Tabela 15 - Microanálise química das magnetitas presentes nos derrames basálticos da Suíte Básica Apoteri. MIC= microfenocristal; $\mathrm{MAT}=$ matriz. FeO e $\mathrm{Fe}_{2} \mathrm{O}_{3}$ calculado segundo Carmichael (1967). 


\subsection{GEOQUÍMICA DE ELEMMENTOS MAIORES}

Para melhor vizualização do comportamento químico dos elementos maiores das rochas da Suíte Básica Apoteri (diques máficos-DM e derrames basálticos-DE) foram calculadas as médias de cada para os diferentes litotipos (Tabela-16).

\begin{tabular}{|c|c|c|c|c|}
\hline óxIDOS & DM (bth) & $\overline{D M}(\mathrm{ab})$ & $\mathrm{DE}(\mathrm{ab})$ & DE (1b) \\
\hline $\mathrm{SiO}_{2}$ & $50.49(0.73)$ & $51.83(0.97)$ & $51.85(0.64)$ & $50.45(0.41)$ \\
\hline $\mathrm{TiO}_{2}$ & $1.14(0.18)$ & $1.39 \times(0.29)$ & $1.36(0.07)$ & $1.22-(0.05)$ \\
\hline $\mathrm{Al}_{2} \mathrm{O}_{3}$ & $16.43(1.14)$ & $15.53(0.93)$ & $15.07 \quad(0.47)$ & $15.44(0.00)$ \\
\hline $\mathrm{FeO}_{t}$ & $11.51 \quad(0.91)$ & $12.45(1.14)$ & $12.13(0.42)$ & $11.75(0.17)$ \\
\hline Mino & $0.16(0.01)$ & $0.16-(0.01)$ & $0.16(0.01)$ & $0.16(0.01)$ \\
\hline $\mathrm{MgO}$ & $6.49(0.68)$ & $5.10(0.76)$ & $5.15 \times(0.09)$ & $6.310 .24)$ \\
\hline $\mathrm{CaO}$ & $10.20 \quad(0.51)$ & $8.68(0.74)$ & $8.34(0.86)$ & $7.72(0.09)$ \\
\hline $\mathrm{Na}_{2} \mathrm{O}$ & $2.41(0.19)$ & $2.70-(0.19)$ & $2.90(0.38)$ & $3.70-(0.15)$ \\
\hline $\mathrm{K}_{2} \mathrm{O}$ & $0.52(0.12)$ & $0.95(0.27)$ & $1.07(0.72)$ & $1.43(0.04)$ \\
\hline $\mathrm{P}_{2} \mathrm{O}_{5}$ & $0.12(0.02)^{-}$ & $0.18-(0.05)$ & $0.16(0.02)$ & $0.12(0.01)$ \\
\hline mg\# & $0.53(0.03)$ & $0.45(0.06)$ & $0.46(0.01)$ & $0.51-(0.01)$ \\
\hline n & 32 & $10 "$ & -6 & 2 \\
\hline
\end{tabular}

Tabela 16- Média dos elementos maiores ( 8 em peso) das rochas da Suíte Básica Apoteri. $\mathrm{n}=$ número de amostras; ( )= desvio padrão; $\mathrm{mg \# =} \mathrm{Mg}^{+2} /\left(\mathrm{Mg}^{+2}+\mathrm{Fe}^{+2}\right)\left[\mathrm{Fe}_{2} \mathrm{O}_{3} / \mathrm{FeO}=0.15\right] ; \mathrm{DM}=$ diques máficos; $\mathrm{DE}=$ derrames basálticos; $b t h=$ toleitico; $a b=$ andesi-basalto; $1 \mathrm{~b}=$ lati-basalto.

As rochas da Suíte Básica Apoteri se caracterizam por constituir dominantemente por diques máficos e lavas de natureza básica que se situam respectivamente no intervalo de 4.11 a 7.298 e 5.0 a 6.568 de $\mathrm{MgO}$ e 49.20 a 53.048 e 50.04 a $52.14 \%$ de $\mathrm{SiO}_{2}$. O número $\mathrm{mg \#}\left[\mathrm{Mg}^{+2}\left(\mathrm{Mg}^{+2}+\mathrm{Fe}\right)\right.$ assumindo $\mathrm{Fe}_{2} \mathrm{O}_{3} / \mathrm{FeO}$ igual a 0.15$]$ varia de 0.37-0.57 (média $0.51 \pm 0.05$ ) para os DM e mg\# 0.45-0.53 (média $0.47 \pm 0.03$ ) para os $\mathrm{DE}$, tais valores são indicativos de líquidos basálticos evoluídos.

De modo geral, os DM e DE mostram nitidas variações composicionais dos elementos maiores com a diminuição dos valores de mg\#, apresentando entretanto para os DE discretas variações e por vezes comportamentos anômalos para determinados elementos (por ex.: $\mathrm{Na}$ e K) (Eigura-17). Vale detacar que não se observa distinção química entre os diques encaixados no embasamento do Complexo Guianense e aqueles encaixados nas 

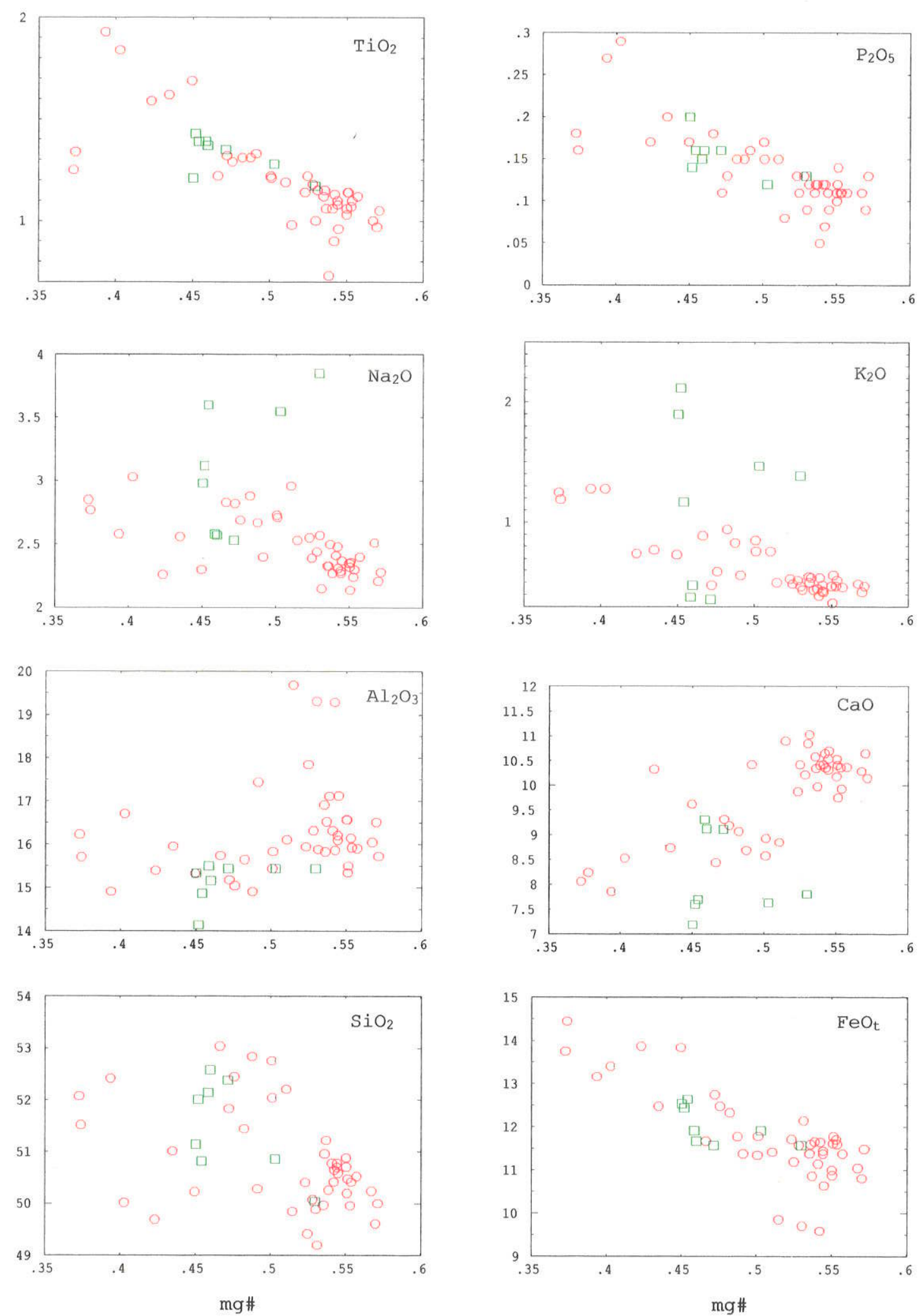

Figura 17- Diagrama de variação entre mg\# valores $\left[\mathrm{Mg}^{+2} /\left(\mathrm{Mg}^{+2}+\mathrm{Fe}^{+2}\right)\right.$; $\left.\mathrm{Fe}_{2} \mathrm{O}_{3} / \mathrm{FeO}=0.15\right]$ versus elementos maiores ( $\frac{\circ}{\circ}$ em peso) para as rochas da Suíte Básica Apoteri. Símbolos como na figura-5. 
outras unidades geológicas pré-cambrianas (Supergrupo Uatumã e Supergrupo Roraima). Deste modo, com a finalidade de ilustrar o grau de evolução magmática destas rochas, foram utilizados diagramas de variação envolvendo elementos maiores em função de mg\# valores, este utilizado como índice de variação, por melhor responder ao comportamento do magmatismo basático durante a cristalização. Assim, com o avanço da cristalização, ou seja com a diminuição do mg\#, observa-se:

Um aumento nos teores de $\mathrm{SiO}_{2}$ tanto para os DM como para os DE ocorrendo uma certa dispersão dos pontos para os DM.

- $\mathrm{Al}_{2} \mathrm{O}_{3}$ e $\circ \mathrm{CaO}$ possuem comportamentos semelhantes, diminuindo seus teores com $O$ avanço da cristalização (DM $=\mathrm{Al}_{2} \mathrm{O}_{3}$ de $\approx 20$ a $15 \%$ e $\mathrm{CaO}$ de $\approx 11$ a $7.5 \% ; \mathrm{DE}=\mathrm{Al}_{2} \mathrm{O}_{3}$ de $\approx 16$ a $14 \%$ e $\mathrm{CaO}$ de $\approx 16$ a 148 ). Porém para os $\mathrm{DE}$ determinadas amostras (RR-02A, RR02B, RR-08A, RR-09C e RR-39) apresentam valores de Ca dispersos do "trend" geral, possivelmente refletindo o elevado grau de saussuritização dos plagioclásios (ver capítulo-5) ou decréscimo do teor de anortita nestas amostras (composições mais andesítica). O comportamento do $\mathrm{CaO}$ e $\mathrm{Al}_{2} \mathrm{O}_{3}$ reflete a importância do plagioclásio e do clinopiroxênio no processo evolutivo, indicando deste modo um fracionamento do tipo gabro.

Em relação ao $\mathrm{Na}_{2} \mathrm{O}$, observa-se de modo geral um discreto aumento à medida que avança a cristalização (caminhando da porção mais a direita do diagrama para a esquerda), a exceção das amostras RR-02A, RR-02B, RR-08A, RR-09C e RR-39 dos $D E$ que são dispersas em relação ao "trend" geral, apresentando valores um pouco mais elevados. O $\mathrm{K}_{2} \mathrm{O}$ comporta-se de modo semelhante ao $\mathrm{Na}_{2} \mathrm{O}$. O excesso de $\mathrm{Na}, \mathrm{K}$ e $\mathrm{H}_{2} \mathrm{O}$ (Apêndice-2) em algumas amostras dos DE pode estar ligada a presença de zeólitas nas amígdalas (ver capítulo-5), apesar das amostras analisadas não apresentarem, pelo menos visíveis, a presença de amígdalas ou ao aumento da molécula albitica nesta amostras.

Observa-se para $\circ \mathrm{FeO}_{t}$ enriquecimento mais ou menos acentuado para os $D M(\approx 10$ a $15 \%)$ e discreto para os DE $(\approx 11$ a 138 ) à medida que o mg\# diminui, sugerindo também um forte controle dos minerais plagioclásio e clinopiroxênio.

Os valores de $\mathrm{TiO}_{2}$ para os $\mathrm{DM}$ permanecem aproximadamente constantes no início da cristalização ( $\mathrm{TiO}_{2}$ entre $1.0 \mathrm{e} 1.38$ ) aumentam moderadamente nas porções mais evoluídas do diagrama $\left(\mathrm{TiO}_{2}\right.$ entre $\left.1.4 \mathrm{e} 1.98\right)$; enquanto que para os $\mathrm{DE}$ há um discreto aumento com a diminuição dos valores de mg\#. O $\mathrm{P}_{2} \mathrm{O}_{5}$ comporta-se de maneira bastante similar ao $\mathrm{TiO}_{2}$.

Considerando as normas CIPW, a maioria das amostras dos diques toleíticos (918) apresentam alto conteúdo em hiperstênio 
normativo (15.82-28.158) com a presença de olivina normativa (0.38-6.988) e apenas três amostras são quartzo normativas (0.52-1.938). Em relação aos diques andesi-basalto a presença de hiperstênio normativo é também expressiva (13.85-26.99\%) apresentando-se quartzo normativo (0.62-4.048) para a maioria das amostras (70\%) e olivina normativa $(0.34-9.00 \%$ ) para as demais. De outra parte para os derrames, a presença de olivina normativa atinge proporções elevadas para os lati-basaltos (15.798) com nefelina normativa também presente (1.37\%), enquanto que nos andesi-basalto se observa hiperstênio normativo (23.77-24.77\%) e quartzo normativo (3.93-4.858) (Apêndice-2).

\subsection{GEOQUIMITCA DOS ELEMERTIOS TRAÇOS}

A tabela-17 mostra a média dos elementos traços ( $\mathrm{Cr}, \mathrm{Ni}$, $\mathrm{Sc}, \mathrm{Ba}, \mathrm{Rb}, \mathrm{Sr}, \mathrm{La}, \mathrm{Ce}, \mathrm{Zr}, \mathrm{Y}, \mathrm{Nb}, \mathrm{e} \mathrm{Nd}$ ) para os $\mathrm{DM}$ e $\mathrm{DE}$ reunidos por tipo litológico.

\begin{tabular}{|c|c|c|c|c|}
\hline ELFHMENTO & DM (bth) & DM (ab) & DE $(a b)$ & $\mathrm{DE} \quad(1 \mathrm{~b})$ \\
\hline $\mathrm{Cr}$ & $120(51)$ & $70(20)$ & $52(26)$ & $107(54)$ \\
\hline $\mathrm{Ni}$ & $89(18)$ & $66-(13)$ & $61(6)$ & $78(1)$ \\
\hline $\mathrm{se}$ & $39(2)$ & $36-73$ & $37(1)$ & $35(0.5)$ \\
\hline Ba & $159(34)$ & $362(211)$ & $268(106)$ & $234(39)$ \\
\hline $\mathbf{R b}$ & $18(7)$ & $34(17)$ & $73(30)$ & $79(13)$ \\
\hline$s x$ & $210-(27)$ & $241(34)$ & $340(67)$ & $308(87)$ \\
\hline Ia & $9-(2)^{-1}$ & $17(5)$ & $13(3)$ & $12(0.5)$ \\
\hline $\mathrm{Ce}$ & $24(5)$ & $42(13)$ & $37 \times(6)$ & $32(0.55$ \\
\hline $2 x$ & $127(23)$ & $1900(48)$ & $179(3)$ & $157(8)$ \\
\hline$Y$ & $24(3)$ & $310(6)$ & $29(1)$ & $26(1)$ \\
\hline $\mathrm{Nb}$ & 7125 & $10(2)$ & $9.5(3)$ & $9(1)$ \\
\hline Nd & $13(2)$ & $19(4)$ & $17(2)$ & $16(0)$ \\
\hline $\mathbf{n}$ & 32 & 10 & 6 & $\ddot{2}$ \\
\hline
\end{tabular}

Tabela 17- Média dos elementos traços (ppm) das rochas da suíte Básica Apoteri. $\mathrm{n}=$ número de amostras; ()$=$ desvio padrão; $\mathrm{DM}=$ diques máficos; $\mathrm{DE}=$ derrames basálticos; bth= toleitico; $a b=$ andesi-basalto; $1 b=1$ lati-basalto.

Os diagramas de elementos traços em função dos valores de mg\# apresentados na figura-18, mostram o seguinte compartamento:

De modo geral, nota-se tanto para os DM como DE uma diminuição dos elementos compativeis $\mathrm{Cr}, \mathrm{Ni}$ e SC com 0 decréscimo de mg\#. O comportamento negativo do Sc versus o mg\# mostra clara influência do clinopiroxênio no fracionamento magmático. 

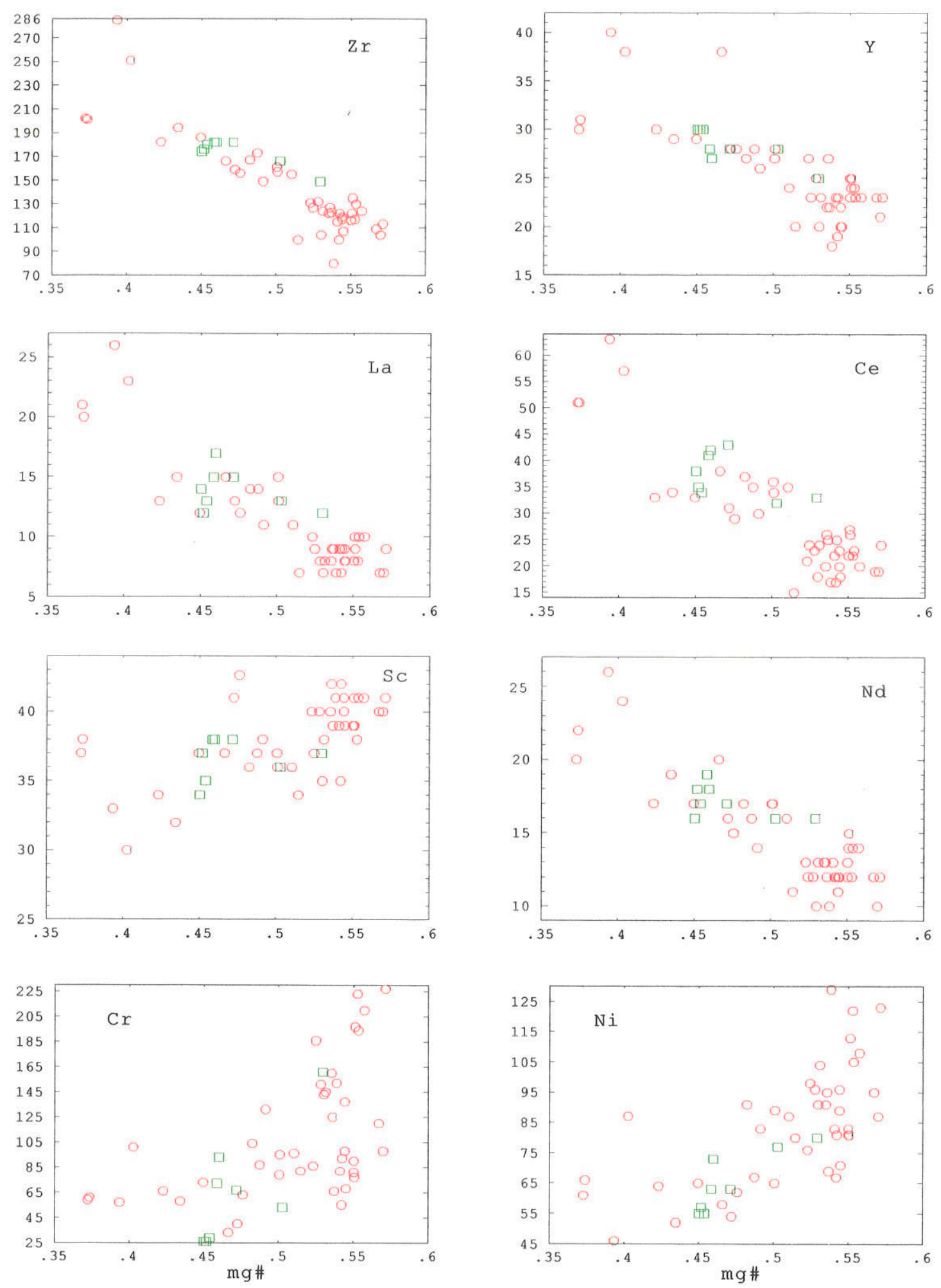

Figura 18- Diagrama de variação entre mg\# valores $\left[\mathrm{Mg}^{+2} /\left(\mathrm{Mg}^{+2}+\mathrm{Fe}^{+2}\right)\right.$; $\left.\mathrm{Fe}_{2} \mathrm{O}_{3} / \mathrm{FeO}=0.15\right]$ e elementos traços (ppm) para as rochas da suíte Básica Apoteri. Símbolos como na figura-5. 

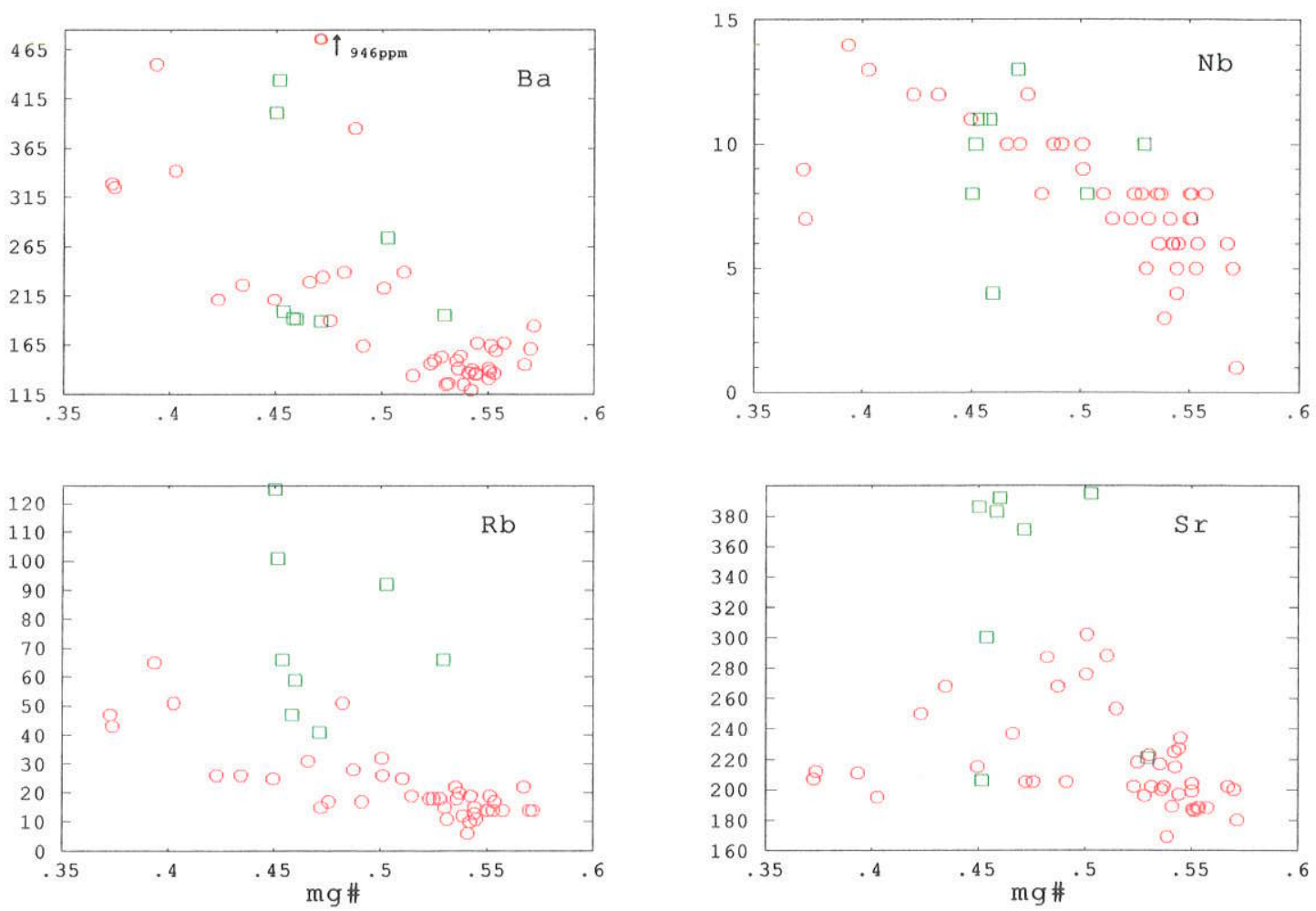

Figura 18- Continuação

As terras raras leves (La e Ce) comportam-se de forma semelhante ao Zr, Y e Nd demonstrando um aumento moderado de seus teores tanto para os DM como para os DE com o decréscimo de mg\# .

O Sr assim como o Rb mostram um discreto aumento com a diminuição de mg\# tanto para os DE como os DM, a exceção das amostras RR-02A, RR-02B, RR-08A, RR-09C e RR-39 dos DE que apresentam-se dispersas do "trend" geral evolutivo.

O Ba apresenta um padrão relativamente constante para os DM e $\mathrm{DE}$, tendendo a um leve enriquecimento à medida que a cristalização avança (porção mais a esquerda do diagrama), embora para algumas amostras dos DE (ex.: RR-39=434ppm, RR-02A $=401 \mathrm{ppm})$ e $\mathrm{DM}$ (ex.: RR-38 = $946 \mathrm{ppm} ; \mathrm{RR}-35 \mathrm{C}=450 \mathrm{ppm} ; \mathrm{RR}-26=$ $386 \mathrm{ppm}$ ) hajam teores um pouco mais elevados.

Como constatado anteriormente, os diques máficos não exibem bandamento e de maneira geral tem granulação homogênea, excluindo a sútil borda resfriada rapidamente ("chilled margin"), não apresentando variação química significativa entre aqueles corpos de granulação fina e aqueles de granulação média 
(Tabela-18). Entretanto, no dique coletado no ponto 18 (RR-18A: contato; RR-18D: a 5m do contato; RR-18E: 10m; RR-18F: 15m; RR18G: 20m), observa-se uma discreta variação química tanto nos elementos maiores como nos elementos traços (Figuras- 19 e 20) da borda (mg\# 0.54) para o centro (mg\# 0.42) apresentando um aumento de $\mathrm{SiO}_{2}, \mathrm{FeO}_{\mathrm{t}}, \mathrm{Na}_{2} \mathrm{O}, \mathrm{K}_{2} \mathrm{O}, \mathrm{TiO}_{2}, \mathrm{P}_{2} \mathrm{O}_{5}$ e elementos incompatíveis e uma diminuição de $\mathrm{CaO}, \mathrm{Al}_{2} \mathrm{O}_{3}, \mathrm{Cr}, \mathrm{Ni}$ e $\mathrm{Sc}$, acompanhando o comportamento do "trend" geral evolutivo destas rochas (Figura-17 e 18).

\section{ELEMENTOS MAIORES}

\begin{tabular}{|c|c|c|c|c|}
\hline & \multicolumn{2}{|c|}{ DM (bth) } & \multicolumn{2}{|c|}{ DM (ab) } \\
\hline ELEMERTOS & $\begin{array}{c}\text { grã média } \\
\mathbf{n}=13\end{array}$ & $\begin{array}{c}\text { grã fina } \\
\mathbf{n}=19\end{array}$ & $\begin{array}{c}\text { grã média } \\
\mathbf{n}=5\end{array}$ & $\underset{n=5}{\operatorname{grãa}} \operatorname{fina}_{n=5}$ \\
\hline $\mathrm{SiO}_{2}$ & $50.32(0.55)$ & $50.49(0.64)$ & $52.26(0.73)$ & $51.74(0.99)$ \\
\hline $\mathrm{TiO}_{2}$ & $1.12(0.09)$ & $1.10(0.20)$ & $1.52 \times(0.23)$ & $1.37(0.24)$ \\
\hline $\mathrm{Al}_{2} \mathrm{O}_{3}$ & $16.62(0.99)$ & $16.52(1.26)$ & $15.31-(0.43)$ & $16.05 \quad(0.38)$ \\
\hline $\mathrm{FeO}_{\mathrm{t}}$ & $11.26(0.58)$ & $11.43(0.94)$ & $12.19(0.69)$ & $13.01 \quad(1.10)$ \\
\hline $\mathrm{MnO}$ & $0.16(0.009)$ & $0.16(0.008)$ & $0.160(0.004)$ & $0.16(0.006)$ \\
\hline $\mathrm{MgO}$ & $6.57=(0.54)$ & $6.60-(0.72)$ & $5.12(0.59)$ & $4.82(0.66)$ \\
\hline $\mathrm{CaO}$ & $10.32(0.34)$ & $10.18(0.56)$ & $8.46(0.36)^{-1}$ & $8.44 \quad(0.29)$ \\
\hline $\mathrm{Na}_{2} \mathrm{O}$ & $2.39(0.11)$ & $2.40-(0.22)$ & $2.63(0.07)$ & $2.84 \quad(0.11)$ \\
\hline $\mathrm{K}_{2} \mathrm{O}$ & $0.50 \quad(0.04)$ & $0.53(0.15)$ & $0.93(0.20)$ & $1.07(0.21)$ \\
\hline $\mathrm{P}_{2} \mathrm{O}_{5}$ & $0.12(0.02)^{\circ}$ & $0.11(0.03)$ & $0.20(0.04)$ & $0.19(0.05)$ \\
\hline
\end{tabular}

ELEMENTOS TRAÇOS

\begin{tabular}{|c|c|c|c|c|}
\hline CI & $125(39)$ & $130(57)$ & $\begin{array}{ll}50 & (24)\end{array}$ & $70(25)$ \\
\hline $\mathrm{Ni}$ & $90-\langle 12\rangle$ & $\left.94^{-20}\right)$ & $-57 \times(9)$ & $72(13)$ \\
\hline Sc & $39(2)$ & $39(2)$ & $35(20)$ & $36(3)$ \\
\hline $\mathbf{R}$ & $17(3)$ & $18(10)$ & $38(16)$ & $40-(9)$ \\
\hline $\mathbf{B a}$ & $144(12)$ & $163(38)$ & $502(269)$ & 2909527 \\
\hline Sx & $204(12)$ & $212(36)$ & $256(26)$ & $231(38)$ \\
\hline Ia & $8 "(1)$ & $9(2)$ & 17945 & $18(4)$ \\
\hline $\mathrm{Ce}$ & $23(3)$ & $23(6)$ & $39(8)$ & $44(8)$ \\
\hline $\mathbf{z}$ & $127(12)$ & $124(26)$ & $2030(49)$ & $195(33)$ \\
\hline $\bar{Y}$ & $23(2)$ & $23(3)$ & $31-(5)$ & $33(4)$ \\
\hline
\end{tabular}

Tabela 18- Média dos elementos maiores ( $8 \mathrm{em}$ peso) e traços (ppm) dos diques máficos com granulação fina e média da suíte Básica Apoteri. Elementos maiores normalizados para 1008 sem perda ao fogo. ()$=$ desvio padrão; $n=$ número de amostras; $g r a ̃=$ granulometria; $\mathrm{DM}=$ diques máficos; $\mathrm{bth}=$ basalto toleitico; $\mathrm{ab}=$ andesi-basalto. 

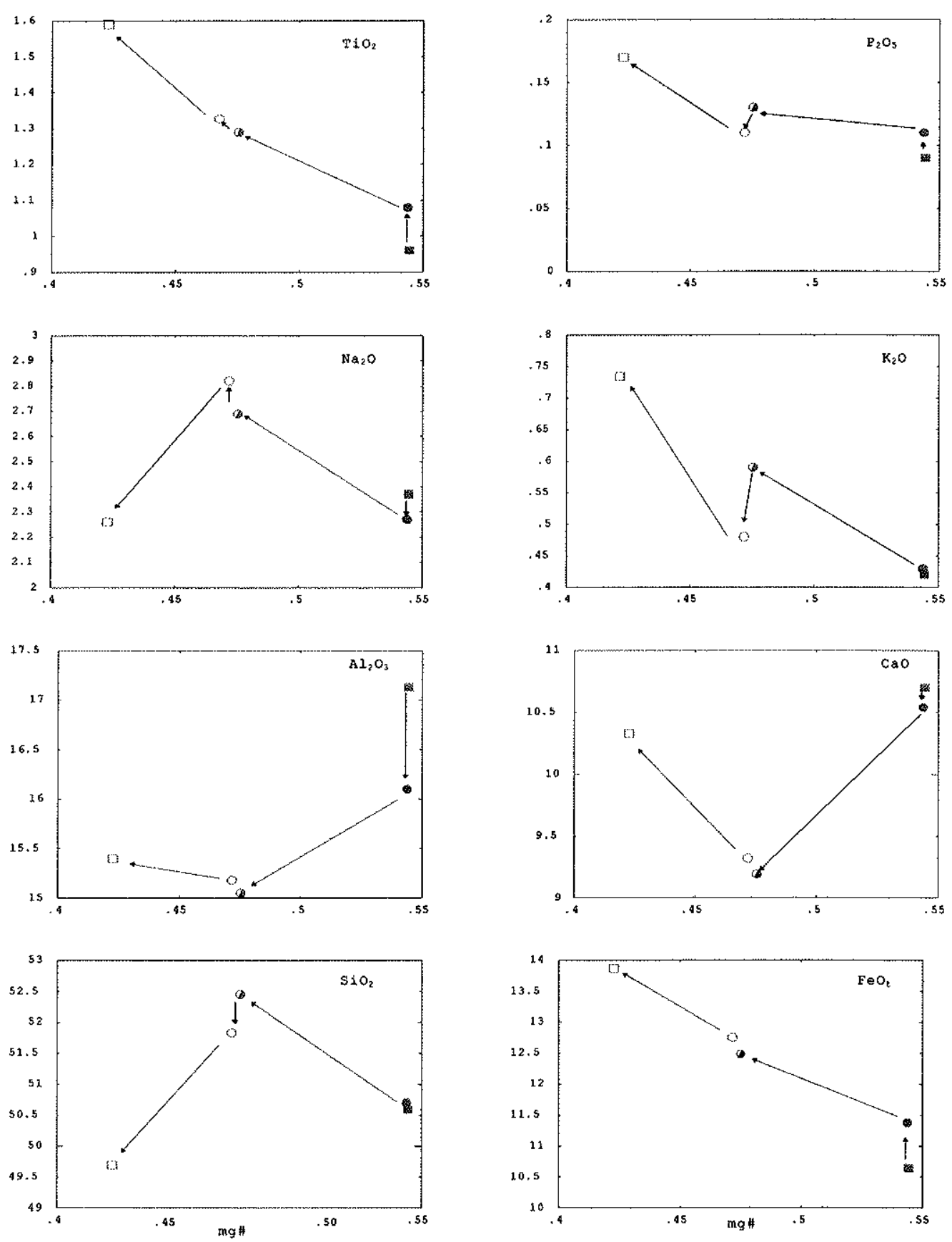

Figura 19- Diagrama de variação mg\# valores $\left[\mathrm{Mg}^{+2} /\left(\mathrm{Mg}^{+2}+\mathrm{Fe}^{+2}\right) ; \quad \mathrm{Fe}_{2} \mathrm{O}_{3} / \mathrm{FeO}^{2}=0.15\right]$ versus elementos maiores ( 8 em peso) das amostras representativas da migração B (Borda) $\rightarrow$ C (Centro) do dique do ponto-18 pertencentes a Suite Básica Apoteri. Elementos maiores normalizados para 1008, sem perda ao fogo. $\mathrm{RR}-18 \mathrm{~A}(\mathrm{~W}) \rightarrow \mathrm{RR}-18 \mathrm{D}(\mathrm{x}) \rightarrow \mathrm{RR}-18 \mathrm{E}(\varnothing) \rightarrow \mathrm{RR}-18 \mathrm{~F}(\mathrm{O}) \rightarrow \mathrm{RR}-18 \mathrm{G}(\mathrm{D})$. 

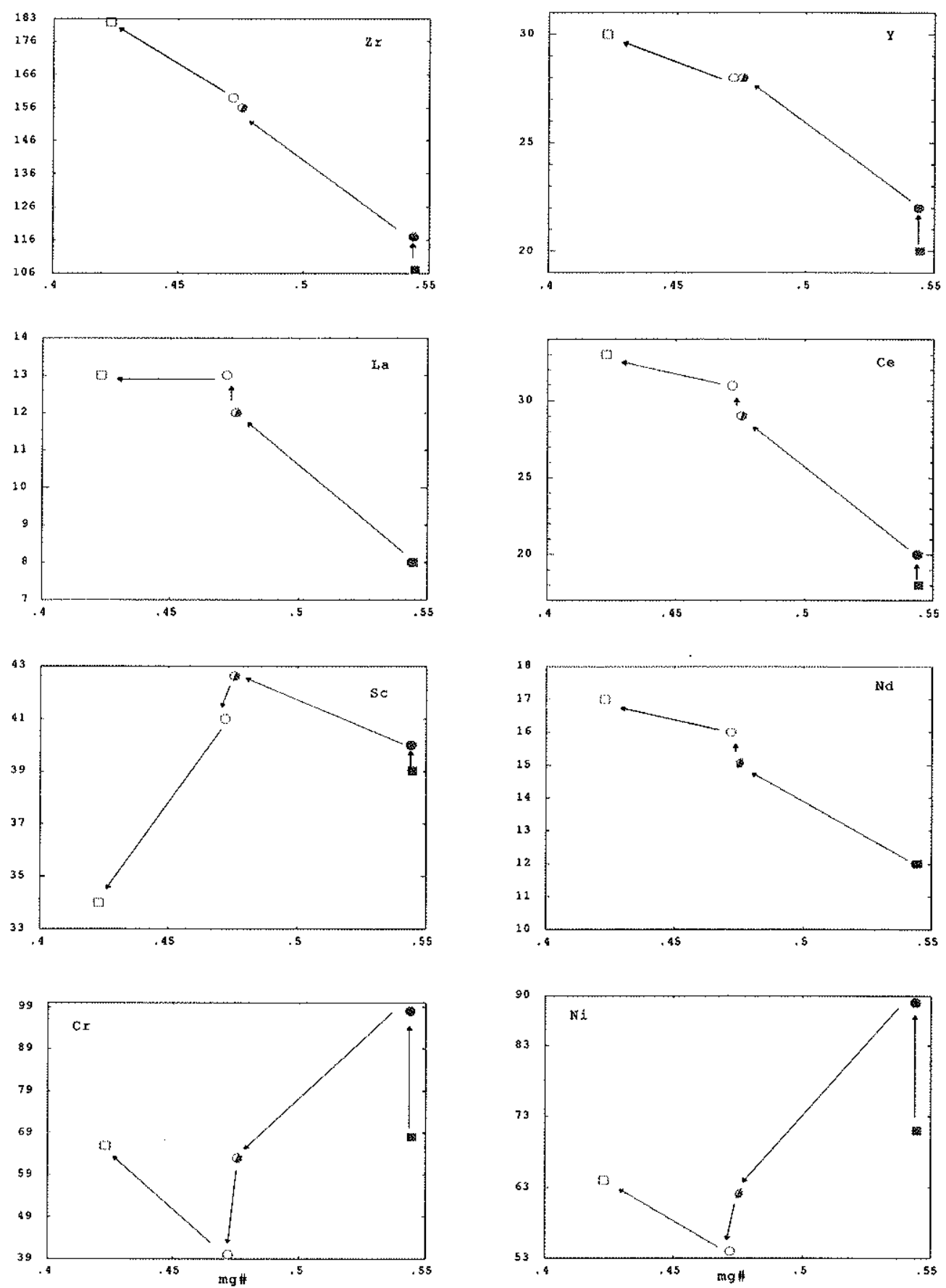

Figura 20- Diagrama de variação $\mathrm{mg \#}$ valores $\left[\mathrm{Mg}^{+2} /\left(\mathrm{Mg}^{+2}+\mathrm{Fe}^{+2}\right) ; \quad \mathrm{Fe}_{2} \mathrm{O}_{3} / \mathrm{FeO}=0.15\right]$ versus elementos traços (ppm) das amostras representativas da migração B (Borda) $\rightarrow$ C (Centro) do dique do ponto-18 pertencentes a Suíte Básica Apoteri. Símbolos como na figura-19. 

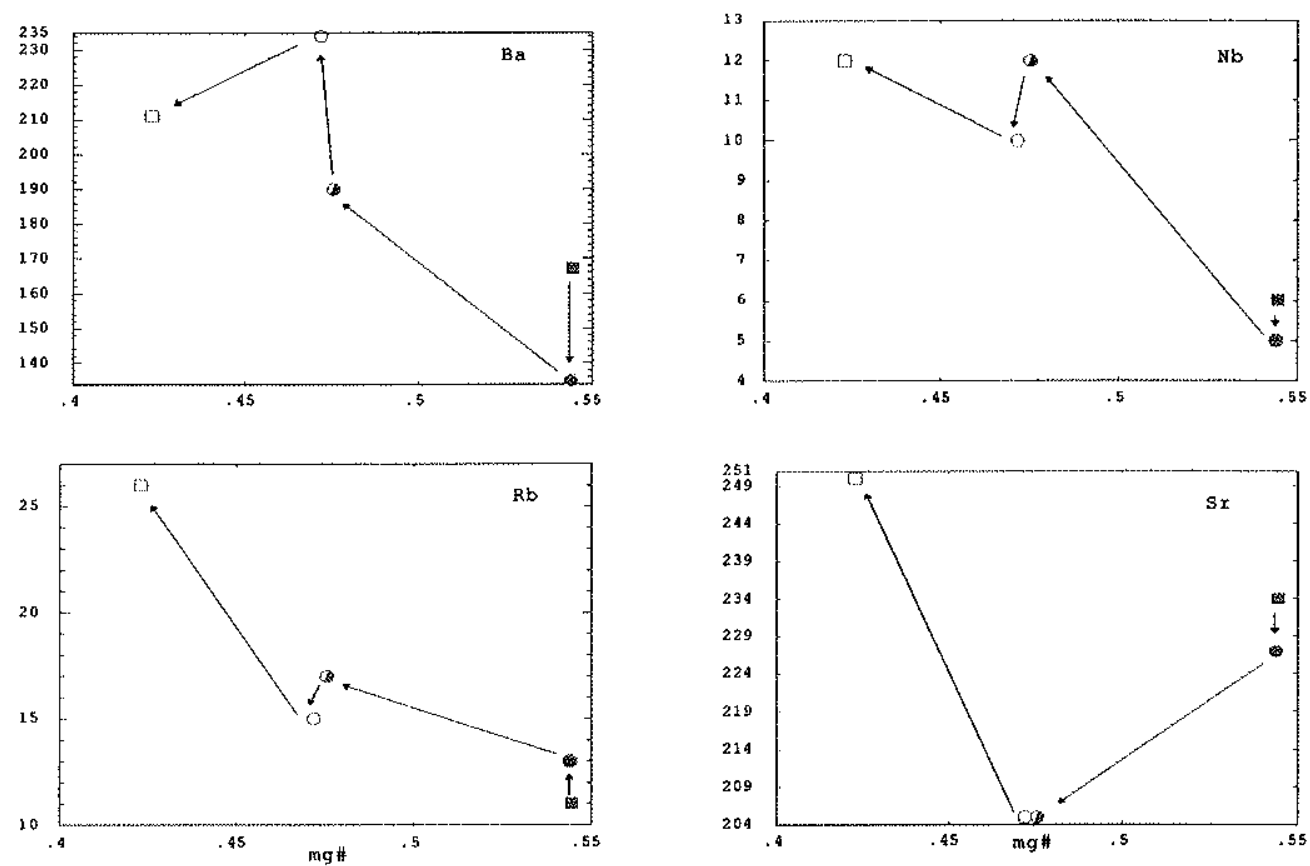

Figura 20- Continuação

7.2.1. APLICAÇÃO DOS ELWMINTOS TRAÇOS INCOMPATÍVEIS NA CARACTERTZAÇÃo DOS PROCESSOS MAGMÁTICOS E NATUREZA QUÍMICA DA FONIE

Vários autores (e.g. Treuil \& Varet, 1973; Allègre et al., 1977; Joron \& Treuil, 1977; Minter et al., 1977; Joron et al., 1978; Vieira Jr., 1991 ab) tem demonstrado a importância da aplicação dos elementos traços incompatíveis (ex.: Th, Ta, Nb, Hf, Zr, La, Ce) como ferramenta para o estudo das propriedades e dos processos de gênese das rochas e da investigação de heterogeneidades do manto. Tais elementos caracterizam-se por apresentarem baixos coeficientes de distribuição cristal/líquido, tendo como consequência pouco ou nenhum fracionamento desses elementos durante os processos de cristalização fracionada ou fusão parcial. Deste modo, através de correlações entre elementos traços incompatíveis é possível obter informações sobre o processo de geração das rochas, bem como investigar a caracteristica química da fonte mantélica.

Num determinado diagrama do tipo $A / B$ vs $A$ ( $A$ e $B$ incompatíveis), onde $A$ possui $D$ (coeficiente de distribuição) muito menor que 1 e $B$ mostra $D$ superior ao de $A$, será configurado uma reta, não necessariamente passando pela origem, 
se o processo for fusão parcial, enquanto que se formarem retas subhorizontais (paralelas a abcissa $X$ ) ter-se-á o processo de cristalização fracionada.

Por outro lado, num diagrama do tipo $C$ vs $D$, onde $C$ e $D$ são elementos incompatíveis, se dispuser uma distribuição relativamente homogênea desses elementos, ou seja a razão C/D permanecer aproximadamente constante para todos os conjuntos de rochas, essa correlação indica que há uma certa homogeneidade da repartição destes elementos sem fracionamento no manto e, consequentemente, esses conjuntos de rochas apresentam características da fonte mantélica semelhantes. Se, ao contrário, a distribuição destes elementos (C e D) for relativamente mais complexa, conformando diferentes retas para os diversos conjuntos de rochas, implica uma certa diversidade química na razão C/D acompanhada da existência de fontes quimicamente diferentes dentro de uma complexa heterogeneidade do manto correspondentes a diferentes estágios de sua diferenciação e evolução (Joron \& Treuil, 1977; Minster et al., 1977; Joron et al., 1978).

\subsubsection{Zr vs elementos incompatíveis (EI)}

A figura-21 mostra a variação do $\mathrm{Zr}$ versus os EI. Observase nesta figura uma correlação positiva entre $0 \mathrm{Zr} e$ os EI, demonstrando razões $\mathrm{Zr} / \mathrm{EI}$ levemente variáveis dentro do mesmo conjunto de rochas (ex.: $\mathrm{Zr} / \mathrm{La}: \mathrm{DM}=9.62-14.67, \mathrm{DE}=10.71-14.67$; Zr/Ce: $\mathrm{DM}=3.94-6.67, \mathrm{DE}=4.23-5.29 ; \mathrm{Zr} / \mathrm{Nb}: \mathrm{DM}=13-29.75, \mathrm{DE}=$ 14-45.50; $\mathrm{Zr} / \mathrm{Y}: \mathrm{DM}=4.37-7.13, \mathrm{DE}=5.80-6.74)$. Estas pequenas diferenças nas razões ( $\mathrm{Zr} / \mathrm{EI}$ ) podem estar sugerindo que as rochas não são estritamente cogenéticas ou relacionadas a um modelo de cristalização fracionada de gabros originados de magmas parentais pouco diferentes entre si, ou até mesmo fontes levemente heterogêneas. 

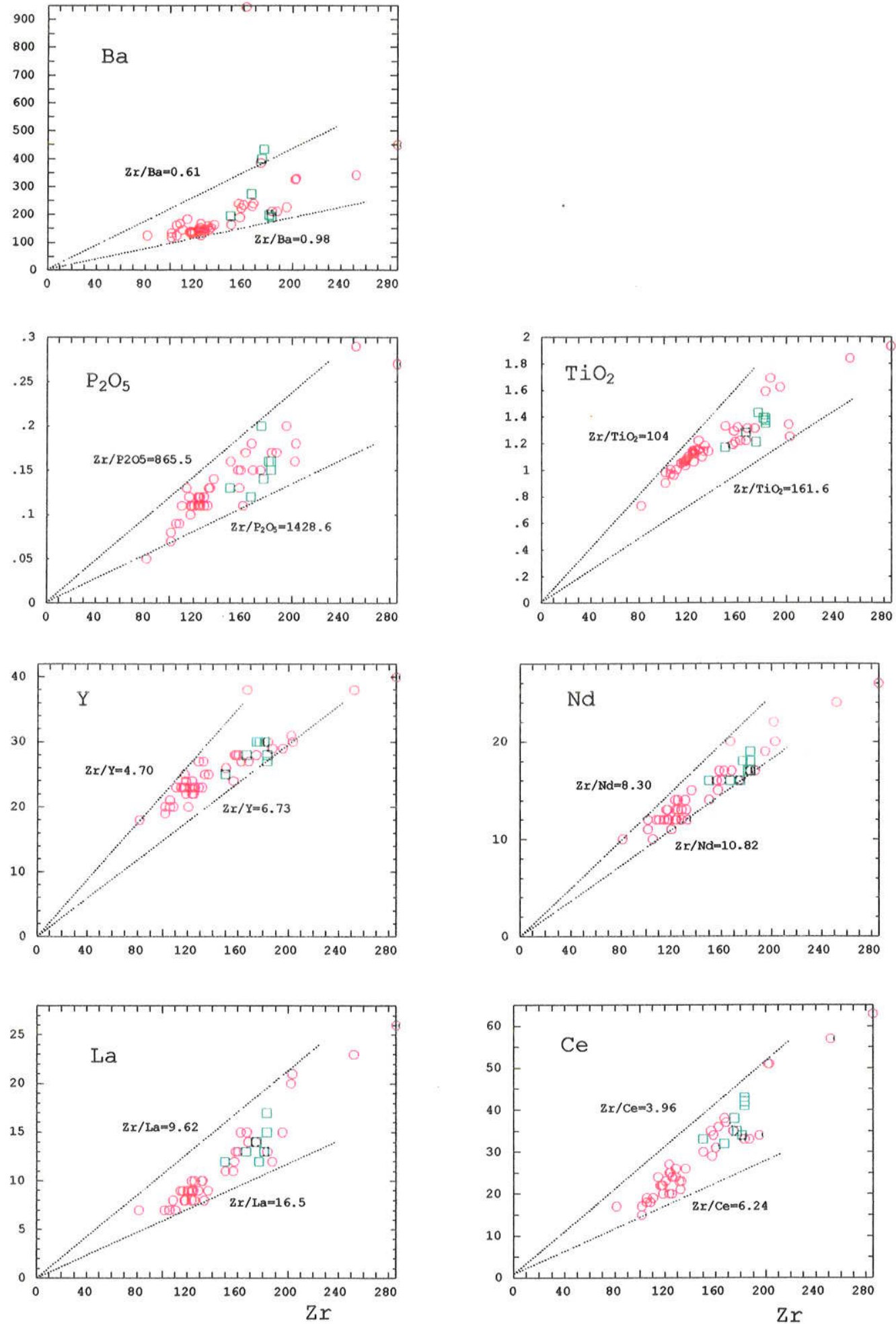

Figura 21- Diagrama de correlação entre Zr (ppm) e elementos traços (ppm) para as rochas da Suíte Básica Apoteri. Símbolos como na figura-5. 


\subsection{PADRÕES DE DISTRIBUIÇÃO DE ELMMENTOS TIFRRAS RARAS} (ETR)

A figura-22 apresenta o padrão de distribuição dos ETR para os $\mathrm{DM}$ e $\mathrm{DE}$, cujas rochas foram agrupadas por tipo litológico (bth, $a b$ e lb) e normalizadas para os condritos (Boynton, 1984).

a)

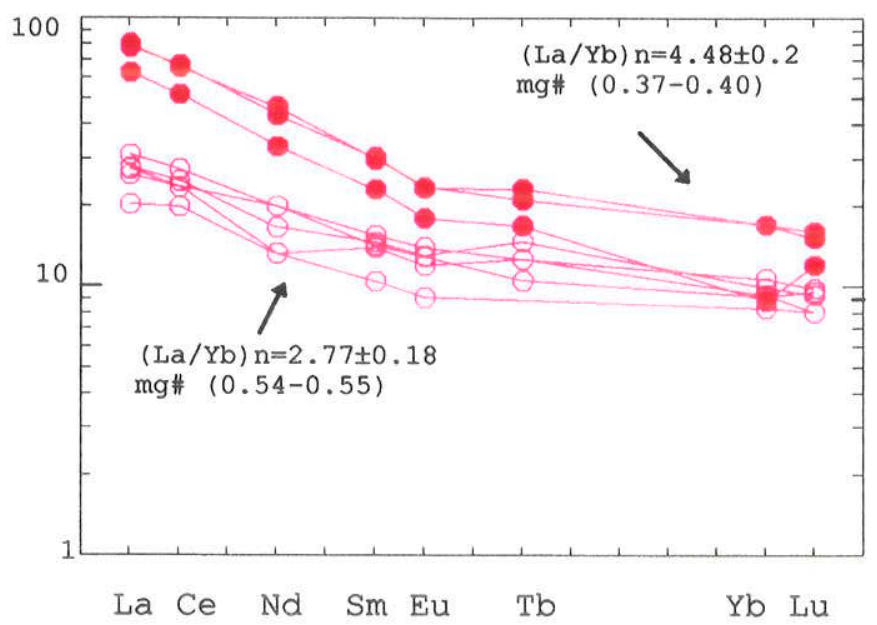

b)
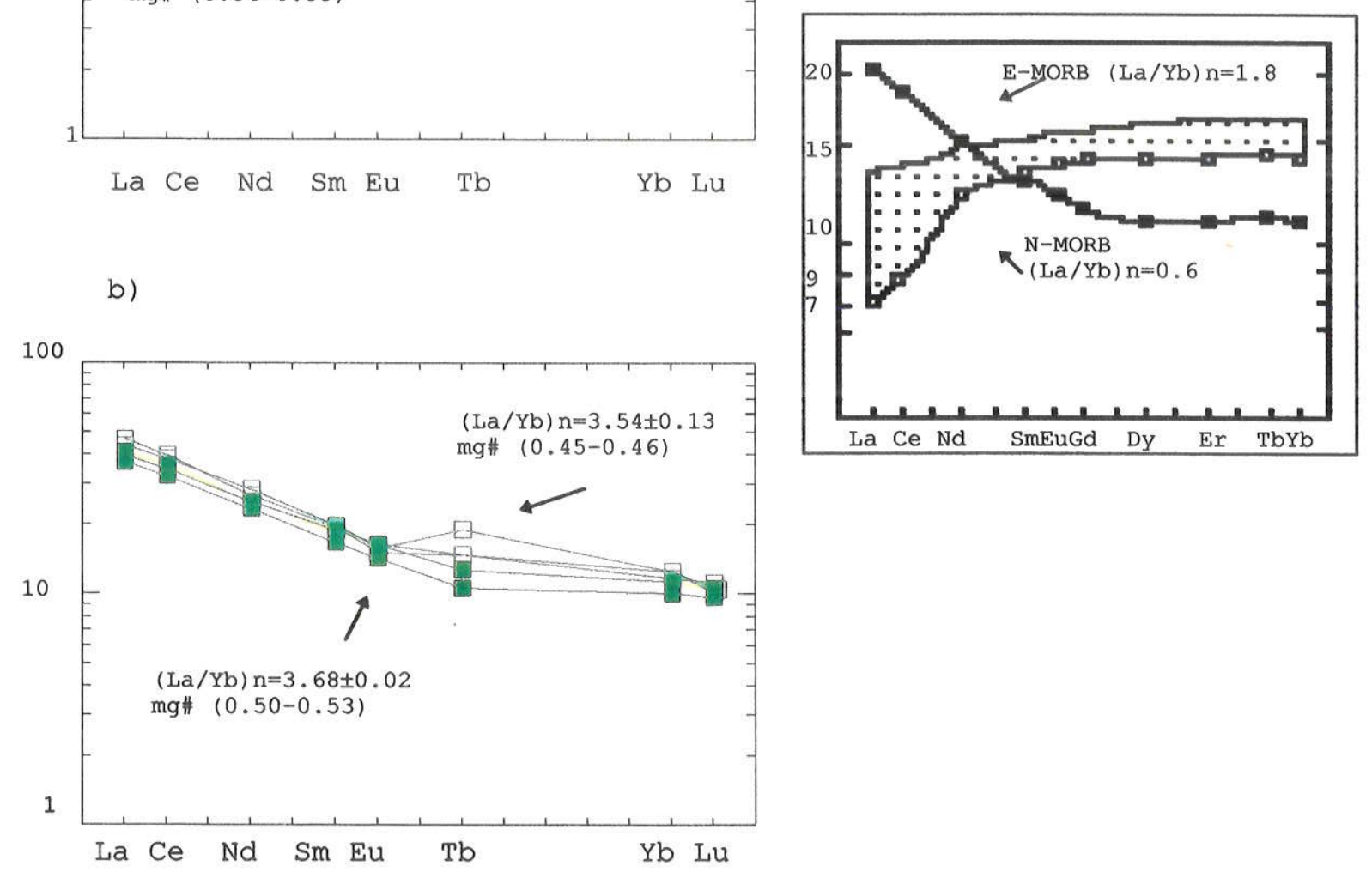

Figura 22- Padrão de distribuição dos elementos terras raras dos DM (a) e DE (b) da Suíte Básica Apoteri normalizados para o condrito de Boynton (1984). Círculos vazios=DM (bth); círculos fechados= DM (ab); quadrado vazio= $\mathrm{DE}(\mathrm{ab})$; quadrado cheio $=\mathrm{DE}(\mathrm{lb})$. A figura inserida no alto do lado direito mostra o modelo do N-MORB e E-MORB para efeito de comparação (Le Roex, 1987). 
De modo geral os padrões de distribuição dos ETR são muito semelhantes entre os DM e DE apresentando ETR (leves) $_{1}$ médio a fortemente enriquecidos em relação aos ETR (intermediário), não ocorrendo variações no enriquecimento de $\mathrm{ETR}_{i}$ em relação $\mathrm{ETR}_{\mathrm{p}}$ (pesadas). Os DM (bth) apresentam padrões de ETR mais empobrecidos em relação aos DM (ab), da mesma forma que OS DE (lb) em relação ao DE (ab), apesar de guardar certo paralelismo entre os conjuntos (DM e DE).

Tanto os DM como os DE possuem padrões médio a fortemente fracionados apresentando valores de ( $\mathrm{La} / \mathrm{Sm})_{\mathrm{n}}$ variando de 1.87-2.71 (média=2.19 \pm 0.36 ), (La/Yb) n de 2.434.68 (média $=3.41 \pm 0.85)$ e $(\mathrm{Sm} / \mathrm{Yb})_{\mathrm{n}}$ de $1.25-1.78$ (média $=1.54$ $\pm 0.16)$ para os DM e para os DE razões (La/Sm) variando de 2.21-2.39 (média $=2.22 \pm 0.09),(\mathrm{La} / \mathrm{Yb})_{\mathrm{n}}$ de $3.48-3.72$ $($ média $=3.64 \pm 0.11)$ e $(\mathrm{Sm} / \mathrm{Yb})_{\mathrm{n}}$ de $1.55-1.66$ (média=1.61 \pm $0.04)$ (Apêndice-3).

Comparando o padrão dos ETR dos DM e DE com o do MORB (Mid-ocean ridge basalts; e.g. Sun \& MCDonough 1989) tipos E (enriched)-MORB e N(normal)-MORB (Le Roex, 1987), inseridos na figura-22, observa-se que tanto os DM como os DE assemelham-se com $\circ$ padrão E-MORB, possuindo no entanto, razões $(\mathrm{La} / \mathrm{Yb})_{\mathrm{n}}$ mais enriquecidas lex.: $(\mathrm{La} / \mathrm{Yb})_{\mathrm{n}}$ : $\mathrm{DM}=3.41 \pm$ $0.85, D E=3.60 \pm 0.11$ versus $E-M O R B=1.8]$. Por outro lado, observa-se que os DM e DE apresentam para algumas razões de elementos incompativeis, importantes diferenças, como por exemplo: $\mathrm{Zr} / \mathrm{Nb}: \mathrm{DM}=18 \pm 4, \mathrm{DE}=21 \pm 9$ versus $\mathrm{E}-\mathrm{MORB}=9$; $\mathrm{K} / \mathrm{Rb}: \mathrm{DM}=249 \pm 38, \mathrm{DE}=120 \pm 43$ versus $\mathrm{E}-\mathrm{MORB}=417 ; \mathrm{Ba} / \mathrm{La}$ : $\mathrm{DM}=17 \pm 3, \mathrm{DE}=19 \pm 8$ versus $\mathrm{E}-\mathrm{MORB}=9$.

A figura-23 mostra o "spidergram" de elementos incompatíveis para OS DM e DE normalizados para O manto primitivo de Sun \& McDonough (1989). Observa-se nesta figura tanto para os $\mathrm{DM}$ como para os $\mathrm{DE}$ um enriquecimento de $\mathrm{Rb}$ em relação ao $\mathrm{K}$ e $\mathrm{Ba}$ (K/Rb: $\mathrm{DM}=153-332, \mathrm{DE}=67-175 ; \quad(\mathrm{Rb} / \mathrm{Ba})_{\mathrm{n}}$ : $\mathrm{DM}=0.44-2.31, \mathrm{DE}=2.42-3.74)$ e nestes elementos em relação $a$ todos os outros. Eles possuem altas razões $\mathrm{Rb} / \mathrm{Sr}$ ( $\mathrm{DM}=0.03-$ $0.31, \mathrm{DE}=0.11-0.32)$, são empobrecidos em $\mathrm{Nb}$ ( $\mathrm{Ba} / \mathrm{Nb}: \mathrm{DM}=16-$ 94, $\mathrm{DE}=14-50 ;(\mathrm{La} / \mathrm{Nb})_{\mathrm{n}}: \mathrm{DM}=1.00-2.77, \mathrm{DE}=1.12-4.25 ; \mathrm{Zr} / \mathrm{Nb}:$ $\mathrm{DM}=13-30, \mathrm{DE}=14-45 ; \mathrm{Ti} / \mathrm{Zr}: \mathrm{DM}=37-59, \mathrm{DE}=42-49)$ e em relação ao fracionamento de plagioclásio possuem anomalias de Eu negativa (Eu/Eu*: $D M=0.65-0.78 ; D E=0.61-0.78$ ), $\circ$ que sugere um fracionamento sob condições de $f_{02}$ relativamente alta (Drake, 1975). 
(a)

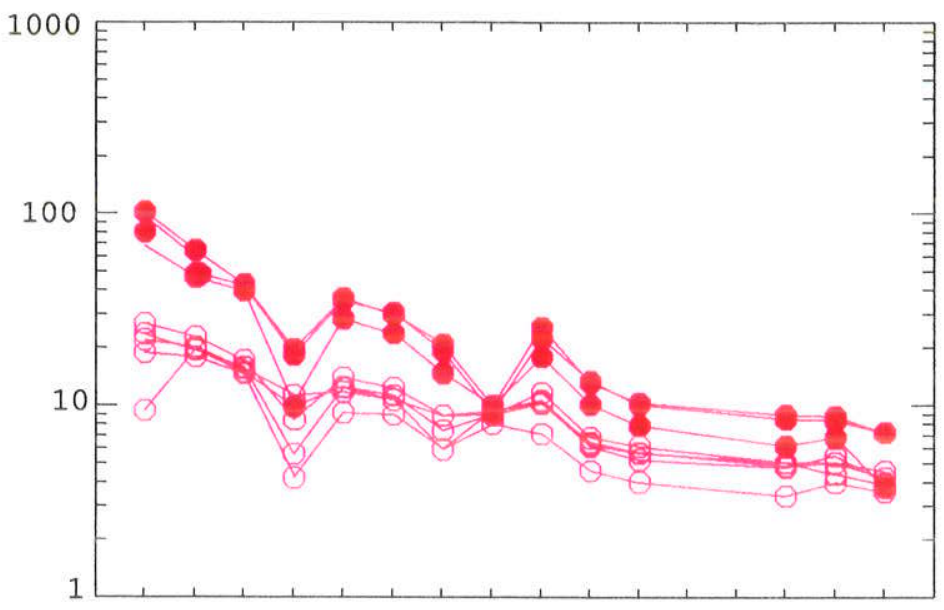

Rb Ba K NbLaCeNdSrZrSmEuGdDyTi Y Yb

(b)

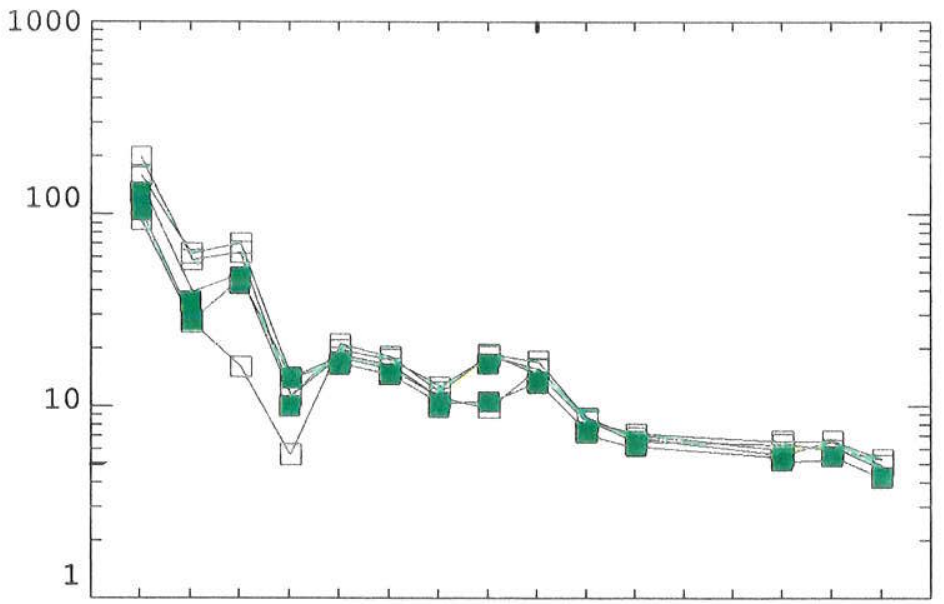

$\mathrm{Rb} \mathrm{Ba} K$ Nb La Ce Nd Sr Zr Sm Eu Gd Dy Ti Y Yb

Figura 23- Padrões de distribuição de elementos incompatíveis normalizados para o manto primitivo de Sun \& McDonough (1989) para os DM (a) e DE (b) da Suíte Básica Apoteri. Acima do lado direito mostra o padrão da média dos E-MORB, N-MORB e OIB (Sun \& McDonough, 1989), para efeito de comparação. 
Comparando o padrão de elementos incompatíveis dos DM e DE COm O N-MORB, E-MORB e OIB (Sun \& MCDonough, 1989), inseridos na figura-22, observa-se que as rochas estudadas assemelham-se com o padrão E-MORB, diferenciando-se deste pela presença de anomalia negativa de $\mathrm{Nb} e$ por apresentar para os elementos LILE (elementos litófilos com ions de grande tamanhol e ETR teores um pouco mais enriquecidos.

Em sintese, os diagramas de variação tomando como índice magmático o mg\# valores, revelaram para os elementos maiores e traços comportamentos semelhantes para os $D M$ e $D E$, ou seja um aumento de $\mathrm{SiO}_{2}, \mathrm{FeO}_{\mathrm{t}}, \mathrm{TiO}_{2}, \mathrm{P}_{2} \mathrm{O}_{5}$ e dos elementos incompatíveis e uma diminuição de $\mathrm{CaO}, \mathrm{Al}_{2} \mathrm{O}_{3}, \mathrm{NaO}, \mathrm{K}_{2} \mathrm{O}, \mathrm{Cr}, \mathrm{Ni}$ e Sc com o avanço da cristalização, sendo que para os $D E$ ocorre teores mais elevados $\mathrm{Na}, \mathrm{K}$ e $\mathrm{H}_{2} \mathrm{O}$ provavelmente associado ao desenvolvimento de estágios tardios de zeólitas hidrotermais nestas rochas. Observa-se ainda concentrações elevadas em relação aos elementos LILE ( $\mathrm{K}, \mathrm{Ba}$ e $\mathrm{Rb}$ ) e baixas dos elementos HFS (elementos de alta densidade de carga) (Nb e Til dos DM e DE para algumas amostras.

o comportamento dos elementos maiores e traços revelam, a priori, que os $D M$ e DE evoluiram possivelmente de uma assembléia do tipo gabro, onde o clinopiroxênio e plagioclásio foram fases minerais importantes no fracionamento.

A grande variação do número mg\# tanto para os DM $10.37-$ $0.57)$ Como para os DE (0.45-0.53) nos leva a sugerir que as rochas não foram formadas por líquidos primários, e que portanto representam magmas mais evoluídos.

Os padrões de distribuição de ETR são semelhantes para os $\mathrm{DM} e \mathrm{DE}$, apresentando-se médio a fortemente fracionados e enriquecidos em ETR $\mathrm{ET}_{1}$ en relação aos ETR, guardando um certo paralelismo entre as curvas.

Os padrões de elementos incompativeis tanto para os DM como para OS $\mathrm{DE}$ mostrou que o $\mathrm{Rb}$ é mais rico em relação ao $\mathrm{K}$ e $\mathrm{Ba} e$ nestes elementos em relação a todos os outros incompatíveis. Possuem altas razões $\mathrm{Rb} / \mathrm{Sr}$ e são fortemente empobrecidos em $\mathrm{Nb}$.

Em geral, os DM e DE mostram padrões semelhantes aos EMORB, possuindo no entanto valores para os elementos LILE e $E^{T} R_{1}$ um pouco mais enriquecidos. 


\subsection{GROCRONOLOGIA}

\subsubsection{ACERVO GBOCRONOLÓGICO}

O acervo geocronológico disponível para o magmatismo básico fanerozóico do Craton Amazônico ( $\mathrm{CA}$ ) é constituído exclusivamente de idades obtidas pelo método K-Ar (e.g. Priem, 1968; Snelling \& McConnell, 1969; Amaral, 1970; Thomaz Filho et al., 1974; Teixeira, 1978; Sial et al., 1987). Vale destacar que todas as idades obtidas para a Suite Básica Apoteri, antes do ano de 1978, foram recalculadas com as novas constantes, comforme proposição de Dalrymple (1979) .

Regionalmente, o padrão de distribuição das idades $\mathrm{K}-\mathrm{Ar}$ para o magmatismo básico fanerozóico do $C A$, obtidos principalmente no sistema rocha total e plagioclásio, revela valores variando desde o início do Paleozóico ( $\approx 570$ Ma) até o final do Mesozóico ( $\approx 65 \mathrm{Ma})$. Neste contexto, são identificados dois ciclos vulcânicos principais: i) com idades no permoTriássico entre 250-200 Ma e, ii) no Juro-Cretáceo cujas idades variam entre 200-125 Ma. A formação do primeiro ciclo vulcânico é relacionada a abertura do oceano Atlântico Norte (separação da América do Norte do conjunto África-América do Sul) enquanto que - segundo ciclo de vulcanismo é vinculado ao processo de abertura do oceano Atlântico sul (Africa da América do Sul) (Thomaz Filho et al., 1974; Teixeira, 1978, Teixeira, 1980).

No Brasil estes dois ciclos vulcânicos apresentam ampla distribuição na região Amazônica, tendo seus exemplos mais notáveis representados pelos diques e "sills" da foz do rio Mapuera no estado do Amazonas e os enxames de diques máficos de Cassiporé no estado do Amapá e a Suíte Básica Apoteri no estado de Roraima.

- conjunto de dados geocronológicos disponíveis para a Suíte Básica Apoteri (diques e derrames basálticos) (Tabela-19) no Brasil (Amaral et al., 1970; Amaral, 1974; Mandetta, 1970; Thomaz Filho et al., 1974), na Guiana (Barron, 1966; Snelling \& McConnel1, 1969; Berrangé, 1973; Berrangé \& Dearnley, 1975), no Suriname (Priem, 1970; Priem et al., 1973; Groenewege \& Bosma, 1970), na Venezuela (Bellizzia, 1972) e na Guiana Francesa (Priem et al., 1968; Teixeira et al., 1985) revela uma distribuição de idades $\mathrm{K}$-Ar variando desde 0 início do Paleozóico ( $\approx 375 \mathrm{Ma}$ - Devoniano Médio) até o final do Mesozóico ( $\approx 116 \mathrm{Ma}$ - Cretáceo Inferior). 
Segundo Berrangé \& Dearnley (1975) os diques máficos possuem diferentes picos de idades $\mathrm{K}$-Ar nos vários países onde eles ocorrem, a saber: Permo-Triássico $(\approx 227$ Ma) no Suriname, Triássico Inferior $(\approx 220 \mathrm{Ma})$ na Guiana e Triássico superior $(\approx 195$ Ma) na Venezuela. Estes mesmos autores advogam a hipótese de que a fase de distensão inicial no desenvolvimento do graben do Takutu (Figura-4) seria representada pela intrusão dos diques máficos, sendo seguida por uma segunda fase, com a formação de falhas profundas com consequente subsidência e formação do graben do Takutu. Nesta segunda fase teria ocorrido a extrusão das lavas basálticas entre Jurássico Inferior e Médio (entre 190-160 Ma atrás). Finalmente, estas lavas vulcânicas teriam sido recobertas pela Eormação Tacutu durante o Cretáceo Inferior.

Os dados isotópicos K-Ar para os diques máficos revelam idades variáveis conforme pode ser observado na tabela-19. Na figura-24 é apresentada a frequencia da distribuição das idades $\mathrm{K}-\mathrm{Ar}$ para os diques máficos no tempo geológico. Neste diagrama observa-se a presença de dois grupos principais de idades, 0 primeiro com valores variando entre $379-363 \mathrm{Ma}(4,5$ 웅 das análises), enquanto que o grupo mais jovem e mais expressivos $(95,58$ das análises) apresenta idades entre 248-130 Ma.

Com respeito ao agrupamento de idades mais antigas, é provável que estes valores estejam representando processos de incorporação de argônio radiogênico a estes diques durante suas intrusões na crosta continental. A incorporação de argônio radiogênico, especialmente vinculados ao sistema rocha total e plagioclásio nestes diques máficos foi originalmente apontada por Montalvão et al. (1975). De outra parte, fenômenos de incorporação de argônio radiogênico associado a diques máficos tem sido observados em outros enxames de diques do Brasil (e.g. Teixeira et al., 1988; Bastos Leal, 1992). Por outro lado, a avaliação dos resultados para o segundo grupo, revela um pico de idade entre 196 e $211 \mathrm{Ma}$, tendo a idade média neste intervalo de $204 \pm 6 \mathrm{Ma}$. Esta idade média pode ser admitida preliminarmente como representante da época de intrusão destes diques na crosta continental, no Jurássico Inferior. 


\begin{tabular}{|c|c|c|c|c|c|c|c|c|}
\hline No. CAMPO & N LAB. & ROCHA & MATERIAL & $8 K$ & $\mathrm{Ar} \mathrm{r}^{0} \mathrm{rad}$ & Ar. atm & $\begin{array}{l}\text { IDADE } \\
\text { tERRO } \\
\text { (M.a.) }\end{array}$ & $\begin{array}{c}\text { REFEREN } \\
\text { - CIA }\end{array}$ \\
\hline
\end{tabular}

A) DERRAMES BASÁLTICOS

BRASII

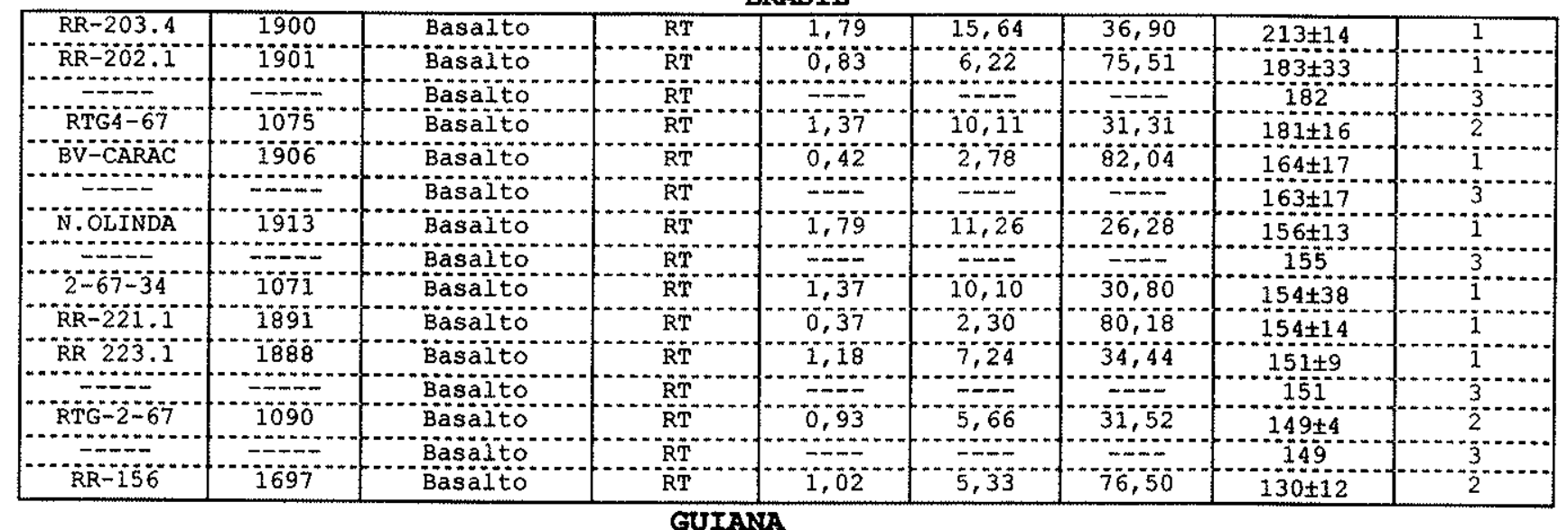

\begin{tabular}{|c|c|c|c|c|c|c|c|c|}
\hline JPB-34 & $-m---$ & Basalto & $\mathrm{RT}$ & 0,61 & 5,10 & $-\cdots$ & $116 \pm 3$ & $\overline{3}$ \\
\hline $7 P B-570^{\circ}$ & $\ldots$ & Bäailto & RT & 0,456 & 3,88 & 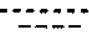 & $118 \pm 4$ & -3 \\
\hline$J 2 B-310^{\circ}$ & בים & $\begin{array}{l}\text { Basaito } \\
\text { Basalto } \\
\text { Basal to }\end{array}$ & $\begin{array}{l}\mathrm{RT} \\
\mathrm{RT} \\
\mathrm{RT}\end{array}$ & $\begin{array}{l}0,958 \\
0,958 \\
0,958\end{array}$ & $\begin{array}{l}8,86 \\
8,94 \\
9,10\end{array}$ & - & $\begin{array}{l}129 \pm 4 \\
130 \pm 4 \\
132 \pm 4\end{array}$ & $\begin{array}{l}3 \\
3 \\
3\end{array}$ \\
\hline $\mathrm{JPB}-322$ & ans & $\begin{array}{l}\text { Basalto } \\
\text { Basalto }\end{array}$ & $\begin{array}{l}\mathrm{RT} \\
\mathrm{RT}\end{array}$ & $\begin{array}{l}0,970^{\circ} \\
0,970\end{array}$ & $\begin{array}{l}11,10 \\
11,50\end{array}$ & $-\cdots$ & $\begin{array}{l}157 \pm 4 \\
163 \pm 5\end{array}$ & 3 \\
\hline$\triangle \mathrm{JPB}-95^{-1}$ & 等 & $\begin{array}{l}\text { Basaito } \\
\text { Basalto }\end{array}$ & $\begin{array}{l}\mathrm{RT}^{\mathrm{RT}} \\
\mathrm{RT}\end{array}$ & $\begin{array}{l}1,100^{\circ} \\
1,100 \\
\end{array}$ & $\begin{array}{l}13,30^{\circ} \\
14,60 \\
\end{array}$ & 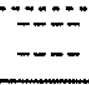 & $\begin{array}{l}167 \pm 5 \\
182 \pm 5 \\
\end{array}$ & $\begin{array}{r}7 \\
3 \\
3\end{array}$ \\
\hline
\end{tabular}

B) DIQUES MÁIICOS

BRASIL

\begin{tabular}{|c|c|c|c|c|c|c|c|c|}
\hline$R R-143$ & 1698 & Diabásio & $R T$ & 0.495 & 0.818 & 24.42 & 270000 & \\
\hline$R R-226$ & $1885^{\circ}$ & Diäbäsio & RT & 0,351 & 0,549 & 68,71 & $363 \pm 32$ & $i$ \\
\hline $\mathrm{RR}=203.4$ & $1895^{\circ}$ & Gäbro & $\overline{\mathrm{RT}}$ & 0,602 & 0,510 & 56,68 & $205 \pm 18$ & 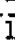 \\
\hline $2-67-34$ & $1071^{\circ}$ & oiabásio & " & 1,367 & 1,0098 & $30,80^{\circ}$ & $155 \pm 38$ & 4 \\
\hline $2-67=2$ & $1090^{\circ}$ & Diabásióo & $\mathrm{RT}$ & 0,9329 & 0,5665 & 31,46 & $150 \pm 38$ & 4 \\
\hline $\mathrm{RR}=76$ & $1697^{-1}$ & Diabásio & $\mathrm{RT}$ & 1,018 & 0,533 & $76,50^{\circ}$ & $130 \pm 19$ & 4 \\
\hline \multicolumn{9}{|c|}{ GUIANA } \\
\hline JPB-68 & 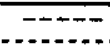 & Diabásio & $\mathrm{RT}$ & $\cdots$ & & & $208 \pm 6$ & 5 \\
\hline$J P B-77$ & 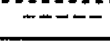 & Diabäsio & $\mathrm{RT}$ & & 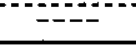 & $\cdots$ & $196 \pm 6$ & $\ddot{4}$ \\
\hline
\end{tabular}

Tabela 19- Tabela geocronojógica $\mathrm{K}-\mathrm{Ar}$ para as rochas da Suite Básica Apoteri (derrames basálticos e diques máficos) do Brasil, Guiana, Guiana Francesa, Suriname e Venezuela. (RT)=rocha total; (PLA)=plagioclásio. Idades recalculadas conforme Dalrymple (1979) com base nas seguintes constantes (IUGS): $\quad{ }^{40} \mathrm{~K} / \mathrm{K}=1,167 \times 10^{-4} \mathrm{~mol} / \mathrm{mol} ; \quad \lambda \beta=4.962 \times 10^{-10} \mathrm{yr}^{-1}$; $\lambda \varepsilon+\lambda^{\prime} \varepsilon=0.581 \times 10^{-10} \mathrm{yr}^{-1} .1=$ Mancietta $(1970) ; 2=$ Amaral (1974); $3=$ Berrangé \& Dearnley (1975); $4=$ Tomaz Filho et al., (1974); 5= Snelling \& McConnell (1969); 6= Teixeira et al. (1984); 7= Teixeira et al. (1985); 8= Priem et a. (1968); 9= Priem et $\equiv 1$. (1973); 10= Priem et al. (1971); 11= Bellizzia (1972). 


\begin{tabular}{|c|c|c|c|c|c|c|c|c|}
\hline $\mathbf{N}^{\circ} \cdot$ CAMPO & $\mathrm{N}^{0} \mathrm{LAB}$ & ROCHA & MATERIAL & $8 \mathrm{~K}$ & $\mathrm{Ar}{ }^{40} \mathrm{rad}$ & $A x^{40} a t m$ & $\begin{array}{l}\text { IDADE } \\
\text { 土ERRO } \\
\text { (M.a.) }\end{array}$ & $\begin{array}{l}\text { REFERÂN } \\
\text {-CIA }\end{array}$ \\
\hline \multicolumn{9}{|c|}{ GUIANA FRANCESA } \\
\hline$G E-49 C(64)$ & 5528 & Dolerito & RT & 0,232 & 2,38 & $-\cdots$ & $248 \pm 21$ & 7 \\
\hline$G \bar{E}-21(57)$ & 5215 & Dolerito & $\mathrm{PLA}$ & 0,693 & 6,51 & - n & $227 \pm 7$ & 6 \\
\hline$G E-3(44)$ & 3166 & Dolerito & $\mathrm{RT}$ & 0,420 & 3,96 & (n) & $223 \pm 12$ & 6 \\
\hline 67 Sur $31(57)$ & 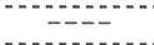 & Dolerito & $\mathrm{PLA}$ & 0,577 & 9,33 & 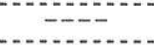 & $216 \pm 6$ & 8 \\
\hline $\mathrm{GE}-1(42)$ & 5218 & Dolerito & PLA & 0,576 & 4,98 & 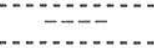 & $210 \pm 6$ & 6 \\
\hline $\mathrm{GE}-1(42)$ & 5218 & Dolerito & PIA & 0,576 & 4,98 & & $210 \pm 6$ & 6 \\
\hline $\mathrm{GF}-38(60)$ & $5226^{-1}$ & Dolerito & $\mathrm{RT}^{-}$ & $1,009^{-1}$ & 7,81 & (n) & $189 \pm 12$ & 7 \\
\hline \multicolumn{9}{|c|}{ SURINAME } \\
\hline 67SUR19 & --- & Dolerito & $\begin{array}{l}\text { RT } \\
\text { RT } \\
\text { RT }\end{array}$ & $\begin{array}{l}0,403 \\
0,404 \\
-\end{array}$ & $\begin{array}{l}6,86 \\
7,54 \\
7,18\end{array}$ & $\begin{array}{l}36,1 \\
44,7 \\
72,7\end{array}$ & $242 \pm 12$ & 9 \\
\hline 67SUR23 & & $\begin{array}{c}\text { Dolerito (R.' } \\
\text { Suriname) }\end{array}$ & $\begin{array}{l}\mathrm{RT} \\
\mathrm{RT} \\
\mathrm{RT}\end{array}$ & $\begin{array}{l}0,585^{-} \\
0,577 \\
-\end{array}$ & $\begin{array}{c}8,53 \\
10,98 \\
9,96\end{array}$ & $\begin{array}{l}40,6 \\
82,0 \\
58,0\end{array}$ & $233 \pm 15$ & $\overline{9}$ \\
\hline 67 SUR24 & -- & $\begin{array}{l}\text { Dolerito } \\
\text { (R.Brown } \\
\text { Swer) }\end{array}$ & $\begin{array}{l}\mathrm{RT} \\
\mathrm{RT}\end{array}$ & $\begin{array}{l}0,399 \\
0,400\end{array}$ & $\begin{array}{l}6,54 \\
6,64\end{array}$ & $\begin{array}{l}51,6 \\
70,8\end{array}$ & $224 \pm 10$ & $\overline{9}$ \\
\hline 67SUR31 & -1 & $\begin{array}{l}\text { Dolerito } \\
\text { (R.Marowijne) }\end{array}$ & RT & $\begin{array}{r}0,577 \\
0,576 \\
\end{array}$ & $\begin{array}{l}9,33 \\
9,30\end{array}$ & $\begin{array}{l}44,1 \\
53,1\end{array}$ & $221 \pm 6$ & $\overline{9}$ \\
\hline 67 SUR22 & & $\begin{array}{c}\text { Dolerito } \\
\text { (R.Kabalebo) }\end{array}$ & $\begin{array}{l}\mathrm{RT} \\
\mathrm{RT}\end{array}$ & $\begin{array}{l}0,502 \\
0,504\end{array}$ & $\begin{array}{l}7,75 \\
7,68\end{array}$ & $\begin{array}{l}60,8 \\
63,4\end{array}$ & $211 \pm 10$ & $\overline{9}$ \\
\hline 69 SUR40 & $=$ & $\begin{array}{l}\text { Dolerito } \\
\text { (R.Corantijn) }\end{array}$ & $\mathrm{RT}$ & - & 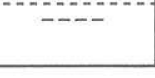 & - & 182 & 10 \\
\hline \multicolumn{9}{|c|}{ VENEZUELA } \\
\hline$-\cdots-$ & $-\cdots-$ & Diabásio & RT & $-\cdots$ & $-\cdots$ & $-\cdots$ & ---- & 11 \\
\hline
\end{tabular}

Tabela 19- Continuação

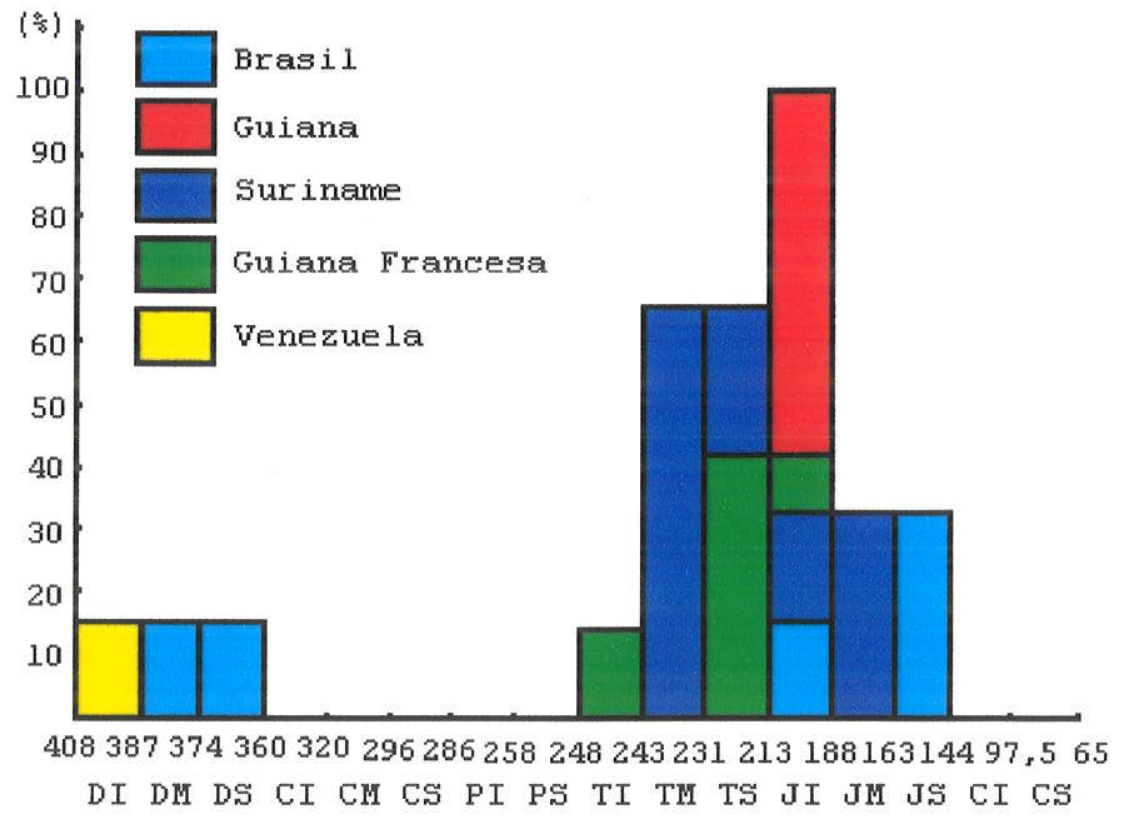

PALEOzóICO

MESOzórco

Figura 24- Diagrama de frequência de distribuição das idades K-Ar individualizadas no tempo geológico para os diques máficos da suite Básica Apoteri no Escudo das Guianas. (Subdivisão do tempo geológico segundo Harland et al., 1982) 
No caso dos derrames basálticos, o conjunto de dados geocronológicas K-Ar apresenta menor intervalo de variação de idades quando comparado com aqueles dos diques máficos (Tabela19). Na figura-25 é apresentada a frequência de distribuição de idades $\mathrm{K}$-Ar no tempo geológico para os derrames basálticos. Neste diagrama, observa-se uma variação de idades entre 213-116 Ma com pico entre 163-149 Ma e idade média neste último intervalo de $154 \pm 15 \mathrm{Ma}$. Esta idade média pode ser admitida, preliminarmente, como representante da idade mínima de formação destas rochas basálticas, durante o Jurássico superior, em conformidade com as interpretações originais de diversos autores (ex: Berrangé \& Dearnley, 1975; Thomaz Filho et al., 1974; Teixeira, 1980).

Cabe destacar adicionalmente, que apesar de possuir um quadro geocronológico K-Ar bem estabelecido, face a eficácea desta metodologia na definição da cronologia de eventos magmáticos mesozóicos (ex: bacia do Paraná), dados isotópicos por outras metodologias (ex: ${ }^{40} \mathrm{Ar}-{ }^{39} \mathrm{Ar}$ e Rb-Sr) são necessários para se demarcar com maior precisão a época de formação deste magmatismo mesozóico. Deste modo, os resultados $\mathrm{Rb}-\mathrm{Sr}$ e $\mathrm{Sm}-\mathrm{Nd}$ obtidos neste trabalho e apresentados a seguir, constituem uma contribuição para o melhor entendimento da época dos processos de fraturamento continental que atuaram no craton Amazônico durante o Fanerozóico. Estes dados isotópicos contribuem também para o conhecimento das variações composicionais do manto subcontinental da plataforma sulamericana ao longo do tempo geológico.

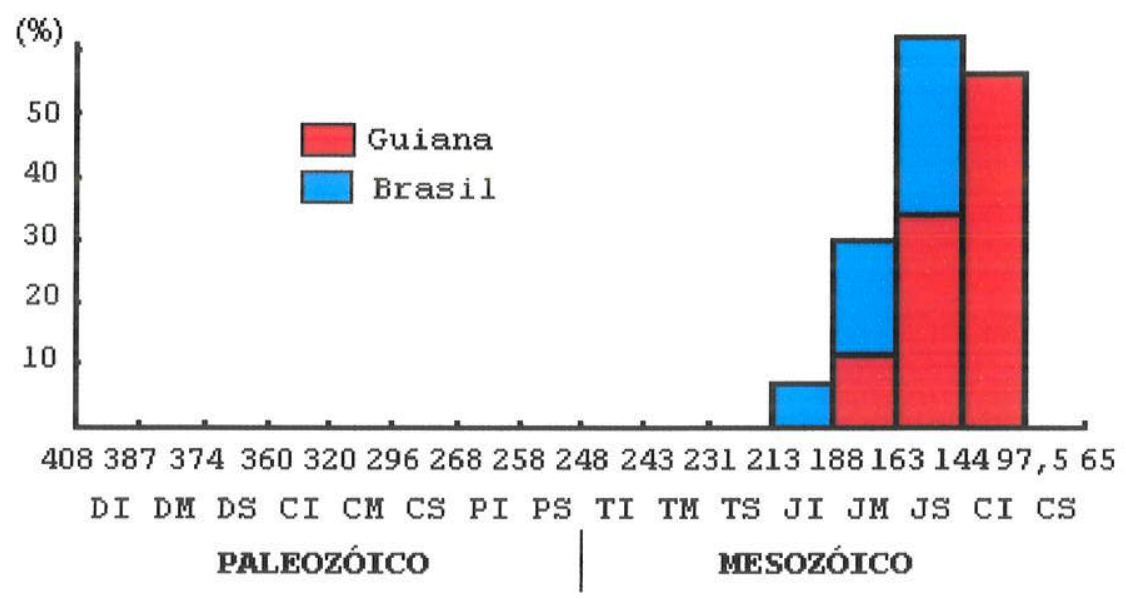

Figura 25- Diagrama de distribuição de frequência das idades K-Ar no tempo geológico para os derrames basálticos da suite Básica Apoteri no Brasil e Guiana. (Subdivisão do tempo geológico segundo Harland et al., 1982). 
As amostras selecionadas para os estudos isotópicos $\mathrm{Rb}-\mathrm{Sr}$ e Sm-Nd realizados nesta pesquisa, passaram por rigorosa avaliação petrográfica e geoquímica, afim de se garantir uma interpretação confiável dos resultados obtidos. Para os diques máficos foram selecionadas amostras completamente isentas de alteração intempérica, enquanto que no caso dos derrames basálticos, por apresentarem reduzido número de amostras isentas de processos de alteração intempérica, foram analisadas algumas amostras com presença de processos de saussuritização e sericitização (aostras RR-02A, RR-02B e RR-39).

\subsubsection{RESULTADOS Rb-ST}

Foram selecionadas 07 amostras dos DM (diques máficos) e 07 amostras do DE (derrames basálticos) para execução de análises isotópicas $\mathrm{Rb}-\mathrm{Sr}$, conforme procedimento descrito no capítulo-2. Os resultados analiticos são apresentados na tabela-20.

\begin{tabular}{|c|c|c|c|c|c|c|}
\hline $\begin{array}{l}\text { AMOSTRA/ } \\
N^{\circ} \text { CPGeO }\end{array}$ & $\mathrm{Rb}$ (ppon) & Sx (ppen) & ${ }^{7} \mathrm{Rb} /{ }^{86} \mathrm{Sr}$ & Exro & ${ }^{87} \mathrm{Sx} /{ }^{86} \mathrm{Sr}$ & Erro $(2 \sigma)$ \\
\hline \multicolumn{7}{|c|}{ DIQUES MÁFICOS } \\
\hline RR-01A/13426 & 16,9 & 95.6 & 0.2504 & & 0,709320 & 0,000070 \\
\hline$R R=164$ & 499 & & 0,7810 & & $0,723180^{\circ}$ & 0100 \\
\hline $\mathrm{RR}-28713424$ & 42,5 & 20 & 0.5958 & & $0,719680^{\circ}$ & 0050 \\
\hline $\mathrm{RR}-31 \mathrm{~B} / 1285$ & 27,1 & 262,6 & 0,2984 & & $0,708230^{\circ}$ & 0,000100 \\
\hline $\mathrm{RR}-35 \mathrm{C} / 12859$ & 63,7 & 205,9 & 0.8960 & 0,0250 & $0,710260^{\circ}$ & $0,000330^{\circ}$ \\
\hline $\mathrm{RR}-36 \mathrm{~A} / 12856$ & 11,8 & 183,4 & 0,1854 & 0,0029 & 0,706580 & 0,000150 \\
\hline
\end{tabular}

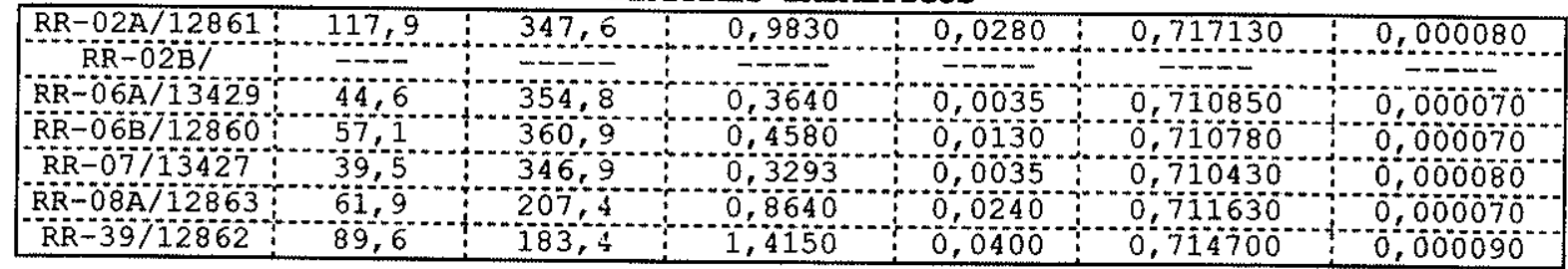

Tabela 20- Dados analíticos Rb-Sr dos diques máficos e derrames basálticos da Suite Básica Apoteri. Dados obtidos por diluição isotópica (para Rb menor que $50 \mathrm{ppm}$ ) e fluorescência de Raios-X.

\subsubsection{Diques máficos}

Os dados Rb-Sr obtidos para os diques máficos produziram uma exrócrona com 04 pontos e idade de $311 \pm 40 \mathrm{Ma}(1 \sigma)$, tendo razão inicial ${ }^{87} \mathrm{Sr} /{ }^{86} \mathrm{Sr}\left(\mathrm{S} \mathrm{r}_{i}\right)$ igual a $0,70695 \pm 0,00018$ (MSWD=76,0) (Figura-26). O alto valor do MSWD se deve à grande dispersão dos pontos em relação a reta obtida, sugerindo a presença de distúrbios isotópicos do sistema Rb-Sr. Cabe destacar que as 
amostras RR-16 e RR-28 não foram consideradas no cálculo da idade ora apresentada. Estes distúrbios isotópicos podem estar vinculados a fenômenos de interação do magma básico com as rochas encaixantes (fenômenos de contaminação crustal).

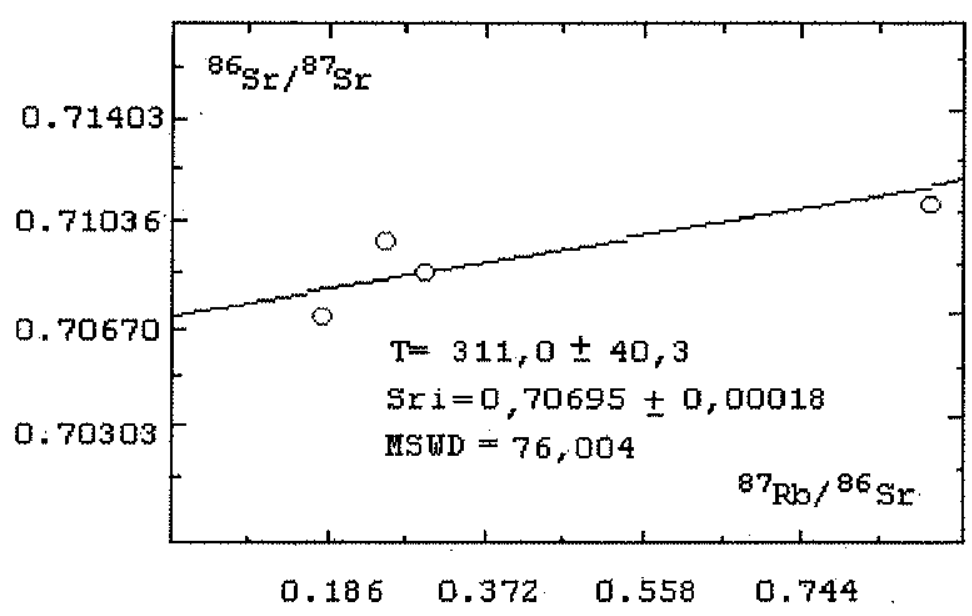

Figura 26- Diagrama "isocrônico" Rb-Sr dos diques máficos da Suíte Básica Apoteri.

Quando. se confronta a idade Rb-Sr apresentada na figura-26, com o padrão de idades K-Ar, apresentado anteriormente, observase que a idade $\mathrm{Rb}-\mathrm{Sr}$ é cerca de $100 \mathrm{Ma}$ mais antiga que o pico médio das idades $\mathrm{K}-\mathrm{Ar}$ (com idade de cerca de $200 \mathrm{Ma}$ ). Os distúrbios isotópicos $\mathrm{Rb}-\mathrm{Sr}$ observados nas amostras analisadas, aliado ao pequeno número de pontos usados no diagrama $\mathrm{Rb}-\mathrm{Sr}$ (praticamente 2 pontos alinhados), e devido a boa definição da idade média obtida pelo histograma $K$-Ar e com valor em torno de $200 \mathrm{Ma}$ para este enxame de diques, admite-se, neste momento, que esta idade média representa com maior precisão, a época de intrusão destes diques na crosta continental, a cerca de $200 \mathrm{Ma}$ atrás, no Jurássico Inferior.

\subsubsection{Derrames basálticos}

No caso dos derrames basálticos, os dados Rb-Sr produziram uma isócrona com idade de $136 \pm 13 \mathrm{Ma}(1 \sigma)$, e razão inicial ${ }^{87} \mathrm{Sr} /{ }^{86} \mathrm{Sr}\left(\mathrm{Sr} r_{i}\right)$ igual a $0,70996 \pm 0,00010 \quad(\mathrm{MSWD}=6,0) \quad$ (Figura-27). Neste caso, ao contrário dos diques máficos, o baixo valor do MSWD aponta o bom alinhamento entre os 04 pontos utilizados na definição da idade. Cabe acrescentar, que as amostras que não foram utilizadas no cálculo da idade (RR-02A, RR-02B e RR-39) por não se alinharem segundo a isócrona obtida, são aquelas que 
apresentam maior grau de saussuritização e sericitização dos plagioclásios.

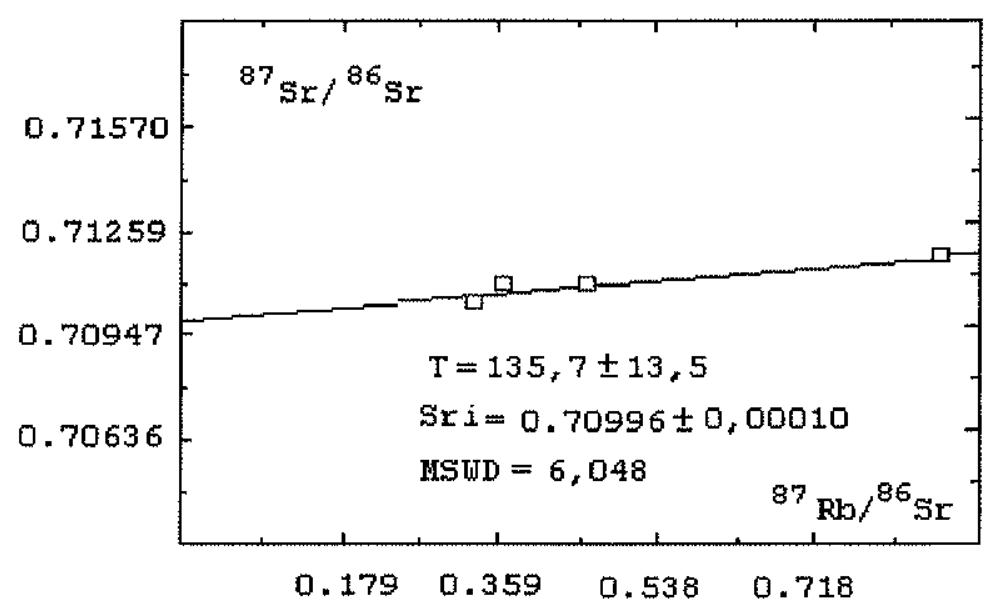

Figura 27- Diagrama isocrônico Rb-Sr para os derrames basálticos da Suíte Básica Apoteri.

A comparação da idade obtida pelo método $\mathrm{Rb}-\mathrm{Sr}$ ( $\approx 136 \mathrm{Ma}$ ) com o conjunto de idades $K-A r$, cujo pico de idade é de aproximadamente $150 \mathrm{Ma}$, sugere a presença de fenômenos de incorporação de argônio radiogênico de rochas mais antigas, durante a formação destes derrames basálticos.

O conjunto de dados isotópicos ora apresentados sugerem que os derrames basálticos da Suíte Básica Apoteri foram formados a cerca de 136 Ma atrás, durante o Cretáceo Inferior, conforme apontam os dados isotópicos Rb-Sr.

\subsubsection{RESULTADOS $S m-N d$}

Foram selecionadas 07 amostras dos diques máficos e 07 dos derrames basálticos para execução das análises isotópicas Sm-Na. Os resultados analíticos são apresentados na tabela-21. Os resultados obtidos não possibilitaram a definição de diagramas isocrônicos e foram utilizados no ítem da geoquímica isotópica, conforme apresentado a seguir. 


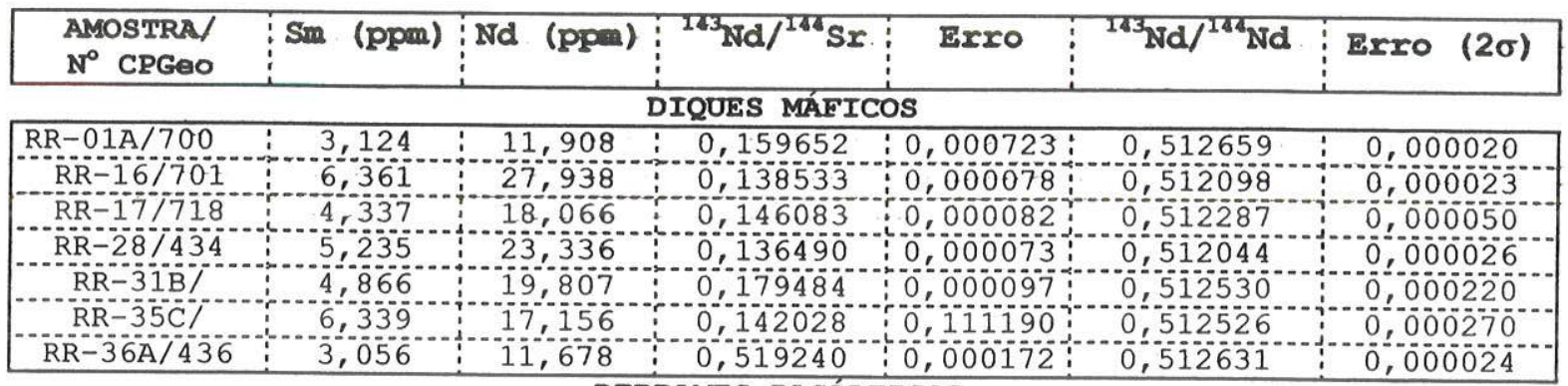

\section{DERRAMES BASÁITICOS}

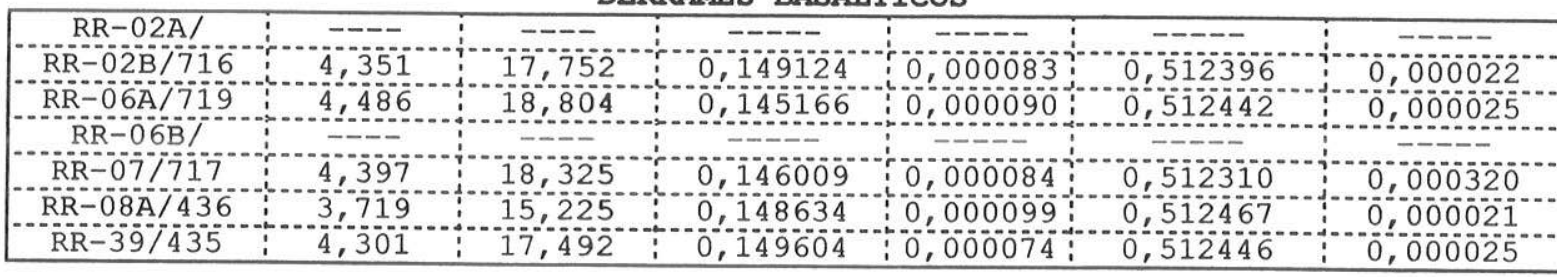

Tabela 21- Dados analíticos Sm-Nd obtidos por diluição isotópica para os diques máficos e derrames basálticos da Suíte Básica Apoteri.

\subsection{GEOQUÍMICA ISOTÓPICA}

A geoquímica isotópica ( $\mathrm{Sr}, \mathrm{Nd}$ e $\mathrm{Pb}$ ) é uma importante ferramenta para caracterizar com maior precisão as características químicas das fontes mantélicas. A importância da caracterização isotópica em estudos petrogenéticos, está na resistência dos isótopos ao fracionamento químico, com consequente representação da evolução magmática de uma suite de rochas, preservando assim, as características originais do magmatismo (Cox et al., 1979).

A partir dos valores das idades obtidas no ítem anterior, para os diques e derrames basálticos da Suíte Básica Apoteri, foram calculadas as razões iniciais de ${ }^{87} \mathrm{Sr} /{ }^{86} \mathrm{Sr}\left(\mathrm{Sr}\right.$ ) e ${ }^{143} \mathrm{Nd} /{ }^{144} \mathrm{Nd}$ $\left(\mathrm{Nd}_{i}\right)$ e valores de $\boldsymbol{\varepsilon}_{\mathrm{Sr}}$ e $\boldsymbol{\varepsilon}_{\mathrm{Nd}}$ de cada amostra analisada na época de formação destas rochas. Estes valores encontram-se listados na tabela-22. 


\begin{tabular}{|c|c|c|c|c|c|}
\hline AMOSTRA & $\mathrm{Rb} / \mathrm{Sr}$ & $\mathrm{Sm} / \mathrm{Nd}$ & 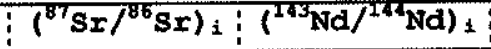 & $\varepsilon_{\mathrm{gx}}$ & $\varepsilon_{\mathrm{Nd}}$ \\
\hline \multicolumn{6}{|c|}{ ZUES MÁFICOS } \\
\hline $\mathrm{RR}=01 \mathrm{~A}$ & 0,09 & 0,26 & 0,51233 & $+63,47$ & $+1,35$ \\
\hline$R R=16$ & 0,27 & 0,23 & 0,72096 & $+237,00$ & 06 \\
\hline $\mathrm{RR}=17$ & & 0,24 & 0,53210 & & 56 \\
\hline$R R=28$ & 0,21 & 0,22 & 0.71886 & $+207,13$ & $-10,06$ \\
\hline $\mathrm{RR}=31 \mathrm{~B}$ & 0.10 & 0,24 & 0,70738 & $+44,21$ & 0,90 \\
\hline$R$ & $0,3 i$ & 0,23 & 0,51234 & $\begin{array}{l}-19 \\
+48,90 \\
+\end{array}$ & 0,79 \\
\hline $\mathrm{RR}=36 \mathrm{~A}$ & 0,06 & $0,26^{6}$ & 0,51242 & $+25,34$ & $+0,82$ \\
\hline
\end{tabular}

DERRAMES BASÁLTICOS

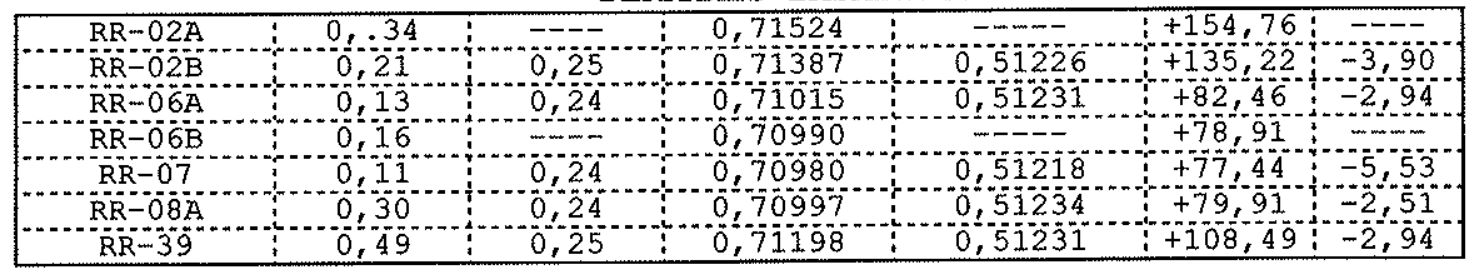

Tabela $22-$ Razões $\mathrm{Rb} / \mathrm{Sr}$ e $\mathrm{Sm} / \mathrm{Nd}$, razões iniciais ${ }^{87} \mathrm{Sr} /{ }^{86} \mathrm{Sr}$ e ${ }^{143} \mathrm{Nd} /{ }^{144} \mathrm{Nd}$ e valores de $\boldsymbol{\varepsilon}_{\mathrm{sx}}$ e $\boldsymbol{\varepsilon}_{\mathrm{Nd}}$ dos diques máficos (recalculados para a idade de to=204Ma) e derrames basálticos (recalculados para a idade de to=136Ma) da Suíte Básica Apoteri.

\subsubsection{Diques máficos}

No diagrama que representa a evolução isotópica de Sr de acordo com o modelo do Reservatório Uniforme (UR) ou "Terra Global" (Figura-28a), se observa que os DM apresentam ampla variação nos seus valores de razão inicial [ $\left(S r_{i}\right)=0,70605-$ 0,$\left.\left.72096 ; t_{0}=204 \mathrm{Ma}\right)\right]$. Neste caso, todas amostras posicionam acima da linha evolutiva da "Terra Global" e apresentam valores de $\boldsymbol{\varepsilon}_{\mathbf{S r}}$ muito variáveis $\left[\varepsilon_{\mathrm{Sr}}=\left(+25,34-+237,00 ; t_{\mathrm{O}}=204 \mathrm{Ma}\right)\right](\mathrm{Tabela}-22)$. Tal comportamento, sugere uma fonte enriquecida na razão Rb/Sr para estes diques e/ou que a participação de fenômenos de contaminação crustal durante a sua intrusão na crosta continental. 


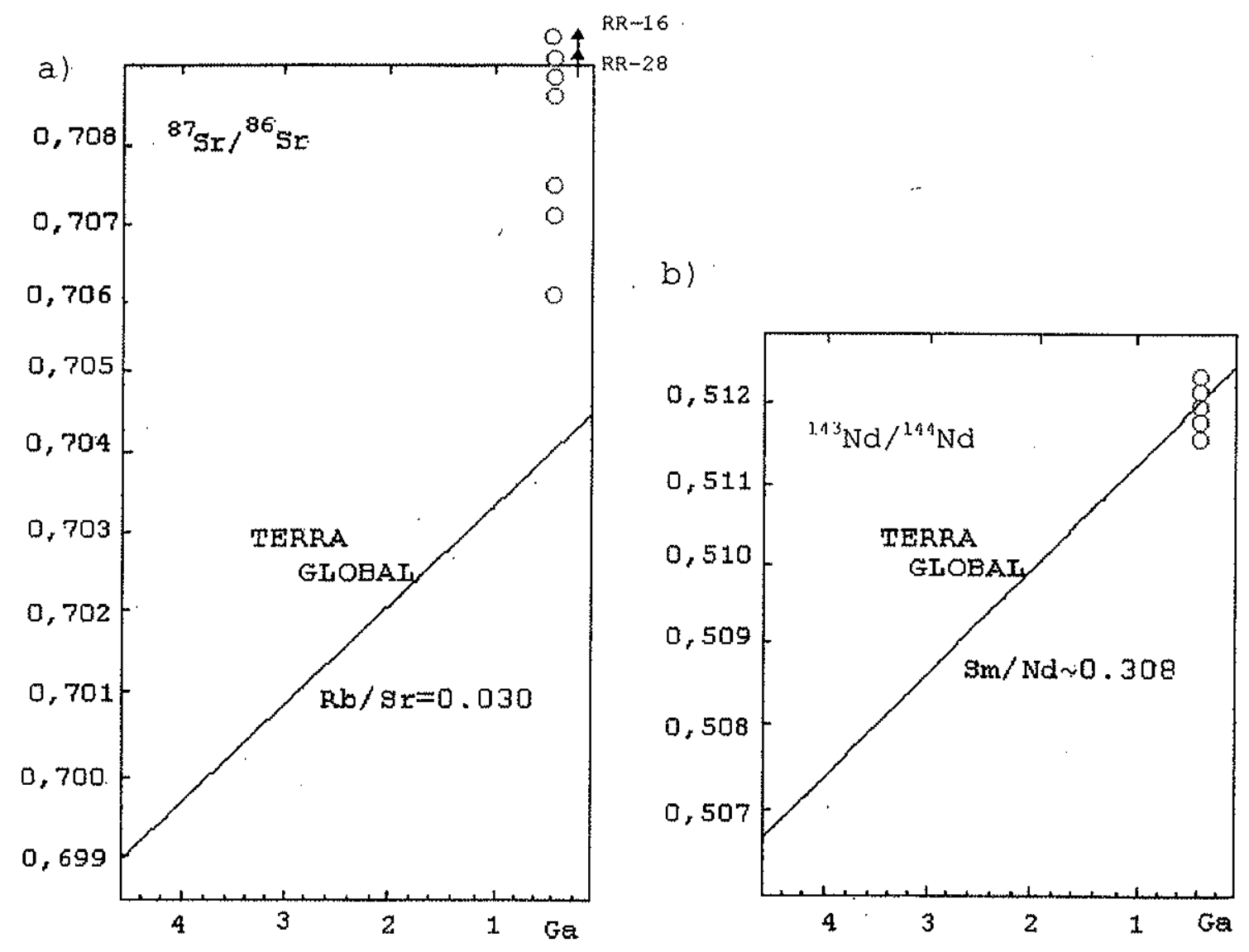

Eigura 28- Diagrama de evolução isotópica do $\mathrm{Sr}\left({ }^{87} \mathrm{Sr} /{ }^{86} \mathrm{Sr}\right.$ inicial) e $\mathrm{Nd}\left({ }^{143} \mathrm{Nd} /{ }^{144} \mathrm{Nd}\right.$ inicial) no tempo geológico para os diques máficos da Suíte Básica Apoteri. ${ }^{87} \mathrm{Sr} /{ }^{86} \mathrm{Sr}$ primordial=0,69898; ${ }^{87} \mathrm{Sr} /{ }^{86} \mathrm{Sr}$ atual $=0,7045$ (Faure, 1986).

No tocante aos isótopos de Nd (Figura-28b), verifica-se que os DM apresentam estreita variação na razão inicial Ndi $\left[N d i=\left(0,51187-0,51242 \quad\left(t_{0}=204 \mathrm{Ma}\right)\right]\right.$, com valores de $\varepsilon_{\mathrm{Nd}}$ variando entre $\left[\varepsilon_{\mathrm{Nd}}=(+1,35\right.$ a $\left.\left.-10,06) ; t_{0}=204 \mathrm{Ma}\right)\right\}(\mathrm{Tabela}-22)$. Observa-se que as amostras estudadas posicionam-se acima (RR-01A e RR-36A), abaixo (RR-16 e RR-28) ou sobre a linha evolutiva da "Terra Global" (RR-17), sugerindo portanto, uma fonte levemente enriquecida e/ou empobrecida nas razões $\mathrm{Sm} / \mathrm{Nd}$.

No diagrama $\varepsilon_{S \mathrm{~V}} \mathrm{Vs} \varepsilon_{\mathrm{Nd}}$ (Figura-29) as amostras dos diques máficos se posicionam predominantemente no campo enriquecido (campos II e IV), apontando assim que estas rochas derivaram de uma fonte enriquecida em comparação a "Terra Global". 


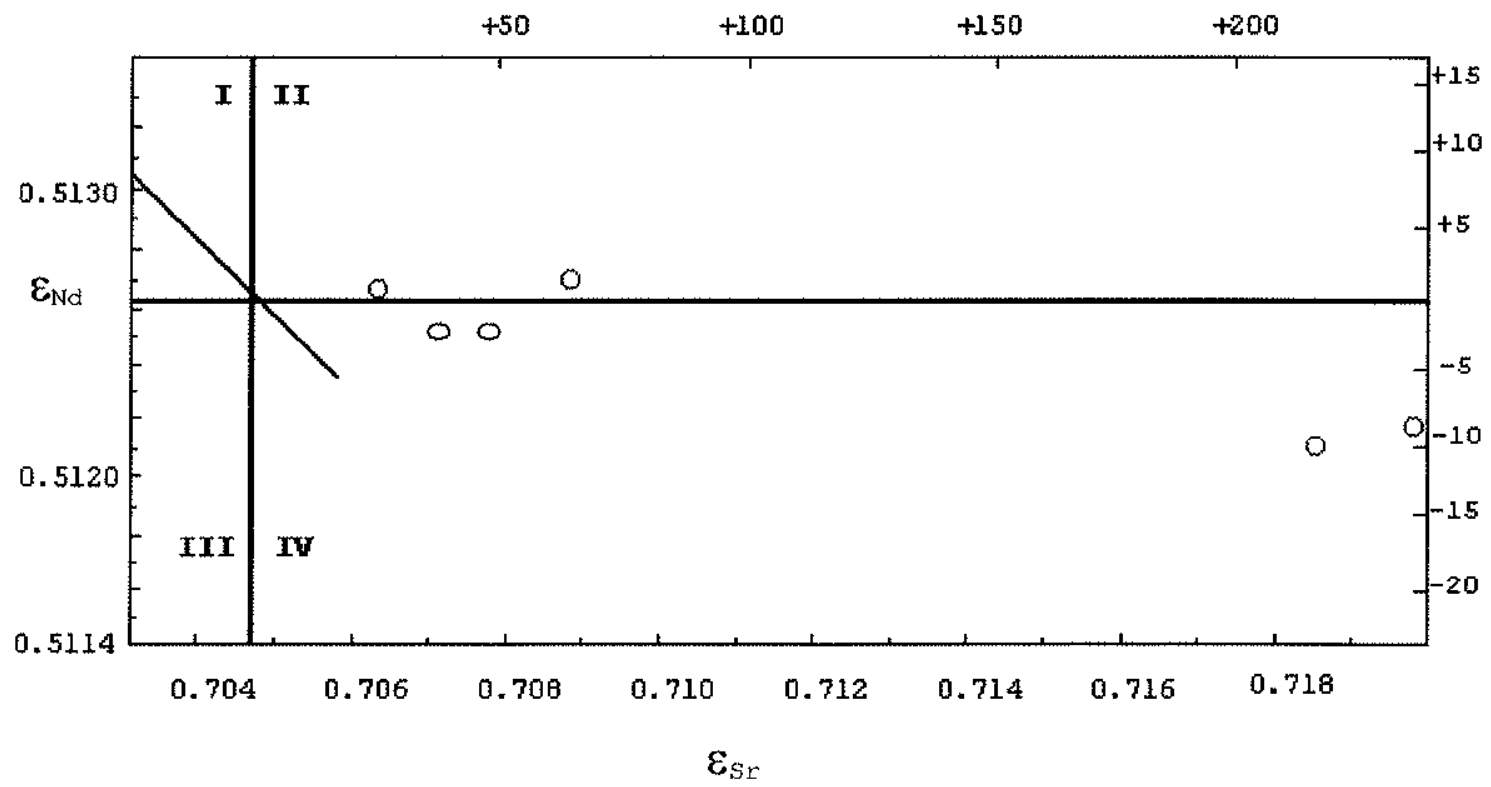

Eigura 29 Diagrama $\varepsilon_{S x} V s \varepsilon_{N d}$ com valores recalculados para to=204Ma representativos dos diques máficos da Suíte Básica Apoteri. Os valores atuais da "Terra Global": ${ }^{87} \mathrm{Sr} /{ }^{86} \mathrm{Sr}=0,7045$ e ${ }^{143} \mathrm{Nd} /{ }^{144} \mathrm{Nd}=0,512638$ (Faure, 1986).

\subsubsection{Derrames Basálticos}

Os derrames basálticos apresentam amplo intervalo de variação nas razões $S r_{i}\left[S r_{1}=10,70980\right.$ e 0,71524 ( $\left.\left.t_{0}=136 \mathrm{Ma}\right)\right]$ com valores de $\varepsilon_{\text {Sr }}$ entre $+77,44$ e 154,76 (Tabela-22). No diagrama da figura-30a é apresentado a evolução do $S r_{i}$ com o tempo onde se observa que todas as amostras posicionam-se acima da linha evolutiva da "Terra Global", sugerindo fonte enriquecida na razão $\mathrm{Rb} / \mathrm{Sr}$ e/ou a presença de fenômenos de contaminação crustal associado a estas rochas.

No diagrama de evolução de $\mathrm{Nd}_{i}$ com o tempo (Figura-30b), se observa que os DE posicionam-se sobre a linha de evolução da "Terra Global". Os valores de $\mathrm{Nd}_{\mathrm{i}}$ variam entre $\left[\mathrm{Nd}_{\mathrm{i}}=(0,51218-\right.$ $\left.0,51234\left(t_{\mathrm{O}}=136 \mathrm{Ma}\right)\right] \mathrm{com}$ valores de $\boldsymbol{\varepsilon}_{\mathrm{Nd}} \quad\left[\boldsymbol{\varepsilon}_{\mathrm{Nd}}=(-2,51\right.$ a $-5,53$; (to $=136 \mathrm{Ma})]$. 
a)

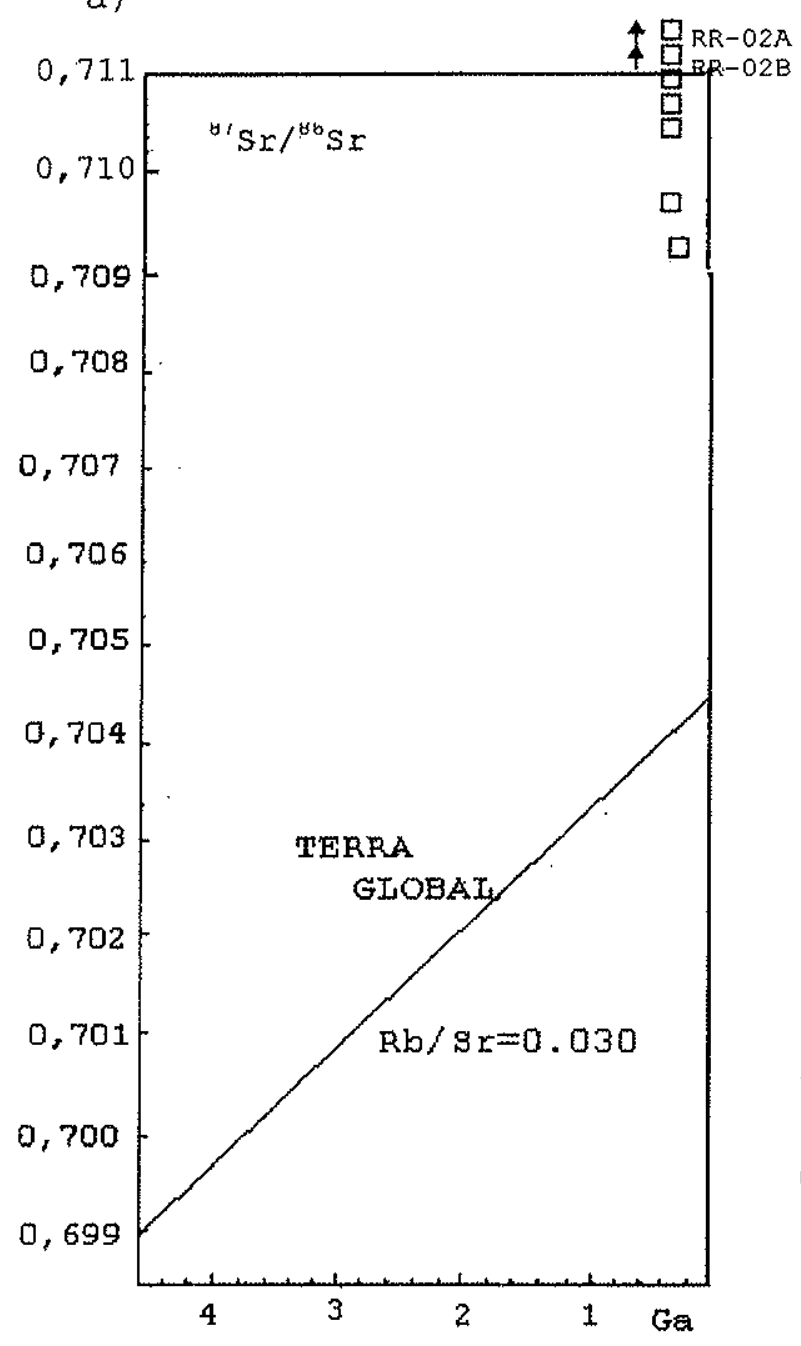

b)

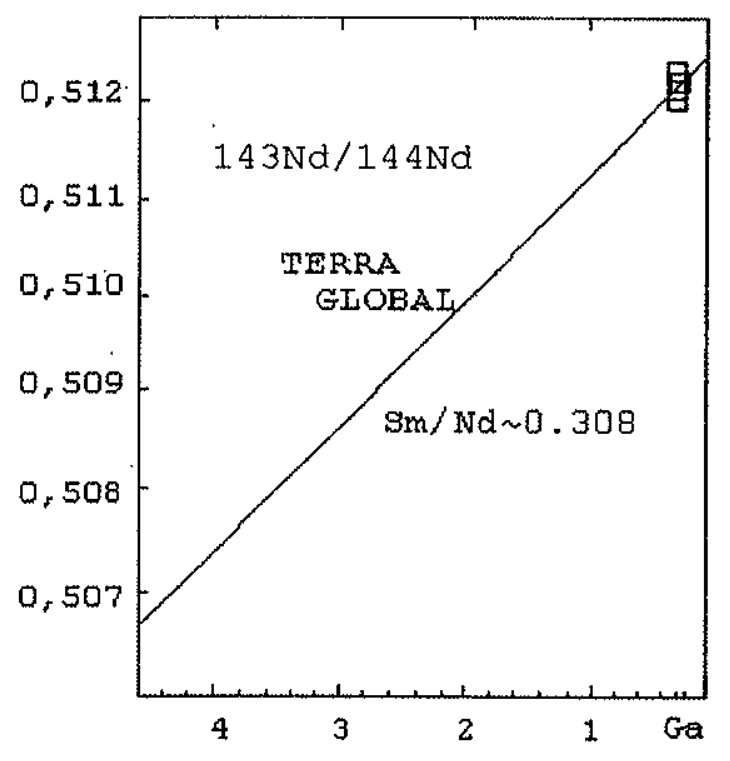

Figura 30-Diagrama de evolução isotópica do $\operatorname{Sr}\left({ }^{87} \mathrm{Sr} /{ }^{86} \mathrm{Sr}\right.$ inicial) e $\mathrm{Nd}\left({ }^{143} \mathrm{Nd} /{ }^{144} \mathrm{Nd}\right.$ inicail) no tempo geológico para os derrames basálticos da Suíte Básica Apotexi. ${ }^{87} \mathrm{Sr} /{ }^{86} \mathrm{Sr}$ primordial=0,69898; ${ }^{87} \mathrm{Sr} /{ }^{86} \mathrm{Sr}$ atual $=0,7045$ (Eaure, 1986).

No diagrama $\varepsilon_{S r} V s \varepsilon_{N d}$ (Figura-31) para os derrames basálticos, a distribuição dos pontos analíticos, sugere que estas rochas foram originadas a partir de uma fonte enriquecida comparativamente com a "Terra Global" e/ou o envolvimento de processos de contaminação crustal, a exemplo do que foi observado para a evolução isotópica de Sr destas rochas. 


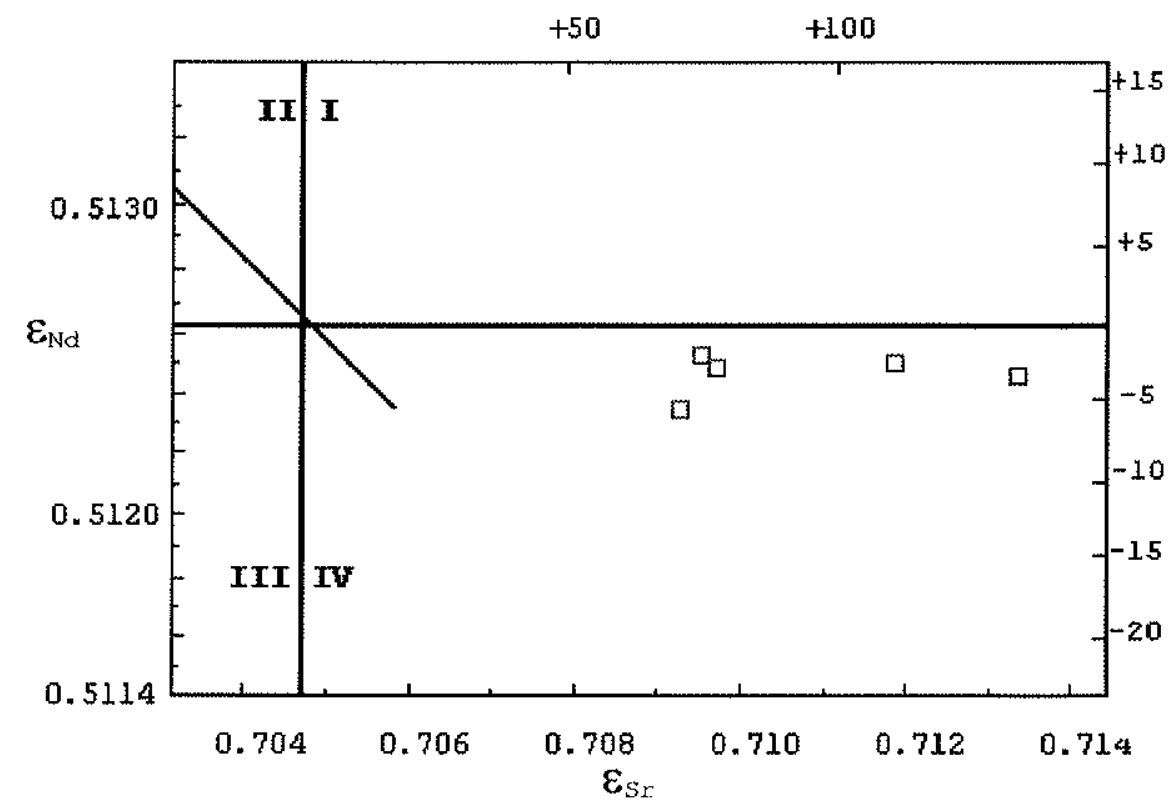

Figura 31 - Diagrama $\boldsymbol{\varepsilon}_{S \mathrm{~V}} \mathrm{~V} \boldsymbol{S} \boldsymbol{\varepsilon}_{\mathrm{Nd}}$ com valores recalculados para idade de $136 \mathrm{Ma}$ representativos dos derrames basálticos da Suíte Básica Apoteri. ${ }^{87} \mathrm{Sr} /{ }^{86} \mathrm{Sr}$ primordial=0,69898; ${ }^{87} \mathrm{Sr} /{ }^{86} \mathrm{Sr}$ atual $=0,7045$ (Faure, 1986). 


\section{CAPÍTULO 9- ASPECTOS PETROGENÉTICOS DO MAGMATISMO BASÁLTICO MESOZÓICO DO ESTADO DE RORAIMA}

O estudo geoquímico apresentado no capítulo-7 demonstrou um enriquecimento em elementos LIL ( $K, \mathrm{Rb}$ e $\mathrm{Ba}$ ) e $\mathrm{ETR}_{1}$ em relação aos elementos HES ( $\mathrm{Zr}, \mathrm{Nb}, \mathrm{Ti}$ ), altas razões $\mathrm{Rb} / \mathrm{Sr}$ ( $\mathrm{DM}=0.03-$ $0.31 ; \mathrm{DE}=0.11-0.32$ ), baixas razões $\mathrm{K} / \mathrm{Rb} \quad(\mathrm{DM}=249 \pm 38 ; \mathrm{DE}=120 \pm$ 43) e anomalias negativas de $\mathrm{Nb}$ ( $\mathrm{Ba} / \mathrm{Nb}: \mathrm{DM}=24 \pm 7, \mathrm{DE}=31 \pm 14$; $\mathrm{La} / \mathrm{Nb}: \mathrm{DM}=1.42 \pm 0.39, \mathrm{DE}=1.26 \pm 0.16)$. Da mesma forma, 0 estudo isotópico (Capitulo-8) demonstrou altas razões iniciais de $\mathrm{Sr}$ radiogênico (DM=0.706-0.721; $\mathrm{DE}=0.709-0.715)$ e baixas razões ${ }^{143} \mathrm{Nd} /{ }^{144} \mathrm{Nd}(\mathrm{DM}=0.5119-0.51224 \mathrm{DE}=0.5122-0.5123)$ para as rochas da Suíte Básica Apoteri.

As características geoquímicas e isotópicas apresentadas para as rochas da Suite Básica Apoteri são típicas de magmas básicos gerados em placas convergentes, associados a fusões da placa subductada contendo componentes sedimentares (e.g. Gill, 1981; Thorpe, 1982; McCulloch \& Gamble, 1991) ou em áreas cratônicas continentais (Ellam \& Cox, 1989; Hergt et al., 1991; Carlson, 1991; Bossi et al., 1993) associadas a:

- Contaminação crustal do magma básico durante a sua passagem para a litosfera (e.g. Brandon et al., 1993);

- Metassomatismo mantélico causado por fluidos introduzidos no manto ou por fusões sub-litosférica (Ellam \& Cox, 1989);

- Interação entre magmas derivados de "plumas" mantélicas com pequenas fusões do manto litosférico continental (Ellam \& Cox, 1989).

As várias hipóteses sugeridas acima para tentar explicar as características "Iitosférica" que estas rochas apresentam mostram que a interpretação de parâmetros geoquímicos e isotópicos, nos quais elas se baseiam, podem a primeira vista, parecer ambíguos ou até mesmo confuso para os diferentes processos, podendo induzir a resultados muito semelhantes ou muitas vezes indistintos. As discussões que seguem, objetivam mostrar o processo que mais se adapta para a geração das rochas da Suite Básica Apoteri.

\section{CONTAMTATaç̃̃o CRUSTAL X METASSOMATISMO MANTŕLICO}

Vários autores têm sugerido que o fenômeno de contaminação crustal possui papel importante na definição das características químicas e isotópicas dos toleítos continentais (DePaolo, 1981; O'Hara \& Mathews, 1981; Duypuy \& Dostal, 1984; Thompson et al., 1984) existindo, em alguns casos, boas evidências para que este 
processo ocorra (Carter et al., 1978; Cox \& Hawkesworth, 1985; Piccirillo et al., 1989). Outros autores acreditam que os dados referenciados na literatura são mais consistentes com a origem puramente mantélica (Hawkesworth \& Vollmer, 1979; Weaver \& Tarney, 1981; Alibert, 1985). Razões La/Nb maiores que 1, por exemplo, tem sido utilizadas como argumento em defesa da contaminação crustal (Thompson et al., 1984), bem como sugerindo a presença de fenômenos de metassomatismo mantélico, devido a presença da fase que reteria na fonte, preferencialmente, Nb (Briqueu et al., 1984).

Entretanto, não há um consenso quanto a ocorrência de processos de contaminação crustal ou metassomatismo mantélico. Entretanto, é provável que a crosta continental foi importante na formação de algumas suítes continentais toleíticas, assim como a origem mantélica associada a influência de componentes ricos em fluidos.

\section{METASSOMATISMO MANHÉLICO}

O enriquecimento do magma básico em elementos LIL associado a uma origem mantélica pode ser explicada pela introdução de fluidos em ambientes relacionados a zonas de subducção, cuja placa subductada é rica em componentes sedimentares, ou relacionada a fusões mantélicas profundas sob a influencia de componentes ricos em fluidos (Gill, 1981; Thorpe, 1982; McCulloch \& Gamble, 1991).

Embora o metassomatismo do manto a partir de fluidos ricos em água seja tipicamente relacionado a desidratação de placas convergentes (Saunders et al., 1980; Gill, 1981; Thorpe, 1982; McCulloch \& Gamble, 1991), características semelhantes as rochas da Suíte Básica Apoteri são bastantes comuns em várias suítes basálticas do Brasil e do mundo (ex.: Sheraton \& Black, 1981; Ellam \& Cox, 1989; Piccirillo et al., 1989; Hergt et al., 1991; Carlson, 1991).

Não existem evidências geológicas sobre ocorrência de subducção contemporânea à formação dos diques máficos e derrames basálticos da Suite Básica Apoteri. Por outro lado, segundo Cordani \& Brito Neves (1982) e Teixeira et al. (1989) o Craton Amazônico alcançou sua estabilidade em tempos Mesoproterozóico, sugerindo assim um ambiente ensiálico para a colocação destas rochas basálticas.

\section{CONTAMINAÇÃO CRUSTAL}

Durante a transferência de fusões mantélicas para a crosta, muita vezes, ocorrem adições ao magma de material crustal circundante ao conduto, seja por assimilação global ou por 
processo de diferenciação. Desta forma, ocorrem alterações no quimismo original do magma. Este processo é facilmente detectado quando analisa-se o comportamento químico dos elementos com alta concentração na crosta (e.g. elementos LILE, Brandon et al., 1993) em relação à concentração destes mesmos elementos nó magma .

Pode-se também avaliar, qualitativamente, a importância do processo de contaminação crustal através de diagramas envolvendo correlações entre um indice de contaminação (razões isotópicas ${ }^{87} \mathrm{Sr} /{ }^{86} \mathrm{Sr}$ e $\left.{ }^{143} \mathrm{Nd} /{ }^{144} \mathrm{Nd}\right)$ e aqueles elementos com alta concentrações na crosta ( $\left.\mathrm{Rb}, \mathrm{Pb}, \mathrm{Th}, \mathrm{Ba}, \mathrm{SiO}_{2} \mathrm{e} \mathrm{K}_{2} \mathrm{O}\right)$ (Menzies \& Kyle, 1990). Utilizando-se este índice de contaminação com um de evolução magmática é possível também caracterizar se as rochas crustais foram assimiladas pelo magma básico durante a sua transferência a crosta.

$\mathrm{Na}$ figura-32 estão apresentados os diagramas entre razão inicial de $\mathrm{Sr}\left[\mathrm{Sri}={ }^{87} \mathrm{Sr} /{ }^{86} \mathrm{Sr}\right)$ i] e $\mathrm{SiO}_{2}, \mathrm{~K}_{2} \mathrm{O}, \mathrm{Ba}, \mathrm{Rb} / \mathrm{Sr}, \mathrm{La} / \mathrm{Yb}$ e 0 mg\# e na figura-33 o diagrama entre a razão inicial de $\mathrm{Nd}$ [Ndi= $\left.\left({ }^{143} \mathrm{Nd} /{ }^{144} \mathrm{Nd}\right) \mathrm{i}\right]$ e $\mathrm{SiO}_{2}, \mathrm{~K}_{2} \mathrm{O}, \mathrm{Ba}, \mathrm{La} / \mathrm{Yb}, \mathrm{Rb} / \mathrm{Sr}$ e mg\# para as rochas da Suite Básica Apoteri. Analisando os diagramas, observa-se que há uma correlação leve a medianamente positiva de Sri com o $\mathrm{SiO}_{2}$, $\mathrm{K}_{2} \mathrm{O}, \mathrm{Ba}, \mathrm{Rb} / \mathrm{Sr}$ e $\mathrm{La} / \mathrm{Yb}$ e negativa com o mg\# tanto para os diques máficos (DM) como para os derrames basálticos (DE) e, entre o Ndi uma correlação negativa com $\mathrm{SiO}_{2}, \mathrm{~K}_{2} \mathrm{O}, \mathrm{Ba}, \mathrm{La} / \mathrm{Yb}, \mathrm{Rb} / \mathrm{Sr}$ e positiva com mg\#.

- comportamento dos elementos com os valores de Sri e Ndi (Figuras-32 e 33) é compativel com a assimilação de materiais crustais pelo magma, uma vez que estas amostras estão dentro de um mesmo intervalo de evolução magmática.

Logo, é sugerido, a priori, que a contaminação crustal assumiu um papel importante na definição das caracteristicas químicas e isotópicas das rochas da Suite Básica Apoteri. Tal contaminação se deu possivelmente de forma diferenciada nos DM, pois existem dentro do conjunto dos DM amostras com diferentes concentrações de $\mathrm{Ba}, \mathrm{Rb} e \mathrm{~K}$, acompanhadas por razões iniciais ${ }^{87} \mathrm{Sr} /{ }^{86} \mathrm{Sr}$ relativamente altas. Por outro lado, existem amostras dos diques máficos que são incompatíveis com tal processo, pois apresentam baixos conteúdos de elementos LILE, tendo ainda registro de corpos com margens de congelamento "chilled margin" (dique RR-18), as quais, segundo Campbel (1980), protegem o magma da erosão termal da encaixante dificultando consequentemente $\circ$ processo de contaminação. 

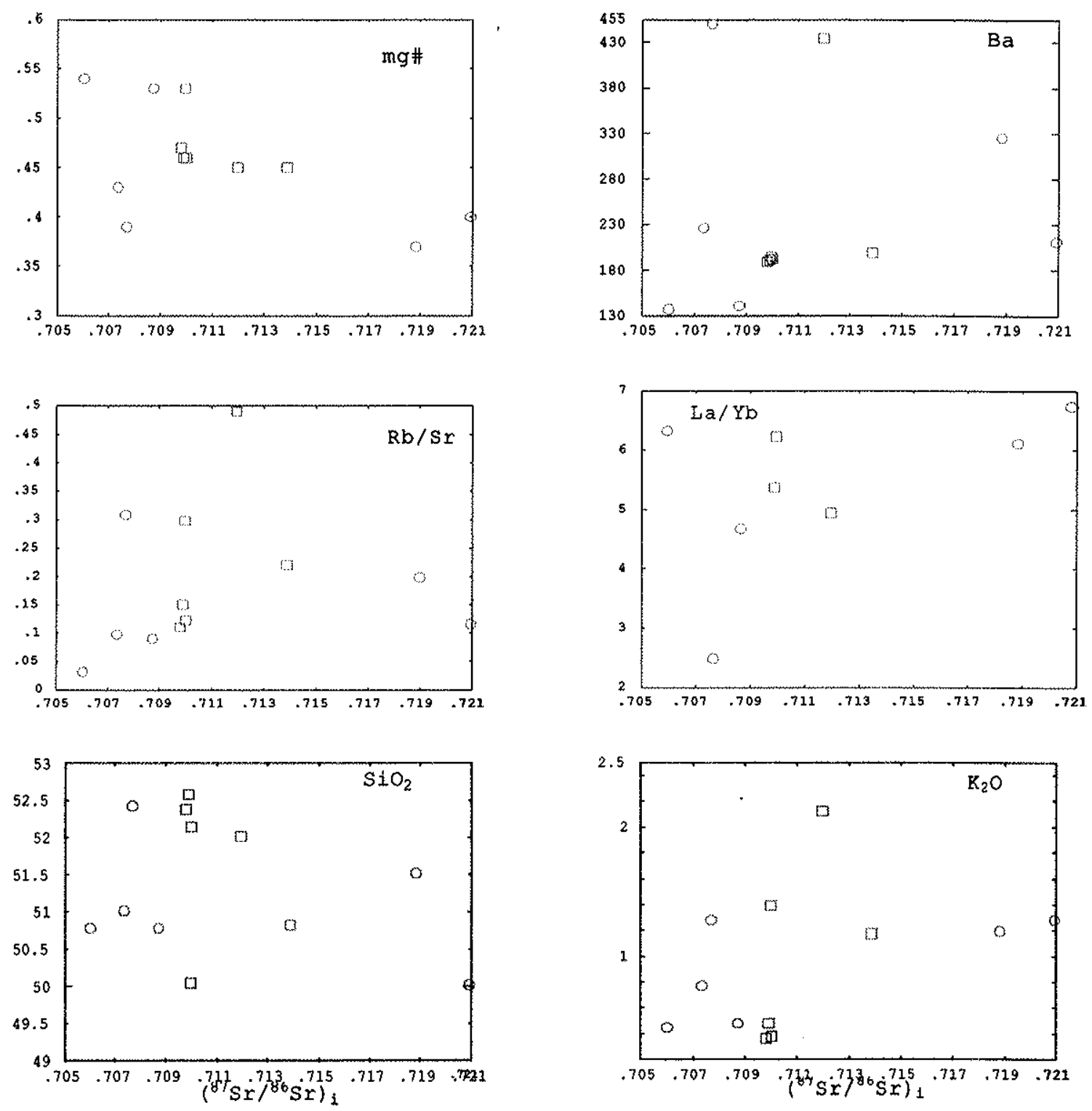

Figura 32- Diagrama de correlação entre $\left({ }^{87} \mathrm{Sr} /{ }^{86} \mathrm{Sr}\right)_{i}$ e $\mathrm{SiO}_{2}, \mathrm{~K}_{2} \mathrm{O}$, $\mathrm{Rb} / \mathrm{Sr}$, La/Yb,e mg\# para os diques máficos (204Ma) e derrames basálticos (136 Ma) da Suíte Básica Apoteri. Símbolos como na figura5 . 

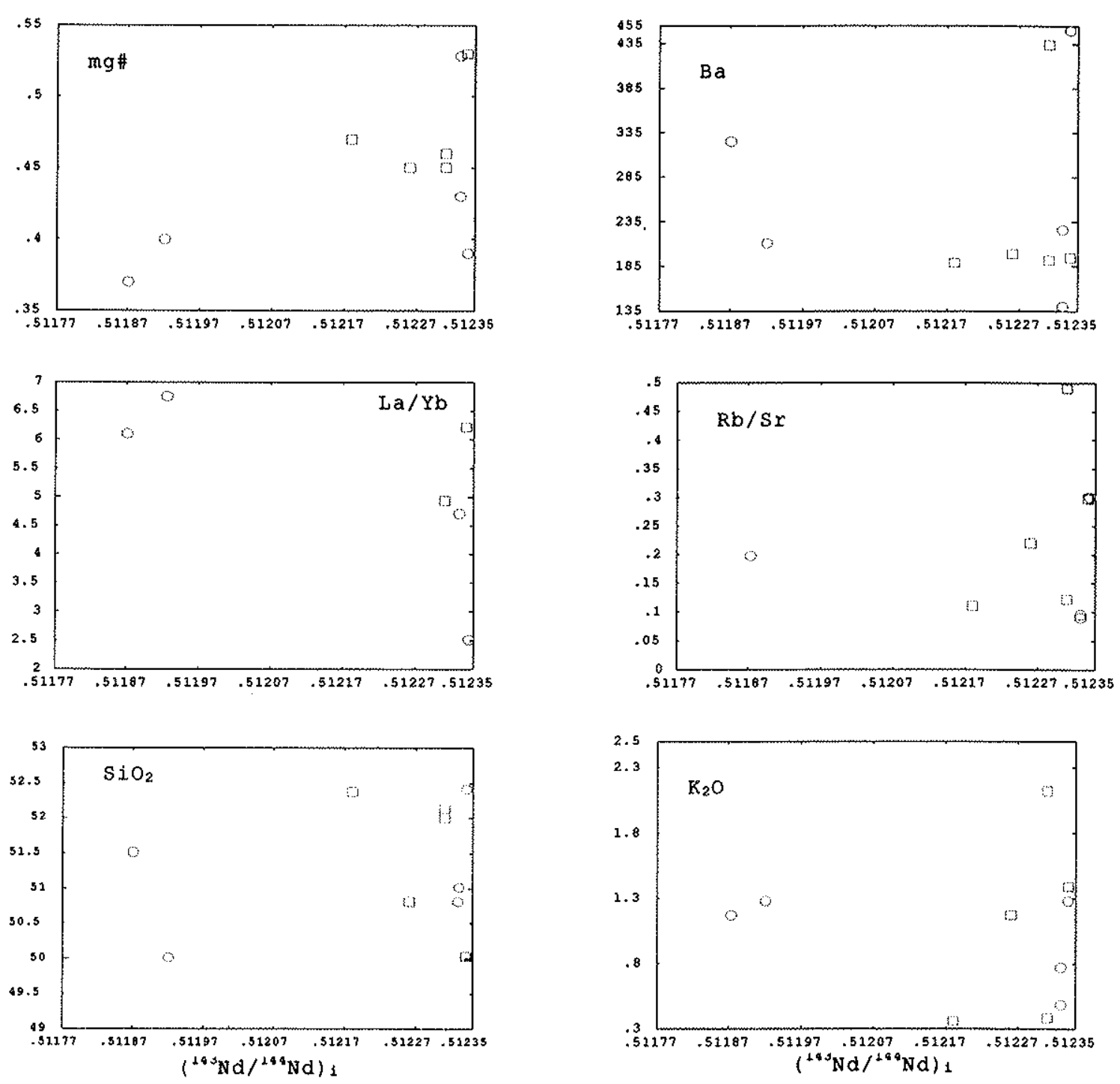

Figura 33- Diagrama de correlação entre $\left({ }^{143} \mathrm{Nd} /{ }^{144} \mathrm{Nd}\right)_{1}$ e $\mathrm{SiO}_{2}, \mathrm{~K}_{2} \mathrm{O}$, $\mathrm{Rb} / \mathrm{Sr}, \mathrm{La} / \mathrm{Yb}, e \mathrm{mg \#}$ para os diques máficos (204Ma) e derrames basálticos (136 Ma) da Suíte Básica Apoteri. Símbolos como na figura5 . 


\subsection{CARACTERÍSTICAS DA FONTE}

A figura-34 mostra a padrão dos elementos incompatíveis dos diques máficos e derrames basálticos "primitivos" obtidos para as amostras menos contaminadas. (ou pouco contaminadas) normalizados para o manto primitivo segundo Hoffmann (1988) e o modelo de fusão correspondentes a 5 a $20 \%$ de uma fonte mantélica primitiva com composição do tipo granada-peridotítica (Sun \& McDonough, 1989). A composição "primitiva" destas rochas foi calculada assumindo 50\% de fracionamento do tipo gabro (20\% olivina, 50\% clinopiroxênio e 30\% plagioclásio) cujo mg\# valores $\left[\mathrm{Mg}^{+2} /\left(\mathrm{Mg}^{+2}+\mathrm{Fe}^{+2}\right)\right]$ está entre 0.67 e 0.77 , os quais são compatíveis com um magma de composição olivina toleíto (mg\# 0.86-0.88) (Jacques \& Green, 1980; Takahashi \& Kushiro, 1983). A assembléia mineral utilizada no cálculo do modelo de fusão está apresentada na figura-34.

a)

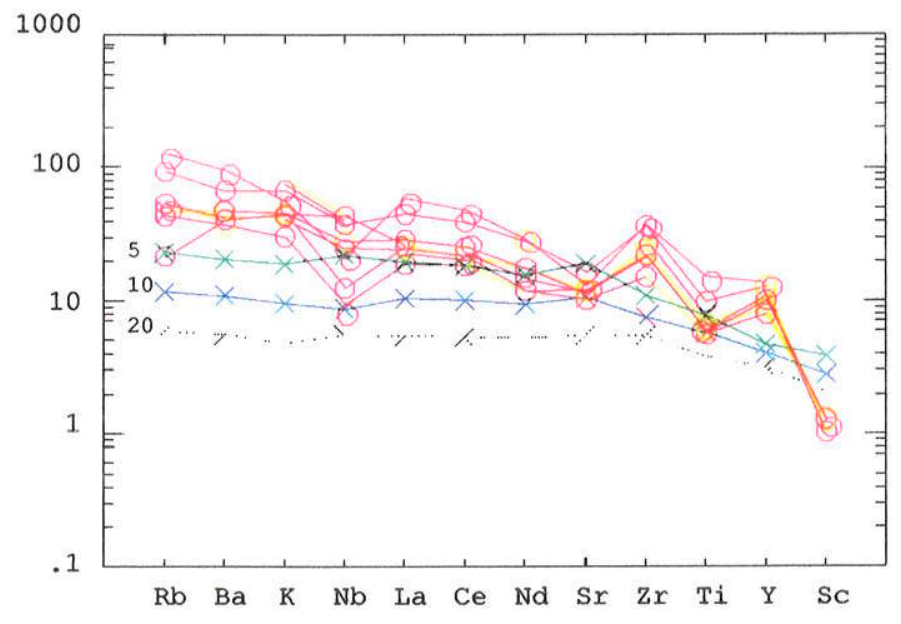

Figura 34- Variação do modelo de elementos traços incompatíveis normalizados para o manto primitivo de Hoffman (1988) dos diques máficos (a) e derrames basálticos (b) da Suíte Básica Apoteri. As curvas de 5, 10 e 20\% correspondem a 50\% de fracionamento (ol20; cpx50 e pla30) de fusão de uma fonte mantélica do tipo granada peridotito (Sun \& McDonough, 1989). Modelo do peridotito: ol=0.50; $\mathrm{opx}=0.27 ; \mathrm{cpx}=0.12 ; \mathrm{gr}=0.11$. Coeficiente de partição segundo Bossi et al. (1983). 
b)

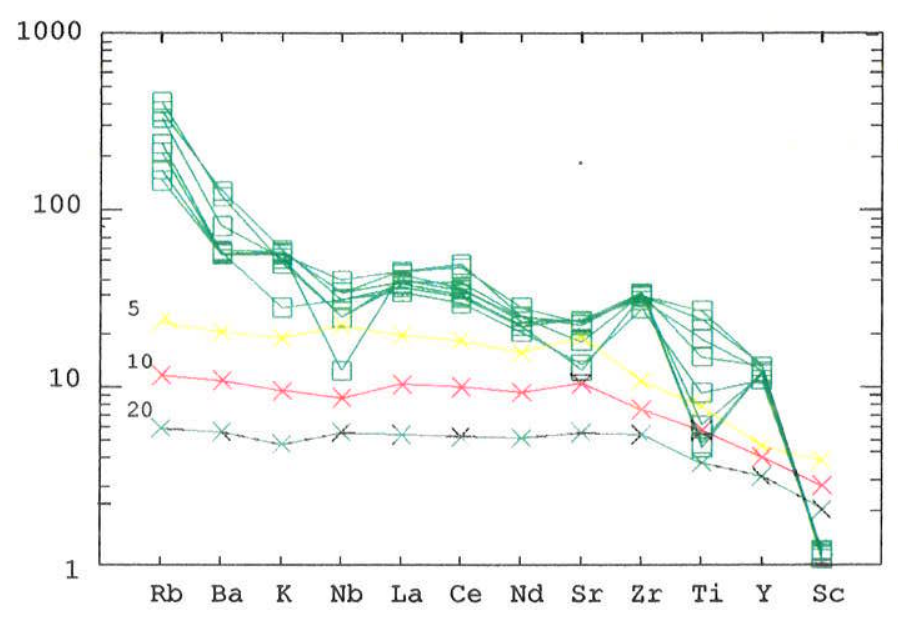

Figura 34- Continuação

Para gerar rochas com composição toleítica é necessário graus de fusão entre 5-10\% (Takahashi \& Kushiro, 1983). Entretanto, se admitirmos 5-10\% de fusão para gerar os DM, observa-se que, algumas amostras, apresentam-se enriquecidas em elementos LILE ( $\mathrm{Rb}, \mathrm{Ba} e \mathrm{~K}$ ) e $\mathrm{Zr}$, mesmo aquelas amostras consideradas menos contaminadas (ex.: RR-01A, RR-22, RR-31B e RR-36A) e empobrecidas em $\mathrm{Nd}$ e Ti (Figura-34). Também para os DE são compatíveis graus de fusão entre 5-10\%, apresentando uma fonte mantélica enriquecida em $\mathrm{Rb}, \mathrm{Ba} e \mathrm{~K}$ e empobrecida em $\mathrm{Nb} e$ Ti (Figura-34).

A forte anomalia negativa de $\mathrm{Nb}$ em relação ao $\mathrm{K}$ e La apresentada tanto nos DM como nos DE (Figura-34) pode ser devido a fatores, como: baixa solubilidade dos elementos HFS ( $\mathrm{Zr}, \mathrm{Nb}$, Ti) em relação aos elementos LILE ( $\mathrm{Rb}, \mathrm{Ba} e \mathrm{~K}$ ) e $\mathrm{TR}_{1}$ ( $\mathrm{La}$, Ce) na presença de fluidos ricos em $\mathrm{H}_{2} \mathrm{O}$ (McCulloch \& Gamble, 1991) ou pela presença de uma fase mineral do tipo "titanatos" residual (rutilo, esfeno, ilmenita, peroviskita) estabilizados em condições ricas em $\mathrm{H}_{2} \mathrm{O}$ (Hellman \& Green, 1979; Saunders et al., 1980) que fracionaria $\mathrm{Nb}$ e $\mathrm{Ti}$ em relação ao $\mathrm{Zr}$. 


\subsection{CARACTERIZAÇÃO DOS PROCESSOS MAGMÁTICOS}

\subsubsection{ANALLISE QUALITATIVA}

- reconhecimento dos processos magmáticos constitui etapa fundamental no estabelecimento de elos petrogenéticos entre ou dentro de associações ígneas. Entretanto, a elucidação de tais processos devem ser baseados em critérios múltiplos, utilizandose de dados de campo, petrográficos, mineralógicos, geoquímicos e isotópicos, para uma melhor exequibilidade na sua determinação.

A utilização de dados geoquímicos (elementos maiores, menores e traços), para definição da cogeneticidade entre as associações magmáticas é etapa primordial para a definição dos processos de geração das rochas. Dessa forma, dependendo da configuração dos dados geoquímicos de uma dada associação de rochas, quando plotadas em diagramas envolvendo dois elementos quaisquer específicos, pode-se inferir sobre o(s) processo(s) magmático(s) atuante(s) (cristalização fracionada, fusão parcial ou mistura de magmas).

A exequibilidade na identificação do(s) processo(s) magmático(s) atuante(s) numa determinada suite de rochas, através de métodos qualitativos, dependerá fundamentalmente das variáveis escolhidas ( $x$ e $y)$. Tal dependência ocorre na medida em que os diversos elementos químicos possuem diferentes comportamentos geoquímicos le.g. raio iônico, eletronegatividade, carga, etc.) e susceptibilidade aos vários processos magmáticos.

Conforme mostrado anteriormente, a análise dos diagramas de variação de elementos maiores em função do mg\# valores $\left[\mathrm{Mg}^{+2} /\left(\mathrm{Mg}^{+2}+\mathrm{Fe}^{+2}\right) ; \mathrm{Fe}_{2} \mathrm{O}_{3} / \mathrm{FeO}=0.15\right]$ (Figura-17) e elementos traços (Figuras-18 e 21) para a suíte Básica Apoteri revela a presença de processo de fracionamento do tipo gabro, em que clinopiroxênio cálcico e plagioclásio foram fases minerais importantes neste fracionamento, visto pelo comportamento de $\mathrm{CaO}, \mathrm{Al}_{2} \mathrm{O}_{3}$ e $\mathrm{Sc}$ e pelo estudo das análises petrográficas (capitulo-5).

\subsubsection{ANÁLISE QUANTITATIVA}

Diversos autores tornaram possivel equacionar e quantificar, através de modelos matemáticos, os processos magmáticos. Ou seja, tratar os dados químicos como funções matemáticas representativas dos processos magmáticos, e a partir 
de diagramas binários específicos, conforme uma função matemática, a qual refletirá o processo magmático atuante (e.g. Treuil \& Varet, 1973; Joron \& Treuil, 1977; Allègre et al., 1977; O'Hara, 1977; Stormer \& Nicholls, 1978; DePaolo, 1981; Vieira Jr, $1991 \mathrm{a}, \mathrm{b}$; entre outros). Estes modelos matemáticos têm sido muito utilizados em suítes de rochas basálticas tendo produzido resultados satisfatórios e viáveis com o processo de evolução petrogenético sugerido pela análise ou tratamento qualitativo dos dados (e.g. Marques, 1983; Marques, 1988; Piccirillo et al., 1990; Bossi et al., 1993; Bellieni et al., 1995; Mazzucchelli et al., 1995; Rivalenti et al., 1995; Pinese, 1997) .

Deste modo, afim de avaliar quantitativamente a viabilidade do processo de cristalização fracionada sugerido pela análise qualitativa, foram efetuados cálculos de balanço de massa para elementos maiores (Stormer \& Nicholls, 1978). As concentrações de elementos traços foram utilizadas para confirmar ou rejeitar a viabilidade do processo de diferenciação proposto, uma vez que estes elementos são bastantes sensíveis a estes processos.

Devido ao número reduzido de amostras dos derrames basálticos, bem como sua pouca representatividade no conjunto, não foi viável, a priori, a aplicação do modelamento matemático para uma possivel determinação quantitativa do processo magmático atuante na formação destas rochas.

\subsubsection{ANÁLISE QUANTITATIVA DOS ELEMENTOS MAIORES}

Para o cálculo de balanço de massa foram utilizadas amostras representativas dos diferentes estágios de evolução e que apresentaram menor grau de contaminação crustal (amostras $\mathrm{RR}-33, \mathrm{MgO}=7.24 \%$; $\mathrm{RR}-01 \mathrm{~A}, \mathrm{MgO}=6.88 \%$; $\mathrm{RR}-18 \mathrm{~A}, \mathrm{MgO}=6.84 \% ; \mathrm{RR}-36 \mathrm{~A}$, $\mathrm{MgO}=6.61 \% ; \quad \mathrm{RR}-43, \mathrm{MgO}=5.78 \%$ 의 $\quad \mathrm{RR}-31 \mathrm{~B}, \mathrm{MgO}=4.83 \% ; \quad \mathrm{RR}-35 \mathrm{C}$, $\mathrm{MgO}=4.30 \%$ ) $\mathrm{O}$ as principais fases minerais (olivina, clinopiroxênio cálcico, pigeonita, ortopiroxênio, magnetita e apatita), possivelmente fracionadas em cada uma das passagens entre pares de amostras e cujas concentrações encontram-se nas tabelas-1, 2, 5 e 9. As fases minerais foram determinadas por meio de microssonda eletrônica (capítulo-6), a exceção das amostras $\mathrm{RR}-43 \quad(\mathrm{MgO}=5.78 \%$ ) $\mathrm{RR}-31 \mathrm{~B} \quad(\mathrm{MgO}=4.83 \%$ ) cujas composições mineralógicas foram extraídas respectivamente das amostras $\mathrm{RR}-36 \mathrm{~A} \quad(\mathrm{MgO}=6.61 \%)$ e $\mathrm{RR}-16 \quad$ (MgO=4.55\%) com estágios de evolução do líquido muito semelhantes daquelas (concentraçōes de Mgo muito próximas). As composições químicas da olivina e apatita foram extraidas da literatura (Deer et al., 1992) e são mostradas no apêndice-5. 
Com estes dados, utilizou-se o programa de cálculo no qual são introduzidas as porcentagens dos óxidos de elementos maiores e as fases minerais selecionadas para cada "trajetória". O programa então resolve, pelo método dos mínimos quadrados, um sistema de equações referentes ao número de óxidos utilizados em função da porcentagem de cada mineral cristalizado, dependente dos números de fases selecionadas para os cálculos. Como resultado, o programa oferece as fases minerais fracionadas e suas proporções em peso em relação ao total fracionado, a fração líquida restante (E) e a somatória dos quadrados dos resíduos ( $\Sigma$ res $^{2}$ ).

Foram testadas todas as passagens de evolução possíveis, efetuando-se para cada uma delas, várias combinações com as fases minerais selecionadas. O critério adotado para verificar a qualidade do ajuste dos elementos maiores, em cada passagem testada, baseou-se fundamentalmente na somatória dos quadrados dos resíduos $\left(\sum r e s^{2}\right)$, obedecendo a seguinte classificação:

\begin{tabular}{|c|c|c|c|c|c|}
\hline AJUSTE & ÓTIMO & BOM & RAZOÁVEL & RUIM & PÉSSIMO \\
\hline Lres $^{2}$ & $\leq 0.2$ & $0.2-0.5$ & $0.5-1.0$ & $1.0-2.0$ & $>2.0$ \\
\hline
\end{tabular}

De todas as hipóteses testadas, foram selecionados os casos que apresentaram maior grau de viabilidade ( res $^{2}$ mais baixos), uma vez que alguns resultados apresentaram-se insatisfatórios devido ao elevado valor da $\operatorname{Lres}^{2}$. Deste modo, as possiveis "trajetórias" de evolução do líquido foram desenhadas da seguinte forma:

- "TRAJETÓRIA 1": RR-33 $\rightarrow$ RR-01A: olivina (48), augita (23.9\%), plagioclásio (48.8\%), pigeonita (16.7\%), magnetita (5.88), apatita $(0.48)$ com Lres $^{2}=0.0057$.

- "TRAJETÓRIA 2": RR-01A $\rightarrow$ RR-18A: plagioclásio (56.5\%), pigeonita $(40.7 \%$ e magnetita $(2.8 \%)$ com Eres $=0.0376$.

- "TRAJETÓRIA 3": RR-18A $\rightarrow$ RR-36A: plagioclásio (41.98), augita (34.2\%), pigeonita (19.98), magnetita (2.98), olivina $(1.18)$ com res $^{2}=0.0070$

- "TRAJETÓRIA 4": RR-36A $\rightarrow$ RR-43: plagioclásio (53.4\%), augita (42.9\%), magnetita (3.3\%), apatita (0.5\%) com res $^{2}=$ 0.7476 .

- "TRAJETÓRIA 5": RR-43 $\rightarrow$ RR-31B: augita (60\%), plagioclásio (40\%), com Eres $^{2}=0.4171$. 
- "TRAJETóRIA 6": RR-31B $\rightarrow$ RR-35C: plagioclásio (61.38), augita (18.7\%), pigeonita (15.3\%), magnetita (4.3\%), apatita $(0.48)$ com res $^{2}=0.2535$.

Estes resultados estão resumidos na tabela-23. Nesta tabela estão apresentadas todas as fases minerais fracionadas e suas proporções em peso em relação ao total fracionado, a fração liquida restante $(F)$ e a somatória dos resíduos quadrados ( $\Sigma$ $\left.\operatorname{res}^{2}\right)$.

\begin{tabular}{|c|c|c|c|c|c|c|c|c|}
\hline TRAJITTÓRIAS & 01 & Cpxca & pla & pigeo & mt & apa & $\boldsymbol{F}$ & Lres ${ }^{2}$ \\
\hline $1-R R-33 \rightarrow R R-01 A$ & 4.4 & 23.9 & 48.8 & 16.7 & 5.8 & 0.4 & 0.91 & 0.0057 \\
\hline $2-R R-01 A \rightarrow R R-18 A$ & ---- & 40.7 & 56.5 & --- & 2.8 & -- & 0.89 & 0.0376 \\
\hline $3-\mathrm{RR}-18 \mathrm{~A} \rightarrow \mathrm{RR}-36 \mathrm{~A}$ & 1.1 & 34.2 & 41.9 & 19.9 & 2.9 & -- & 0.91 & 0.0070 \\
\hline $4-R R-36 A \rightarrow R R-43$ & $-\cdots$ & 42.9 & 53.4 & ---- & 3.3 & 0.5 & 0.79 & 0.7476 \\
\hline $5-R R-43 \rightarrow R R-31 B$ & --- & 60 & 40 & ---- & --- & -- & 0.96 & 0.4171 \\
\hline $6-R R-31 B \rightarrow R R-35 C$ & --- & 18.7 & 61.3 & 15.3 & 4.3 & 0.4 & 0.63 & 0.2535 \\
\hline
\end{tabular}

Tabela 23- Resultados obtidos na aplicação do modelo de cristalização fracionada para elementos maiores de cada trajetória analisada. ol=olivina; cpxca=augita; pla=plagioclásio; pigeo=pigeonita;

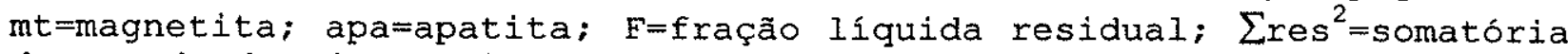
dos quadrados dos residuos relativos dos elementos maiores.

De modo geral, os resultados indicados para as possibilidades de fracionamento apresentaram valores significantemente baixos para a soma dos quadrados residuais para a maioria das passagens testadas, com ajustes variando de ótimo (trajetórias 1,2 e 3), bom (trajetórias 5 e 6) a razoáveis (trajetória 4), envolvendo um fracionamento dominado por plagioclásio, augita e pigeonita e quantidades subordinadas de magnetita, olivina e apatita. A consistência de tais resultados, indica que o modelo de cristalização fracionada pode ter sido o processo gerador destas rochas. A seguir será feito o modelamento para os elementos traços na tentativa de confirmação de tal processo magmático.

\subsubsection{ANÁLISE QUANTITATIVA DOS ELEMENTOS TRAÇOS}

Com a finalidade de verificar se os elementos traços determinados estão de acordo com o processo de diferenciação proposto pelo ajuste de elementos maiores, uma vez que tais elementos são bastantes sensíveis e apresentam, nos processos de 
cristalização, comportamento previsto pela lei de fracionamento de Rayleigh, utilizou-se a seguinte expressão:

$$
\mathrm{C}_{1}^{\mathrm{i}}=\mathrm{C}_{0}^{i} \cdot \mathrm{E}^{(\mathrm{DI}-1)}
$$

onde:

$$
\begin{aligned}
& \mathrm{C}_{1}{ }^{i}=\text { concentração do elemento } i \text { no magma final; } \\
& \mathrm{C}_{0}{ }^{i}=\text { concentração do elemento } i \text { no magma inicial; } \\
& F=\text { Eração líquida restante após o fracionamento; } \\
& D^{i}=\text { coeficiente de distribuição global do elemento i. }
\end{aligned}
$$

O coeficiente de distribuição global (D) é definido como sendo o resultado final da distribuição de um elemento em todas as fases minerais que constituem o sólido fracionado e é determinado pela expressão:

$$
D=\sum_{j=1}^{n} x_{j} \cdot D_{j}^{i}
$$

onde:

$D=$ coeficiente de distribuição global;

$\mathrm{x}_{\mathrm{j}}=$ porcentagem em peso da fase

fracionada $j$;

$D_{j}{ }^{i}=$ coeficiente de partição do

elemento i no mineral j;

$\mathrm{n}=$ número de fases fracionadas.

Para a resolução das equações acima ( 1 e 2) é necessário o conhecimento dos coeficientes de partição (Kd) para os diversos elementos referentes aos vários minerais fracionados (Arth, 1976; Irving, 1978; Hanson, 1980; Henderson, 1984). Como o D é fortemente dependente da temperatura (T), pressão (P) e fugacidade de oxigênio $\left(f_{\mathrm{O} 2}\right)$ e composição dos magma, procurou-se extrair da literatura valores de $\mathrm{Kd}$ semelhantes aquelas das condições das rochas estudadas (Apêndice-6)

Os cálculos de coeficientes de partição global para os diversos elementos traços foram executadas utilizando-se a expressão (2), além da proporção em peso de cada fase fracionada $\left(x_{j}\right)$, adquirida no balanço de massa de elementos maiores (Tabela23) e o coeficiente de partição de cada fase mineral $\left(D_{j}\right)$.

As concentrações $\left(C_{1}\right)$ dos vários elementos traços e elementos terras raras para a amostra mais evoluida foram 
calculadas por meio da expressão concentracões $\left(\mathrm{C}_{0}\right)$ correspondentes as tomando-se a fração líquida residual de massa de elementos maiores.
(1), considerando-se as amostras menos evoluídas e (F) fornecida pelo balanço

Feito todos os cálculos, observa-se que de modo geral o ajuste dos elementos traços e terras raras apresentam uma boa concordância com um processo de cristalização fracionada, pois os resultados calculados estão bem próximos daqueles analisados, a exceção do $\mathrm{Ni}$ e $\mathrm{Cr}$ que afastaram-se um pouco dos valores observados, possivelmente devido a possiveis fracionamentos de sulfetos (Tabela-24). Nota-se, para a maioria dos elementos traços que a variação entre os valores calculados e observados é inferior a 25-30\%. Tal diferença pode ser considerada razoável, tendo em vista os erros experimentais na determinação dos elementos e a incerteza dos coeficientes de partição extraídos da literatura, mesmo sendo bem próximos as condições das rochas estudadas.

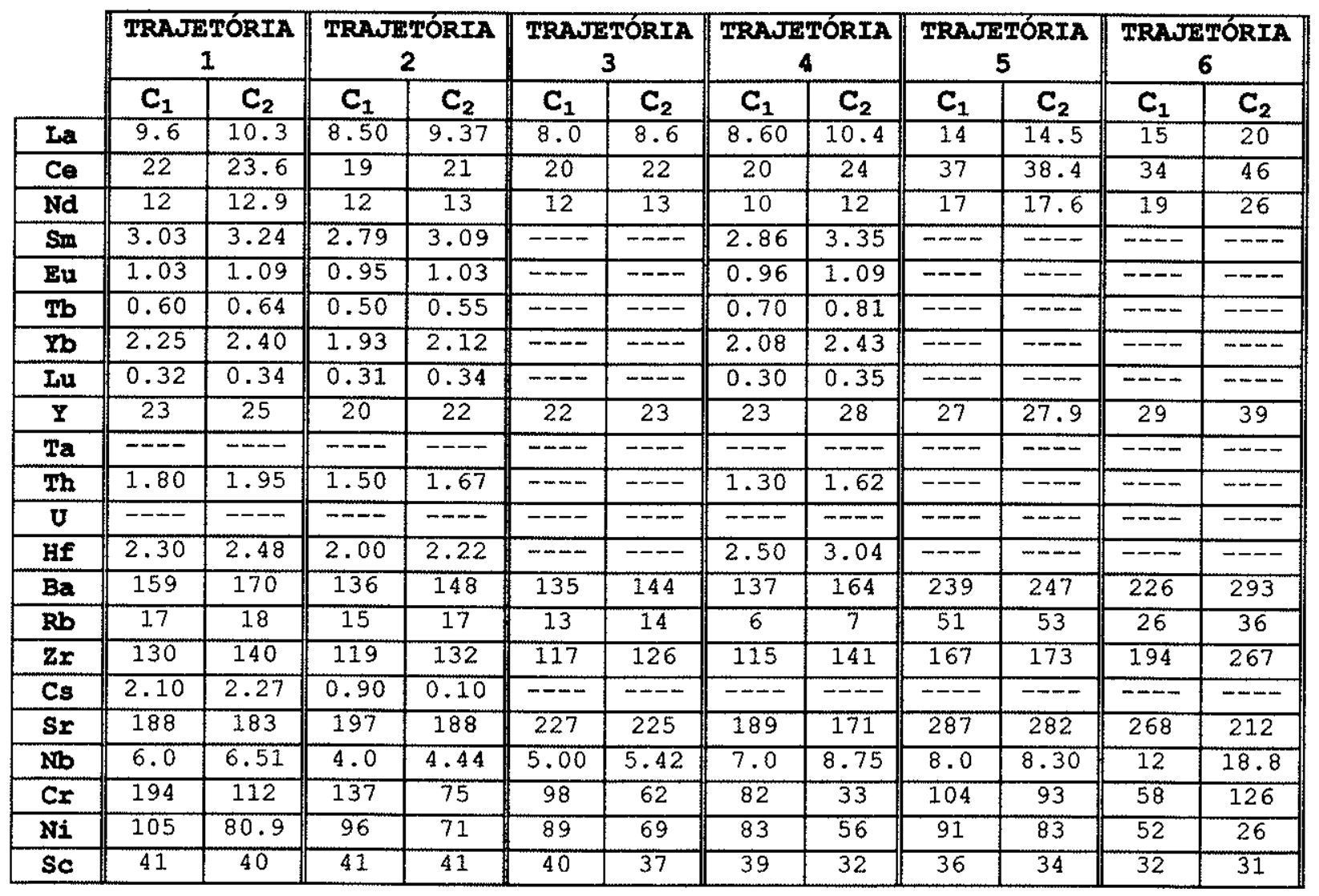

Tabela 24- Resultados do modelamento geoquímico para elementos traços e terras raras para os diques máficos da suite Básica Apoteri, calculados a partir das proporções das fases minerais obtidas pelo balanço de massa de elementos maiores da tabela-23. $\mathrm{C}_{1}=$ concentração analisada; $\mathrm{C}_{2}=$ concentração calculada. 


\subsection{COMPARAÇÃo COM OUTRAS ROCHAS BASÁLTICAS MESOZÓICAS}

As rochas da Suíte Básica Apoteri podem ser relacionadas cronologicamente ao magmatismo basáltico mesozóico que ocorre no Escudo das Guianas: ao Minor Dykes e Diques Rupununi, na Guiana; ao Apatoe Dykes, no Suriname; Cayenne Dykes, na Guiana Francesa e a Província Magmática de Roraima, na Venezuela. Entretanto, existem na literatura poucos dados enfocando os aspectos geoquímicos e petrogenéticos deste magmatismo, a exceção da Guiana que possui um acervo de dados de geoquímica de elementos maiores, alguns traços e elementos terras raras.

Segundo Choudhuri (1978), Choudhuri \& Milner (1971), Choudhuri et al. (1977) os diques máficos mesozóicos que ocorrem na Guiana, intrusivos no Escudo das Guianas são de caráter toleítico revelando para os elelemntos terras raras (ETR) enriquecimento de ETR leves e empobrecimento de ETR pesadas e ausência de anomalia de Eu. Através de razões U/Th e valores de $\mathrm{U} e \mathrm{Th}$ é sugerida uma fonte enriquecida para a geração desta rochas.

Em relação aos derrames basálticos que ocorrem na Guiana não existem estudos detalhados de sua caracterização geoquímica/petrogenética. Segundo Berrangé \& Dearnley (1975) os derrames possuem excesso de $\mathrm{Na}, \mathrm{K}$ e $\mathrm{H}_{2} \mathrm{O}$ relacionado a presença de zeólitas nas amígdalas.

Na Plataforma Sulamericana as rochas da suite Básica Apoteri podem ser comparadas com as províncias basálticas mesozóicas, tais como: Diabásio Cassiporé (Lima et al., 1974) de idade $201 \pm 23 \mathrm{Ma}(\mathrm{K}-\mathrm{Ar}$ ), Diabásio Penatecaua (Issler et al., 1974)

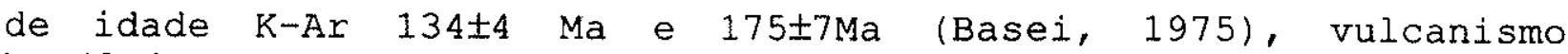
basáltico da Bacia do Paraná e da região do Arco de Ponta Grossa com idades entre 119 e 145Ma (K-Ar e Rb-Sr) (Amaral et al., 1966; Piccirillo et al., 1987; Mantovani et al., 1985). 
Os estudos efetuados deste trabalho permitem as seguintes considerações:

1- A Suíte Básica Apoteri é constituída por rochas de caráter intrusivo (diques máficos) e extrusivo (derrames basálticos) de idade Jurássico Inferior (204Ma) e Cretáceo Inferior (136Ma) respectivamente, alojadas em terrenos précambrianos. Os diques máficos (DM) localizam-se preferencialmente a $\mathrm{NE}$ da cidade de Boa Vista onde constituem um enxame de diques e com menor expressão geográfica a WNW da cidade de Boa Vista, próximo a localidade do Taiano. Os derrames basálticos (DE) ocorrem de forma menos expressiva que os diques máficos, tendo seus principais afloramentos situados próximos a cidade de Boa Vista até as imediações da localidade de Bonfim.

2- Os DM, de modo geral, preenchem fraturas extensionais segundo direções N40-5OE e NNE-SSW, Com espessuras variáveis (predomínio de 3 a 8 metros) e extensões variando desde algumas centenas de metros até aproximadamente $50 \mathrm{Km}$. Os DE afloram principalmente em pequenos morros e colinas e nos leitos dos rios, constituindo basaltos maciços a amigdaloidais.

3- Através da classificação química os DM posicionaram-se no campo dos basaltos toleíticos e andesi-basaltos e os DE nos andesi-basaltos e lati-basaltos, demonstrando uma afinidade toleítica para a maioria dos corpos, a exceção de algumas amostras dos DE que apresentaram tendências mais calcio alcalinas/transicionais (com razões álcalis/silica maiores).

4- Os DM são caracterizados por apresentar texturas ofiticas a subofiticas, tendo como minerais predominantes plagioclásio $\left(\mathrm{An}_{43-70}\right)$, piroxênios [augita $\left(W_{31-42}\right.$, ortopiroxênio $\left(W_{1-4}\right)$ e pigeonita $\left.\left(W_{10-16}\right)\right]$. Quartzo forma intercrescimento gráfico com feldspato alcalino. Minerais opacos, anfibólio (ferro-edenita e edenita), biotita e apatita ocorrem como minerais acessórios. Os DE apresentam texturas integranular a intersertal, predominando o plagioclásio (bastante saussuritizado/sericitizado) e piroxênio augita ( $\left.\mathrm{WO}_{34-40}\right)$ comumente bordejado por clorita e rara pigeonita (Wogmil). Minerais opacos e apatita constituem os minerais acessórios. O material intersticial comum é o vidro e quando as amígdalas estão presentes são preenchidas por quartzo, carbonato, apatita e zeólitas.

5- Os piroxênios (ricos e pobres em cálcio) dos DM mostraram que seus conteúdos de wo decrescem dos estágios de cristalização precoce para os tardios, acompanhados por um enriquecimento de Fs, caracterizando a natureza toleítica destes 
corpos. Para os DE este comportamento é mais sútil denotando seu caráter mais cálcio-alcalino/transicional. As temepraturas obtidas para a cristalização dos piroxênios e plagioclásios tanto dos DM como para os $D E$ nos leva a admitir que o magma atingiu, no mínimo, temperatura da ordem de $1100^{\circ} \mathrm{C}$.

6- Os dados geoquímicos de elementos maiores, menores, traços e terras raras revelaram comportamentos semelhantes entre os $\mathrm{DM} e \mathrm{DE}$ aumentando em $\mathrm{SiO}_{2}, \mathrm{FeO}_{t}, \mathrm{TiO}_{2}, \mathrm{P}_{2} \mathrm{O}_{5}$ e elementos incompatíveis e diminuindo em $\mathrm{CaO}, \mathrm{Al}_{2} \mathrm{O}^{3}, \mathrm{Na}_{2} \mathrm{O}, \mathrm{K}_{2} \mathrm{O}, \mathrm{Cr}, \mathrm{Ni}$ e $\mathrm{SC}$ com o avanço da cristalização. A grande variação dos mg\# valores $\left[\mathrm{Mg}^{+2} /\left(\mathrm{Mg}^{+2}+\mathrm{Fe}^{+2}\right)\right]$ tanto para os DM $(0.37-0.57)$ e os DE $(0.45-0.53)$ nos leva a sugerir que as rochas não foram formadas por líquidos primários e que portanto representam magmas evoluidos. Adicionalmente as razões $\mathrm{Zr} / \mathrm{elementos}$ incompatíveis mostram diferenças mínimas entre os $D M$ e $D E$, refeltindo possivelmente uma leve heterogeneidade na fonte mantélica.

7- O comportamento dos elementos maiores e traços nos permitiu constatar que os $\mathrm{DM}$ e $\mathrm{DE}$ evoluiram de uma assembléia do tipo gabro, onde o clinopiroxênio e plagioclásio foram fases minarais importantes no fracionamento.

8- Os padrões de distribuição de elementos terras raras (ETR) são semelhantes entre os DM [(La/Yb)n entre 2.43 e 4.68] e $\mathrm{DE}[(\mathrm{La} / \mathrm{Yb}) \mathrm{n}$ entre 3.48 e 3.72] apresentando-se médio a fortemente fracionados e enriquecidos em ETR leves em relação aos ETR pesadas, guardando um certo paralelismo entre as curvas.

9- Os padrões de elementos incompativeis tanto para os DM como para os $\mathrm{DE}$ mostrou que $\mathrm{O} \mathrm{Rb}$ é mais enriquecido em relação ao $\mathrm{K}$ e $\mathrm{Ba}$ e nestes elementos em relação a todos os outros incompatíveis. Possuem altas razões $\mathrm{Rb} / \mathrm{Sr}$ e são fortemente empobrecidos em $\mathrm{Nb} e \mathrm{Ti}$. Em geral, mostram padrões semelhantes aos E-MORB, possuindo no entanto valores para os elementos LILE e ETR leves um pouco mais elevados.

10- Os dados Rb-Sr indicaram idades do Carbonífero Inferior $(311 \pm 40 \mathrm{Ma})$ para os DM e do Cretáceo Inferior (136 $113 \mathrm{Ma}$ ) para os DE. Entretanto, devido ao alto valor do MSWD (76) e o desalinhamento dos pontos na errócrona dos DM, admitiu-se neste trabalho a idade média $\mathrm{K}-\mathrm{Ar}$ de $204 \mathrm{Ma}$ (Jurássico Inferior) para os DM. Por outro lado, para OS DE OS dados Rb-Sr revelaram idade de $136 \mathrm{Ma}$, sugerindo assim que a formação destes derrames basálticos se deu durante o Cretáceo Inferior.

12- Os valores de $\varepsilon S r$ vs eNd indicaram que os DM e DE derivaram de uma fonte enriquecida comparativamente a "Terra Global" sugerindo, em concordância com os dados geoquímicos, fenômenos de interação crustal com a crosta continental. 
Adicionalmente os elementos como $\mathrm{SiO}_{2}, \mathrm{~K}_{2} \mathrm{O}, \mathrm{Ba}, \mathrm{Rb} / \mathrm{Sr}, \mathrm{La} / \mathrm{Yb}$ apresentam relação positiva com 0 índice contaminante $\left({ }^{87} \mathrm{Sr} /{ }^{86} \mathrm{Sr}\right.$ inicial).

13- A evolução dos DM está quantitativamente (balanço de massa de elementos maiores e fracionamento de Rayleigh) de acordo com um processo de cristalização fracionada do tipo gabro onde o clinopiroxênio e plagioclásio foram fases importantes durante o processo evolutivo.

14- Considerando aquelas amostras menos contaminadas (ou pouco contaminadas) e recalculando-as para uma possível composição "primitiva" (50\% de fracionamento de um gabro: 2080livina, 50\%clinopiroxênio, 30\%plagioclásio; mg\# 0.67-0.77) observou-se que seriam necessários graus de fusão em torno de $10 \%$ para gerar as rochas da Suíte Básica Apoteri e que a fonte mantélica seria enriquecida em ETR leves, elementos LILE e Zr e empobrecidas em $\mathrm{Nb}$ e $\mathrm{Ti}$.

15- Os dados geoquímicos e isotópicos sugerem que as rochas da Suite Básica Apoteri se derivaram de uma fonte mantélica enriquecida e que foram diferentemente contaminados por componentes crustais durante a sua colocação na crosta continental em tempos Mesozóicos. 
ALIBERT, C. (1985) Sr-Nd isotopic and REE study of late Triassic dolerites from the Pyrenees (France) and the Messejana dyke (Spain and Portugal). Earth Planet. Sci. Lett., 73: 81-90.

ALLÉGRE, C.J.; TREUIL, M.; MINSTER, J.F.; MINSTER, B.; ALBAREDE, F. (1977) systematic use of trace elements in igneous processes. Part I: fractional crystallization processes in volcanic suites. Contribution of Mineralogy and Petrology, $60: 57-75$.

ALMEIDA, E.F.M.; MELCHER, G.C.; CORDANI, U.G.; KAWASHITA, K.; VANDOUROS, V. (1968) Radiometric age determinations from northern Brazil. Bol. Bras. Geol., 17: 3-14.

ALMEIDA, F.E.M.; HASUI, Y.; BRITO NEVES, B.B. (1976) The upper precambriam of South America. Boletim IG-USP, 7: 45-80.

ALMEIDA, F.F.M.; HASSUI, Y.; BRITO NEVES, B.B.; EUCK, R.A. (1981) Brazilian strutural provinces: an introdution. Earth Sci., Rev., Special Issw, 17: 1-29. Amsterdam.

AMARAL, G. (1974) Geologia Pré-Cambriana da Região Amazônica. Tese de Doutorado. Instituto de Geociências-Universidade de São Paulo, São Paulo, 212 p.

AMARAL, G.; CORDANI, U.G.; KAWASHITA, K.; REYNOLDS, J.H. (1966) Potassium argon dates of basaltic rocks from southern Brazil. Geoch. Cosm. Acta, 31: 117-142.

AMARAL, G.; RAMGRAB, G.E.; OLIVEIRA, I.W.B.; MANDETTA, P.; DAMIÃO, R.N. (1970) Determinações geocronológicas e considerações sobre a estratigrafia do Pré-Cambriano na porção setentrional do Território de Roraima. In: Congresso Brasileiro de Geologia, 24. Brasilia, DF, 1970. Boletim especial no 1, Brasilia, SBG. p. 77-79.

ARTH, J.G. (1976) Behavior of trace elements during magmatic processes - A summary of theoretical models and their applications. J. Research U.S. Geol. Survey, 4: 41-47.

BARRON, C.N. (1966) Notes on the stratigraphy of the Lower Roraima Eormation in the Potaro-Lawang area of British Guiana, and on the discovery of acid intrusive within it. Caribean Geological Conference, 3. Georgetown, 1966. Anais. Georgetown, British Guiana, 1966.

BASEI, M.A.S. (1975) Geocronologia do território federal de Roraima e parte norte do estado de Amazonas. In: BRASIL. MME/DNPM/RADAM. Relatório Interno, Belém, fev. 19p.il. 
BASEI, M.A.S. (1978) O vulcanismo ácido-intermediário na região Amazônica. XXX Congresso Brasileiro de Geologia, v.6, p. 2409-2422, Recife-PE.

BASEI, M.A.S. \& TEIXEIRA, W. (1975) Geocronologia do Território de Roraima. Conferência Geológia Interguianas. Belém, 1975. Anais. Belém, MME/DNPM. p. 453-473.

BASTOS LEAL, L.RL. (1992) Geocronologia Rb-Sr e K-Ar, evolução isotópica e implicações tectônicas dos enxames de diques máficos de Uauá e Vale do rio Curaça, Bahia. Dissertação de Mestrado. IG/USP. São Paulo. 118p.

BASTOS LEAL, L.R.; TEIXEIRA,W.; PICCIRILLO, E.M.; MENEZES LEAL, A.B.; GIRARDI, V.A.V. (1994) Geocronologia Rb-Sr e K-Ar do enxame de diques máficos de Uauá, Bahia (Brasil). Geochimica Brasiliensis, (8): 99-114.

BELLIENI, G. ; PICCIRILLO, E.M.; ZANETTIN, B. (1981) Classification and nomenclature of basalts. Contribution $n^{\circ}$ 81, IUGS, Subcomission on the systematic of Igneous Rocks, $19 \mathrm{p}$.

BELLIENI, G.; BROTZU, P.; COMIN-CHIARAMONTI, P.; ERNESTO, M.; MELEI, A.J.; PACCA, I.; PICCIRILLO, E.M. (1984) Flood basalts to ryolite suites in the southern Paraná plateau (Brazil): Paleomagnetism, petrogenesis and geodynamic implications. J. Petrology, 25: 579-618.

BELLIENI, G.; PICCIRILLO, E.M.; PETRINI, R.; GIRARDI, V.A.V.; MENEZES LEAL, A.B.; TEIXEIRA, W. ; BASTOS LEAL, L.R.; DEMIN, A.; COMIN-CHIARAMONTI, P.; TANER DE OLIVEIRA, M.A.E. (1995) Petrological and Sr-Nd evidence bearing on Early Proterozoic magmatic events of the subcontinental mantle: São Franciscop craton (Uauá, NE Brazil). Contr. Mineral. Petrol., 122: 252261.

BELIIZZIA, C.M. (1972) Paleotectônica del escudo de Guyana. Conferência Geológica Interguianas, 9. Puerto Ordaz, 1972. Memória. Puerto Ordaz, Venezuela, Ministério das Minas e Hidrocarburos, 1972. p. 251-305.

BERRANGÉ, J.P. (1973) A synopsis of the geology of southern Guyana. Report Inst. Geol. Science. Overseas Division. Photogeological Unit. London. (26): 1-11.

BERRANGÉ, J.P. \& DEARNLEY, R. (1975) The Apoteri volcanic Formation-Tholeiitic flows in the north Savanas Graben of Guyana and Brazil. Geologishe Rundshau, 64(3): 883-899.

BOSSI, J.; CAMPAL, N.; CIVETTA, L.; DEMARCHI, G.; GIRARDI, V.A.V.; MAZZUCCHELII, M.; NEGRINI, L.; RIVALENTI, G.; FRAGOSO CESAR, A.R.S.; SINIGOI, S.; TEIXEIRA, W.; PICCIRILLO, E.M.; MOLESINI, M. (1993) Early proterozoic dike 
swarms from Western Uruguay: geochemistry, Sr-Nd isotopes and petrogenesis. Chem. Geol., 106: 263-277.

BOUGAULT, H (1976) Evidence de la cristallization fractionnée au niveau d'une dorsale médio oceanique. Co-Ni-Cr dans les échantilions de la zone FAMOUS et du leg 37 du D.S.P. Bulletin de la Société Géologique de France, 7: 1207-1212.

BOYNTON, W.V. (1984) Cosmochemistry of rare earth elements: meteorite studies. In: Henderson, P. (ed) Rare earth elements geochemistry. Elsevier, Amsterdan, p. 63-114.

BRANDON, A.D; HOOPER, P.R.; GOLES, G.G.; LAMBERT, R.S.J. (1993) Evaluating crustal contamination in continental basalts: the isotopic composition of the Picture Gorge Basalt of the Columbia River Basalt Group. Contrib. Mineral. Petrol., 114: 452-464.

BRIQUEU, L.; BOUGAULT, H.; JORON, J.L. (1984) Quantification of $\mathrm{Nb}, \mathrm{Ta}, \mathrm{Ti}$ and $\mathrm{V}$ anomalies in magmas associated with subductio zones: petrogenetic implications. Earth Planetary Science Letters, 68: 297-308.

BROWN, G.M. (1957) Pyroxenes from the early and middle stages of fractionation of the Skaergaard intrusion, East Greenland. Miner. Mag., 31: 511-543.

BROWN, C.B. \& SAWKINS, J.G. (1875) Reports on the physical and economic geology of British Guiana. London. Longmass Green. 297 p.

BROWN, G.M. \& VINCENT, E.A. (1963) Pyroxenes from the late stages of fracionation of the Skaergaard intrusion, East Greenland. J. Petrology, 4: 175-197.

BUDDINGTON, A.F. \& LINDSLEY, D.H. (1964) Iron-titanium oxide minerals and synthetic equivalents. Journal of Petrology, 5: 310-357.

CARLSON, R.W. (1991) Physical and chemical evidence on the cause and source characteristics of flood basalt volcanism. Aust. J. Earth Sci., 38: 525-544.

CARMICHAEL, I.S.E. (1964) The petrology of Thingmuli a Terciary volcano in eastern Iceland. J. Petrology, 5:435-460.

CARMICHAEL, I.S.E. (1967) The iron-titanium oxides of sialic volcanic rocks and their associated ferromagnesium silicates. Contr. Miner. Petrol., 14: 36-64.

CARMICHAEL, I.S.E.; TURNER, J.J.; VERHOOGEN, J. (1974) IgneOus petrology. McGraw-Hill, New York, 739p.

CARTER, S.R.; EVENSEN, N.M.; HAMILTON, P.J.; O'NIONS, R.K. (1978) Neodymium and stroncium isotopic evidence for crystal contamination of continental volcanics. Science, 202: 743747 . 
CHOUDHURI, A. (1978) Chemical trends in tholeiitic dykes of different ages from Guiana. Chem. Geol., 22: 79-85.

CHOUDHURI, A. (1981) Petrologia dos diques basálticos da região norte do Escudo Guianês. Tese de Livre Docência. UNESP-Rio Claro, São Paulo. 133p.

CHOUDHURI, A. \& MILNER, M.W. (1971) Basic magmatism in Guiana Continental Drift. Nature Physical Science, 232: 154-155.

CHOUDHURI, A.; YLER, S.S.; VASCONCELIOS, M.B.A. (1984) U, Th and rare earth elements in Mesozoic tholeiite dykes from the northern Guiana Shield. Anais do II Simposio Amazônico, p. 171-177.

CLARKE, D. (1993) Newpet- version 7.10- Reference Manual Memorial university of Newfourland. Centre for earth Resources Research, Canadá.

COLLERSON, K.D. \& SHERATON, J.W. (1986) Age and geochemical characteristics of a mafic dyke swarms in the Archean Vestfold Block, Anatarctica: inferences about Proterozoic dyke emplacement in Gondwana. J. Petrology, 27 (4): 853-886.

COOMBS, D.C. (1963) Trend and affinities of basaltic magmas and pyroxenes as illustraded on the diopside-olivine-silica diagram. Special Paper Min. Soc. Am., 1: 227-250.

CORDANI, U.G. \& BRITO NEVES, B.B. (1982) The geologic evolution of South America during the Archaean and Early Proterozoic. Rev. Bras. Geosc., 12: 78-88.

CORDANI, U.G.; TASSINARI, C.C.G.; TEIXEIRA, W.; BASEI, M.A.S.; KAWASHITA, K. (1979) Evoluçãotectônica da Amazônia com base nos dados geocronológicos. Actas 2 Congr. Geol. Chileno, Arica, Chile, 4: 137-148.

COSTA, J.B.S.; REIS NETO, J.; PINHEIRO, S.da S.; PESSOA, M.R. (1991) Organização litoestrutural do Proterozóico Médio do extremo norte do Estado de Roraima. In: Simpósio de Geologia da Amazônia, SBG, p. 179-192.

COX, K.G.; BELL, J.D.; PUNKHURST, R.J. (1979) The interpretation of igneous rochs. Ed. George Allen \& Unwin (Publishers)

Ltda. London, $450 \mathrm{p}$.

COX, K.G. \& HAWKESWORTH, C.J. (1985) Geochemical stratigraphy of the Deccan Traps at Mahabaleshwar, western Ghats, India, with implications for the open system magmatis processes. J. Petrology, 26(2): 355-377.

DALRYMPLE, G.B. (1979) Critical tables of conversion of $\mathrm{K}-\mathrm{Ar}$ ages from old to new constants. Geology, 7: 558-560.

DEER, W.A.; HOWIE, R.A.; ZUSSMAN, J. (1980) In introdution to the rock forming minerals. London, Logman, 528p. 
DE LA ROCHE, H.; LETERRIER, J.; GRANDCLAUD, P.; MARCHAL, M. (1980) A classification of volcanic and plutonic rocks using R1-R2 - diagram and map of element analyses. Its relationships with current nomenclature. Chemical Geological, 29: 183-210.

DE PAOLO, D.J. (1981) Trace element and isotopic effects of combined wallrock assimilation and fractional crystallization. Earth Plan. Sci. Lett., 53: 189-202.

DRAKE, M.J. (1975) The oxidation state of eropium as an indicator of oxygen fugacity. Geochim. Acta, 39: 55-64.

DUPUY, C. \& DOSTAL, J. (1984) Trace element geochemistry of some continental tholeiites. Earth Plan. Sci. Lett., 67: 61-69.

ELLAM, R.M. \& COX, K.G. (1989) A Proterozoic lithospheric source fot the Karoo magmatism: evidence from the Nuanetsi picrites. Earth Planet. Sci. Lett., 105: 330-342.

FAURE, G. (1986) Principle of isotope geology. New York. John Wiley \& Sons (2 $\underline{a}$ ed.) 589p.

ERAGA, L.M.; REIS, N.J.; VIEIRA, R. HADDAD, R.C. (1996) Suite intrusiva Pedra Pintada- um registro do magmatismo póscolisional no estado de Roraima. V Simpósio Geol. Amazônia, SGG, Belém-Pa, p. 76-78.

ERANZINI, M.; LEONI, L.; SAITA, M. (1975) Revisione di una metodologia analitica per fluorescenza-X, basata sulla correzione completa degli effeti di matrice. Rend. Soc. It. Miner. Petrol., 31: 365-378.

FRICK, U. \& STEIGER, R.H. (1974) K-Ar dating of some Guyana Shield Dyke Rocks. In: GANSSER, A., 1974. The Roraima Problem (South America). Verhand1. Na-tur. Ges., 84: 80-100.

GAUDETTE, H.E. \& OLSZEWSKI Ir, W.J. (1985) Geochronology of the basement rocks, Amazonas territory, Venezuela, and the tectonic evolution of the western Guiana shield. Geol. Mijnb., 64 : 131-144.

GIBBS, A.K. (1987) Contrasting styles of continental mafic intrusions in the Guiana Shield. In: Halss \& Fahrig (Eds). Geological Association of Canada, Special Paper, 34: 457465 .

GIBBS, A.K. \& BARRON, C.N. (1983) The Guiana Shield reviewed. Episodes, 2: 7-14.

GILL, J. (1981) Orogenic andesites and plate tectonics. Springer, Berlin Heidelberg New York, 390 pp.

GROENEWEG, W. \& BOSMA, W. (1970) A review of the stratigraphy in Suruname. In: Guiana Geological Conference, 8a, Georgetown, 1969. proceedings... Departament Geol. Mines, Georgetown, p. 1-32, 1970 i.l. 
HADDAD, C.R. et al. (1987) Projeto: geologia e potencial econômico do Supergrupo Uatumã na região do médio CotingoRR. Relatório Final. Convênio FUA/CNPq. Fundação Universidade do Amazonas. Instituto de Ciências Exatas. Departamento de Geociências, 39p.

HALLS, H.C. (1982) The importance and potencial of mafic dyke swarms in studies of geodynamic process. Geoscience Canada, $9(3): 145-154$.

HALLS, H.C. \& FAHRIG, W.F. (1987) Mafic dyke swarms. Geological Association of Canada, Special Paper, 34: 503p.

HANSON, G.N. (1980) Rare earth elements in petrogenetic studies of igneous systems. Ann. Rev. Earth Planet. Sci., 8: 371406 .

HARGRAVES, R.B. (1968) Paleomagnetism of the Roraima dolerites. Geophisical Journal, London, 16: 147-160.

HARLAND, W.B.; COX, A.V.; LLEWELLYN, P.G.; PICKTON, C.A.G.; EMITH, A.G.; WALTERS, R. (1982) Ageologic time scale, Cambridge University Press, Cambridge, $131 \mathrm{p}$.

HASSUI, $Y$ \& ALMEIDA, F.F.M. (1985) The Central Brazil shield reviewed. Episodes, 8: 29-37.

HAWKES, D.D. (1966) The petrology of the Guyana dolerites. Geological Magazine, London, 103: 320-335.

HAWKESWORTH, C.J. \& VOLLMER, R. (1979) Crustal contamination versus enriched mantle $143 \mathrm{Nd} / 144 \mathrm{Nd}, 87 \mathrm{Sr} / 86 \mathrm{Sr}$ evidence from the Italian volcanics. Contr. Miner. Petrol., 69: 151-165.

HEBEDA, E.H.; BOELRIJK, N.A.I.M.; PRIEM, H.N.A.; VERDURMEN, E.A.H.; VERSCHURE, R.H. (1973) Excess radiogenic argon in the precambrian Avanavero dolerite in western Surinam (South America). Earth Planetary Sciences Letters, 20(2): 189-200.

HELLMAN, P.L. \& GREEN, T.H. (1979) The role of sphene as an accessory phase in the high pressure partial melting of hydrous mafic compositions. Earth plan. Sci. Lett., 42: 191201.

HENDERSON, P. (1984) General geochemical properties and abundances of the rare earth elements. In: Rare earth element geochemistry, HENDERSON, P. (ed), Elseviers Publ. Co., Amsterdam, 1-32.

HERGT, J.M.; PEATE, D.W.; HAWKESWORTH, C.J. (1991) The petrogenesis of Mesozoic Gondwana low-Ti floos basalts. Earth Planet. Sci. Lett., 105: 134-148.

HOFFMAN, H.W. (1988) Chemical differentiation of the earth in the relationship between mantle continental crust and oceanic crust. Earth Plan. SCi. Lett., 90: 297-314. 
IRVINE, T.N. \& BARAGAR, W.R.A. (1971) A guide to the chemical classification of common rocks. Canadian Journal Earth Science, 8: 523-548.

IRVING, A.J. (1978) Areview of experimental studies of crystal/liquid trace element partitioning. Geochim. Cosmochim. Acta, 42: 743-770.

ISHII, T. (1975) The relations between temperature and composition of pigeonites in some lavas and their application to geothermometry. Mineralogical of Journal, $8(1): 48-57$.

ISSLER, R.S.; ANDRADE, A.R.F.; MONTALVÃO, R.M.G.; GUIMARÃES, G.; SILVA, G.G.; LIMA, M.I.C. (1974) Geologia da follha NA/BA.22 Macapá. In: Brasil DNPM. Radambrasil, Folha SA.22, Belém, Levantamentos de Recursos Naturais, 5.

JACQUES, A.L. \& GREEN, D.H. (1980) Anydrous melting of peridotite $0-15 \mathrm{~Kb}$ pressure and the genesis of tholeiitic basalts. Contrib. Mineral. Petrol., 73: 287-310.

JONES, J.P. (1985) The Southern border of the Guaporé Shield in western Brazil and Bolivia: an interpretation of its geologic evolution. Precambriam Research, 28: 111-136.

JORON, J.L. \& TREUIL, M. (1977) Utilization des propiétés des éléments fortment hygromagmatophiles pour l'etude de la composition chemique et de l'hétérogénéité du manteau. Bulletin de la Société Geológique de France.t. XIX, 6: 11971205.

JORON, J.L.; BOUGAULT, H.; WOOD, D.A.; TREUIL, M. (1973) Application de la geochimie des elements traces à l'étude des propriétés et des processus de genése de croûte océanique et du manteau supérieur. Bulletin de la société Geológique de France. 4:521-531.

KAWASHITA, K. (1972) O método $\mathrm{Rb}-\mathrm{Sr}$ em rochas sedimentares. Aplicação para as bacias do Paraná e Amazonas. Instituto Geoc./USP, Tese de Doutorado, 111p. (inédito).

KERR, P.F. (1959) Optical Mineralogy. McGraw-Hill. New York, 3ed., 442p.

KRETZ, R. (1982) Transfer and exchange equilibria in a portion of the pyroxene quadrilateral as deduced from natural and experimental data. Geochimical Cosmochimica Acta, 46: 411421.

KUDO, A.M. \& WEILL, D.F. (1970) An igneous plagioclase geothemometer. Contribution of Mineralogy and Petrology, 25: $52-65$.

LEAKE, B.E. (1978) Nomencleture of amphiboles. American Mineralogy, 63:1023-1052 
LE BAS, M.J.; LE MAITRE, R.W.; STRECKEISEN, A.; ZANETTIN, B. (1986) A chemical classification of volcanic rocks based on total alkali-silica diagram. Journal of Petrology, 27: 745750 .

LEONI, L. \& SAITTA, M. (1976) X-ray fluorescence analysis of 29 trace elements in rock and mineral standards. Rend. Soc. It. Miner. petrol., 32: 497-510.

LE ROEX, A.P. (1987) Source regions of mid-ocean ridge basalts: evidence for enrichment processes. In: Menzies, M.A., Haw Kesworth C.J. (eds) Mantle metassomarism, Academic Press, London, p. 389-422.

LETERRIER, J.; MAURY, R.C.; THONON, P.; MARCHAL, M. (1982) Clynopiroxenes composition as a method of identification of the magmatic affinities of paleo-volcanic series. Earth Plan. SCi. Lett., 59: 139-154.

LIMA, M.I.C.; MONTALVÃO, R.M.G.; ISSLER, R.S.; OLIVEIRA, A.S.; BASEI, M.A.S.; ARAUJO, J.F.V.; SCOLVA, G.G. (1974) Geologia. In: Brasil. DNPM. Radambrasil, folha NA/NB.22, Macapá, Levantamentos e Recursos Naturais, v.6, $120 \mathrm{p}$.

MACDONALD, G.A. \& KATSURA, T. (1964) Chemical composition of Hawaian Lavas. Journal of Petrology, 5: 82-133.

MACDOUGALL, J.D. (1988) Continental flood basalts. Kluwer Academic Publishers, Dordrecht, The Netherlands.

MANDETTA, P. (1970) Datações geocronológicas de rochas do Território Federal de Roraima. Belém, DNPM, 1970.

MANTOVANI, M.; CORDANI, U.G.; ROISEMBERG, A. (1985) Geoquímica isotópica em vulcânicas ácidas da Bacia do Paraná e implicações genéticas associadas. Rev. Bras. Geoc., 15(1): $61-65$.

MARQUES, L.S. (1983) Estudo do comportamento geoquímico de alguns elementos traços determinados em rochas vulcânicas da Bacia do Paraná. Dissertação de Mestrado, IAG/USP, 172p.

MARQUES, L.S. (1989) Caracterização geoquímica das rochas vulcânicas da Bacia do paraná: implicações petrogenéticas. Tese de Doutoramento. IAG/USP, $175 \mathrm{p}$.

MATHEZ, E.A. (1973) Refinement of the Kudo-Weill plagioclase thermometer and its application to basaltic rocks. Contribution of Mineralogy and Petrology, 41:61-72.

MAZZUCHELLI, M.; RIVALENTI, G.; PICCIRILLO, E.M.; GIRARDI, V.A.; CIVETTA, L.; PETRINI, R. (1995) Petrology of the Proterozoic mafic dyke swarms of Uruguay and constraints on their mantle source composition. Prec. Research, 74: 177-194.

MCCONNELL, R.B. \& WILLIAMS, E. (1969) Distribution and provisional correlation of the Precambrian of the Guyana 
Shield. In: Guyana Geological Conference, 80, Georgetown, 1969, Proceedings, Geol. Surv. of Guyana, p. 1-22, 1970.

MCCONNELL, R.B.; MASSON SMITH, D.; BERRANGÉ, J.P. (1969) Geological and geophysical evidence for a rift valley in the Guiana Shield. Geologie en Mijnbouw, 48:189-200.

MCCULLOCH, M.T. \& GAMBLE, J.A. (1991) Geochemical and geodynamical constraints on subdution zone magmatism. Earth Planet. SCi Lett., 102: 358-374.

MCDOUGALL, I. (1968) Isotopic dating of the Roraima dolerites. Geophysical Journal of the Royal Astronomic Society, London, 16: $141-145$.

MCDOUGALL, I.; COMPSTON, W.; HAWKES, D.D. (1963) Leakage of radiogenic argon and stron tium from minerals in proterozoic dolerites from British Guiana. Nature, 198(4880): 564-567.

MELO, A.F.F.; SANTOS, A.J. dos; CUNHA, M.T.P. da; CAMPOS, M.J.F.; D'ANTONA, R. de J.G. (1978) Projeto Molibdênio em Roraima. Relatório Final. Ministério das Minas e Energia, Departamento Nacional da Produção Mineral. Convênio DNPM/CPRM, Relatório Inédito, 6v. Manaus, AM.

MENDOZA, V. et al. (1975) Evolution geoquimica de rocas graniticas de la Guyana Venezuela. In: Conferencia Geologica Interguianas, 10a, Belém-PA. Anais..., Belém, DNPM, 558-575.

MENEZES LEAL, A.B. (1992) O enxame de diques máficos de UauáBahia: caracterização petrológica e geoquímica. Dissertação de Mestrado, IG-USP, São Paulo, 126p.

MENEZES LEAL, A.B. (1994) Magmatismo básico da porçao nordeste do estado de Roraima. I Workshop de Pós-Graduação do IG-USP. resumos Expandidos, p.18. Sãp Paulo-SP, 1994.

MENEZES LEAL, A.B. \& GIRARDI, V.A.V. (1994) Magmatismo básico da porção nordeste do estado de Roraima: aspectos geológicos e petrográficos (aspectos preliminares). XXXVIII Cong. Bras. Geol., v.3, p. 79-81. Balneario do Camboriu-SC.

MENEZES LEAL, A.B.; BELLIENI, G.; GIRARDI, V.A.V.; BASTOS LEAL, L.R.; TEIXEIRA, W.; PICCIRILLO, E.M. (1995) Contribuição ao estudo petrológico e geoquímico dos enxames de diques máficos de Uauá, Bahia, Brasil. Geochi. Brasil., 9(1): 6190.

MENEZES LEAL, A.B.; GIRARDI, V.A.V.; BASTOS LEAL, A.B. (1996) Magmatismo Basáltico mesozóico no Escudo das Guianas, norte do Craton Amazônico (estado de Roraima): aspectos geoquímicos e geocronológicos. XXXIX Cong. Bras. Geol., v.6: 170-172. Salvador-BA.

MENZIES, M.A. \& KYLE, P.R. (1990) Continental volcanism: a crust-mantle probe. In: MENZIES, M.A. (ed) Continental 
mantle. Oxford Science Publications. Clarendon Press, Oxford, pp. 157-177.

MICHARD, A.; GURRIET, P.; SOUNANT, M.; ALBARED, F. (1985) Nd isotopes in french fanerozoic shales: external vs internal aspects of crustal evolution. Geochimica et Cosmochimica Acta, 49(2): 601-610.

MINSTER, J.F.; MINSTER, J.B.; TREUIL, M.; ALLEGRÉ, C.J. (1977) Systematic use of trace elements in igneous processes. Part II: inverse problem of the fractional crystallization process in volcanic suites. Contribution of Mineralogy and Petrology, 61: 49-77.

MOHR, P.A. (1987) Crustal contamination in mafic sheets: a summary. In: Mafic Dyke Swarms. Geological Association of Canada, special Paper, 34: 75-80.

MONTALVÃO, R.M.G. \& BEZERRA, P.E.C. (1985) Evolução geotectônica do Craton Amazônico durante o Arqueano e Proterozóico. Anais II Simp. Geol. Amazonia, Belém, Brasil, SBG. vol. 1, p. 282297.

MONTALVÃO, R.M.C.de; MUNIZ, M. de B.; ISSLER, R.S.; DALLAGNOL, R.; LIMA, M.I.C.de; FERNANDEZ, P.E.C.A.; SILVA, C.G.da (1975) Geologia da Folha NA-20-Boa Vista; parte das folhas NA-21-Tumucumaque; NB-20-Roraima e NB-21. In: Projeto Radambrasil, v. 8, Rio de Janeiro, RJ.

NORAN INSTRUMENTS (1990) Quantitative analysis for scanning electron microscopes operators manual. Wisconsin, USA.

O'HARA, M.J. (1977) Geochemical evolution during fractional crystallization of a periodically refilled magma chamber. Nature, 226: 503-507.

O'HARA, M.J. \& MATHEWS, R.E. (1981) Geochemical evolution in an advancing, periodically, replenished, periodically tapped, continuosly fracionated magma chamber. J. Geol. Soc. London, 138: $237-277$.

OLIVEIRA, E.P. \& MONTES, M.L. (1984) Os enxames de diques máficos do Brasil. XXXIII Congresso Brasileiro de Geologia, Rio de Janeiro, 1984,4137-4154.

OLIVEIRA, E.P. \& TARNEY, J. (1990) Petrogenesis of the Canindé de São Francisco Complex: a major late Proterozoic gabbroic body in the Sergipe Foldbelt, north eastern Brazil. J.S. Am. Earth SCi, 3: 125-140.

ONSTOTT, T.C.; HARGRAVES, R.B.; YORK, D. (1984) Dating Precambriam diabase dykes of Venezuela using paleomagnetic and $\mathrm{Ar}^{40} / \mathrm{Ar}^{39}$ methocis. Anais II Symposium Amazônico, Manaus, Brasil, DNPM, 2: 513-518. 
PAPIKE, J.J.; CAMERON, K.; BALDNIN, K. (1974) Amphiboles and pyroxenes: caracterization of the other than quadrialteral components and estimated of ferric iron from microproble data. Bul1. Geol. Soc. Am. , 6: 1053-1054.

PATCHETT, P.J.; BYLUND, G.; UPTON, B.G.J. (1978) Paleomagnetism and the Greenville orogeny: new $\mathrm{Rb}-\mathrm{Sr}$ ages from dolerites in Canada and Groeland. Earth and Planet. Sci. Lett., 40: 349364 .

PICCIRILLO, E.M.; RAPOSO, M.I.B.; MELEI, A.J.; COMINCHIARAMONTI, P.; BELLIENI, G.; CORDANI, U.G.; KAWASHITA, K. (1987) Bimodal fissural volcanic suites from the Parana basin (Brazil): $\mathrm{K}-\mathrm{Ar}$ age, $\mathrm{Sr}$ isotopics and geochemistry. Geochim. Brasil., 1(1): 53-69.

PICCIRILLO, E.M.; CIVETA, L.; PETRINI, R.; LONGINELLI, A.; BELLIENI, G.; COMIN-CHIARAMONTI, P.; MARQUE, L.S.; MELEI, A.J. (1989) Regional variations within the Paraná basalts (Southern Brazil): evidence for subcontinental mantle heterogeneity and crustal contamination. Chem. Geol., 75: 103-122.

PICCIRILLO, E.M.; BELLIENI,G.; CAVAZZINI, G.; COMIN-CHIARAMONTI, P.; PETRINI, R.; MELFI, A.J.; PINESE, J.P.P.; ZANTEDESCHI, P.; DE MIN, A. (1990) Lower Cretaceous tholeitic dyke swarms from the Ponta Grossa Arch (southeast Brazil): petrology, Sr-Nd isotopes and genetic relationships with the Paraná flood volcanics. Chem. Geol., 89: 19-48.

PINESE, J.P.P. (1989) Caracterização petrológica e geoquímica dos diques do Arco de Ponta Grossa. Dissertação de Mestrado. IAG-USP, São Paulo. 196p.

PINESE, J.P.P. (1997) Geoquímica, geologia isotópica e aspectos petrológicos dos diques máficos pré-cambrianos da região de Lavras (MG), porção sul do Craton do São Francisco. Tese de Doutorado. IG-USP, $129 \mathrm{p}$.

PINHEIRO, S. da S.; REIS, N.J.; COSTI, H.T. (1990) Geologia da região de Caburai. Nordeste de Roraima. Texto Explicativo. Programa de Levantamentos Básicos do Brasil, Brasilia, 91p.

POLDERVAART, A. \& HESS, H.H. (1951) Pyroxene in the crystalization of basaltic magmas. J. Geology, 59: 472-489.

PRIEM, H.N.A.; HEBEDA, E.A.; BOELRIJK, N.A.I.M.; VERSCHURE, R.H. (1968) Isotopic age determinations on suriname rocks, 3 . proterozoic and Permo-Triassic basalt magmatism in the Guiana Shield. Geologie in Mynbouw, 47(1): 17-20.

PRIEM, H.N.A.; BOELRIJK, N.A.I.M.; HEBEDA, E.A.; VERDURMEN, E.A.; VERSCHURE, R.H. (1969) Isotopic geochronology in Suriname. In: Guiana Geological Conference, 8a, Georgetown. Proceeding... Georgetown, British Guyana, p. 11-15, 1970. 
PRIEM, H.N.A. (1970) Additional K-Ar measurements on PermoTriassic dolerites from Suriname. A.R.Z.W.O. Laboratory Isotopen Geology, Amsterdan, 87-88.

PRIEM, H.N.A.; BOELRIJK, N.A.I.M.; HEBEDA, E.H.; VERDURMEN, E.A.; VERSCHURE, R.H. (1971) Isotopic ages of the TransAmazonian acidic magmatism and the nickerie metamorphic episode in the Precambriam basement of suriname. South America. Geol. Soc. America Bull., 82(6): 1667-1680.

PRIEM, H.N.A.; BOELRIJK, N.A.I.M.; HEBEDA, E.H.; VERDURMEN, E.A.; VERSCHURE, R.H. (1973) Age of pre-cambriam Roraima Formation in Northeastern South America: evidence from isotopic dating of Roraima pyroclastic volcanic in Surinam. Geological Society of America Bulletin, 84(5): 1677-1684.

RAMGRAB, G.E.; BONFIM, L.E.C.; MANDETTA, P. (1972) Projeto Roraima, 2 a fase. Manaus, DNPM/CPRM, 1972. v.2.

REIS, N.J.; PINHEIRO, S. da S.; CARVALHO, S.E. (1985) Subdivisão estratigráfica da Eormação Suapi-Grupo Roraima-Território Federal de Roraima. In: Simpósio de Geologia da Amazônia, 2, Belém, Pará, 1985. Anais... Belém. SBG, Núcleo Norte. 1985, v.1, p. $408-420$.

REIS, N.J. \& PINHEIRO, S. da S. (1986) Síntese estratigráfica do Território Federal de Roraima. Manaus, CPRM, 1986. 39p (Inédito).

RICHARD, L.R. (1995) Minpet for Windows- version 2.02- Reference Manual Minpet Geological Software, Quebec, Canadá.

RIVALENTI, G.; MAZZUCHELLI, M.; PETRINI, R.; GIRARDI, V.A.V.; BOSSI, J.; CAMPAL, N. (1995) Petrology of late Proterozoic mafic dikes in the Nico Perez region, central Uruguay. Mineralogy and Petrology, 55: 239-263.

SANTOS, J.O.S. (1976) Subdivisão do Pré-cambriano da Amazônia, uma sugestão. CPRM/SUREG-AM, Manaus, AM.

SANTOS, J.O.S. (1985) A subdivisão estratigráfica do grupo Roraima. Simpósio de Geologia da Amazônia, 2, Belém, PA, v.1, p. 421-431.

SANTOS, J.O.S. \& LOGUERCIO, S.O.C. (1984) A parte meridional do Craton Amazônico. In: Geologia do Brasil. Ministério das Minas e Energia/DNPM, p. 93-127.

SANTOS, J.O.S. \& REIS NETO, J.M. (1982) Algumas idades de rochas graniticas do cráton Amazônico. In: Congresso Brasileiro de Geologia, 32, Salvador, Bahia. 1982. Anais....Salvador, SBG, 1982, v.1, p. 339-348.

SANTOS, J.O.S.; ARAUJO NETO, H.; SANTOS, A.J. dOS; OLIVETRA, J.R. de (1977) Principais manifestações básicas nãoorogênicas da Plataforma Amazônica. Manaus. CPRM, 1977, 132p. (Relatório Inédito). 
SATO, K.; TASSINARI, C.C.G.; KAWASHITA, K.; PETRONILHO, I. (1995) O método geocronológico $\mathrm{Sm}-\mathrm{Nd}$ no IG/USP e suas aplicações.

SATO, K. \& TASSINARI, C.C.G. (1996) Idades dos principais eventos de diferenciação manto-crosta do Craton Amazônico, com base em idades modelo Sm-Nd. V Simpósio de Geologia da Anmazônia, Belém, 1996, SBG/NO, p. 388-390.

SAUNDERS, A.D.; TARNEY, J.; WEAVER, S.D. (1980) Transverse geochemical variations across the Antartic peninsula: implications for the genesis of calc-alkaline magmas. Earth Plan. Sci. Lett., 46: 344-360.

SCHOBBENHAUS, C.; HOPPE, A.; LORK, A.; BAUMANN, A. (1994) Idade $\mathrm{U}-\mathrm{Pb}$ do magmatismo Uatumã no norte do Craton Amazônico, escudo das Guianas (Brasil): primeiros resultados. XXXVIII Congresso Brasileiro de Geologia, v.2, p. 395-397. Resumos Expandidos. Balneario do Camboriú, SC.

SHERATON, J.W. \& BLACK, L.P. (1981) Geochemistry and geocrhonology of proterozoic tholeiite dykes of East Antarctica: evidence for mantle metassomatism. Contr. Mineral. Petrol., 78: 305-317.

SIAL, A.N.; OLIVEIRA, E.P.; CHOUDHURI, A. (1987) Mafic dyke swarms of Brazil. In: Mafic Dyke Swarms, Halls \& Fahrig (Eds) Geological Association Canada, Special Paper, 34: 467481 .

SNELLING, N.J. (1963) Age of the Roraima Formayion, British Guiana. Nature, 198:1079-1080.

SNELLING, N.J. \& BERRANGÉ, J.P. (1969) The geochronology of Guyana: results obtained during the period 1966-1969, Geol. Sur. Gyuana. In: Guyana Geological Conference, 8 a, Proceedings... Geogetown, Britsh Guyana, IV, 20p, 1970.

SNELLING, N.J. \& MCCONNELI, R.B. (1969) The geochronology og Guyana. Geologie en Mijnbouw, 48(2): 201-213.

STEIGER, R.H. \& JAGUER, C. (1978) Subcomission on geochronology: convention of the use of decay constants in geocrhonology and cosmochronology. Contributions to the geologic time scale. Studies in Geology, 6: 67-72.

STORMER Jr., J.C. \& NICHOLLS, J. (1978) XLFRAC: a program for the interactive testing of magmatic differentiation models. Computer \& Geoscience, 4: 143-159.

SUCSZCZINSKY, E.F. (1970) La géologic et la tectonique de la platáforme Amazonienne. Geologishe Rundshau, 59(3):12321253.

SUN, S.S. \& MCDONOUGH, W.F. (1989) Chemical and isotopic systematic of oceanic basalts: implications for mantle 
composition and processes. In: Saunders, A.D. \& Norry, M.J. (eds) Magmatism in the ocean basins, Geol. Soc. London spec. Publ., 42: 315-345.

TAKAHARI, E. \& KUSHIRO, I. (1983) Melting of a dry peridotite at high pressure and basalt magma genesis. Am. Mineral, 68: 859-879.

TASSINARI, C.C.G. (1996) O mapa geocronológico do Craton Amazônico: revisão dos dados isotópicos. Tese de Livre Docência. IG-USP, São Paulo, 139p.

TASSINARI, C.C.G.; TEIXEIRA, W.; JUNIOR, O.S. (1989) Archean and Early Proterozoic crustal evolution of Amazonian Craton, Brazil. $28^{\text {th }}$ International Geological Congress, Washington, D.C. USA, p. 3-221.

TASSINARI, C.C.G.; CORDANI, U.G.; NUTMAN, A.P.; BITTENCOURT, J.S.; TAYLOR, P.N. (1996) Gochronological systematics on the basement rocks from the Rio Negro-Juruena Province (Amazonian Central) and tectonic implications. International Geology Review, 38: 161-175.

TATE, G.H.H. (1945) Notas sobre a região do Monte Roraima. Bol. Geogr. do C.W.G., 3(33):1-33.

TEIXEIRA, W. (1978) Significação tectônica do magmatismo anorogênico básico e alcalino na região Amazônica. Dissertação de Mestrado. Instituto de Geociências. Universidade de São Paulo, 99p.

TEIXEIRA, W. (1980) Significação tectônica do magmatismo anorogênico básico-alcalinoi de idade fanerozóica na região Amazônica. Anais do XXXI Cong. Bras. Geol., v.5, p. 27602772. Balneário do Camboriú-SC.

TEIXEIRA, W.; OJIMA, S.K.; KAWASHITA, K. (1984) A evolução geocronológica de rochas metamórficas e ígneas da faixa móvel Maroni-Itacaiunas na Guiana Francesa. Anais do II Symposium Amazônico, Manaus, AM, p. 75-81.

TEIXEIRA, W.; KAWASHITA, K.; TAYLOR, P.N.; OJIMA, S.K.; VIEIRA, A.G. (1985) Reconhecimento geocronológico da Guiana Francesa: novos dados, integração e implicações tectônicas. Anais do II Simpósio de Geologia da Amazônia, Belém, 1: 194207.

TEIXEIRA, W.; TASSINARI, C.C.G.; CORDANI, U.G.; KAWASHITA, K. (1986) A geochronology review of the Amazonian Craton. 99th Geological Society of America Annual Meeting, Abstr., San Antonio, $\mathrm{Tx}, 18: 770$.

TEIXEIRA, W. ; PECCHIO, M.; TAME, N.R.; KAWASHITA, K. (1988) Geocronologia $\mathrm{K} / \mathrm{Ar}$ do enxame de diques da parte meridional do Craton do São Francisco e implicações no contexto 
geotectônico. XXXV Congresso Brasileiro de Geologia, Anais. SBG. p. 2870-2878, Belém-PA.

TEIXEIRA, W.; TASSINARI, C.C.G.; CORDANI, U.G.; KAWASHITA, K. (1989) A review of the geochronology of the Amazonian Craton: tectonic implications. Precambriam Research, 42: 213-227.

THOMPSON, A.N.; MORRISON, M.; HENDRY, G.L.; PARRY, S.J. (1984) An assesment of the relative roles of crustal and mantle in magma genesis: and elemental approach. Philosophical Transactions of the Royal Society of London, 310: 549-590.

THORPE, R.S. (1982) Andesites: orogenic andesites and related rocks. Wiley, New York, $724 \mathrm{pp}$.

TOMAZ FILHO, A.; CORDANI, U.G.; OBERDAN, M. (1974) Idades K-Ar de rochas basálticas da bacia Amazônica e sua significação tectônica regional. XXVIII Congresso Brasileiro de Geologia. Anais... Porto Alegre-RS. v.6, p. 273-278.

TREUIL, M. \& VARET, J. (1973) Critéres volcanologiques, petrologiques et géoquimiques de la gênese et de la différenciation des magmas basaltiques: exemple de l'Afar. Bolletin de la Société Géologique de Erance, 7(15): 506p.

VIEIRA Jr, N. (1990a) Processos magmáticos: I-um algoritmo de identificação. Pesquisas, 17(1-2): 45-52.

VIEIRA Jr, N. (1990b) Processos magmáticos: II-um algoritmo de quantificação. Pesquisas, 17(1-2): 53-61.

WEAVER, B.L. \& TARNEY, J. (1981) Chemical changes during dyke metamorphism in high-grade basement terrains. Nature, 289: $47-49$.

WILLIAMS, E.; CANNON, R.T.; MCCONNELI, R.B. (1967) The folded precambrian of northern Guyana related to the geology of the Guyana Shield. Geol. Surv. Guyana Rec., Geogetown, 5, 1967.

WINDLEY, B.F. (1984) The evolving continente. John Winley and Sons, 2ed, 391p.

WOOD, B.J. \& BANNO, S. (1973) Garnet-orthopyroxene and orhopyroxene-clinopyroxene relationship in simple and complex system. Contribution of Mineralogy and Petrology, 42 : $109-124$.

YODER, H.S. Jr. \& TILLEY, C.E. (1962) Origin of basalt magmas: an experimental study of natural and synthetic rock systems. Journal of Petrology, 3: 342-532.

ZANETTIN, B. (1984) Proposed new chemical classification of volcanic rocks. Episodes, 7: 19-20. 


\section{Apêndices}

Apêndice 1- Tabela com os dados de campo das rochas pertencentes a Suíte Básica Apoteri.

Apêndice 2- Análises químicas de rocha total para as rochas pertencentes a Suíte Básica Apoteri.

Apêndice 3- Análises químicas de elementos terras raras para as rochas pertencentes a Suite Básica Apoteri.

Apêndice 4- Tabela com as descrições petrográficas simplificadas das rochas pertencentes a Suite Básica Apoteri.

Apêndice 5- Análises químicas da olivina e apatita utilizadas no cálculo de balanço de massa para elementos maiores.

Apêndice 6- Coeficientes de partição mineral/1íquido utilizados nos modelos de cristalização fracionada para od diques máficos da Suíte Básica Apoteri. 


\section{Apêndice- 1}

Tabela com os dados de campo das rochas pertencentes a suíte Básica Apoteri e suas respectivas rochas encaixantes

ABREVIATURAS UTILIZADAS:

C. Guian. = Complexo Guianense

R. Vulc. = Rocha vulcânica do Grupo Surumu

Sgr. RR = Supergrupo Roraima

Gr. Sara. = Granito Saracura

$\mathrm{DM}=$ Dique máfico

$\mathrm{DE}=$ Derrame basáltico 


\begin{tabular}{|c|c|c|c|c|c|c|}
\hline AMOSTRA & $\begin{array}{l}\text { LATITUTE } \\
\text { (N) }\end{array}$ & $\begin{array}{l}\text { LONGITUDE } \\
\text { (W) }\end{array}$ & $\begin{array}{c}\text { DIREÇÃO } \\
\text { DIQUE }\end{array}$ & $\begin{array}{l}\text { ESPESSURA } \\
\text { (II) }\end{array}$ & [RNCA IXANTTE & $\begin{array}{c}\text { TIPO } \\
\text { LITOLÓGICO }\end{array}$ \\
\hline RR-01 & $61^{\circ} 19^{\prime} 01^{\prime \prime}$ & $3^{\circ} 12^{\prime} 19^{\prime \prime}$ & $\mathrm{N} 40 \mathrm{E}$ & --- & C. Guian. & DM \\
\hline $\mathbf{R R}-02$ & $60^{\circ} 43^{\prime} 55^{\prime \prime}$ & $2^{\circ} 58^{\prime} 23^{\prime \prime}$ & & 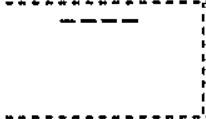 & & $\begin{array}{c}\text { DE } \\
\text { Nova } \\
\text { Olinda) }\end{array}$ \\
\hline$R R-03$ & $60^{\circ} 17^{\prime} 17^{\prime \prime}$ & $4^{\circ} 30^{\prime} 49^{\prime \prime}$ & $\mathrm{E}-\mathrm{W}$ & 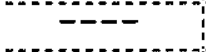 & vulc. & $\mathrm{DM}$ \\
\hline$R R-05$ & $60^{\circ} 10^{\prime} 42^{\prime \prime}$ & $3^{\circ} 12^{\prime} 51^{\prime \prime}$ & $\because-$ & $\cdots$ & & $\begin{array}{l}\mathrm{DE} \text { (Morro } \\
\text { Redondo) }\end{array}$ \\
\hline$R R-06$ & $60^{\circ} 52^{\prime} 30^{\prime \prime}$ & $2^{\circ} 42^{\prime} 19^{\prime \prime}$ & & & & $\begin{array}{l}\mathrm{DE} \text { (a sul } \\
\text { de Nova } \\
\text { Olinda) }\end{array}$ \\
\hline $\mathbf{R R}=07$ & $60^{\circ} 51^{\prime} 57^{\prime \prime}$ & $2^{\circ} 40^{\prime} 42^{\prime \prime}$ & & & & $\begin{array}{l}\mathrm{DE}(i \mathrm{dem} \\
\mathrm{RR}-06)\end{array}$ \\
\hline $\mathbf{R R}-08$ & $60^{\circ} 45^{\prime} 00^{\prime \prime}$ & $2^{\circ} 52^{\prime} 30^{\prime \prime}$ & $-\cdots$ & & & $\begin{array}{l}\text { DE (rio } \\
\text { Cauamé) }\end{array}$ \\
\hline RR-09 & $60^{\circ} 50^{\prime} 21^{\prime \prime}$ & $2^{\circ} 55^{\prime} 10^{\prime \prime}$ & 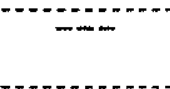 & & & $\begin{array}{c}D E(1 \mathrm{dem} \\
\mathrm{RR}-06)\end{array}$ \\
\hline$R R-14$ & $60^{\circ} 10^{\prime} 32^{\prime \prime}$ & $4^{\circ} 35^{\prime} 27^{\prime \prime}$ & $\mathrm{NE}$ & $\approx 5$ & $\mathrm{Sg} x=\mathrm{RR}$ & $\mathrm{DM}$ \\
\hline$R R-15$ & $60^{\circ} 10^{\prime} 58^{\prime \prime}$ & $4^{\circ} 32^{\prime} 40^{\prime \prime}$ & & & & \\
\hline$R R-16$ & $60^{\circ} 10^{\prime} 10^{\prime \prime}$ & $4^{\circ} 34^{\prime} 49^{\prime \prime}$ & $\mathrm{NE}$ & -1 & $S g r . R$ & $\mathrm{DM}$ \\
\hline$R R-17$ & $60^{\circ} 13^{\prime} 30^{\prime \prime}$ & $4^{\circ} 34^{\prime} 21^{\prime \prime}$ & $\mathrm{NE}$ & & Sgr. RR & $\mathrm{DM}$ \\
\hline$R R-18$ & $60^{\circ} 17^{1} 17^{\prime \prime}$ & $4^{\circ} 30^{\prime} 49^{\prime \prime}$ & $\mathrm{NE}$ & $\approx 50$ & R. vuic. & $\mathrm{DM}$ \\
\hline$R R-19$ & $60^{\circ} 19^{\prime} 11^{\prime \prime}$ & $4^{\circ} 31^{\prime} 21^{\prime \prime}$ & $=-$ & $\ldots$ & R. Vuilc. & $\mathrm{DM}$ \\
\hline$R R-22$ & $60^{\circ} 14^{\prime} 19^{\prime \prime}$ & $4^{\circ} 31^{\prime} 34^{\prime \prime}$ & $=-$ & $\cdots$ & Sgr. RR & $\mathrm{DM}$ \\
\hline$R R-23$ & $60^{\circ} 20^{\prime} 48^{\prime \prime}$ & $4^{\circ} 29^{\prime} 43^{\prime \prime}$ & -- & & R. Vuic. & $\mathrm{DM}$ \\
\hline$R R-24$ & $60^{\circ} 20^{\prime} 48^{\prime \prime}$ & $4^{\circ} 28^{\prime} 05^{\prime \prime}$ & $\mathrm{NE}$ & $\approx 3$ & R. vuic. & $\mathrm{DM}$ \\
\hline$R R-25$ & $60^{\circ} 08^{\prime} 22^{\prime \prime}$ & $4^{\circ} 37^{\prime} 05^{\prime \prime}$ & $\mathrm{N} 30-40 \mathrm{E}$ & $\approx 15$ & R. Vuic. & $\mathrm{DM}$ \\
\hline$R R-26$ & $60^{\circ} 18^{\prime} 06^{\prime \prime}$ & $4^{\circ} 27^{\prime} 49^{\prime \prime}$ & $\mathrm{N} 25 \mathrm{E}$ & $\approx 5$ & R. Vuic. & $\mathrm{DM}$ \\
\hline$R R-28$ & $60^{\circ} 15^{\prime} 15^{\prime \prime}$ & $4^{\circ} 27^{\prime} 35^{\prime \prime}$ & $=$ & - & R. Vulc. & $\mathrm{DM}$ \\
\hline$R R-31$ & $59^{\circ} 56^{\prime} 15^{\prime \prime}$ & $4^{\circ} 27^{\prime} 03^{\prime \prime}$ & $\mathrm{N} 35 \mathrm{E}$ & $\approx 4$ & $\mathrm{R} \cdot$ Vulc. & $\mathrm{DM}$ \\
\hline$R R-32$ & $59^{\circ} 53^{\prime} 02^{\prime \prime}$ & $4^{\circ} 23^{\prime} 18^{\prime \prime}$ & $\approx N 40 E$ & $\approx 10$ & $\mathrm{R} . \mathrm{vulc}$ & $\mathrm{DM}$ \\
\hline$R R-33$ & $59^{\circ} 50^{\prime} 05^{\prime \prime}$ & $4^{\circ} 23^{\prime} 02^{\prime \prime}$ & $\mathrm{N} 40 \mathrm{E}$ & $=-$ & R. Vuic. & $\mathrm{DM}$ \\
\hline$R R-34$ & $59^{\circ} 38^{\prime} 34^{\prime \prime}$ & $3^{\circ} 54^{\prime} 38^{\prime \prime}$ & $\mathrm{NE}$ & $\approx 40$ & R. Vuic. & $\mathrm{DM}$ \\
\hline$R R-35$ & $60^{\circ} 05^{\prime} 37^{\prime \prime}$ & $4^{\circ} 23^{\prime} 02^{\prime \prime}$ & $\mathrm{NE}$ & $\approx 20$ & R. Vulc. & $\mathrm{DM}$ \\
\hline$R R-36$ & $60^{\circ} 28^{\prime} 38^{\prime \prime}$ & $4^{\circ} 21^{\prime} 04^{\prime \prime}$ & $\mathrm{NE}$ & $\approx 50$ & R. Vuic. & DM \\
\hline$R R-37$ & $60^{\circ} 18^{\prime} 06^{\prime \prime}$ & $4^{\circ} 09^{\prime} 43^{\prime \prime}$ & $\mathrm{NE}$ & $\approx 30$ & R. vulc. & $\mathrm{DM}$ \\
\hline$R R-38$ & $60^{\circ} 20^{\prime} 53^{\prime \prime}$ & $4^{\circ} 12^{\prime} 25^{\prime \prime}$ & (n..... & & R. Vuic. & DM \\
\hline$R R-39$ & $59^{\circ} 55^{\prime} 10^{\prime \prime}$ & $3^{\circ} 20^{\prime} 05^{\prime \prime}$ & $=-$ & & & $\begin{array}{l}\text { DE (rio } \\
\text { Arraia) }\end{array}$ \\
\hline$R R-40$ & $59^{\circ} 53^{\prime} 02^{\prime \prime}$ & $3^{\circ} 21^{\prime 2} 5^{\prime \prime}$ & 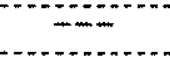 & 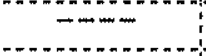 & & $\mathrm{DE}$ \\
\hline$R R-41$ & $59^{\circ} 38^{\prime} 34^{\prime \prime}$ & $3^{\circ} 54^{\prime} 38^{\prime \prime}$ & $\ldots$ & $=0$ & & $\mathrm{DM}$ \\
\hline$R R-42$ & $60^{\circ} 08^{\prime} 50^{\prime \prime}$ & $3^{\circ} 55^{\prime} 10^{\prime \prime}$ & 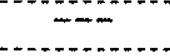 & nan & C. Guian. & $\mathrm{DM}$ \\
\hline $\mathrm{RR}-43$ & $60^{\circ} 12^{\prime} 51^{\prime \prime}$ & $3^{\circ} 55^{\prime} 42^{\prime \prime}$ & $=$ & $=$ & C. Guian. & $\mathrm{DM}$ \\
\hline$R R-44$ & $60^{\circ} 06^{\prime} 25^{\prime \prime}$ & $4^{\circ} 01^{\prime} 52^{\prime \prime}$ & $\mathrm{N} 30 \mathrm{E}$ & $\approx 40$ & C. Guian. & DM \\
\hline$R R-46$ & $59^{\circ} 55^{\prime} 10^{\prime \prime}$ & $3^{\circ} 57^{\prime} 35^{\prime \prime}$ & $\mathrm{NE}$ & 20 & Gr. Sara. & $\mathrm{DM}$ \\
\hline
\end{tabular}




\begin{tabular}{|c|c|c|c|c|c|c|}
\hline AMOSTRA & $\begin{array}{l}\text { ILATITUDE } \\
\text { (N) }\end{array}$ & $\begin{array}{l}\text { LONGITUDE } \\
\text { (F) }\end{array}$ & $\begin{array}{c}\text { DIREÇÃo } \\
\text { DIQUE }\end{array}$ & $\begin{array}{c}\text { ESPESSURA } \\
\text { (m) }\end{array}$ & ENCA TXANTE & $\begin{array}{c}\text { TIPO } \\
\text { IITOLÓGICO }\end{array}$ \\
\hline$R R-48$ & $60^{\circ} 06^{\prime} 09^{\prime \prime}$ & $4^{\circ} 04^{\prime} 49^{\prime \prime}$ & N35E & $\approx 5$ & c. Guian. & $\mathrm{DM}$ \\
\hline$R R-50$ & $59^{\circ} 54^{\prime} 38^{\prime \prime}$ & $4^{\circ} 06^{\prime} 09^{\prime \prime}$ & $\mathrm{N} 30 \mathrm{E}$ & $\approx 4$ & R. Vulc. & $\mathrm{DM}$ \\
\hline$R R-5 I$ & $60^{\circ} 08^{\prime} 50^{\prime \prime}$ & $4^{\circ} 12^{\prime} 51^{\prime \prime}$ & $\mathrm{NE}$ & $\approx 6$ & $\mathrm{R}$. vulc. & $\mathrm{DM}$ \\
\hline$R R-52$ & $60^{\circ} 05^{\prime} 05^{\prime \prime}$ & $4^{\circ} 09^{\prime} 16^{\prime \prime}$ & & $=--$ & $\mathrm{R}$. & $\mathrm{DM}$ \\
\hline$R R-53$ & $60^{\circ} 05^{\prime} 05^{\prime \prime}$ & $4^{\circ} 12^{\prime} 19^{\prime \prime}$ & $\mathrm{NE}$ & $\approx 5$ & R. Vulc." & $\mathrm{DM}$ \\
\hline$R R-54$ & $60^{\circ} 03^{\prime} 45^{\prime \prime}$ & $4^{\circ} 18^{\prime} 19^{\prime \prime}$ & $\mathrm{N} 50 \mathrm{E}$ & $\approx 2$ & R. Vulc." & $\mathrm{DM}$ \\
\hline$R R-55$ & $60^{\circ} 00^{\prime} 00^{\prime \prime}$ & $4^{\circ} 13^{\prime} 55^{\prime \prime}$ & $\mathrm{N} 30 \mathrm{E}$ & $\approx 3$ & R. Vulc. & $\mathrm{DM}$ \\
\hline$R R-56$ & $59^{\circ} 54^{\prime} 06^{\prime \prime}$ & $4^{\circ} 10^{\prime} 26^{\prime \prime}$ & $\mathrm{NE}$ & $\approx 10$ & $\mathrm{R} . \mathrm{VuIC}$ & $\mathrm{DM}$ \\
\hline $\mathrm{RR}-57$ & $59^{\circ} 54^{\prime} 06^{\prime \prime}$ & $4^{\circ} 15^{\prime} 26^{\prime \prime}$ & $\mathrm{N} 45 \mathrm{E}$ & $\approx 4$ & $\mathrm{R}$. Vulc. & $\mathrm{DM}$ \\
\hline
\end{tabular}




\section{Apêndice-2}

Análises químicas de rocha total para as rochas pertencentes a Suíte Básica Apoteri

ABREVIATURAS UTILIZADAS:

P.F. = Perda ao fogo

nd $=$ elemento não determinado

* = abaixo do limite de detecção

Class. = Classificação segundo De La Roche et al. (1980);

Bellieni et al. (1981). bth = basalto toleítico; $a b=$ andesibasalto; $1 b=$ lati basalto. 


\begin{tabular}{|l|l|l|l|l|l|l|l|l|}
\hline AMOSTRA & RR-01A & RR-01B & RR-01C & RR-14 & RR-16 & RR-17 & RR-18A & RR-18D \\
\hline
\end{tabular}

\section{ELEMENTOS MATORES (\% em PESO)}

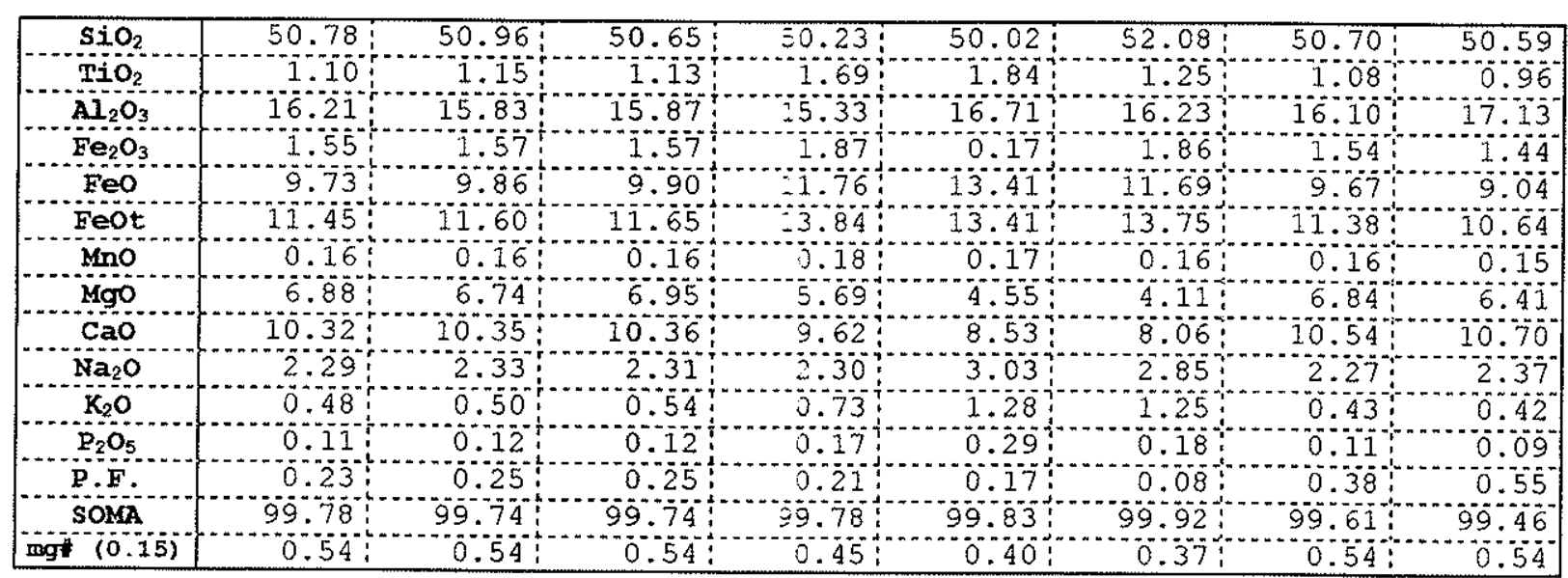

NORMA (CIPW)

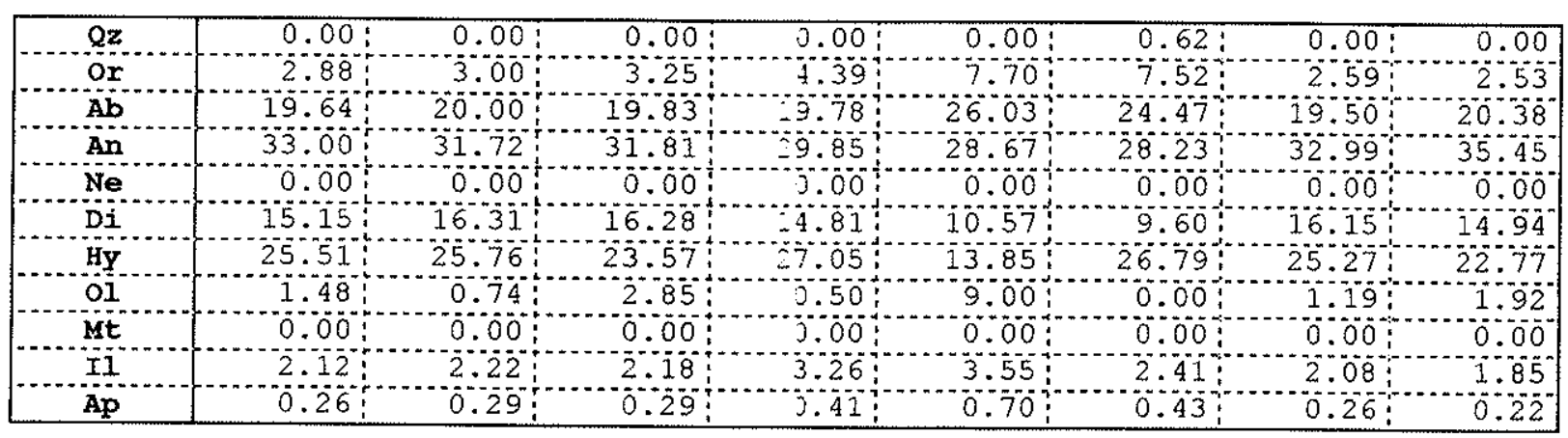

ELEMENTOS TZZÇOS (PPM)

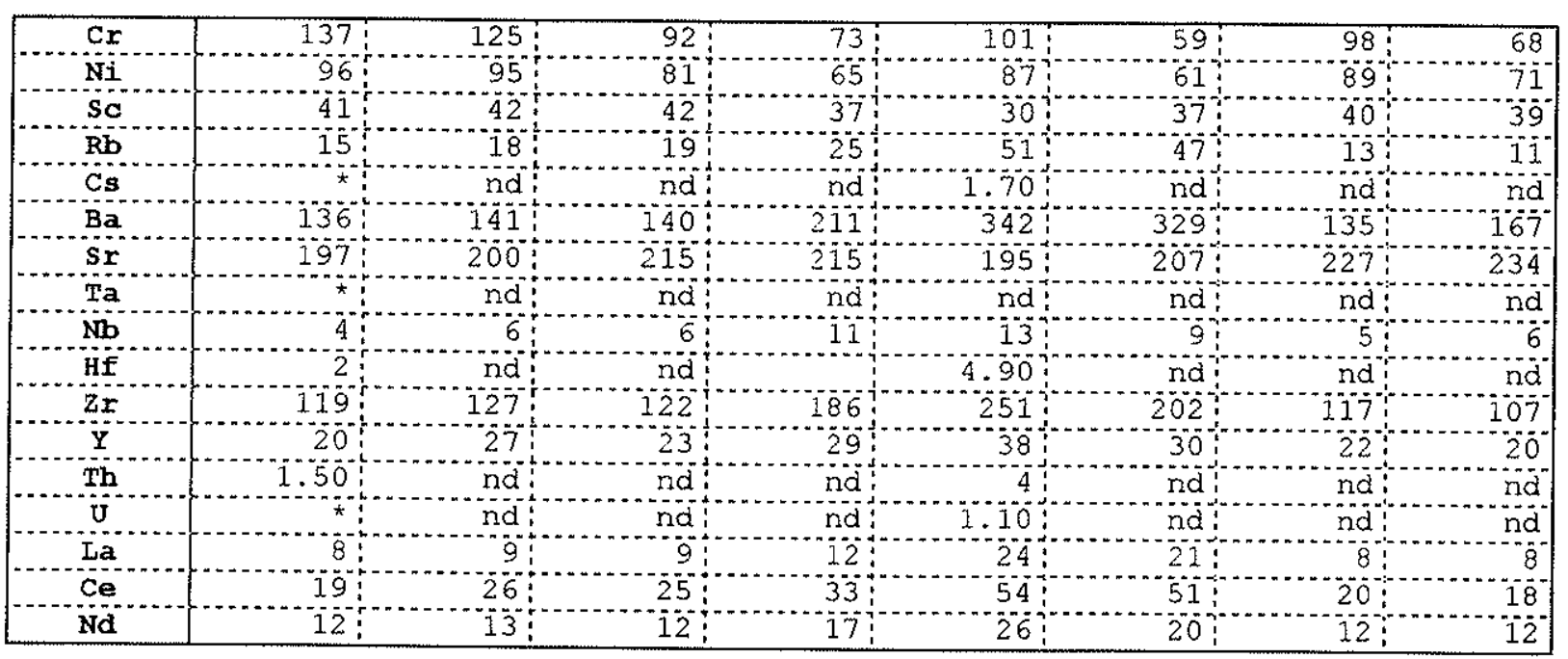




\begin{tabular}{|l|l|l|l|l|l|l|l|l|}
\hline AMOSTRA & RR-18E & RR-18E & RR-18G & RR-22 & RR-25B & RR-26 & RR-28 & RR-31A \\
\hline
\end{tabular}

\section{ELEMENTOS MAIORES (옹 em peSO)}

\begin{tabular}{|c|c|c|c|c|c|c|c|c|}
\hline $\mathrm{SiO}_{2}$ & 51.83 & 52.45 & 49.69 & 50.26 & 53.04 & 52.84 & 51.52 & 50.41 \\
\hline $\mathrm{TiO}_{2}$ & 1.32 & 1.29 & 1.59 & 0.73 & 1.22 & 1.31 & 1.34 & 1.14 \\
\hline $\mathrm{Al}_{2} \mathrm{O}_{3}$ & 15.18 & 15.05 & $15: 40$ & 17.12 & 15.74 & 14.91 & 15.71 & 15.9 \\
\hline $\mathrm{Fe}_{2} \mathrm{O}_{3}$ & 1.72 & 1.68 & 1.87 & 1.57 & 1.58 & 1.59 & & 1.58 \\
\hline Feo & 10.84 & 10.61 & 11.79 & 9.91 & 9.92 & 1001 & 12.28 & 99 \\
\hline $\mathrm{FeO}_{\mathrm{t}}$ & 12.75 & 12.48 & 13.87 & 11.66 & 11.67 & 11.78 & 14.45 & 11.72 \\
\hline MT & 0.17 & 0.16 & 0.19 & 0.16 & 0.15 & 0.16 & 0.161 & 0.16 \\
\hline $\mathrm{MgQ}$ & 5.74 & 5.70 & 5.12 & 6.85 & 5.13 & 5.64 & 4.34 & 6.47 \\
\hline $\mathrm{CaO}$ & 9.32 & 9.19 & 10.33 & 10.41 & 8.44 & 8.69 & 8.26 & 9.8 \\
\hline $\mathrm{Na}_{2} \mathrm{O}$ & 2.82 & 2.69 & 2.26 & 2.27 & 2.83 & 2.67 & 2.77 & 2.55 \\
\hline $\mathrm{K}_{2} \mathrm{O}$ & 0.48 & 0.59 & 0.74 & 0.44 & 0.89 & 0.83 & 1.19 & 0.5 \\
\hline $\mathrm{P}_{2} \mathrm{O}_{5}$ & 0.11 & 0.13 & 0.17 & 0.05 & 0.18 & 0.15 & 0.16 & 0.13 \\
\hline P.F. & 0.27 & 0.28 & 0.64 & 0.06 & 0.71 & $\frac{1.01}{0.01}$ & $\begin{array}{l}0.10 \\
0=0 \\
0\end{array}$ & $1: 05$ \\
\hline SOMA & 99.72 & 99.73 & 99.36 & 99.95 & 99.29 & 98.98 & $99: 901$ & $98 \cdot 94$ \\
\hline $\mathrm{mg} \#(0.15)$ & 0.47 & 0.47 & 0.42 & 0.54 & 0.46 & 0.49 & $0.37:$ & 0.52 \\
\hline
\end{tabular}

NORMA (CIPW)

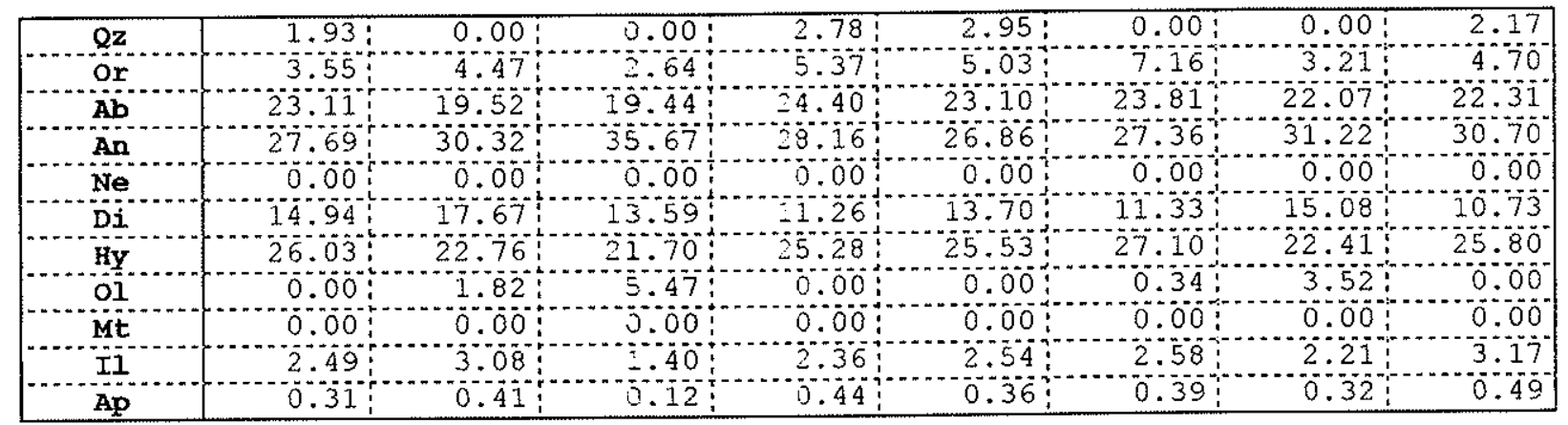

ELEMENTOS IZACOS (pPM)

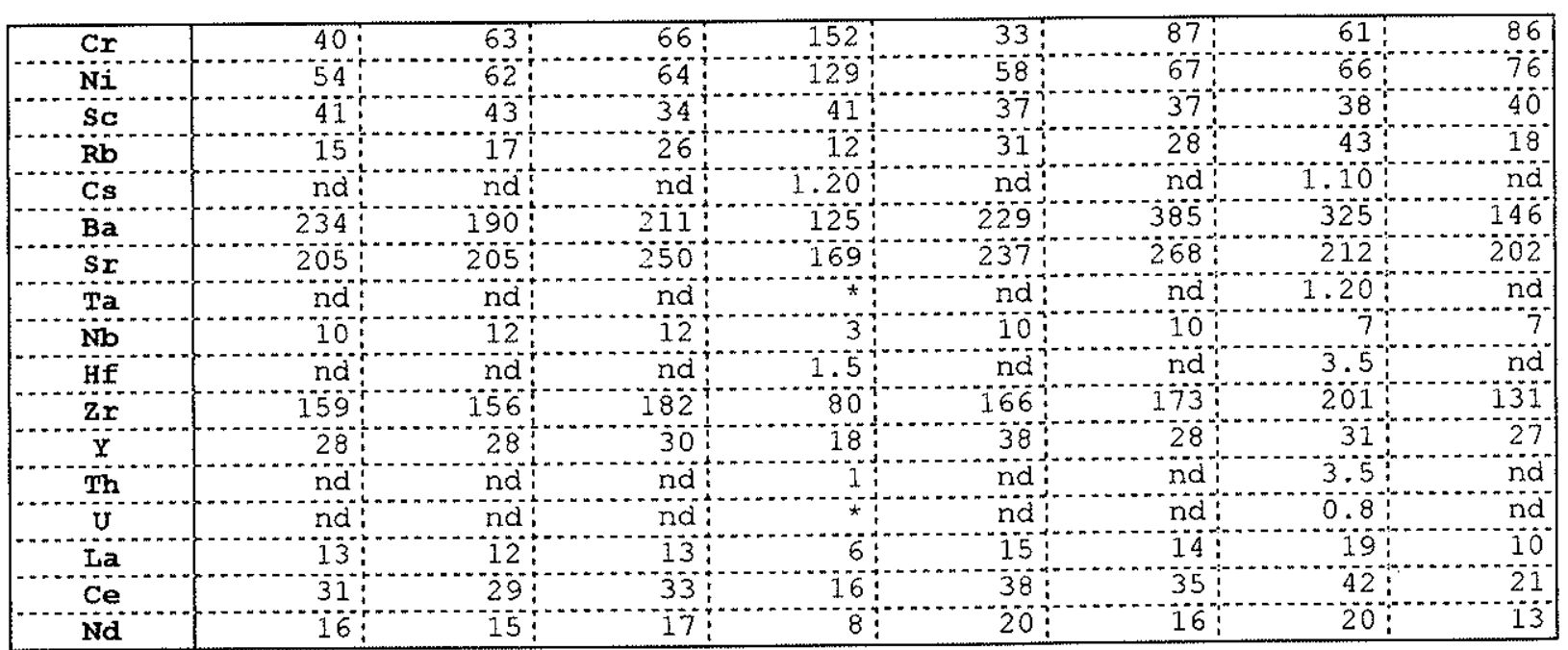




\begin{tabular}{|c|c|c|c|c|c|c|c|c|}
\hline AMOSTRA & $R R-31 B$ & $R R-32$ & $\mathbf{R R}-\mathbf{3 3}$ & $R R-34$ & $\mathbf{R R}-35 \mathbf{A}$ & $R R-35 B$ & $\mathbf{R R}-35 \mathbf{C}$ & $\mathrm{RR}-36 \mathrm{~A}$ \\
\hline \multicolumn{9}{|c|}{ ELEMENTOS MAIORES } \\
\hline $\mathrm{SiO}_{2}$ & 51.02 & 52.0 & 50.4 & 49.9 & 50.42 & 50.89 & 52.42 & 50.78 \\
\hline $\mathrm{TiO}_{2}$ & 1.62 & 1.2 & $=$ & 1.0 & 0.90 & 1.03 & 1. & 1.06 \\
\hline $\mathrm{Al}_{2} \mathrm{O}_{3}$ & 5.96 & 15.8 & & 6.1 & 19.2 & 6.58 & 4.91 & 6.32 \\
\hline $\mathrm{Fe}_{2} \mathrm{O}_{3}$ & 1.68 & 1.5 & & 1.5 & 1.29 & 1.48 & 78 & 1.50 \\
\hline Feo & 10.61 & 10.0 & 9.8 & 9.9 & 8.15 & 9.35 & $11: 19$ & 9.48 \\
\hline $\mathrm{FeO}_{\mathrm{t}}$ & 12.48 & 11.7 & 1.6 & $11: 7$ & 9.59 & 11.00 & 13.17 & $1: 15$ \\
\hline Mino" & 0.16 & 0.1 & 0.1 & 0.1 & 0.12 & 0.15 & 0.16 & 0.16 \\
\hline $\mathrm{MgO}$ & 4.83 & 5.9 & & 7.2 & 5.7 & 6.77 & $4: 30$ & 6.61 \\
\hline $\mathrm{CaO}$ & 8.74 & 8.9 & & 10.3 & 10.65 & 10.18 & 7.8 & 0.42 \\
\hline $\mathrm{Na}_{2} \mathrm{O}$ & & 30 & & 2.2 & 2.48 & 2.35 & 2 & 2.41 \\
\hline $\mathrm{K}_{2} \mathrm{O}$ & 0 & 0.7 & 0.5 & 0.4 & 0.30 & 0.47 & & 0.45 \\
\hline $\mathrm{p}_{2} \mathrm{O}_{5}$ & $0=20$ & 0.1 & 0.1 & 0.1 & $0=0$ & 0.11 & 0.2 & 0.12 \\
\hline P.F. & 1.66 & 0.4 & 0.8 & & 0.35 & 0.47 & 1.11 & 0.51 \\
\hline SOMA & $98: 34$ & 99.5 & & & 99.6 & 99.53 & 98.8 & 99.48 \\
\hline$m g \#(0.15)$ & 0.43 & 0.5 & 3.5 & 0.5 & 0.54 & 0.55 & 0.30 & 0.54 \\
\hline
\end{tabular}

NORMA (CIPW)

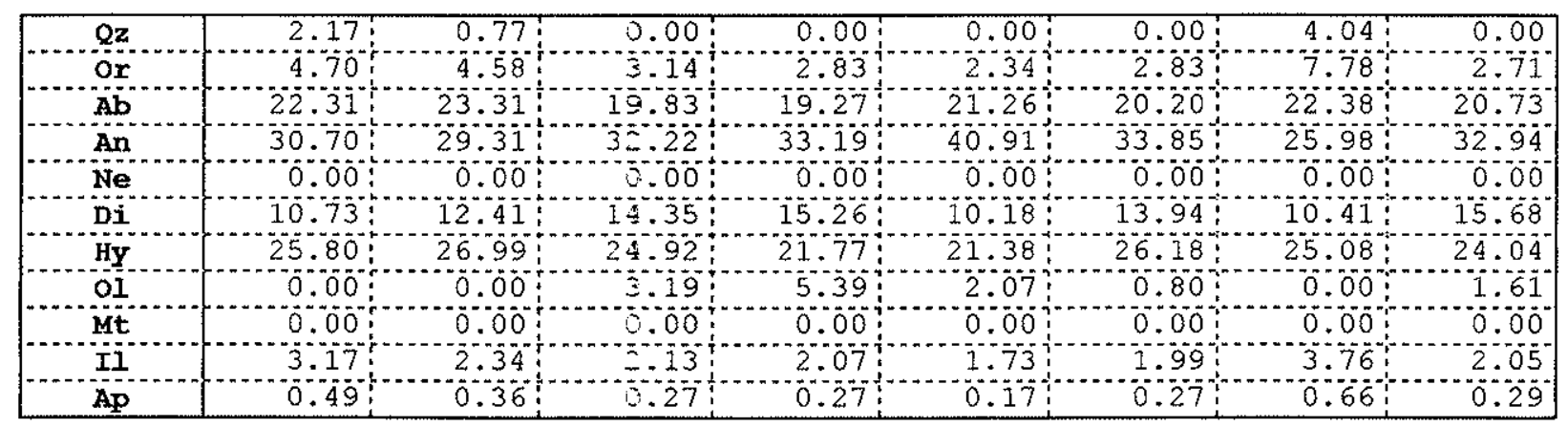

ELEMENTOS TRAÇOS (ppm)

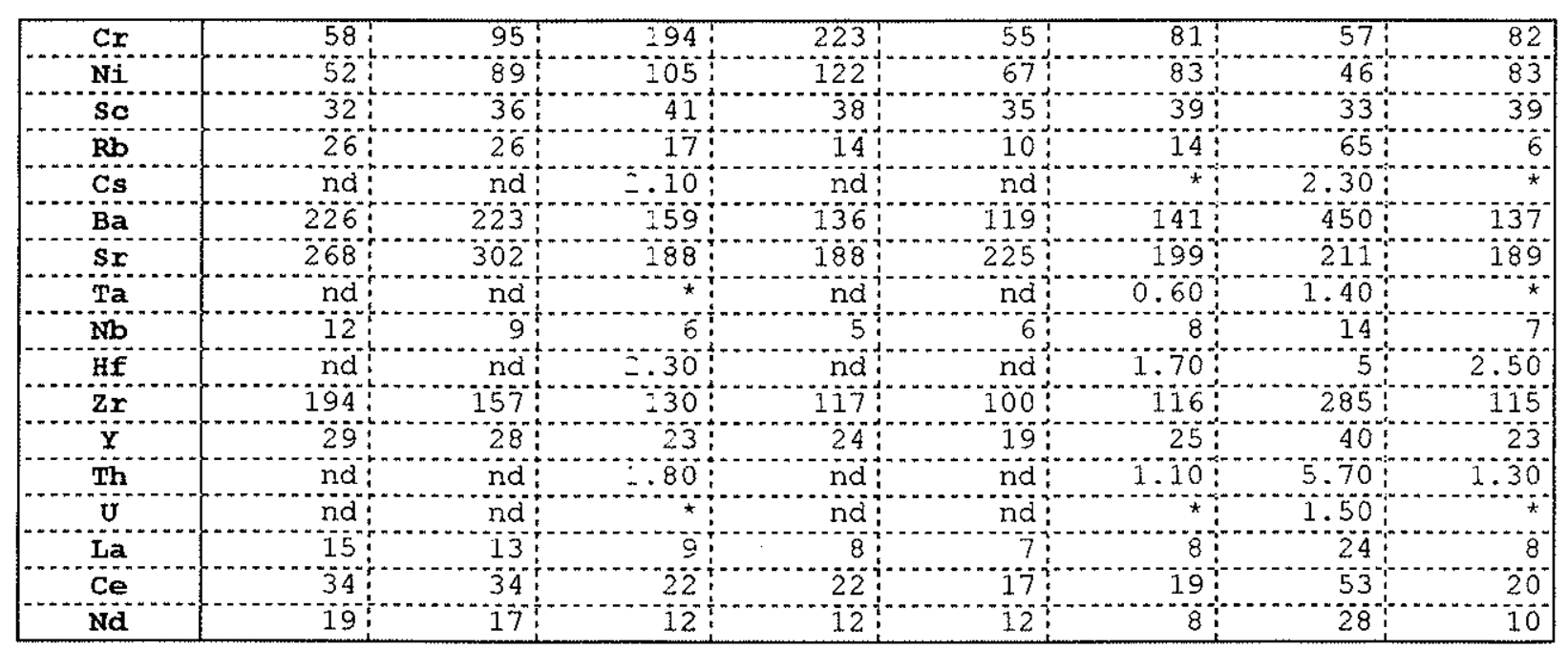

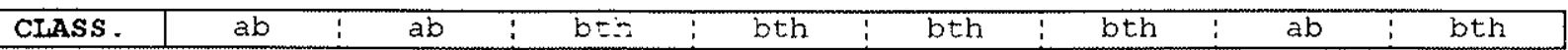


\begin{tabular}{|l|l|l|l|l|l|l|l|l|}
\hline AMOSTRA & RR-36B & RR-37B & RR-38 & RR-42B & RR-42C & RR-43 & RR-44 & RR-46A \\
\hline
\end{tabular}

\section{ELEMENTOS MATORES (응 em peso)}

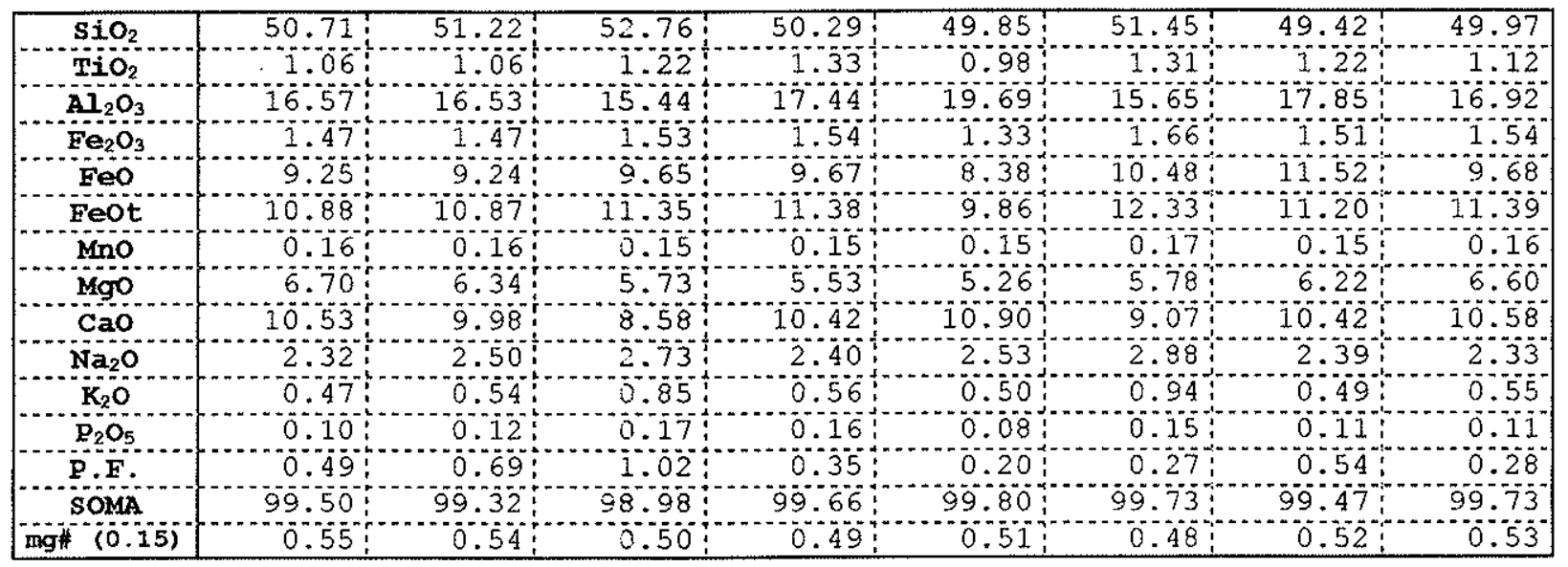

NORMA (CIPW)

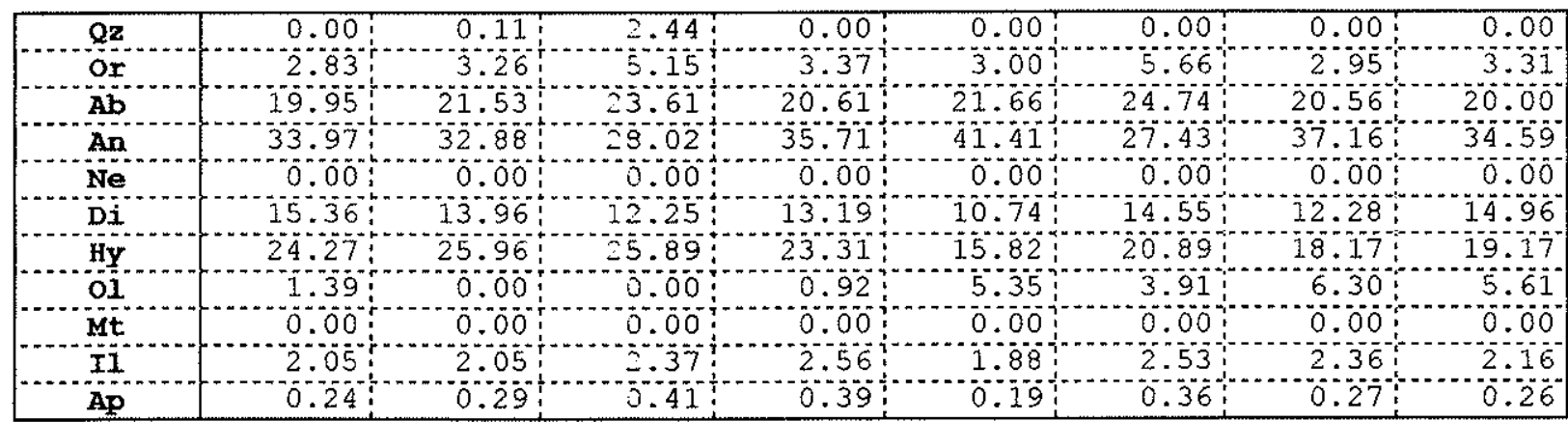

ELEMENTOS TRAÇOS (PPM)

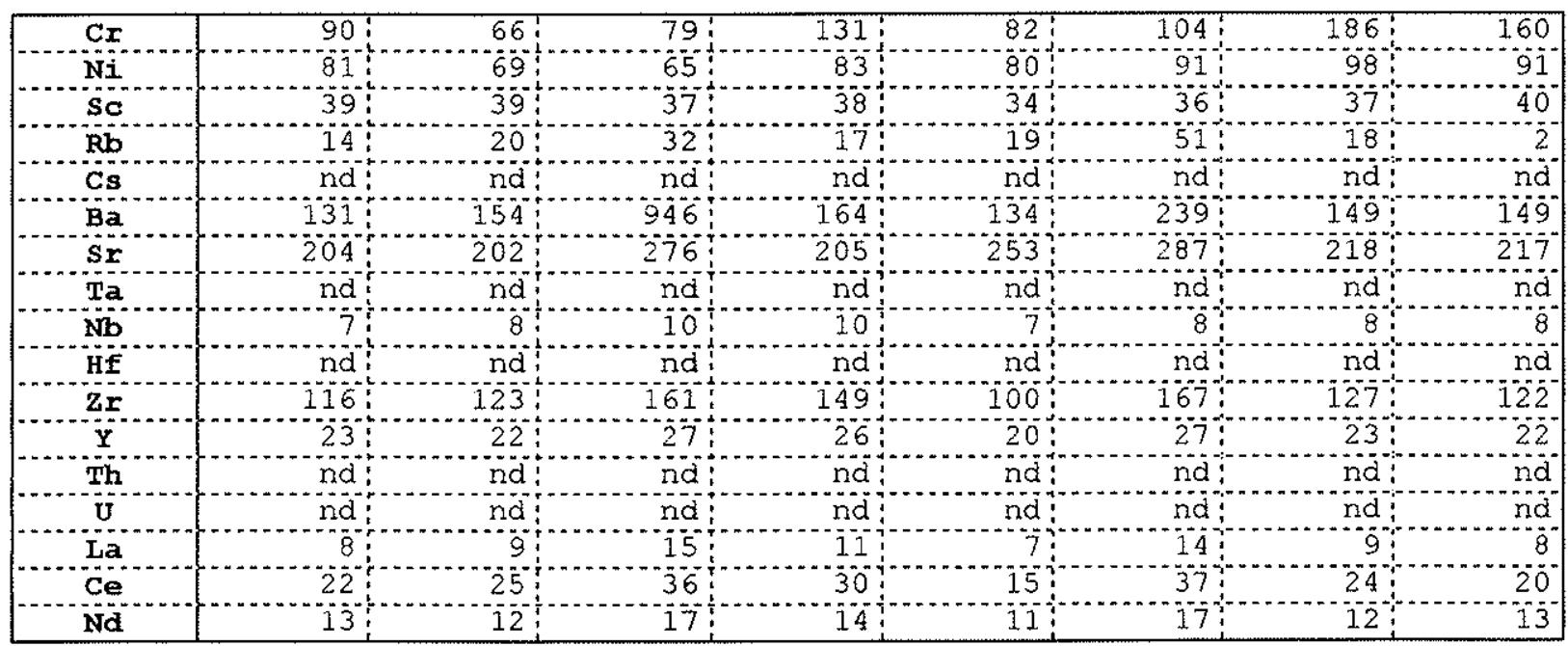

CIASS. 


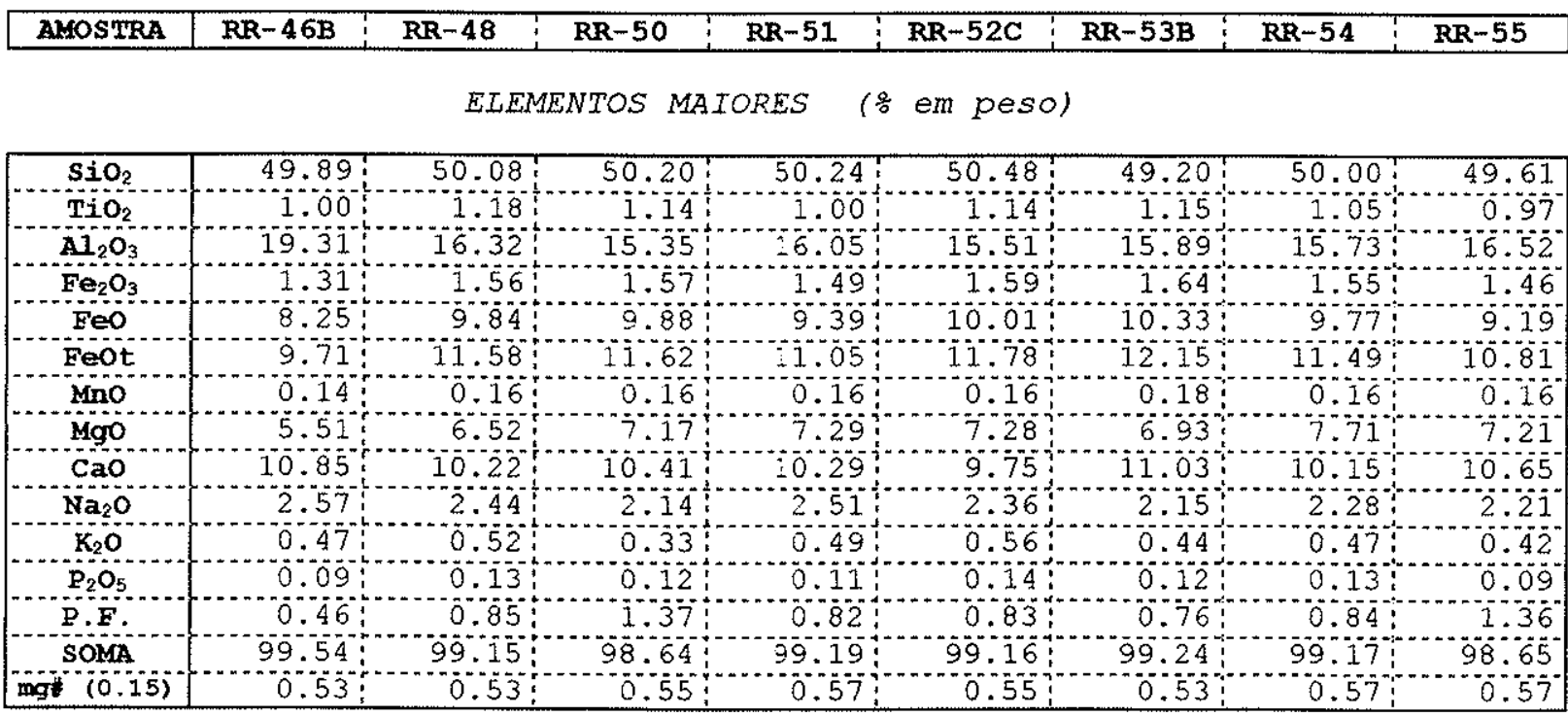

\section{NORMA (CIPW)}

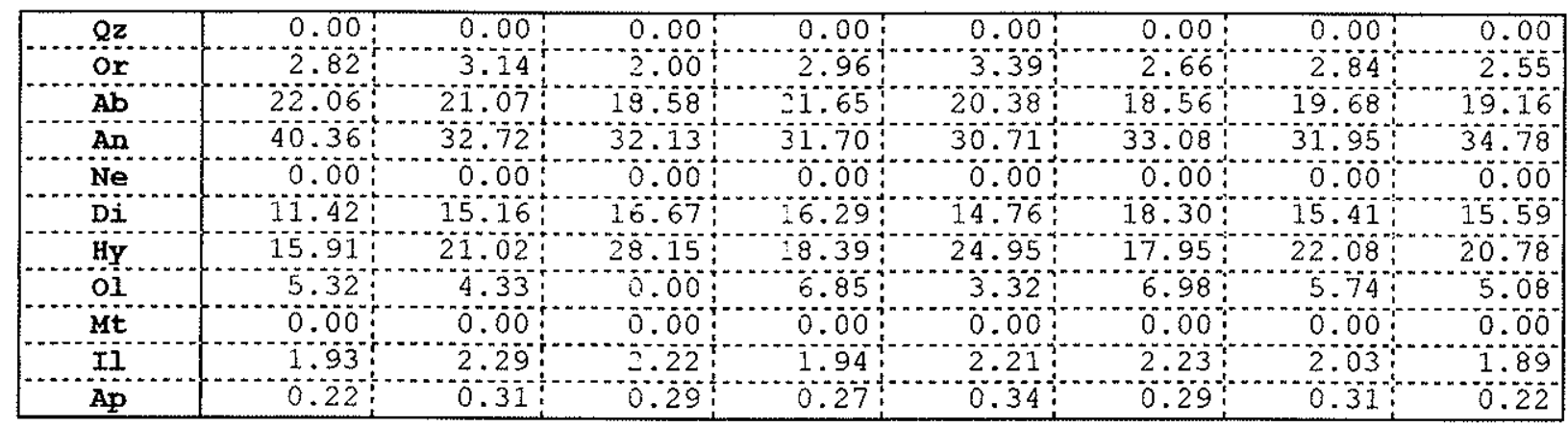

ELEMENTOS IZACOS (pPM)

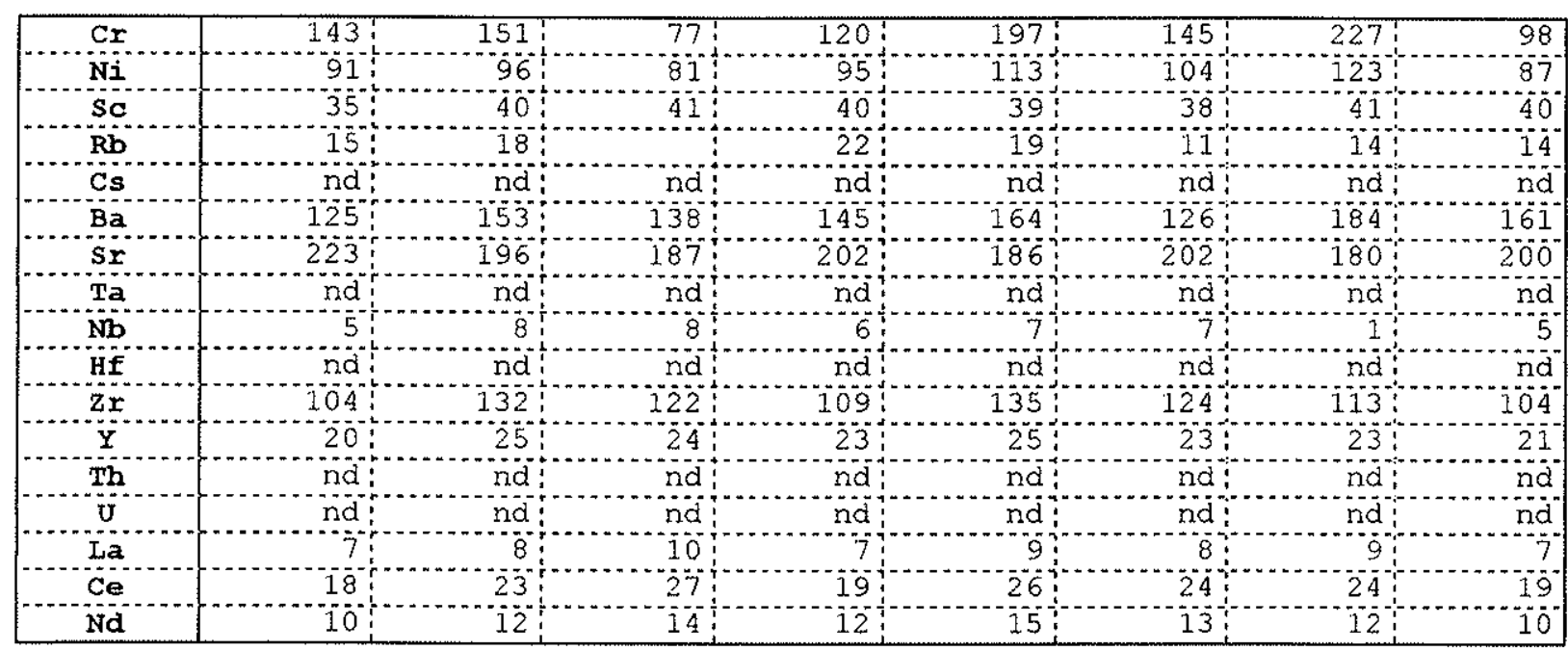




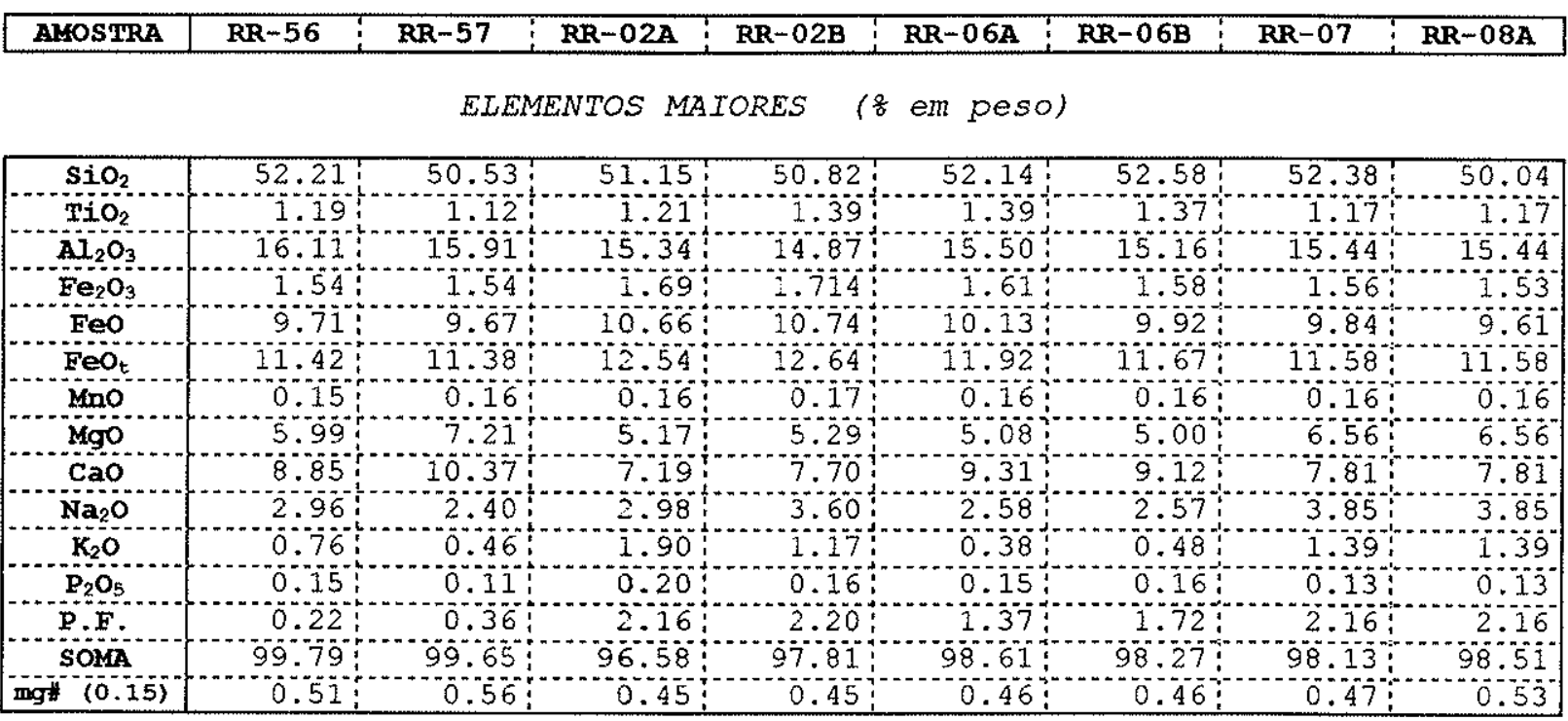

NORMA (CIPW)

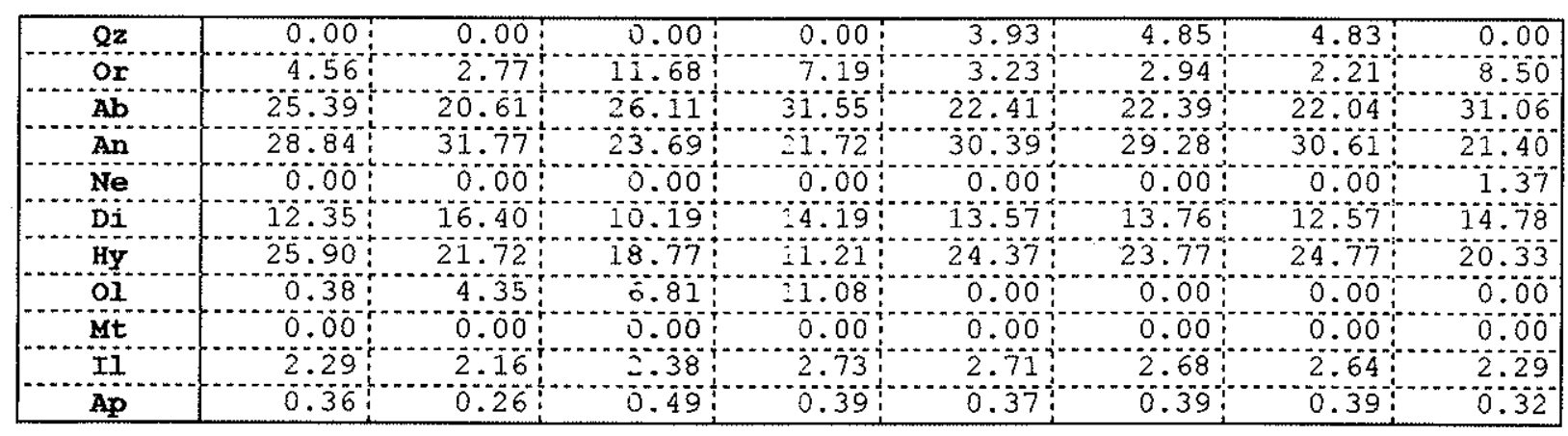

ELEMENTOS TRACYOS (PpM)

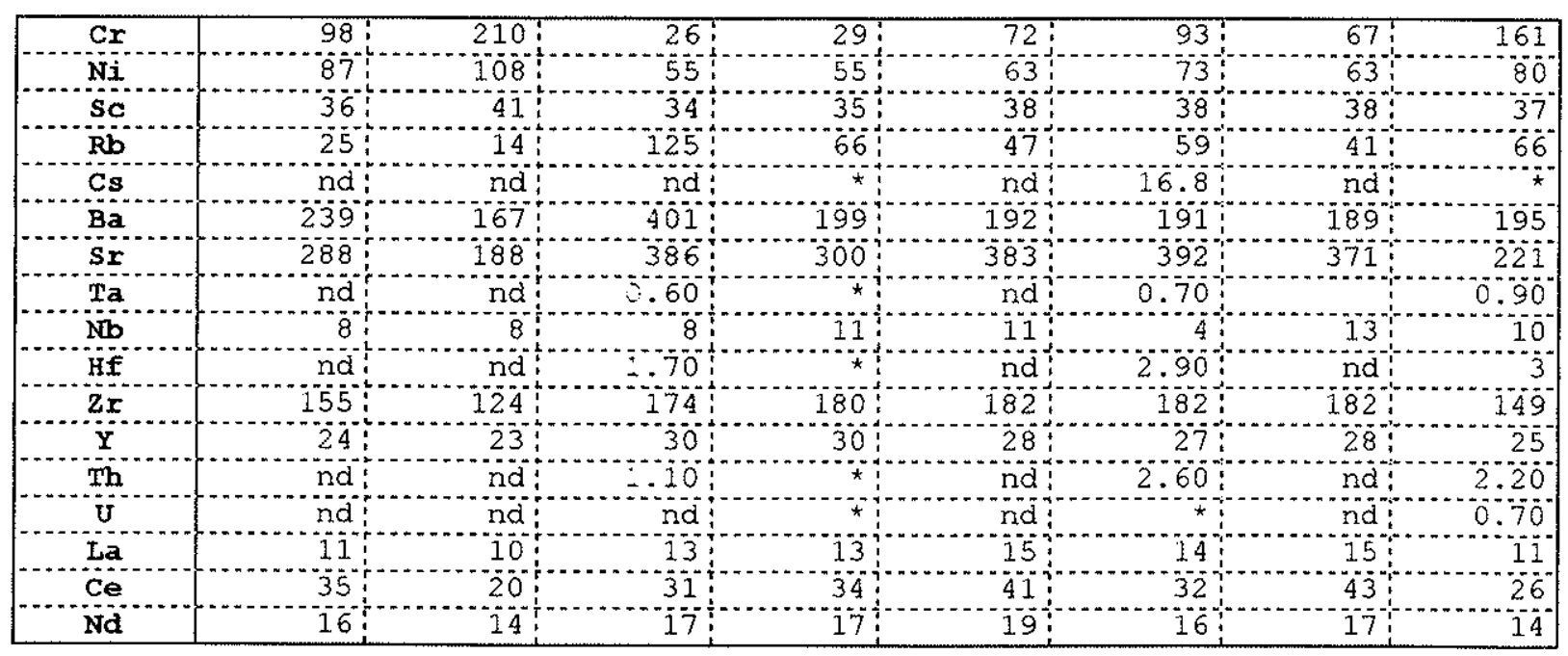

CIASS . 


\begin{tabular}{|l|l|l|}
\hline AMOSTRA & RR-09C & RR-39 \\
\hline
\end{tabular}

ELEMENTOS MAIORES (응 em pesO)

\begin{tabular}{|c|c|}
\hline $\mathrm{SiO}_{2}$ & $50.86: 52.01$ \\
\hline $\mathrm{riO}_{2}$ & 1.43 \\
\hline $\mathrm{Al}_{2} \mathrm{O}_{3}$ & 14.14 \\
\hline $\mathrm{Fe}_{2} \mathrm{O}_{3}$ & 1.87 \\
\hline FeO & 11.76 \\
\hline $\mathrm{FeO}_{\mathrm{t}}$ & $12: 44$ \\
\hline $\mathrm{MnO}$ & 0.17 \\
\hline $\mathrm{MgO}$ & 5.16 \\
\hline $\mathrm{CaO}$ & 7.60 \\
\hline $\mathrm{Na}_{2} \mathrm{O}$ & 3.12 \\
\hline $\mathrm{K}_{2} \mathrm{O}$ & 1.47 \\
\hline $\mathrm{P}_{2} \mathrm{O}_{5}$ & 0.14 \\
\hline P.F & 1.49 \\
\hline SOMA & $98.51:$ \\
\hline mgit $(0.15)$ & $0.50 \quad 0.45$ \\
\hline
\end{tabular}

NORMA (CIPW)

\begin{tabular}{|c|r|r|}
\hline Qz & 0.00 & 0.00 \\
\hline $0 x$ & 8.96 & 12.95 \\
\hline $\mathrm{Ab}$ & 30.86 & 27.19 \\
\hline $\mathrm{An}$ & 22.47 & 18.87 \\
\hline $\mathrm{Ne}$ & 0.00 & 0.00 \\
\hline $\mathrm{Di}$ & 13.19 & 16.11 \\
\hline $\mathrm{By}$ & 14.85 & 24.37 \\
\hline $\mathrm{OI}$ & 6.98 & 0.00 \\
\hline $\mathrm{Mt}$ & 0.00 & 0.00 \\
\hline $\mathrm{II}$ & 2.80 & 2.71 \\
\hline $\mathrm{Ap}$ & 0.34 & 0.37 \\
\hline
\end{tabular}

ELEMENTOS TRAÇOS (pPM)

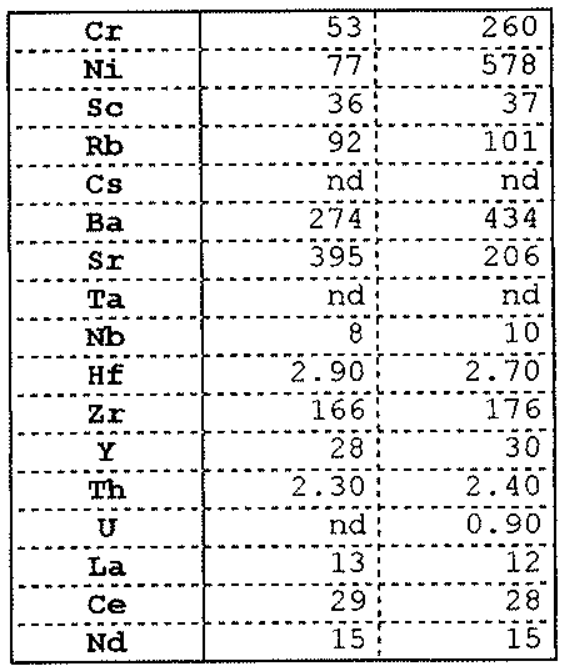

\begin{tabular}{l|l:l} 
CIASS & lb & $a b$
\end{tabular} 


\section{Apêndice-3}

Análises químicas de elementos terras raras para as rochas pertencentes a Suíte Básica Apoteri

$(\mathrm{TR} / \mathrm{TR})_{\mathrm{n}}=$ terras raras normalizadas para condrito (Boynton, $1984)$ 
DIQUES MÁEICOS

\begin{tabular}{|c|c|c|c|c|c|c|c|c|}
\hline ELEMENTO & RR-01A & $\mathrm{RR}-16$ & $R R-22$ & $R R-28$ & RR-33 & $R R-35 B$ & $R R-35 C$ & $R R-36 A$ \\
\hline Ia & 8.5 & 24.2 & 6.3 & 19.4 & 9.6 & 8.10 & 24.8 & 8.6 \\
\hline $\mathrm{Ce}$ & 19 & 54 & 16 & $4 \ddot{2}$ & 22 & 19 & 53 & 20 \\
\hline $\mathrm{Na}$ & 12 & 26 & 8 & 200 & 12 & 8 & 28 & 10 \\
\hline $\mathrm{sm}$ & 2.79 & 5.93 & 2.04 & 4.50 & 3.03 & 2.72 & 5.82 & 2.86 \\
\hline $\mathrm{Eu}$ & 0.95 & 1.71 & 0.67 & 1.32 & 1.03 & 0.88 & 1.73 & 0.96 \\
\hline $\mathrm{Tb}$ & 0.50 & 1.10 & 0.50 & 0.80 & 0.60 & 0.60 & $1.00^{-}$ & 0.770 \\
\hline $\mathrm{Yb}$ & 1.93 & 3.57 & 1.75 & 3.11 & 2.25 & 1.96 & 3.57 & 2.08 \\
\hline Lu & 0.31 & 0.52 & 0.26 & 0.39 & 0.32 & 0.26 & 0.49 & 0.30 \\
\hline$(\mathrm{Ia} / \mathrm{Sm})_{n}$ & 1.92 & 2.57 & 1.94 & 2.71 & 1.99 & 1.87 & 2.68 & 1.89 \\
\hline$(\mathrm{La} / \mathrm{Yb})_{n}$ & 2.97 & 4.57 & 2.43 & 4.20 & 2.88 & 2.78 & 4.68 & 2.78 \\
\hline$(\mathrm{sm} / \mathrm{Yb}) \mathrm{n}$ & 1.55 & $1: 78$ & 1.25 & 1.55 & 1.45 & 1.49 & 1.75 & 1.48 \\
\hline$\left(\mathrm{Eu} / \mathrm{Eu}{ }^{*}\right)$ & 0.78 & 0.65 & 0.65 & 0.67 & 0.74 & 0.67 & 0.69 & 0.66 \\
\hline
\end{tabular}

DERRAMES BASÁLTICOS

\begin{tabular}{|c|c|c|c|c|c|}
\hline ELEMENTO & $R R-02 A$ & $R R-06 B$ & $R R-08 A$ & RR-09C & $R R-39$ \\
\hline $\mathrm{Ce}$ & 13.50 & 14.4 & 11.5 & 12.7 & 12.3 \\
\hline La & 31 & 32 & 26 & 29 & 28 \\
\hline $\mathrm{Nd}$ & 17 & 16 & 14 & 15 & 15 \\
\hline $\mathrm{sm}$ & 3.84 & 3.79 & 3.24 & 3.63 & 3.69 \\
\hline Eu & 1.15 & 1.10 & 1.04 & 1.19 & 1.20 \\
\hline $\mathrm{Tb}$ & 0.90 & $0.70^{\circ}$ & $=0.50$ & 0.60 & 0.7 \\
\hline $\mathrm{Yb}$ & 2.61 & $2.61^{\circ}$ & 2.09 & 2.34 & 2.43 \\
\hline $\mathrm{Iu}$ & 0.33 & 0.34 & 0.31 & $0.34^{-}$ & 0.36 \\
\hline$(\mathrm{Ia} / \mathrm{Sm})_{\mathrm{n}}$ & 2.21 & 2.39 & 2.23 & 2.20 & 2.09 \\
\hline$(\mathrm{La} / \mathrm{Y} b)_{n}$ & 3.48 & 3.72 & 3.71 & 3.66 & 3.41 \\
\hline$(\mathrm{sm} / \mathrm{Yb})_{n}$ & 1.57 & 1.55 & 1.66 & 1.66 & 1.63 \\
\hline$(\mathrm{Eu} / \mathrm{Eu} *)$ & 0.61 & 0.66 & 0.78 & 0.78 & 0.73 \\
\hline
\end{tabular}

O ralor de Eu* foi determinado pela interpolação linear entre os elementos Sm e Yb, uma vez que o Gd não foi analisado. 


\section{Apêndice-4}

Tabela com as descrições petrográficas simplificadas das rochas pertencentes a Suite Básica Apoteri

ABREVIATURAS UTILIZADAS:

TEXTURAS: Sof= subofitica; of = ofitica; Fpf= fracamente porfiritica; Mpf= medianamente porfiritica; Ig=intergranular; Is $=$ intersertal.

MINERALOGIA: Minerais essenciais ( $>5 \circ)$; Minerais acessórios (<5\%); MaCro= macrofenocristal; Feno= fenocristal; Micro= microfenocristal

anf= anfibólio; $a p=$ apatita; $b i=b i o t i t a ; ~ c a r b=$ carbonato; $c l=$ clorita; $c p x=$ augita; ep= epídoto; $\mathrm{Kfd}=$ feldspato alcalino; op= opacos; opx= ortopiroxênio; pig= pigeonita; pl= plagioclásio;

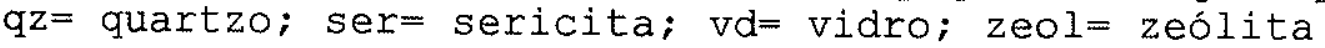

NOMENCLATURA (De La Roche et al., 1980); Bellieni et al., 1981): bth= basalto toleítico; $a b=$ andesi-basalto; lb= lati-basalto

OUTRAS ABREVIATURAS:

GRÃ $=$ granulometria

Mipg= micropegmatito

Ves $=$ vesicula

* = sem análise química de rocha total 
DIQUES MÁFICOS

\begin{tabular}{|c|c|c|c|c|c|c|c|c|}
\hline \multirow[t]{2}{*}{ AMOSTRA } & \multirow[t]{2}{*}{ GRÃ } & \multirow[t]{2}{*}{ TEXTURA } & \multicolumn{4}{|c|}{ MINERAIS ESSENCIAIS } & \multirow{2}{*}{$\begin{array}{l}\text { MINERAIS } \\
\text { ACESSÓRIOS }\end{array}$} & \multirow{2}{*}{$\begin{array}{c}\text { NOMENCLA } \\
\text { TURA }\end{array}$} \\
\hline & & & MACRO & FEANO & MICRO & MATRIZ & & \\
\hline RR-01A & média & af, sof & $\mathrm{cpx}$ & $\begin{array}{l}\text { pl, cpx } \\
\text { pig, op }\end{array}$ & $\begin{array}{l}\text { aug,pl, } \\
\text { op,pig }\end{array}$ & $\begin{array}{l}\mathrm{cpx}, \mathrm{pl} \\
\mathrm{pig}\end{array}$ & $\begin{array}{l}c I, b i, \text { anf, ap } \\
\text { mipg, KFd }\end{array}$ & $\overline{\mathrm{bth}}$ \\
\hline $\mathrm{RR}-0 \mathrm{HB}$ & fina & of & & $\mathrm{cpx}, \mathrm{pl}$ & $\begin{array}{l}\text { cpx, pi, } \\
\text { pig, op }\end{array}$ & $\begin{array}{l}\mathrm{pi}, \mathrm{cpx}, \\
\mathrm{pig}, \mathrm{op}\end{array}$ & $\begin{array}{l}\mathrm{cl}, \mathrm{ap}, \text { anf }, \mathrm{bi} \\
\text { mipg }\end{array}$ & bth \\
\hline $\mathrm{RR}-\mathrm{O} \mathrm{IC}$ & média & of & $\mathrm{p} x$ & cpx, & $\begin{array}{l}\mathrm{cpx}, \mathrm{pl} \\
\mathrm{pig}, \mathrm{op}\end{array}$ & $\begin{array}{l}\mathrm{pl}, \mathrm{cpx} \\
\mathrm{pig}, \mathrm{op}\end{array}$ & $\begin{array}{l}\text { ci,bi, anf, ar } \\
\text { mipg,KFd }\end{array}$ & $\mathrm{bth}$ \\
\hline$R R-03$ & média & sof & $\mathrm{cpx}$ & op & $\begin{array}{l}\mathrm{pl}, \mathrm{cpx} \\
\text { op }\end{array}$ & $\mathrm{pl}, \mathrm{cpx}$ & $\begin{array}{l}\mathrm{cl}, \text { anf, } a \mathrm{p}, \mathrm{b} \\
\mathrm{qz}, \mathrm{mipg}\end{array}$ & x \\
\hline$R R-14$ & média & of & & $\begin{array}{l}\mathrm{pI}, \mathrm{cpx}, \\
\mathrm{op}\end{array}$ & pl, cpx, & $\mathrm{pl}, \mathrm{cpx}$ & $c l, a p, a n f, q z$ & $\mathrm{bth}$ \\
\hline $\mathrm{RR}-16$ & fina & 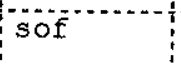 & & $\mathrm{pl}, \mathrm{cpx}$ & pl, cpx, & $\mathrm{pl}, \mathrm{cpx}$ & $c l, a n f, a p, q$ & $a$ \\
\hline $\overrightarrow{R R}=17$ & fina & sof & & pl, cpx, & $\mathrm{pl}, \mathrm{cpx}$ & $\mathrm{pl}, \mathrm{cpx}$ & $\mathrm{cl}, \mathrm{ap}, \mathrm{anf}, \mathrm{bi}$ & $a b$ \\
\hline$R R-18 A$ & $\begin{array}{l}\text { muito } \\
\text { fina a } \\
\text { fina }\end{array}$ & $m \bar{f}$ & & $\mathrm{pl}, \mathrm{cpx}$ & $\mathrm{pi}, \mathrm{cpx}$ & afanitica & mip & $\mathrm{bth}$ \\
\hline $\mathrm{RR}-18 \mathrm{D}$ & fina & & & $\mathrm{pi}, \mathrm{cpx}$ & $\mathrm{pl}, \mathrm{cpx}$ & $\mathrm{pl}, \mathrm{cpx}, \mathrm{o}$ & & $\mathrm{ab}$ \\
\hline $\mathrm{RR}-18 \mathrm{E}$ & fina & ig & & $\begin{array}{l}\text { pi, cpx, } \\
\text { op }\end{array}$ & $\mathrm{pl}, \mathrm{cpx}$ & $\mathrm{pl}, \mathrm{cpx}, \mathrm{op}$ & $\begin{array}{l}c i, a n f, q z, a \\
\text { mipg }\end{array}$ & $\mathrm{bth}$ \\
\hline$R R-18 \mathrm{E}$ & médiä & sof & & $\begin{array}{l}\mathrm{pl}, \mathrm{cpx}, \\
\text { op }\end{array}$ & $\begin{array}{l}\mathrm{pl}, \mathrm{cpx}, \\
\text { op }\end{array}$ & $p \mathrm{i}, \mathrm{cpx}, \mathrm{op}$ & $\begin{array}{l}c l, a n f, q z, a p, b i \\
\text { mipg }\end{array}$ & $\mathrm{bth}$ \\
\hline $\mathrm{RR}-18 \mathrm{G}$ & média & sof & & pl, $\mathrm{cpx}$, & $\begin{array}{l}\mathrm{pl}, \mathrm{cpx}, \\
\mathrm{op}\end{array}$ & $\mathrm{pi}, \mathrm{cpx}$ & $\begin{array}{l}c l, a p, q z, b i, \\
\text { mcpg }\end{array}$ & $\mathrm{bth}$ \\
\hline$\because \mathrm{RR}-19$ & média & of & $\mathrm{epx}$ & pl, cpx, & pl, cpx, & $p i, c p x$, & $\begin{array}{l}\mathrm{cl}, \mathrm{ap}, \mathrm{qz}, \mathrm{bi} \\
\mathrm{mipg}, \mathrm{KFd}\end{array}$ & \\
\hline$R R-22$ & fina & & & op & pp & $\mathrm{pl}, \mathrm{cpx}$ & $c 1, b i, a p, q z$ & bth \\
\hline$R$ & fina & sof & & pi,cpx, & $\begin{array}{l}\mathrm{pi}, \mathrm{cpx} \\
\mathrm{pig}, \mathrm{op}\end{array}$ & $\begin{array}{l}\mathrm{pi}, \mathrm{cpx} \\
\text { pig, op }\end{array}$ & $c i, a p, q z$, ser, ep & \\
\hline$R R-2 Q$ & fina & $\ddot{s c}$ & & $\mathrm{pl}, \mathrm{cpx}$ & $\mathrm{pl}, \mathrm{cpx}$, & $\mathrm{pl}, \mathrm{cpx}, \mathrm{op}$ & $\mathrm{cl}, \mathrm{ap}, \mathrm{qz}, \mathrm{ser}$ & \# \\
\hline$R=25 A$ & fina & 0 & & $\mathrm{px}$ & $\mathrm{pl}, \mathrm{cpx}$, & $\mathrm{pl}, \mathrm{cps}$ & $c l, a n f, a p, q z$ & $\star-$ \\
\hline$R R-25 B$ & fina & sof & & $\mathrm{pl}, \mathrm{ppx}$ & $\mathrm{p} 1, \mathrm{cpx}$ & $p i, c p x, o p$ & ci, anf, $\mathrm{qz}, a \mathrm{p}$ & $a b$ \\
\hline$R R-26$ & média & of & & op & $\mathrm{pl}, \mathrm{cpx}$ & $p l, c p x, o p$ & cl, $q z$, ap, anf, ep & $a b$ \\
\hline $\mathrm{RR}-28$ & fina & sof & & op & pi, cpx, & $\mathrm{pi}, \mathrm{cpx}, \mathrm{op}$ & $\begin{array}{l}\text { cl, } b i, a n f, a p, q z \\
\text { mipg }\end{array}$ & $\mathrm{ab}$ \\
\hline $\mathrm{RR}-3 \mathrm{IA}$ & média & sof & pl & pl, cpx, & $\begin{array}{l}\mathrm{p} 1, \mathrm{cpx}, \\
\text { op }\end{array}$ & $\mathrm{p} \hat{\mathrm{l}}, \mathrm{cpx}, \mathrm{op}$ & $\begin{array}{l}\mathrm{ci}, \mathrm{anf}, \mathrm{qz}, \mathrm{ap}, \mathrm{bi} \\
\text { ep, ser, mipg }\end{array}$ & bth \\
\hline $\mathrm{RR}-3 \mathrm{IB}$ & médià & 01 & 8 & pl, cpx, & pi, cpx, & $\mathrm{pl}, \mathrm{cpx}, \mathrm{op}$ & $\begin{array}{l}\text { cl, anf, qz, ap, bi } \\
\text { mipo, ep ser }\end{array}$ & \\
\hline $\mathrm{RR}-32$ & fina & of & & $\mathrm{pl}, \mathrm{cpx}$ & pl, & $\mathrm{pl}, \mathrm{cpx}, \mathrm{op}$ & $\begin{array}{l}\mathrm{ci}, \mathrm{ap}, \mathrm{qz}, \mathrm{bi}, \\
\mathrm{mipg}\end{array}$ & $a b$ \\
\hline $\mathrm{RR}-33^{2}$ & fina & sof & & $\begin{array}{l}\text { pi,cpx, } \\
\text { pig, op }\end{array}$ & $\begin{array}{l}\text { pí, cpx, } \\
\text { pig, op }\end{array}$ & $\begin{array}{l}\text { pi,cpx, } \\
\text { pig, op }\end{array}$ & $\begin{array}{l}\text { cl, anf, ap, } \mathrm{q} z, \mathrm{bi} \\
\text { mipg }\end{array}$ & $\mathrm{bth}$ \\
\hline$R R-34$ & fina & $o f$ & & op & $\begin{array}{l}\text { pl,cpx, } \\
\text { opx, pig } \\
\text { op }\end{array}$ & $\begin{array}{l}\text { pi, cpx, op } \\
\text { pig, opx }\end{array}$ & $\begin{array}{l}\mathrm{ci}, \mathrm{qz}, \mathrm{ap}, \mathrm{bi}, \\
\text { mipg }\end{array}$ & $\mathrm{bth}$ \\
\hline$R R-35 A$ & fina & $\bar{f}$ & & $\begin{array}{l}\mathrm{pl}, \mathrm{cpx}, \\
\text { op }\end{array}$ & op & $\mathrm{pl}, \mathrm{cpx}, \mathrm{op}$ & $\begin{array}{l}\mathrm{cl}, \mathrm{ap}, \mathrm{qz}, \mathrm{bi}, \\
\mathrm{mipg}\end{array}$ & beh \\
\hline
\end{tabular}




\begin{tabular}{|c|c|c|c|c|c|c|c|c|}
\hline \multirow[t]{2}{*}{ AMOSTRA } & \multirow[t]{2}{*}{ GRÃ } & \multirow[t]{2}{*}{ TEXTURA } & \multicolumn{4}{|c|}{ MINERAIS ESSENCIAIS } & \multirow{2}{*}{$\begin{array}{c}\text { MINERAIS } \\
\text { ACESSÓRIOS }\end{array}$} & \multirow{2}{*}{$\begin{array}{c}\text { NOMENCLA } \\
\text { TURA }\end{array}$} \\
\hline & & & MACRO & FENO & MICRO & MATRIZ & & \\
\hline $\mathrm{RR}-35 \mathrm{~B}$ & média & of & $\mathrm{pl}, \mathrm{cpx}$ & $\begin{array}{l}\mathrm{pl}, \mathrm{cpx}, \\
\mathrm{op}\end{array}$ & $\begin{array}{l}\mathrm{pl}, \mathrm{cpx} \\
\mathrm{pig}, \mathrm{op}\end{array}$ & $\begin{array}{l}\text { pl, cpx, op } \\
\text { pig, opx }\end{array}$ & $\begin{array}{l}c 1, a p, a n f, q z, b i \\
m i p g\end{array}$ & bth \\
\hline$R=35 C$ & médiä & of & $\mathrm{pi}, \mathrm{ppx}$ & $\begin{array}{l}\text { pi, cpx, } \\
\text { pig, op }\end{array}$ & $\begin{array}{l}\text { pl, cpx, } \\
\text { pig, opx } \\
\text { op }\end{array}$ & $\begin{array}{l}\text { pi,cpx, op } \\
\text { pig, opx }\end{array}$ & $\begin{array}{l}\text { cl, ap, anf, } a z, b i \\
\text { ser, mipg }\end{array}$ & $a$ \\
\hline$R R-36 A$ & Eina & sof & & pi, & $\mathrm{pP}, \mathrm{cpx}$ & $\mathrm{pl}, \mathrm{cpx}, \mathrm{op}$ & $\begin{array}{l}\mathrm{ci}, \mathrm{ap}, \mathrm{bi}, \mathrm{anf}, \mathrm{qz} \\
\mathrm{mipg}\end{array}$ & $\mathrm{bth}$ \\
\hline$R R-36 B$ & médiä & of & & op & $p_{\mathrm{pp}}, \mathrm{cpx}$, & $\mathrm{pl}, \mathrm{cpx}, \mathrm{op}$ & $\begin{array}{l}\mathrm{cl}, \mathrm{ap}, \mathrm{anf}, \mathrm{q} z, \mathrm{bi} \\
\operatorname{mipg}\end{array}$ & \\
\hline$R R-36 C$ & média & sof & $\mathrm{pl}, \mathrm{cpx}$ & $\begin{array}{l}\mathrm{cpx}, \mathrm{pi} \\
\mathrm{op}\end{array}$ & $\begin{array}{l}\mathrm{pl}, \mathrm{cpx}, \\
\mathrm{op}\end{array}$ & pl, cpx,op & 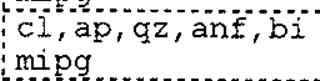 & \\
\hline $\mathrm{RR}-37 \mathrm{~A}$ & fina & $\mathrm{ig}$ & & $\begin{array}{l}\mathrm{pl}, \mathrm{cpx}, \\
\text { op }\end{array}$ & $\begin{array}{l}\mathrm{pi}, \mathrm{cpx}, \\
\text { op }\end{array}$ & $\mathrm{pl}, \mathrm{cpx}, \mathrm{op}$ & $\begin{array}{l}\text { cl, ap, qz, ser, } \\
\text { mipg }\end{array}$ & \\
\hline$R R=37 B$ & média & sof & & op & pi, cpx, & $\mathrm{pl}, \mathrm{cpx}, \mathrm{op}$ & $\begin{array}{l}\text { li,anf,ap, qz, ep } \\
\text { ser,mipg }\end{array}$ & $b \mathrm{th}^{-}$ \\
\hline $\mathrm{RR}-38$ & médiä & sof & & $\begin{array}{l}\mathrm{pl}, \mathrm{cpx} \\
\mathrm{op}\end{array}$ & op & $\mathrm{pl}, \mathrm{cpx}, \mathrm{op}$ & $\begin{array}{l}\text { cl, ap, anf, qz,ep } \\
\text { ser }\end{array}$ & $\mathrm{ab}$ \\
\hline$R R-41$ & média & sof & & $\begin{array}{l}\text { pl, cpx } \\
\text { pig, op }\end{array}$ & $\begin{array}{l}\text { pl, } \\
\text { pig, op }\end{array}$ & $\begin{array}{l}\text { pl, cpx, op } \\
\text { pig }\end{array}$ & $\begin{array}{l}c 1, a p, q z, s e r, e p \\
\text { carb }\end{array}$ & \\
\hline$R R-42 A$ & média & sóf & $\mathrm{pi}, \mathrm{cpx}$ & $\begin{array}{l}\text { pj, cpx, } \\
\text { pig, op }\end{array}$ & $\begin{array}{l}\text { pi, cpx, } \\
\text { pig, op }\end{array}$ & $\begin{array}{l}\text { pi, } \mathrm{ppx}, \mathrm{op} \\
\text { pig }\end{array}$ & $\begin{array}{l}c i, a p, a n f, b i, q z \\
\text { ser, ep, mipg }\end{array}$ & \\
\hline$R \mathrm{R}-42 \mathrm{~B}$ & média & sof & $\mathrm{pi}, \mathrm{cpx}$ & op & $\begin{array}{l}\mathrm{pi}, \mathrm{cpx} \\
\mathrm{op}\end{array}$ & $\mathrm{pl}, \mathrm{cpx}, \mathrm{op}$ & $\begin{array}{l}c i, a p, a n f, b i, q z \\
\text { ser, ep, mipg }\end{array}$ & beh \\
\hline $\mathrm{RR}-42 \mathrm{C}$ & fina & ig & & $\begin{array}{l}\text { pi, } \mathrm{cpx}, \\
\text { op }\end{array}$ & $\begin{array}{l}\text { pl, cpx, } \\
\text { op }\end{array}$ & $\mathrm{pi}, \mathrm{cpx}, \mathrm{op}$ & $\begin{array}{l}\mathrm{cl}, \mathrm{ap}, \mathrm{bi}, \text { anf, } \mathrm{qz} \\
\text { ser, ep, mipg }\end{array}$ & $\mathrm{bth}$ \\
\hline$R R=43$ & fina & fpf & & $\mathrm{pl}, \mathrm{cpx}$ & $\mathrm{pl}, \mathrm{cpx}$, & $\mathrm{pl}, \mathrm{cpx}, \mathrm{op}$ & $a p, q z$ & $\mathrm{bth}$ \\
\hline$\ddot{R R}=44$ & médià & of & $\mathrm{pi}, \mathrm{cpx}$ & $\mathrm{pl}_{\mathrm{op}}$ & $p_{o p} \overline{1, c p x}$, & $\mathrm{pl}, \mathrm{cpx}, \mathrm{op}$ & $\begin{array}{l}\text { cl,ap,anf, } \mathrm{qz}, \mathrm{ep} \\
\text { ser, mipg }\end{array}$ & $\mathrm{h}$ \\
\hline $\mathrm{RR}-46 \mathrm{~A}$ & fina & sof & & $\mathrm{pl}, \mathrm{cpx}$ & $\begin{array}{l}\text { pi,cpx, } \\
\text { op }\end{array}$ & $\mathrm{pl}, \mathrm{cpx}, \mathrm{op}$ & $\begin{array}{l}c i, a p, a n f, b i, q z \\
\text { ser, ep, mipg }\end{array}$ & $\mathrm{bth}$ \\
\hline $\mathrm{RR}-46 \mathrm{~B}$ & média & sof & $\mathrm{pi}, \mathrm{cpx}$ & $\begin{array}{l}\text { pl, } \mathrm{cpx}, \\
\text { op }\end{array}$ & $\begin{array}{l}\mathrm{pl}, \mathrm{cpx}, \\
\text { op }\end{array}$ & $\mathrm{pi}, \mathrm{cpx}, \mathrm{op}$ & $\begin{array}{l}c 1, a p, a n f, b i, q z \\
\text { ser, ep, mipg }\end{array}$ & bth \\
\hline$R R-46 C$ & média & of & pil, $\mathrm{ppx}$ & $\begin{array}{l}\text { pi, } \mathrm{cpx}, \\
\text { op }\end{array}$ & $\begin{array}{l}\text { pl, cpx, } \\
\text { pig, op }\end{array}$ & $\begin{array}{l}\mathrm{pi}, \mathrm{cpx}, \mathrm{op} \\
\mathrm{pig}\end{array}$ & $\begin{array}{l}\mathrm{cl}, \mathrm{ap}, \mathrm{bi}, \mathrm{anf}, \mathrm{qz} \\
\text { ser, ep, mipg, KFd }\end{array}$ & \\
\hline $\mathrm{RR}-48$ & média & sof & $\mathrm{pi}, \mathrm{cpx}$ & pi, & $\begin{array}{l}\text { pi, cpx, } \\
\text { op }\end{array}$ & $\mathrm{pi}, \mathrm{cpx}, \mathrm{op}$ & $\begin{array}{l}\mathrm{cl}, \mathrm{ap}, \mathrm{anf}, \mathrm{bi}, \mathrm{qz} \\
\text { ser,ep, mipg }\end{array}$ & $\mathrm{bth}$ \\
\hline$\pi \approx R-50$ & fina & sof & & pl, cpx, & $\begin{array}{l}\mathrm{pi}, \mathrm{cpx}, \\
\mathrm{op}\end{array}$ & pi, cpx,opi & $\begin{array}{l}\text { cl,ap,bi, qz, } \\
\text { ipg }\end{array}$ & $\mathrm{bth}$ \\
\hline$R R-51$ & média & sof & $\mathrm{pl}, \mathrm{cpx}$ & pi, & $\begin{array}{l}\mathrm{pl}, \mathrm{cpx} \\
\mathrm{op}\end{array}$ & $\mathrm{pl}, \mathrm{cpx}, \mathrm{pp}$ & $\begin{array}{l}c l, a p, b i, \text { anf, } q z \\
\text { ser, ep, mipg }\end{array}$ & $\mathrm{bth}$ \\
\hline $\mathrm{RR}-52 \mathrm{~A}$ & fina & $i g$ & & $\begin{array}{l}\text { pl, } \\
\text { op }\end{array}$ & $\begin{array}{l}\mathrm{pi}, \mathrm{cpx}, \\
\text { op }\end{array}$ & $\mathrm{pl}, \mathrm{cpx}, \mathrm{op}$ & $\begin{array}{l}\text { ci, ap, bi, qz,ep } \\
\text { ser, carb, mipg }\end{array}$ & \\
\hline $\mathrm{RR}-52 \mathrm{~B}$ & fina & sôf & & pl, cpx, & $\begin{array}{l}\text { pi, } \mathrm{cpx}, \\
\text { op }\end{array}$ & $\mathrm{pl}, \mathrm{cpx}, \mathrm{op}$ & $\begin{array}{l}\text { cl, ap, anf, } \\
\text { ser, ep, carb, } \\
\text { mcpg }\end{array}$ & \\
\hline$\ddot{R} R-520$ & média & só & $\mathrm{pi}, \mathrm{cpx}$ & pi, $\mathrm{ppx}^{\mathrm{p}}$ & $\mathrm{pi}_{\mathrm{op}}$ & $\mathrm{pl}, \mathrm{cpx}, \mathrm{op}$ & $\begin{array}{l}\text { cl, ap, anf }, q z, \\
\text { mipg }\end{array}$ & $b \operatorname{th}$ \\
\hline $\mathrm{RR}-53 \mathrm{~A}$ & fina & sof & & $\begin{array}{l}\mathrm{pi}, \mathrm{px} \\
\text { piq, op }\end{array}$ & $\begin{array}{l}\text { pi,cpx, } \\
\text { pig, op }\end{array}$ & $\begin{array}{l}\text { pi,cpx, op } \\
\text { pig }\end{array}$ & $\begin{array}{l}\mathrm{ci}, \mathrm{ap}, \mathrm{anf}, \mathrm{bi}, \mathrm{qz} \\
\text { ser, ep, carb. } \\
\text { mcpg }\end{array}$ & \\
\hline$R=53 B$ & média & số & & $\begin{array}{l}\text { pi, } p \text { px } \\
\text { pig, op }\end{array}$ & $\begin{array}{l}\text { pi,cpx, } \\
\text { pig, op }\end{array}$ & $\begin{array}{l}\mathrm{pl}, \mathrm{cpx}, \mathrm{op} \\
\mathrm{pig}\end{array}$ & $\begin{array}{l}\text { cl, ap, anf, bi, } q z \\
\text { ser, carb, ep, } \\
\text { mcpg }\end{array}$ & $\mathrm{bth}^{-}$ \\
\hline
\end{tabular}




\begin{tabular}{|c|c|c|c|c|c|c|c|c|}
\hline \multirow[t]{2}{*}{ AMOSTRA } & \multirow[t]{2}{*}{ GRÃ } & \multirow[t]{2}{*}{ TEXTURA } & \multicolumn{4}{|c|}{ MINERAIS ESSENCIAIS } & \multirow{2}{*}{$\begin{array}{c}\text { MINERAIS } \\
\text { ACESSÓRIOS }\end{array}$} & \multirow{2}{*}{$\begin{array}{l}\text { NOMENCLA } \\
\text { TURA }\end{array}$} \\
\hline & & & MACRO & FrinO & MICRO & MATRIZ & & \\
\hline $\mathrm{RR}-54$ & fina & sof & & $\begin{array}{l}\text { pl,cpx, } \\
\text { op }\end{array}$ & $\begin{array}{l}\mathrm{pl}, \mathrm{cpx}, \\
\text { op }\end{array}$ & $\mathrm{pl}, \mathrm{cpx}, \mathrm{op}$ & $\begin{array}{l}\mathrm{cl}, \mathrm{ap}, \mathrm{anf}, \mathrm{bi}, \mathrm{qz} \\
\text { ser, mcpg }\end{array}$ & th \\
\hline$R R-55$ & fina & sof & & $\mathrm{pl}, \mathrm{cpx}$ & pp & $\mathrm{pl}, \mathrm{cpx}, \mathrm{op}$ & $\begin{array}{l}\text { ep, ser, carb, ti, } \\
\text { mcpg }\end{array}$ & $\mathrm{bth}$ \\
\hline$\widetilde{R} R=56$ & fina & sof & & $\mathrm{pl}, \mathrm{cpx}$ & $\mathrm{pl}, \mathrm{cpx}$, & $\mathrm{pl}, \mathrm{cpx}, \mathrm{op}$ & $\begin{array}{l}\text { ap, } 1, q z, \text { ser, ep } \\
\text { carb }\end{array}$ & $\mathrm{bth}$ \\
\hline $\mathrm{RR}-57$ & fina & Són & & $\begin{array}{l}\mathrm{pi}, \mathrm{cpx}, \\
\text { op }\end{array}$ & $\begin{array}{l}\text { pl, cpx, } \\
\text { op }\end{array}$ & $\mathrm{pi}, \mathrm{cpx}, \mathrm{op}$ & $c l, a p, a n f, q z$ & bth \\
\hline
\end{tabular}

\section{DERRAMES BASÁLTICOS}

\begin{tabular}{|c|c|c|c|c|c|c|c|c|}
\hline \multirow[t]{2}{*}{ AMOSTRA } & \multirow[t]{2}{*}{ GRÃ } & \multirow[t]{2}{*}{ TEXTORA } & \multicolumn{4}{|c|}{ MINERAIS ESSENCIAIS } & \multirow{2}{*}{$\begin{array}{l}\text { MINERAIS } \\
\text { ACESSÓRIOS }\end{array}$} & \multirow{2}{*}{$\begin{array}{l}\text { NOMENCLA } \\
\text { TURA }\end{array}$} \\
\hline & & & MACRO & FENO & MICRO & MATRIZ & & \\
\hline$R R-02 A$ & $\begin{array}{l}\text { fina a } \\
\text { muito } \\
\text { fina }\end{array}$ & ig & & 51 & $\begin{array}{l}\mathrm{pl}, \mathrm{cpx}, \\
\text { op }\end{array}$ & $\mathrm{pl}, \mathrm{cpx}, \mathrm{op}$ & $\begin{array}{l}\mathrm{cl}, a p, q z, c a r b, \\
\text { ser }\end{array}$ & o \\
\hline $\mathrm{RR}-02 \mathrm{~B}$ & $\begin{array}{l}\text { fina a } \\
\text { minato }\end{array}$ & $\dot{i g}$ & & 1 & $\begin{array}{l}\text { pl, } \overline{c p x} \text {, } \\
\text { op }\end{array}$ & $\mathrm{pi}, \mathrm{cpx}, \mathrm{op}$ & $\begin{array}{l}\text { cl, ap, qz, carb, } \\
\text { ser, vd }\end{array}$ & 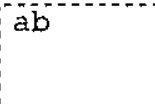 \\
\hline $\mathrm{R} R-05 \mathrm{~A}$ & fina & $g$ & & $5 \mathrm{i}, \mathrm{cpx}$ & $\begin{array}{l}\mathrm{pl}, \mathrm{cpx}, \\
\text { op }\end{array}$ & $\mathrm{pi}, \mathrm{cpx}, \mathrm{op}$ & $\begin{array}{l}c l, a p, q z, c a r b, \\
\text { ser, ep, zeol }\end{array}$ & \\
\hline $\mathrm{RRO} B \mathrm{~B}$ & Einà & 9 & & op & $\mathrm{pl}, \mathrm{cpx}$, & $\mathrm{pl}, \mathrm{cpx}, \mathrm{op}$ & $\begin{array}{l}\text { cl, ap, qz, carb, } \\
\text { ser, ep }\end{array}$ & \\
\hline$R \mathrm{R}-0 \overline{\mathrm{C}} \mathrm{C}$ & fina & ig & & i, cpx & pl, $\mathrm{ppx}$, & $\mathrm{pl}, \mathrm{cpx}, \mathrm{op}$ & $\begin{array}{l}\text { cl, ap, qz, carb, } \\
\text { ser, ep, ves/zeol } \\
\text { qz, carb, cl, pl }\end{array}$ & \\
\hline $\mathrm{RR}-36 \mathrm{~A}$ & fina & is & & $\mathrm{i}, \mathrm{cpx}$ & pl, cpx, & $\mathrm{pl}, \mathrm{cpx}, \mathrm{op}$ & $c 1, a p, q z, v d$ & $b$ \\
\hline$R R-j 6 B$ & fina & is & & i, cpx & pl, cpx, & $\mathrm{pl}, \mathrm{cpx}, \mathrm{op}$ & $\mathrm{cl}, \mathrm{ap}, \mathrm{qz}, \mathrm{vd}$ & \\
\hline$R R-57$ & fina & is & & $\mathrm{i}, \mathrm{cpx}$ & $\mathrm{p} 1, \mathrm{cpx}$, & $\mathrm{pl}, \mathrm{cpx}, \mathrm{op}$ & $\mathrm{cl}, \mathrm{ap}, \mathrm{qz}, \mathrm{va}$ & o \\
\hline $\mathrm{RR}-38 \mathrm{~A}$ & fina" & $\ddot{i g}$ & & $\mathrm{si}, \mathrm{cpx}$ & $\mathrm{pl}, \mathrm{cpx}$ & $\mathrm{pl}, \mathrm{cpx}, \mathrm{op}$ & cl, ap, qz, carb, & \\
\hline$R R-3 B$ & fina & $i g$ & & $1, \mathrm{cpx}$ & $\mathrm{p} 1, \mathrm{cpx}$ & $\mathrm{pi}, \mathrm{cpx}, \mathrm{op}$ & $\begin{array}{l}\text { ci, ap, qz, carb, } \\
\text { ep, ser, ves/cl, } \\
\text { zeol, qz, carb }\end{array}$ & \\
\hline $\mathrm{R} R-29 \mathrm{~A}$ & fina & $\overrightarrow{i g}$ & & 1َ & $\mathrm{pi}, \mathrm{cpx}$ & $p \bar{l}, c p x, o p$ & $\begin{array}{l}c 1, a p, q z, c a r b, \\
\text { ser,vd }\end{array}$ & \\
\hline $\mathrm{RR}-9 \mathrm{~B}$ & fina & ig & & $\mathrm{pi}$ & $\mathrm{pl}, \mathrm{cpx}$ & $p i, c p x, o p$ & $\begin{array}{l}c l, a p, q z, c a r b \\
\text { ser, vd }\end{array}$ & \\
\hline $\overrightarrow{R R}-\hat{9} \vec{C}$ & fina & ig & & $\overline{\mathrm{pi}}$ & $\mathrm{pl}, \mathrm{cpx}$ & $p \bar{l}, c p x, o p$ & $c 1, a p, q z, c a r b$ & $\mathrm{Bb}$ \\
\hline $\mathrm{RR}-9 \mathrm{D}$ & finä & ig & & $\bar{p} \bar{p}$ & $\mathrm{pi}, \mathrm{cpx}$ & $p i, c p x, o p$ & $\begin{array}{l}\text { cl, ap, qz, carb, } \\
\text { ser, ves/zeol, qz } \\
\text { cl, carb }\end{array}$ & \\
\hline$R R=-39$ & fina & $\mathrm{ig}$ & & $\overline{\mathrm{i}}$ & $\mathrm{pl}, \mathrm{cpx}$ & $\mathrm{pi}, \mathrm{cpx}, \mathrm{op}$ & $\begin{array}{l}c 1, a p, q z, c a r b, \\
\text { ser }\end{array}$ & $a b$ \\
\hline$R R=0^{\circ}$ & Eina & $i g$ & & $\bar{p}$ & $\mathrm{p} i, \mathrm{cpx}$ & $\mathrm{pl}, \mathrm{cpx}, \mathrm{op}$ & $\begin{array}{l}\text { cl, ap, qz, carb, } \\
\text { ser, ves/zeol, cl } \\
q z, \text { carb }\end{array}$ & - \\
\hline
\end{tabular}




\section{Apêndice-5}

Análise química da olivina e apatita utilizada no cálculo do balanço de massa para elementos maiores.

Dados extraidos de Deer et al. (1992) 


\begin{tabular}{|c|c|c|}
\hline ELFMENTO & OLIVINA & APATITA \\
\hline $\mathrm{SiO}_{2}$ & 38.30 & 0.00 \\
$\mathrm{MiO}_{2}$ & 0.00 & 0.00 \\
\hline $\mathrm{Al}_{2} \mathrm{O}_{3}$ & 0.00 & 0.00 \\
\hline $\mathrm{MeOt}$ & 17.03 & 0.00 \\
\hline $\mathrm{MnO}$ & 0.30 & 0.00 \\
\hline $\mathrm{MgO}$ & 43.00 & 0.00 \\
\hline $\mathrm{CaO}_{2} \mathrm{O}$ & 0.37 & 61.04 \\
\hline $\mathrm{K}_{2} \mathrm{O}$ & 0.00 & 0.00 \\
\hline $\mathrm{P}_{2} \mathrm{O}_{5}$ & 0.00 & 0.00 \\
\hline TOTAL $^{2}$ & 0.00 & 38.96 \\
\hline
\end{tabular}




\section{Apêndice- 6}

Coeficientes de partição mineral/liquido utilizados nos modelos de cristalização fracionada para as rochas da suite Básica Apoteri. $\quad \mathrm{Ol}=$ olivina; $\mathrm{Cpx}=$ augita; $\mathrm{Pig}=$ pigeonita; $\mathrm{Pl}=$ plagioclásio; $M t=$ magnetita; $A p=$ apatita. Dados extraídos Marques (1988) e Bossi et al. (1993). 


\begin{tabular}{|c|c|c|c|c|c|c|}
\hline \multirow[t]{2}{*}{ ELEMENTO } & \multicolumn{6}{|c|}{ MINERAL } \\
\hline & Ol & Cpx & Pig & P1 & Mt & $\mathrm{Ap}$ \\
\hline $\mathrm{La}$ & 0.008 & 0.11 & 0.024 & 0.18 & 0.24 & 8.2 \\
\hline $\mathrm{Ce}$ & 0.008 & 0.15 & 0.026 & 0.14 & 0.22 & 96 \\
\hline $\mathrm{Nd}$ & 0.008 & 0.30 & 0.039 & 0.10 & 0.23 & 10.0 \\
\hline $\mathrm{sm}$ & 0.009 & 0.52 & 0.060 & 0.072 & 0.24 & 10.2 \\
\hline Eu & 0.009 & 0.50 & 0.051 & $0.40^{\circ}$ & 0.22 & 6.9 \\
\hline $\mathrm{Tb}$ & 0.011 & 0.67 & 0.13 & 0.058 & 0.27 & 10.9 \\
\hline Yo & 0.017 & 0.65 & 0.29 & 0.040 & 0.28 & 6.4 \\
\hline Lu & 0.020 & 0.64 & 0.34 & 0.035 & 0.27 & 5 \\
\hline$Y$ & 0.01 & 0.4 & 0.2 & 0.02 & 0.4 & 2.7 \\
\hline Ta & 0.04 & 0.07 & 0.03 & 0.04 & 0.3 & 0.04 \\
\hline Th & 0.02 & 0.02 & 0.03 & 0.02 & 0.3 & 5 \\
\hline $\mathrm{U}$ & 0.01 & 0.03 & 0.01 & 0.03 & 0.1 & 4 \\
\hline Hf & 0.03 & 0.3 & $0.04^{-1}$ & 0.03 & 0.4 & 0.06 \\
\hline $\mathrm{Ba}$ & 0.01 & 0.05 & 0.03 & 0.4 & 0.2 & 0.05 \\
\hline $\mathrm{Rb}$ & 0.05 & 0.02 & $0.02^{\circ}$ & 0.1 & 0.09 & 0.04 \\
\hline $\mathrm{Nb}$ & 0.01 & 0.1 & 0.12 & 0.01 & & \\
\hline $2 x$ & 0.04 & 0.2 & 0.08 & 0.07 & 0.3 & 0.3 \\
\hline $\mathrm{Cs}$ & 0.05 & 0.02 & 0.02 & 0.1 & 0.09 & 0.9 \\
\hline$S Y$ & 0.01 & 0.2 & 0.03 & 2.5 & 0.08 & 0.06 \\
\hline$K$ & 0.001 & 0.002 & & 0.01 & & \\
\hline $\mathrm{Ti}$ & 0.02 & 0.3 & & 0.004 & & \\
\hline$C x$ & 2.4 & 6 & 13 & 0.06 & 69 & 0.04 \\
\hline $\mathrm{Ni}$ & 14 & 5 & 8 & 0.06 & 15 & 0.04 \\
\hline Sc & 0.3 & 4 & 2 & 0.04 & 1.5 & 0.05 \\
\hline
\end{tabular}

